\title{
Clinical and echocardiographic parameters to characterize atrial fibrillation
}

Citation for published version (APA):

de Vos, C. B. (2014). Clinical and echocardiographic parameters to characterize atrial fibrillation. [Doctoral Thesis, Maastricht University]. Maastricht University. https://doi.org/10.26481/dis.20141217cv

Document status and date:

Published: 01/01/2014

DOI:

$10.26481 /$ dis.20141217cv

Document Version:

Publisher's PDF, also known as Version of record

\section{Please check the document version of this publication:}

- A submitted manuscript is the version of the article upon submission and before peer-review. There can be important differences between the submitted version and the official published version of record.

People interested in the research are advised to contact the author for the final version of the publication, or visit the DOI to the publisher's website.

- The final author version and the galley proof are versions of the publication after peer review.

- The final published version features the final layout of the paper including the volume, issue and page numbers.

Link to publication

\footnotetext{
General rights rights.

- You may freely distribute the URL identifying the publication in the public portal. please follow below link for the End User Agreement:

www.umlib.nl/taverne-license

Take down policy

If you believe that this document breaches copyright please contact us at:

repository@maastrichtuniversity.nl

providing details and we will investigate your claim.
}

Copyright and moral rights for the publications made accessible in the public portal are retained by the authors and/or other copyright owners and it is a condition of accessing publications that users recognise and abide by the legal requirements associated with these

- Users may download and print one copy of any publication from the public portal for the purpose of private study or research.

- You may not further distribute the material or use it for any profit-making activity or commercial gain

If the publication is distributed under the terms of Article $25 \mathrm{fa}$ of the Dutch Copyright Act, indicated by the "Taverne" license above, 
Clinical and echocardiographic parameters to characterize atrial fibrillation 
Copyright (C) 2014 by Cees B de Vos. All rights reserved.

ISBN: 978-90-6464-824-3

Cover: Fenne Roefs

Thesis layout: Tiny Wouters

Printed by: GVO drukkers \& vormgevers B.V. | Ponsen \& Looijen

Financial support by the Dutch Heart Foundation and Stichting Hartsvrienden RESCAR is gratefully acknowledged.

Further financial support granted by Bayer Health Care, Boehringer Ingelheim, Biotronic, Sanofi-Aventis, St Jude medical, and Servier is gratefully acknowledged. 


\title{
Clinical and echocardiographic parameters to characterize atrial fibrillation
}

\author{
PROEFSCHRIFT \\ Ter verkrijging van de graad van doctor \\ aan de Universiteit Maastricht, \\ op gezag van de Rector Magnificus, Prof. dr. L.L.G. Soete, \\ volgens het besluit van het College van Decanen, \\ in het openbaar te verdedigen op \\ woensdag 17 december 2014 om 16.00 uur
}

door

\section{Cees B de Vos}

Geboren op 20 oktober 1980 te Liempde, Nederland 
Promotor

Prof. dr. HJGM Crijns

\section{Co-promotor}

Dr. RG Tieleman

\section{Beoordelingscommissie}

Prof. dr. HP Brunner-La Rocca, (voorzitter)

Prof. dr. JJ Bax (LUMC, Leiden)

Prof. dr. IC van Gelder (UMCG, Groningen)

Prof. dr. AP Gorgels

Prof. dr. FW Prinzen 


\section{Contents}

$\begin{array}{lll}\text { Chapter } 1 \text { General introduction } & 9\end{array}$

Part I Clinical parameters to characterize patients with atrial fibrillation $\quad 21$

Chapter 2 Autonomic trigger patterns and anti-arrhythmic treatment of paroxysmal atrial fibrillation: Data from the Euro Heart Survey

Chapter 3 Progression from paroxysmal atrial fibrillation to more sustained forms: clinical correlates and prognosis

Editorial: Progression of paroxysmal to persistent atrial

fibrillation: Factors promoting the HATCH score.

Chapter 4 Progression of atrial fibrillation in the RecordAF cohort: clinical correlates and the effect of rhythm control therapy

Part II Echo-electrocardiography to identify the substrate for atrial fibrillation during sinus rhythm

Chapter 5 Atrial activation time determined by transthoracic Doppler tissue imaging can be used as an estimate of the total duration of atrial electrical activation

Chapter 6 Clinical and echocardiographic correlates of intra-atrial conduction delay

Chapter 7 Atrial tissue Doppler imaging for prediction of new-onset atrial fibrillation

Part III Echo-electrocardiography to characterize the atrial substrate during atrial fibrillation

Chapter 8 The fibrillating atrial myocardium visualized: an unexploited source of information

Chapter 9 Atrial fibrillatory wall motion and degree of atrial remodeling in patients with atrial fibrillation: a tissue velocity imaging study 
Chapter 10 The mechanical fibrillation pattern of the atrial myocardium is associated with acute and long-term success of electrical cardioversion in patients with persistent atrial fibrillation

Chapter 11 General discussion

Summary

Samenvatting

Dankwoord

Curriculum vitae

173

List of publications

175

Valorisatie

179 



\section{Chapter 1}

General introduction 
Chapter 1 


\section{General introduction}

Atrial fibrillation (AF) is the most common sustained cardiac arrhythmia in clinical practice. $^{1}$ The estimated prevalence of $A F$ is $0.4 \%$ to $1 \%$ in the general population. In people older than 80 years, the estimated prevalence of AF is more than $8 \%{ }^{2}$ During the past 20 years, hospital admissions for AF have increased by $66 \%{ }^{3}$ and $\mathrm{AF}$ has been recognized as a condition associated with chronic disabilities for which chronic disease management is needed. ${ }^{4-6}$ Due to aging of the "baby-boom generation" and the fact that people get older in general, it is expected that the number of patients with AF will increase tremendously within the next decades.

\section{Impact of atrial fibrillation}

AF results in contractile dysfunction of both atria of the heart. As a consequence the arrhythmia may produce hemodynamic impairment resulting in heart failure and thromboembolic events such as stroke, all of which lead to significant morbidity and mortality. The mortality rate is twice as high in patients with AF compared to patients in normal sinus rhythm. In addition, AF is associated with frequent hospitalizations, and impaired quality of life. ${ }^{7}$ Palpitations and dyspnea are the most common clinical symptoms in patients with AF. On the other hand about one third of the patients are asymptomatic. However, outcome between symptomatic AF patients and "silent" AF patients does not seem to differ.

Recent studies show that subclinical or silent AF is associated with a significantly increased risk of ischemic stroke. ${ }^{8,9}$ In $20-26 \%$ of all ischemic strokes patients appear to also have otherwise asymptomatic and heretofore undetected silent AF. ${ }^{10-12}$ More intense rhythm monitoring results in better detection of silent $A F{ }^{13}$ Also, as many as 30 to $45 \%$ of patients known with AF harbour asymptomatic attacks. ${ }^{14}$ Therefore, patients are not always aware of the arrhythmia and not triggered to visit a cardiologist and receive appropriate treatment. It must be noted that paroxysmal, persistent or permanent $A F$ and silent or symptomatic $A F$ all carry the same risk for stroke. ${ }^{15}$ The high morbidity rates of untreated - even silent - AF and as a consequence high costs urge adequate detection of patients at risk for the development of the arrhythmia and its major complications. "On-time" management of AF significantly reduces the complication-rate, i.e.: warfarin and aspirin reduce the occurrence of stroke by $60 \%$ and $20 \%$, respectively. ${ }^{1,16}$ In addition, the newer direct thrombin inhibitors and factor $\mathrm{Xa}$ inhibitors are very effective drugs preventing thromboembolisms in patients with AF. ${ }^{17-19}$

The most recent update of the ESC guidelines for the management of AF stress the importance of screening for $A F$ in patients of 65 years or older. ${ }^{20}$ However, it remains to be seen whether efficient screening programs can be developed and if intervention in terms of stroke and vascular preventive therapy can be effective. 


\section{Screening for atrial fibrillation}

As mentioned above, AF may result in lethal complications even before it has been diagnosed. Therefore, there is a need for primary prevention by screening to detect patients at risk for the development of AF. In addition, early diagnosis and treatment may prevent the progression of AF to sustained forms refractory to therapeutic interventions. $^{21}$

Several screening methods to detect new-onset atrial fibrillation were studied in the past. The investigators of the SAFE study show that active screening for atrial fibrillation in a general population detects additional cases over current practice. ${ }^{22}$ They show that the preferred method of screening in patients aged 65 or over in primary care is opportunistic pulse taking with follow-up electrocardiography. However, opportunistic pulse checks are unlikely to identify paroxysmal AF and many strokes occur in people with paroxysmal AF. ${ }^{23}$ Other investigators proposed a more intense intermittent rhythm monitoring in patients with high risk for AF and high risk for stroke. ${ }^{24}$ More severe screening methods were described to detect AF in patients with stroke using long-term telemetry, pacemakers or implantable cardiac monitors. In patients with cryptogenic stroke, long term rhythm monitoring yielded short term incidences of new AF of $17-23 \%$ after screening the rhythm for 3 weeks to one year. ${ }^{12,13}$ Except for pacemakers and implantable cardiac monitors, the other screening approaches are not extremely yielding. Recently, Healey et al. have shown that subclinical atrial high rate events can be detected effectively by the atrial lead of an artificial pacemaker. Importantly, they showed that these subclinical arrhythmias increase the risk of stroke significantly $(1.7 \%$ per year compared to $0.7 \%$ in patients without atrial high rate events). ${ }^{8}$ However, using these devices for primary prevention of $A F$ in a general population is not feasible. In contrast to continuous monitoring using Holter in pacemaker, opportunistic screening reveals only $1.6 \%$ new AF per year whereas the "spontaneous" incidence is approximately $1 \%$ per year. ${ }^{22}$ Finding and optimizing the best technique for screening silent $A F$ is a crucial clinical need and might require new tools. ${ }^{25}$

To enhance its efficiency screening should target populations with the highest predicted short term incidence of AF. In other words targeted screening and its potential to steer upstream therapy as well as rhythm control should be studied.

\section{How to improve screening for new-onset AF}

Observational population studies such as the Framingham Heart study, the Manitoba Follow-up study and the Cardiovascular Health study reported several clinical and electrocardiographic and echocardiographic parameters that are associated with the development of new-onset AF. ${ }^{4,16,26-31}$ The clinical and electrocardiographic factors associated with new-onset AF are higher age, male sex, the presence of diabetes, hypertension, congestive heart failure, valve disease, obesity, coronary artery disease and $\mathrm{p}$-wave duration. Left atrial enlargement, increased left ventricular wall thickness, 
left ventricular diastolic dysfunction and a reduced left ventricular fractional shortening are predictive echocardiographic parameters for new-onset AF. ${ }^{32,33}$ However, these currently available risk stratification measures have limited predictive value in the individual patient. ${ }^{2}$ More recently Schnabel and colleagues developed a risk score based on clinical, electrocardiographic and echocardiographic parameters with a good predicting ability regarding new-onset AF (C-statistic 0.78$).^{34}$ This scoring system could be used to identify those who could benefit from ECG monitoring and aggressive control of correctable predisposing factors. However, in a validation study, the predictive ability of the tool was slightly lower. ${ }^{35}$

Besides the "classical" clinical, electrocardiographic, and echocardiographic parameters, there seems to be a link between serum based biomarkers (natriuretic peptides) $)^{36,37}$ and specific arrhythmia patterns on Holter recordings such as excessive supraventricular ectopic activity ${ }^{9}$ or after exercise testing ${ }^{38}$, and the development newonset $\mathrm{AF}$ and stroke.

Screening in high risk subsets of patients prone to develop AF and at the same time harboring a high stroke risk once $A F$ has surfaced may be a strong strategy for combating stroke. High profile screening should then focus on populations which have an a priori chance of developing AF of at least $10 \%$ per year. Such an approach may help identify high risk patients in chronic sinus rhythm in whom - once AF is detected timely initiated anticoagulation may prevent strokes. The notion that screening in high risk patients may discover AF frequently and lend a basis for prevention of (further) strokes is illustrated by several recent studies mentioned above.

Using AF prediction rules or parameters derived from scene of calamity imaging may help to steer screening toward arrhythmogenic subjects. In this respect, screening may be made more efficient by restricting it to patients with highly arrhythmogenic risk markers. Presumably, it is most efficient to combine several arrhythmogenic risk markers.

Since there is evidence that the remodeling of the atria initiating and maintaining the arrhythmia is already present before the first episode of AF occurs, patients demonstrating atrial remodeling - and therefore at risk for AF - could be selected for primary AF prevention (Figure 1.1). ${ }^{39}$

The total atrial conduction time (TACT) - defined as the time interval between the initiation of the atrial activation in the sinus node to the last atrial depolarization from the same activation front - could be a valuable parameter to predict the onset of AF. Atrial dilatation and conduction slowing may both result in prolongation of the TACT. In this thesis, we evaluated PA-TDI an echocardiographic tool to determine the TACT. 


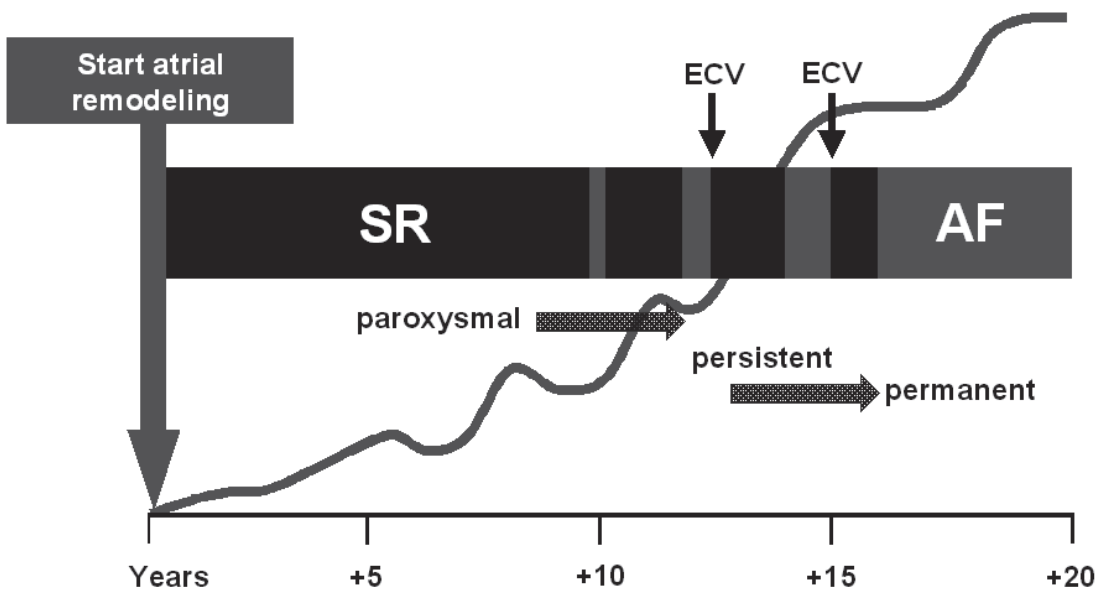

Figure 1.1 Hypothetical representation of the time course of atrial substrate remodeling in relation to the clinical appearance of AF. (based on Cosio et al. Europace. 2008, modified by Prof. dr. IC van Gelder, UMCG, Groningen).

\section{Prediction of AF progression}

In clinical practice, one should distinguish between the clinical AF type (paroxysmal AF or more persistent forms of AF). This will affect the individual treatment strategy for each patient. Previous studies identified several parameters that were associated with AF progression: valvular disease, alcohol consumption, age, left atrial dimension and amount of atrial enlargement over time, stroke, and heart failure. ${ }^{15,40-42}$ However, correction for possible confounders was not always performed, and the currently available risk stratification parameters resulting from these studies have limited predictive value in individual patients. In this thesis we re-analysed clinical parameters of AF progression in a large cohort of patients with self-terminating arrhythmia.

Progression of AF can be related to autonomic (dis)balance. ${ }^{43,44}$ This balance must be taken into consideration when choosing medication to treat the arrhythmia. ${ }^{10}$ In this thesis, we studied the effect of autonomic trigger patterns on AF progression, and the effects of medication.

One could hypothesize that aggressive treatment of reversible causes of $\mathrm{AF}$ progression may prevent the progression to sustained forms refractory to therapeutic interventions. Therefore, a better prediction of AF progression is essential.

\section{Prediction of response to therapy}

When AF occurs, there are several ways to treat the arrhythmia. ${ }^{10}$ When the patient is symptomatic, most patients undergo a pharmacological or electrical cardioversion to 
restore normal sinus rhythm. To prevent recurrences, a large part of the patients is treated with oral anti-arrhythmic drugs, catheter ablation near the ostia of the pulmonary veins, or AF surgery. Unfortunately, therapy does not always result in lasting sinus rhythm and we do not know to which therapy the patient will have the best response. Therefore at present the physicians basically use a "trial and error" strategy to choose the appropriate rhythm control therapy for their AF patients. On the whole, this is unacceptable because therapy for AF can be perilous and result in complications. ${ }^{45}$ Electrical cardioversion requires general anesthesia. Anti-arrhythmic drugs can cause pro-arrhythmia, heart failure and conduction disorders. Ablation surgery and catheter ablation near the ostia of the pulmonary veins are invasive procedures that may lead to infection, perforation, stroke, bleeding and death.

As we have to avoid unnecessary exposure of the patient to the risks of therapy, we require powerful tools to assist the physician in the choice of the best individual therapy for each patient with AF. In order to achieve better treatment of AF, we have to select patients for the therapy they are likely to respond to. The intracardiac electrogram may be used to estimate the amount of atrial remodeling by evaluating parameters such as its morphology and the atrial fibrillation cycle length (AFCL). ${ }^{46}$ Assessment of these parameters may help predicting arrhythmia prognosis and response to therapy. However, this requires an invasive procedure. Recently, a strong correlation was found between the $\mathrm{AFCL}$ and the duration of the cyclic atrial fibrillatory wall motion determined with tissue Doppler imaging. ${ }^{47}$ In this thesis, we studied the correlation between the mechanical atrial fibrillatory wall motion pattern using non-invasive tissue velocity echocardiography and the electrical intracardiac waveform. 


\section{Aims of this thesis}

The main goals of this thesis are to provide novel clinical and echocardiographic tools to predict AF onset and its progression. Since autonomic AF is a clinical entity which has remained unexplored in larger patient populations, we focused on vagal and adrenergic trigger patterns and its implications for initiation and progression of AF. Also we studied large AF populations to see whether simple to obtain clinical scores could predict AF progression. In parallel we set out to look for heretofore unused or underused information from within the atrial wall. At present, nearly all non-invasive parameters known to predict onset and progression of AF as well as success of rhythm control therapy are only obliquely related to the scene of calamity. We reasoned that the scene of calamity, i.e. the very atrial wall itself, contains hidden information which may appear useful with respect to initiation and progression of AF. Based on previous observations from our lab we aimed to explore the clinical and electrophysiological correlates of new electro-echocardiographic parameters. The specific aim here was to in-depth characterize the atrial substrate in patients with AF. In addition, we set out to explore the potential clinical usefulness of our new electro-echocardiographic tools in patients with AF. 


\section{References}

1. Chugh SS, Blackshear JL, Shen WK, Hammill SC, Gersh BJ. Epidemiology and natural history of atrial fibrillation: clinical implications. J Am Coll Cardiol 2001;37:371-378.

2. Furberg CD, Psaty BM, Manolio TA, Gardin JM, Smith VE, Rautaharju PM. Prevalence of atrial fibrillation in elderly subjects (the Cardiovascular Health Study). Am J Cardiol 1994;74:236-241.

3. Friberg J, Buch P, Scharling H, Gadsbphioll N, Jensen GB. Rising rates of hospital admissions for atrial fibrillation. Epidemiology 2003;14:666-672.

4. Krahn AD, Manfreda J, Tate RB, Mathewson FA, Cuddy TE. The natural history of atrial fibrillation: incidence, risk factors, and prognosis in the Manitoba Follow-Up Study. Am J Med 1995;98:476-484.

5. Stewart S, Murphy NF, Walker A, McGuire A, McMurray JJ. Cost of an emerging epidemic: an economic analysis of atrial fibrillation in the UK. Heart 2004;90:286-292.

6. Le Heuzey JY, Paziaud O, Piot O, Said MA, Copie X, Lavergne T, Guize L. Cost of care distribution in atrial fibrillation patients: the COCAF study. Am Heart J 2004;147:121-126.

7. Thrall G, Lane D, Carroll D, Lip GY. Quality of life in patients with atrial fibrillation: a systematic review. Am J Med 2006;119:448 e441-419.

8. Healey JS, Connolly SJ, Gold MR, Israel CW, Van Gelder IC, Capucci A, Lau CP, Fain E, Yang S, Bailleul C, Morillo CA, Carlson M, Themeles E, Kaufman ES, Hohnloser SH. Subclinical atrial fibrillation and the risk of stroke. N Engl J Med 2012;366:120-129.

9. Binici Z, Intzilakis T, Nielsen OW, Kober L, Sajadieh A. Excessive supraventricular ectopic activity and increased risk of atrial fibrillation and stroke. Circulation 2010;121:1904-1911.

10. Camm AJ, Kirchhof P, Lip GY, Schotten U, Savelieva I, Ernst S, Van Gelder IC, Al-Attar N, Hindricks G, Prendergast B, Heidbuchel H, Alfieri O, Angelini A, Atar D, Colonna P, De Caterina R, De Sutter J, Goette A, Gorenek B, Heldal M, Hohloser SH, Kolh P, Le Heuzey JY, Ponikowski P, Rutten FH. Guidelines for the management of atrial fibrillation: the Task Force for the Management of Atrial Fibrillation of the European Society of Cardiology (ESC). Eur Heart J 2010;31:2369-2429.

11. Cotter PE, Martin PJ, Ring L, Warburton EA, Belham M, Pugh PJ. Incidence of atrial fibrillation detected by implantable loop recorders in unexplained stroke. Neurology 2013;80:1546-1550.

12. Tayal AH, Tian M, Kelly KM, Jones SC, Wright DG, Singh D, Jarouse J, Brillman J, Murali S, Gupta R. Atrial fibrillation detected by mobile cardiac outpatient telemetry in cryptogenic TIA or stroke. Neurology 2008;71:1696-1701.

13. Ritter MA, Kochhauser S, Duning T, Reinke F, Pott C, Dechering DG, Eckardt L, Ringelstein EB. Occult atrial fibrillation in cryptogenic stroke: detection by 7-day electrocardiogram versus implantable cardiac monitors. Stroke 2013;44:1449-1452.

14. Israel CW, Gronefeld G, Ehrlich JR, Li YG, Hohnloser SH. Long-term risk of recurrent atrial fibrillation as documented by an implantable monitoring device: implications for optimal patient care. J Am Coll Cardiol 2004;43:47-52.

15. Nieuwlaat R, Prins MH, Le Heuzey JY, Vardas PE, Aliot E, Santini M, Cobbe SM, Widdershoven JW, Baur $\mathrm{LH}$, Levy S, Crijns HJ. Prognosis, disease progression, and treatment of atrial fibrillation patients during 1 year: follow-up of the Euro Heart Survey on atrial fibrillation. Eur Heart J. 2008;29:1181-1189.

16. Benjamin EJ, Levy D, Vaziri SM, D'Agostino RB, Belanger AJ, Wolf PA. Independent risk factors for atrial fibrillation in a population-based cohort. The Framingham Heart Study. JAMA 1994;271:840-844.

17. Connolly SJ, Ezekowitz MD, Yusuf S, Eikelboom J, Oldgren J, Parekh A, Pogue J, Reilly PA, Themeles E, Varrone J, Wang S, Alings M, Xavier D, Zhu J, Diaz R, Lewis BS, Darius H, Diener HC, Joyner CD, Wallentin L. Dabigatran versus Warfarin in Patients with Atrial Fibrillation. $N$ Engl J Med 2009;361:1139-1151.

18. Connolly SJ, Eikelboom J, Joyner C, Diener HC, Hart R, Golitsyn S, Flaker G, Avezum A, Hohnloser SH, Diaz R, Talajic M, Zhu J, Pais P, Budaj A, Parkhomenko A, Jansky P, Commerford P, Tan RS, Sim KH, Lewis BS, Van Mieghem W, Lip GY, Kim JH, Lanas-Zanetti F, Gonzalez-Hermosillo A, Dans AL, Munawar M, O'Donnell M, Lawrence J, Lewis G, Afzal R, Yusuf S. Apixaban in patients with atrial fibrillation. $N$ Engl J Med 2011;364:806-817.

19. Patel MR, Mahaffey KW, Garg J, Pan G, Singer DE, Hacke W, Breithardt G, Halperin JL, Hankey GJ, Piccini JP, Becker RC, Nessel CC, Paolini JF, Berkowitz SD, Fox KA, Califf RM. Rivaroxaban versus warfarin in nonvalvular atrial fibrillation. N Engl J Med 2011;365:883-891. 
20. Kirchhof P, Lip GY, Van Gelder IC, Bax J, Hylek E, Kaab S, Schotten U, Wegscheider K, Boriani G, Brandes A, Ezekowitz M, Diener H, Haegeli L, Heidbuchel H, Lane D, Mont L, Willems S, Dorian P, Aunes-Jansson M, Blomstrom-Lundqvist C, Borentain M, Breitenstein S, Brueckmann M, Cater N, Clemens A, Dobrev D, Dubner S, Edvardsson NG, Friberg L, Goette A, Gulizia M, Hatala R, Horwood J, Szumowski L, Kappenberger L, Kautzner J, Leute A, Lobban T, Meyer R, Millerhagen J, Morgan J, Muenzel F, Nabauer M, Baertels C, Oeff M, Paar D, Polifka J, Ravens U, Rosin L, Stegink W, Steinbeck G, Vardas P, Vincent A, Walter M, Breithardt G, Camm AJ. Comprehensive risk reduction in patients with atrial fibrillation: emerging diagnostic and therapeutic options--a report from the 3rd Atrial Fibrillation Competence NETwork/European Heart Rhythm Association consensus conference. Europace 2012;14:8-27.

21. Van Gelder IC, Haegeli LM, Brandes A, Heidbuchel H, Aliot E, Kautzner J, Szumowski L, Mont L, Morgan J, Willems S, Themistoclakis S, Gulizia M, Elvan A, Smit MD, Kirchhof P. Rationale and current perspective for early rhythm control therapy in atrial fibrillation. Europace 2011;13:1517-1525.

22. Fitzmaurice DA, Hobbs FD, Jowett S, Mant J, Murray ET, Holder R, Raftery JP, Bryan S, Davies M, Lip GY, Allan TF. Screening versus routine practice in detection of atrial fibrillation in patients aged 65 or over: cluster randomised controlled trial. BMJ 2007;335:383.

23. Seligmann C. Proposed screening is too simple and not focused enough. BMJ 2012;344:e2257.

24. Engdahl J, Andersson L, Mirskaya M, Rosenqvist M. Stepwise screening of atrial fibrillation in a 75year-old population: implications for stroke prevention. Circulation 2013;127:930-937.

25. Ahmad Y, Kirchhof P. Gone fishing (for silent atrial fibrillation). Circulation 2013;127:870-872.

26. Kannel WB, Wolf PA, Benjamin EJ, Levy D. Prevalence, incidence, prognosis, and predisposing conditions for atrial fibrillation: population-based estimates. Am J Cardiol 1998;82:2N-9N.

27. Vaziri SM, Larson MG, Benjamin EJ, Levy D. Echocardiographic predictors of nonrheumatic atrial fibrillation. The Framingham Heart Study. Circulation 1994;89:724-730.

28. Brand FN, Abbott RD, Kannel WB, Wolf PA. Characteristics and prognosis of lone atrial fibrillation. 30year follow-up in the Framingham Study. JAMA 1985;254:3449-3453.

29. Psaty BM, Manolio TA, Kuller LH, Kronmal RA, Cushman M, Fried LP, White R, Furberg CD, Rautaharju PM. Incidence of and risk factors for atrial fibrillation in older adults. Circulation 1997;96:2455-2461.

30. Smith JG, Platonov PG, Hedblad B, Engstrom G, Melander O. Atrial fibrillation in the Malmo Diet and Cancer study: a study of occurrence, risk factors and diagnostic validity. Eur J Epidemiol 2010;25:95-102.

31. Guidera SA, Steinberg JS. The signal-averaged $\mathrm{P}$ wave duration: a rapid and noninvasive marker of risk of atrial fibrillation. J Am Coll Cardiol 1993;21:1645-1651.

32. Tsang TS, Barnes ME, Bailey KR, Leibson CL, Montgomery SC, Takemoto Y, Diamond PM, Marra MA, Gersh BJ, Wiebers DO, Petty GW, Seward JB. Left atrial volume: important risk marker of incident atrial fibrillation in 1655 older men and women. Mayo Clin Proc 2001;76:467-475.

33. Tsang TS, Gersh BJ, Appleton CP, Tajik AJ, Barnes ME, Bailey KR, Oh JK, Leibson C, Montgomery SC, Seward JB. Left ventricular diastolic dysfunction as a predictor of the first diagnosed nonvalvular atrial fibrillation in 840 elderly men and women. J Am Coll Cardiol 2002;40:1636-1644.

34. Schnabel RB, Sullivan LM, Levy D, Pencina MJ, Massaro JM, D'Agostino RB, Sr., Newton-Cheh C, Yamamoto JF, Magnani JW, Tadros TM, Kannel WB, Wang TJ, Ellinor PT, Wolf PA, Vasan RS, Benjamin EJ. Development of a risk score for atrial fibrillation (Framingham Heart Study): a community-based cohort study. Lancet 2009;373:739-745.

35. Schnabel RB, Aspelund T, Li G, Sullivan LM, Suchy-Dicey A, Harris TB, Pencina MJ, D'Agostino RB, Sr., Levy D, Kannel WB, Wang TJ, Kronmal RA, Wolf PA, Burke GL, Launer LJ, Vasan RS, Psaty BM, Benjamin EJ, Gudnason V, Heckbert SR. Validation of an atrial fibrillation risk algorithm in whites and African Americans. Arch Intern Med 2010;170:1909-1917.

36. Wang TJ, Larson MG, Levy D, Benjamin EJ, Leip EP, Omland T, Wolf PA, Vasan RS. Plasma natriuretic peptide levels and the risk of cardiovascular events and death. N EngljJ Med 2004;350:655-663.

37. Smith JG, Newton-Cheh C, Almgren P, Struck J, Morgenthaler NG, Bergmann A, Platonov PG, Hedblad $B$, Engstrom G, Wang TJ, Melander O. Assessment of conventional cardiovascular risk factors and multiple biomarkers for the prediction of incident heart failure and atrial fibrillation. J Am Coll Cardiol 2010;56:1712-1719.

38. Folkeringa RJ, Hartgers J, Tieleman RG, Gorgels AP, Dassen WR, Crijns HJ. Atrial extrasystoles after exercise predict atrial fibrillation in patients with left ventricular hypertrophy. Heart 2006;92:545-546. 
39. Cosio FG, Aliot E, Botto GL, Heidbuchel H, Geller CJ, Kirchhof P, De Haro JC, Frank R, Villacastin JP, Vijgen J, Crijns H. Delayed rhythm control of atrial fibrillation may be a cause of failure to prevent recurrences: reasons for change to active antiarrhythmic treatment at the time of the first detected episode. Europace 2008;10:21-27.

40. Kerr CR, Humphries KH, Talajic M, Klein GJ, Connolly SJ, Green M, Boone J, Sheldon R, Dorian P, Newman D. Progression to chronic atrial fibrillation after the initial diagnosis of paroxysmal atrial fibrillation: results from the Canadian Registry of Atrial Fibrillation. Am Heart J 2005;149:489-496.

41. Parkash R, Green MS, Kerr CR, Connolly SJ, Klein GJ, Sheldon R, Talajic M, Dorian P, Humphries KH. The association of left atrial size and occurrence of atrial fibrillation: a prospective cohort study from the Canadian Registry of Atrial Fibrillation. Am Heart J. 2004;148:649-654.

42. Ruigomez A, Johansson S, Wallander MA, Garcia Rodriguez LA. Predictors and prognosis of paroxysmal atrial fibrillation in general practice in the UK. BMC Cardiovasc Disord 2005;5:20.

43. Coumel P, Attuel P, Lavallee J, Flammang D, Leclercq JF, Slama R. The atrial arrhythmia syndrome of vagal origin. Arch Mal Coeur Vaiss 1978;71:645-656.

44. Coumel P. Cardiac arrhythmias and the autonomic nervous system. J Cardiovasc Electrophysiol 1993;4:338-355.

45. Lafuente-Lafuente C, Mouly S, Longas-Tejero MA, Mahe I, Bergmann JF. Antiarrhythmic drugs for maintaining sinus rhythm after cardioversion of atrial fibrillation: a systematic review of randomized controlled trials. Arch Intern Med 2006;166:719-728.

46. Capucci A, Biffi M, Boriani G, Ravelli F, Nollo G, Sabbatani P, Orsi C, Magnani B. Dynamic electrophysiological behavior of human atria during paroxysmal atrial fibrillation. Circulation 1995;92:1193-1202.

47. Duytschaever M, Heyse A, de Sutter J, Crijns H, Gillebert T, Tavernier R, Tieleman R. Transthoracic tissue Doppler imaging of the atria: a novel method to determine the atrial fibrillation cycle length. $J$ Cardiovasc Electrophysio. 2006;17:1202-1209. 


\section{Part}

Clinical parameters to characterize patients with atrial fibrillation 


\section{Chapter 2}

Autonomic trigger patterns and anti-arrhythmic treatment of paroxysmal atrial fibrillation:

data from the Euro Heart Survey

CB de Vos, R Nieuwlaat, HJGM Crijns, AJ Camm, JY LeHeuzey, CJ Kirchhof, A Capucci, G Breithardt, PE Vardas, R Pisters, RG Tieleman 


\section{Abstract}

Aims

To investigate the clinical characteristics, management, and outcome of patients with paroxysmal atrial fibrillation (AF) associated with autonomic triggers.

Methods and results

One thousand five hundred and seventeen patients with paroxysmal AF participated in the Euro Heart Survey on AF. We categorized patients according to trigger pattern as reported by the physician: adrenergic (AF associated with exercise, emotion or during daytime only and absence of vagal triggers), vagal (postprandial or night time only, without presence of adrenergic triggers) and mixed (combination of vagal and adrenergic triggers). Vagal AF was found in 91 patients (6\%), adrenergic in 229 patients (15\%) and mixed in 175 (12\%) patients. Underlying heart disease was equally prevalent in the three groups. Among patients with vagal AF, $73 \%$ were treated with nonrecommended drugs according to the guidelines. In vagal AF, non-recommended treatment was associated with a shift to persistent or permanent AF in $19 \%$ of the patients, compared with none in the group receiving recommended treatment $(P=0.06)$.

\section{Conclusion}

This study is the first to address the issue of autonomic trigger patterns and AF in a large population. Autonomic trigger patterns were seen frequently in paroxysmal AF patients. Autonomic influences should be taken into consideration since nonrecommended treatment may result in aggravation of vagal AF. 


\section{Introduction}

Atrial fibrillation (AF) is the most common sustained cardiac arrhythmia. The condition is frequently associated with structural heart disease, although a substantial number of patients have no underlying heart disease. ${ }^{1}$ The autonomic nervous system is known to contribute to the initiation, perpetuation, ventricular response rate, and termination of $\mathrm{AF}$, but its precise role remains controversial.

While the data are mainly empiric, there are two types of autonomic induced AF pointed out in the literature. Coumel and coworkers ${ }^{2-6}$ described adrenergic and vagal forms of AF. They reported that the adrenergic mediated episodes of AF are typically triggered by exercise and emotional stress, commonly associated with polyuria, and occur mainly during the day. Adrenergic AF is described to occur in the presence of heart disease. ${ }^{7}$ The vagal form is characterized by male predominance, younger age, minimal tendency to progress to permanent $A F$, and onset at rest or at night and after intake of food or alcohol. Episodes of vagal AF are typically preceded by progressive bradycardia. Studies using heart rate variability have confirmed vagal and adrenergic modes of onset of $A F^{8-11}$ Furthermore, there is support for the notion that autonomic modulation influences early recurrences after electrical cardioversion. ${ }^{12,13}$

Epidemiologic data on the prevalence or prognosis of autonomic AF are presently lacking. Furthermore, there is no controlled study examining the response to therapy in vagal or adrenergic AF. However, as in the previous guidelines, the 2006 ACC/AHA/ESC guidelines for the management of patients with AF contain specific recommendations regarding the medical treatment of patients with vagal or adrenergic AF. ${ }^{14}$ Beta-blocking drugs, sotalol, digitalis and propafenone are considered unsuitable since they may exacerbate the episodes of vagal induced $A F$, whereas in adrenergic AF drugs with beta-blocking properties are thought to be beneficial. These recommendations are primarily based on assumptions, since controlled studies on this subject are lacking.

The Euro Heart Survey on AF presents a unique overview of AF management in a large group of patients in several European countries. ${ }^{15}$ We identified the clinical characteristics and management of patients with paroxysmal AF associated with autonomic triggers among the patients in the Euro Heart Survey. To our knowledge, this study is the first to address the issue of AF triggers, autonomic trigger patterns, their clinical characteristics, management and outcome in a large population AF patients.

\section{Methods}

A detailed description of the methods, data collection, validation, and the first results of the Euro Heart Survey on AF have been presented by Nieuwlaat et al. ${ }^{15}$ 
In 2003 and 2004, 5333 AF patients were enrolled in this survey. These patients were enrolled in 182 hospitals among 35 different member countries of the European Society of Cardiology. Inclusion criteria were: age $>18$ years and AF on ECG or Holter recording in the previous 12 months or at the time of inclusion. Enrolment of consecutive patients took place at the outpatient clinic, cardiology ward, emergency department, electrical cardioversion department, electrophysiology laboratory, pacemaker and defibrillator implantation department, and cardiac surgery department.

AF was classified in five categories. The arrhythmia was first detected AF in 978 patients, paroxysmal AF in 1517 patients, persistent AF in 1167 patients, permanent AF in 1541 patients and unknown type of AF in 130 patients. In the present study, only the records from patients with paroxysmal AF were evaluated, leaving a study population of 1517 patients.

In the Euro Heart Survey, data were collected from medical records and medical information systems or entered by the attending physician.

The physicians were asked to report whether the following triggers for AF were present: caffeine intake, alcohol intake, inhalation of toxic gas or electrocution, electrolyte disturbances, acute myocardial infarction, exercise, emotion, postprandial occurrence, and sleep apnoea syndrome. Additionally, circadian rhythms were identified to determine whether the arrhythmia occurred during both day and night, during daytime mainly or started during the night (or was present at wake up).

Using the clinical characteristics of patients with autonomic predominance, we defined an adrenergic, a vagal, and a mixed trigger pattern. The adrenergic trigger pattern was defined as follows: initiated by exercise or emotion and/or present mainly during daytime without reported vagal triggers. We classified patients in the vagal group if AF occurred postprandially and/or was present during the night only without presence of any adrenergic triggers. Patients were classified in the mixed AF group when a combination of at least one adrenergic and one vagal trigger was present.

Patient management was performed consistent with common local practice.

The guidelines contest prescription of a beta-blocker, sotalol, digitalis or propafenone in patients with vagal AF. On the other hand, some drugs are recommended for adrenergic AF (i.e. treatment with a beta-blocker, sotalol, digitalis or amiodarone). In the present study, we evaluated the effect of guideline adherence (recommended treatment) and non-compliance with the guidelines (non-recommended treatment) regarding prescription of medication in autonomic $A F$.

To evaluate regional differences, we divided the patients into three geographical locations:Western, Central and Mediterranean Europe as defined previously. ${ }^{15}$

\section{Statistical analysis}

Data analysis was performed with SPSS statistical software (SPSS, Inc., release 12.0.1). Continuous variables are reported as meantstandard deviation and categorical 
variables as observed number of patients (percentage). Whether there was a difference in characteristics, treatment or outcome between the three groups with vagal, adrenergic, and mixed trigger patterns was tested with ANOVA for continuous and $\chi^{2}$ for categorical variables and these $P$-values are reported in the tables. Post hoc pairwise analysis was performed using Bonferroni and the corresponding $P$-values were reported in the text. When comparing two groups, differences for continuous variables were tested with an independent t-test and differences for categorical variables were tested with $\chi^{2}$. All tests performed were two-sided. Overall, a $P$-value of $<0.05$ was considered to be statistically significant.

\section{Results}

\section{Atrial fibrillation triggers}

One or more triggers were reported in 640 (42\%) patients with paroxysmal AF. In 535 (35\%) patients no triggers were found and in 342 (23\%) patients the physician did not verify the presence of triggers. No differences regarding baseline characteristics, medical history, and previous interventions were found between the latter group and patients in whom the presence of triggers was verified by the physician (data not shown).

Exercise and emotion were the most frequently reported triggers of AF (Figure 2.1). Patients with triggers were somewhat younger compared with the patients in whom no trigger was found. Patients without triggers had less thyroid disease, more often sick sinus syndrome and an implanted pacemaker. No significant differences concerning other baseline characteristics were found (Table 2.1).

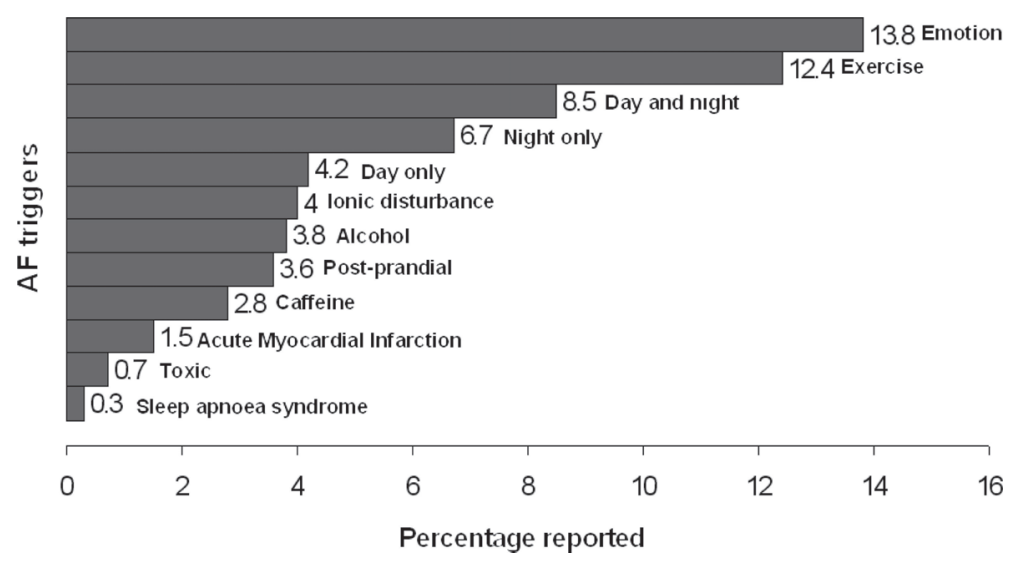

Figure 2.1 Percentages of triggers reported in patients with paroxysmal atrial fibrillation in the Euro Heart Survey. 
Table 2.1 Characteristics of paroxysmal atrial fibrillation patients with vs. without triggers.

\begin{tabular}{lccc}
\hline & Any trigger & No triggers found & $P$-value \\
\hline $\mathrm{n}$ & 640 & 535 & 0.012 \\
Age (years) & $62 \pm 13$ & $64 \pm 13$ & 0.149 \\
Female & $258(40 \%)$ & $238(45 \%)$ & 0.870 \\
Lone AF & $102(16 \%)$ & $86(16 \%)$ & \\
Underlying heart disease & & & 0.222 \\
Heart failure & $156(25 \%)$ & $114(21 \%)$ & 0.337 \\
Coronary artery disease & $210(33 \%)$ & $162(30 \%)$ & 0.575 \\
Valvular heart disease & $118(19 \%)$ & $91(17 \%)$ & 0.280 \\
Mitral stenosis & $41(6 \%)$ & $26(5 \%)$ & 0.164 \\
Hypertension & $414(65 \%)$ & $325(61 \%)$ & 0.047 \\
Other diseases & & & 0.803 \\
Thyroid disease & $36(6 \%)$ & $17(3 \%)$ & 0.023 \\
Pulmonary disease & $82(13 \%)$ & $66(12 \%)$ & 0.420 \\
Sick sinus syndrome & $31(5 \%)$ & $43(8 \%)$ & 0.783 \\
Peripheral vascular disease & $43(7 \%)$ & $30(6 \%)$ & 0.247 \\
Renal failure & $37(6 \%)$ & $33(6 \%)$ & 0.497 \\
Malignancy & $31(5 \%)$ & $19(4 \%)$ & 0.569 \\
Stroke/TIA & $62(10 \%)$ & $46(9 \%)$ & 0.358 \\
Previous interventions & & & 0.675 \\
Pharmacological cardioversion & & & 0.008 \\
Electrical cardioversion & $328(51 \%)$ & $283(53 \%)$ & $127(24 \%)$ \\
Catheter ablation & $167(26 \%)$ & $28(5 \%)$ & $41(8 \%)$ \\
Pacemaker & $37(6 \%)$ & & \\
\hline
\end{tabular}

\section{Autonomic trigger patterns}

Autonomic trigger pattern according to our definition could be identified in 495 of the patients with paroxysmal AF (33\%): in 91 patients (6\%) a vagal trigger pattern was present, 229 patients (15\%) had an adrenergic trigger pattern, and 175 patients (12\%) a mixed trigger pattern (Table 2.2). No differences regarding underlying heart disease, age or other baseline characteristics were found between patients with vagal, adrenergic, and mixed AF.

Vagal AF was not restricted to lone AF since hypertension (71\%), coronary artery disease $(29 \%)$ and heart failure (24\%) were often present among the patients with a vagal trigger pattern. No differences regarding events during follow-up were found between the three autonomic trigger pattern groups (Table 2.3).

\section{Autonomic trigger patterns and drug therapy}

We compared therapy between patients with adrenergic and vagal triggers of AF to investigate the relationship between potential trigger patterns and clinical management. Patients with vagal AF were treated more often with Class Ic antiarrhythmic drugs compared with patients with adrenergic AF $(P=0.007)$, as suggested by the guidelines. Although not recommended, patients with a vagal trigger pattern were frequently treated with a beta-blocker, sotalol, digoxin or propafenone (Figure 
2.2). No differences were found between the prescription of ACE (angiotensin converting enzyme)-inhibitors, AT(angiotensin)II receptor blockers, dihydropyridin calcium channel blockers, diuretics and statins between the vagal and adrenergic AF group. In total, $72 \%$ of the patients with vagal AF used non-recommended medication, especially betablockers. In the patients with vagal AF, beta-blockers (including sotalol) were prescribed in 51 patients (57\%). On the other hand, $36 \%$ of the patients with adrenergic AF did not receive a beta-blocker.

Table 2.2 Characteristics of patients with an adrenergic, vagal and mixed trigger pattern.

\begin{tabular}{|c|c|c|c|c|}
\hline & $\begin{array}{c}\text { Adrenergic } \\
\text { trigger pattern }\end{array}$ & $\begin{array}{c}\text { Vagal trigger } \\
\text { pattern }\end{array}$ & $\begin{array}{c}\text { Mixed } \\
\text { trigger pattern }\end{array}$ & P-value \\
\hline $\mathrm{N}$ & 229 & 91 & 175 & \\
\hline Age (years) & $62 \pm 13$ & $62 \pm 14$ & $62 \pm 13$ & 0.609 \\
\hline Female & $94(41 \%)$ & $38(42 \%)$ & $73(42 \%)$ & 0.988 \\
\hline Body Weight & $81 \pm 15$ & $80 \pm 19$ & $80 \pm 16$ & 0.906 \\
\hline $\mathrm{BMI}$ & $27 \pm 5$ & $28 \pm 6$ & $27 \pm 5$ & 0.484 \\
\hline Heart rate at inclusion (when SR) (BPM) & $69 \pm 13$ & $66 \pm 15$ & $69 \pm 17$ & 0.533 \\
\hline Heart rate at inclusion (when AF) (BPM) & $110 \pm 32$ & $109 \pm 40$ & $106 \pm 29$ & 0.390 \\
\hline Lone AF & $35(15 \%)$ & $14(16 \%)$ & $37(21 \%)$ & 0.268 \\
\hline \multicolumn{5}{|l|}{ Underlying heart diseases } \\
\hline Heart failure & $58(25 \%)$ & $22(24 \%)$ & $34(20 \%)$ & 0.368 \\
\hline Coronary artery disease & $69(30 \%)$ & $26(29 \%)$ & $55(31 \%)$ & 0.891 \\
\hline Valvular heart disease & $43(19 \%)$ & $18(20 \%)$ & $28(16 \%)$ & 0.698 \\
\hline Mitral stenosis & $16(7 \%)$ & $7(8 \%)$ & $8(5 \%)$ & 0.508 \\
\hline Hypertension & $149(65 \%)$ & $65(71 \%)$ & $109(62 \%)$ & 0.331 \\
\hline \multicolumn{5}{|l|}{ Other diseases } \\
\hline Thyroid disease & $12(6 \%)$ & $5(6 \%)$ & $8(5 \%)$ & 0.906 \\
\hline Pulmonary disease & $25(11 \%)$ & $6(7 \%)$ & $22(13 \%)$ & 0.322 \\
\hline Sick sinus syndrome & $8(3 \%)$ & $7(8 \%)$ & $10(6 \%)$ & 0.261 \\
\hline Peripheral vascular disease & $16(7 \%)$ & $2(2 \%)$ & $12(7 \%)$ & 0.220 \\
\hline Renal failure & $12(5 \%)$ & $5(6 \%)$ & $7(4 \%)$ & 0.804 \\
\hline Malignancy & $7(3 \%)$ & $5(6 \%)$ & $9(6 \%)$ & 0.429 \\
\hline Major bleeding & $2(1 \%)$ & $1(1 \%)$ & $2(1 \%)$ & 0.960 \\
\hline Stroke / TIA & $25(11 \%)$ & $8(9 \%)$ & $16(9 \%)$ & 0.796 \\
\hline \multicolumn{5}{|l|}{ Previous interventions } \\
\hline Pharmacological cardioversion & $125(55 \%)$ & $43(47 \%)$ & $98(56 \%)$ & 0.374 \\
\hline Electrical cardioversion & $63(28 \%)$ & $22(24 \%)$ & $62(35 \%)$ & 0.107 \\
\hline Catheter ablation & $12(5 \%)$ & $3(3 \%)$ & $17(10 \%)$ & 0.082 \\
\hline Pacemaker & $8(4 \%)$ & $7(5 \%)$ & 0 & 0.542 \\
\hline
\end{tabular}

BMI: Body Mass Index, SR: Sinus Rhythm, BPM: Beats Per Minute, TIA: Transient Ischemic Attack. 
Table 2.3 Events during follow-up of patients with an adrenergic, vagal and mixed trigger pattern.

\begin{tabular}{lcccc}
\hline & $\begin{array}{c}\text { Adrenergic trigger } \\
\text { pattern }\end{array}$ & $\begin{array}{c}\text { Vagal trigger } \\
\text { pattern }\end{array}$ & $\begin{array}{c}\text { Mixed } \\
\text { trigger pattern }\end{array}$ & $P$-value \\
\hline $\mathrm{N}$ & 229 & 91 & 175 & \\
Outcome at 1 year: & $170(97 \%)$ & $74(96 \%)$ & $142(99 \%)$ & 0.214 \\
$\quad$ Survival & $31(22 \%)$ & $17(25 \%)$ & $30(23 \%)$ & 0.847 \\
Pharmacological cardioversion & $19(14 \%)$ & $9(13 \%)$ & $18(14 \%)$ & 0.991 \\
Electrical cardioversion & $12(8 \%)$ & $8(12 \%)$ & $17(13 \%)$ & 0.278 \\
Catheter ablation & $50(41 \%)$ & $25(43 \%)$ & $55(51 \%)$ & 0.358 \\
Admission for AF & $65(52 \%)$ & $29(50 \%)$ & $65(60 \%)$ & 0.444 \\
Cardiovascular Hospitalizations & $115(79 \%)$ & $49(77 \%)$ & $106(88 \%)$ & 0.093 \\
AF consultations during follow-up & $22(14 \%)$ & $9(14 \%)$ & $18(14 \%)$ & 0.995 \\
AF type worsening at 1 year & & & & 0.141 \\
(persistent or permanent) & $60(40 \%)$ & $20(31 \%)$ & $59(46 \%)$ & $0.965)$ \\
Symptoms at 1 year & &
\end{tabular}

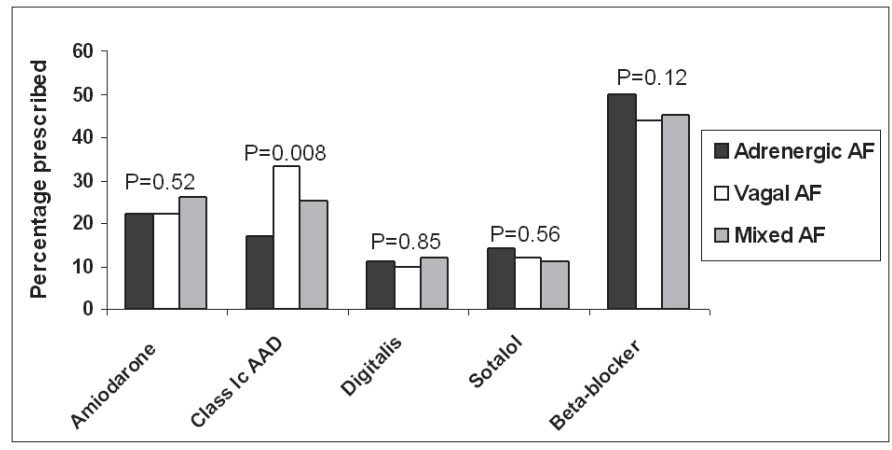

Figure 2.2 Prescription of medication in autonomic atrial fibrillation (AAD: anti-arrhythmic drugs).

In the Euro Heart Survey, physicians were also asked to report 1 year follow-up items regarding worsening of paroxysmal $A F$ to persistent or permanent $A F$, number of pharmacological cardioversions, number of electrical cardioversions, number of ablations, and the frequency of admissions and consultations. Complete follow-up data were available for $53-70 \%$ of the patients with adrenergic AF and $62-73 \%$ of the patients having vagal AF depending on each item studied. To evaluate the effect of the choice of medical therapy, we looked at dissimilarities regarding baseline characteristics and outcome at 1-year follow-up among patients with autonomic trigger patterns receiving recommended and non-recommended treatment. As represented in Table 2.4, there were no significant differences in patient characteristics and medication in patients with vagal AF receiving recommended and non-recommended therapy. Nonrecommended treatment was associated with a clear trend towards aggravation of vagal AF. In the vagally mediated paroxysmal AF patients, non-recommended treatment was associated with a deterioration to persistent or 
permanent $\mathrm{AF}$ in $19 \%$ of the patients during 1-year follow-up, compared with none in the group treated with recommended medication $(P=0.06)$ (Figure 2.3).

Table 2.4 Characteristics and outcome of paroxysmal AF patients with a vagal or adrenergic trigger pattern who received recommended and non-recommended treatment.

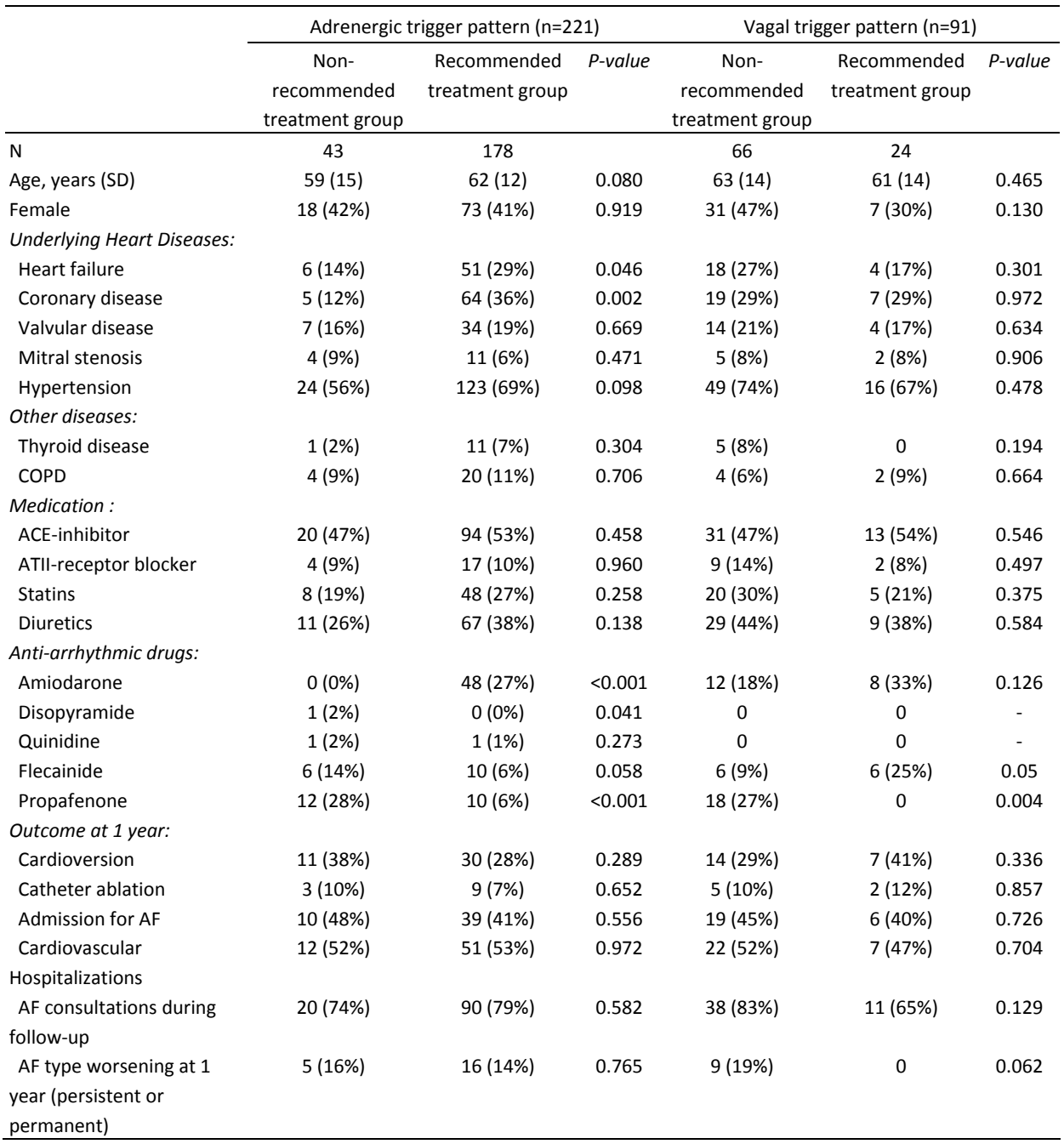

COPD: Chronic Obstructive Pulmonary Disease; ACE: Angiotensin-Converting Enzyme; ATII: angiotensin II

In the adrenergic group, more heart failure and coronary artery disease were present in the patients receiving recommended therapy. No difference in progression to persistent or permanent AF was found in adrenergic AF between the groups treated with recommended and non-recommended medication. Concerning the other indicators of outcome such as AF interventions, hospitalizations and consultations, no 
major differences were found between recommended and non-recommended treatment in both vagal and adrenergic AF.

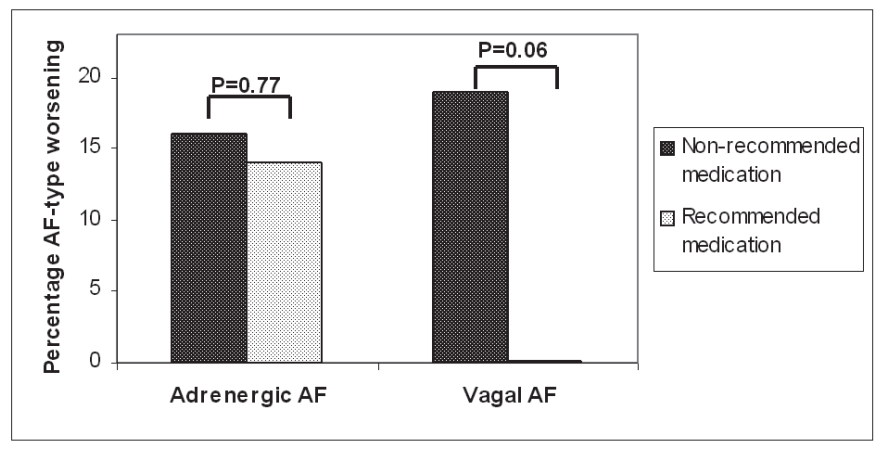

Figure 2.3 Effect of (non-)recommended treatment on worsening of atrial fibrillation (AF)-type (shift from paroxysmal $A F$ at baseline to persistent or permanent $A F$ at follow-up or from persistent $A F$ at baseline to permanent $\mathrm{AF}$ at follow-up).

\section{Regional disparity and (non-)recommended treatment}

A few differences between European regions were observed. The largest number of patients in whom the physician did not verify the presence of triggers resided in Western Europe (54\%) compared with only $21 \%$ in Central Europe and $25 \%$ in Mediterranean Europe. In case the presence of triggers was verified by the physician, the relative distribution of triggers and autonomic trigger patterns were similar across Europe (data not shown).

In the Mediterranean countries, a larger proportion of the population was treated in accordance with the ACC/AHA/ESC guidelines for the management of patients with vagal $A F$ as $41 \%$ of the patients received recommended treatment according to the guidelines compared with $20 \%$ in Central Europe and $19 \%$ in Western Europe. In adrenergic AF, the percentage of patients receiving recommended medication was similar in Central, Mediterranean, and Western Europe.

\section{Discussion}

The Euro Heart Survey provides a unique insight into the characteristics of patients with triggers for AF and the way they are presently treated. To our knowledge, this is the first large observational study to provide an overall picture of autonomic trigger patterns for AF, its management and outcome. Physicians reported triggers in $42 \%$ of paroxysmal AF patients in the survey. An autonomic trigger pattern (adrenergic, vagal or mixed) was present in $33 \%$ of all patients. In contrast to the general opinion on 
autonomic $\mathrm{AF}$, there were no differences in patient characteristics and prevalence of concomitant heart disease in patients with vagal or adrenergic AF. In fact, we recorded heart failure, coronary artery disease, valvular heart disease and hypertension in as many patients having the vagal form of the arrhythmia as in patients with adrenergic AF. Also, both patient groups are of similar age. Despite the fact that physicians themselves reported the triggers in their patients, they presumably did not always correctly recognize the autonomic pattern, since $72 \%$ of the patients with vagal AF and $20 \%$ of the patients with adrenergic AF did not receive the recommended medication according to the ACC/AHA/ESC guidelines for the management of patients with AF.14 Although patients seem to respond well to what is considered non-recommended treatment, the present data suggest that especially in patients with vagal $A F$, this may be detrimental because of potential aggravation of the arrhythmia pattern. Among the patients with adrenergic AF, no significant differences in outcome (or trends) were found between the patients using recommended and non-recommended treatment. One could hypothesize that this would reduce the clinical relevance of adrenergic AF. On the other hand, adrenergic AF patients receiving recommended medication had more underlying heart disease such as coronary artery disease or heart failure (Table 2.4) making them more vulnerable for recurrent AF and the development of more sustained forms of the arrhythmia.

\section{Patients with triggers for atrial fibrillation}

The presence of paroxysmal $\mathrm{AF}$ is an interplay between initiating triggers and a perpetuating substrate. An arrhythmogenic substrate may develop with age or with prolonged exposure to underlying heart disease. ${ }^{16}$ Triggers may develop from high adrenergic tone, which may also increase the awareness of palpitations in case of an arrhythmia. In our study, patients in whom triggers were reported were somewhat younger and more often had thyroid disease. In contrast, patients with reported triggers of AF less often had sick sinus syndrome and pacemaker implantation, possibly because of their lower age. In case of pacemaker implantation, symptoms and therefore reported trigger-frequency may decrease.

At the time of the survey, physicians might have been less aware of the relation between obstructive sleep apnoea syndrome (OSAS) and AF, since the reported incidence is low. On the other hand, considering the relatively normal BMI (body mass index) of patients in this European survey, the prevalence of OSAS may have been truly low.

\section{Clinical characteristics of patients with vagal or adrenergic atrial fibrillation}

The precise role of the autonomic nervous system in the initiation, perpetuation, and termination of AF remains undefined..$^{7-10,17}$ The clinical history is a consistent tool to 
determine which type of autonomic predominance results in a destabilization of the arrhythmogenic substrate. $^{3}$

The clinical characteristics of vagal and adrenergic AF have been described previously. According to Coumel et al., ${ }^{4}$ the vagally induced form of AF would occur typically in middle aged males without demonstrable heart disease, and arises more frequently than adrenergic AF. Adrenergic AF would typically occur in the presence of heart disease and can be associated with disorders such as pheochromocytoma and hyperthyroidism. ${ }^{7}$ Our results reveal a different picture of these patients: vagal AF occurred in elderly men whose age did not differ from that in the general Euro Heart Survey population. In addition, many of the vagal AF patients had underlying heart disease. Furthermore, adrenergic AF was identified more frequently among the patients of the Euro Heart Survey than vagal AF (ratio 3:2).

\section{Drug therapy and autonomic atrial fibrillation}

As the initiation of AF can be related to autonomic balance, this balance must be taken into consideration in the choice of medication to treat the arrhythmia. ${ }^{5}$

The guidelines on AF treatment recommend a different approach concerning the choice of rate-control and antiarrhythmic drugs in patients with vagal or adrenergic AF. ${ }^{14}$ The recommendations seem to be based on empirical evidence since controlled studies on the effect of different drugs in autonomic induced AF are lacking. In the vagally mediated form of the arrhythmia, the guidelines advice to avoid treatment with beta-blocking drugs, sotalol, propafenone or digitalis, as they may worsen symptoms. Among the patients with adrenergic AF, the guidelines advise beta-blockers as first line treatment, followed by sotalol or amiodarone.

The results from the present study suggest that physicians do not seem to choose drug therapy based upon the autonomic pattern of induction of AF. Most remarkable was the finding that the frequency of beta-blocker administration was not altered by the presence of vagal triggers for AF (44\% still received betablocker) or sympathetic triggers (36\% did not receive a beta-blocker).

In general, physicians want to prevent high heart rates during recurrences of AF. Also, during treatment with Class Ic antiarrhythmic drugs, rate-control medication is advised to prevent 1:1 conduction in the case of Ic atrial flutter. Therefore, ratecontrolling drugs such as beta-blockers and digitalis are used frequently. However, nondihydropiridine calcium channel blockers (i.e. verapamil and diltiazem) could be used as safe alternatives. Furthermore, the need for rate control in patients with paroxysmal vagal AF may be less, since the heart rate during vagal AF is usually not as high as in adrenergic AF. ${ }^{18}$ On the other hand, vagal AF patients also suffer frequently from underlying heart disease necessitating the application of a beta-blocker.

Among the patients with adrenergic AF, use of recommended treatment was particularly seen in patients suffering from chronic heart failure and coronary artery 
disease. We assume that this is explained by the fact that a beta-blocker is indicated in both heart failure and coronary disease.

Although only borderline significant, there is a clear trend towards deterioration of the arrhythmia to persistent or even permanent AF in patients with vagal AF receiving nonrecommended treatment. Clinical consumption (electrical or pharmacological cardioversions, catheter ablations, hospitalizations, consultations) was equal in both groups receiving recommended and nonrecommended medication.

\section{Study limitations}

In this non-randomized study, we performed a subgroup analysis of the Euro Heart Survey. As a result, our findings should be interpreted with care. An observed poor statistical significance in a subgroup may be a result of lack of power due to small numbers rather than absence of a relation. On the other hand, experimentwise type I error may be the result of multiple testing in this study.

Regrettably, there are no quantitative measures known to reproduce vagal or adrenergic predominance. The assessment of triggers in patients with AF is challenging. Adequate history taking is essential in the identification of trigger patterns as it might be difficult to discriminate between triggers that initiate the arrhythmia and factors that worsen the symptoms. In clinical practice, triggers such as exercise and emotion can be misinterpreted and wrongly recognized as triggers for AF. The physician has a crucial role in identifying this bias. Our report is based on this clinical judgement by the physician. Since data on triggers were not verified in $23 \%$ of the patients, the reported numbers on prevalence of triggers and autonomic trigger patterns are probably underestimated.

\section{Conclusion}

The Euro Heart Survey is the first large observational study to provide a description of the clinical characteristics of paroxysmal AF patients having triggers and autonomic trigger patterns, its management, and outcome. An autonomic trigger pattern (vagal or adrenergic) was found in almost one-third of the patients. Patients with vagal AF have similar characteristics to patients with adrenergic AF and much more frequently underlying heart disease than previously thought. Physicians do not seem to choose rhythm or rate control medication based upon autonomic trigger pattern of AF. However, the role of autonomic influences should be taken into consideration in order to achieve an optimal management of the disease as non-recommended treatment may result in aggravation of the arrhythmia. 


\section{References}

1. Chugh SS, Blackshear JL, Shen WK, Hammill SC, Gersh BJ. Epidemiology and natural history of atrial fibrillation: clinical implications. J Am Coll Cardiol 2001;37:371-378.

2. Coumel P. Cardiac arrhythmias and the autonomic nervous system. J Cardiovasc Electrophysiol 1993; 4:338-355.

3. Coumel P. Paroxysmal atrial fibrillation: a disorder of autonomic tone? Eur Heart J 1994;15(Suppl. A):9-16.

4. Coumel P. Autonomic influences in atrial tachyarrhythmias. J Cardiovasc Electrophysiol 1996;7:9991007.

5. Coumel P, Thomas O, Leenhardt A. Drug therapy for prevention of atrial fibrillation. Am J Cardiol 1996;77:3A-9A.

6. Coumel P. Clinical approach to paroxysmal atrial fibrillation. Clin Cardiol 1990;13:209-212.

7. Chen J, Wasmund SL, Hamdan MH. Back to the future: the role of the autonomic nervous system in atrial fibrillation. Pacing Clin Electrophysiol 2006;29:413-421.

8. Bettoni M, Zimmermann M. Autonomic tone variations before the onset of paroxysmal atrial fibrillation. Circulation 2002;105:2753-2759.

9. Tomita T, Takei M, Saikawa Y, Hanaoka T, Uchikawa S, Tsutsui H, Aruga M, Miyashita T, Yazaki Y, Imamura H, Kinoshita O, Owa M, Kubo K. Role of autonomic tone in the initiation and termination of paroxysmal atrial fibrillation in patients without structural heart disease. J Cardiovasc Electrophysiol 2003;14:559-564.

10. Zimmermann M, Kalusche D. Fluctuation in autonomic tone is a major determinant of sustained atrial arrhythmias in patients with focal ectopy originating from the pulmonary veins. I Cardiovasc Electrophysiol 2001;12:285-291.

11. Fioranelli M, Piccoli M, Mileto GM, Sgreccia F, Azzolini P, Risa MP, Francardelli RL, Venturini E, Puglisi A. Analysis of heart rate variability five minutes before the onset of paroxysmal atrial fibrillation. Pacing Clin Electrophysiol 1999;22:743-749.

12. Bertaglia E, Zoppo F, Bonanno C, Pellizzari N, Frigato N, Pascotto P. Autonomic modulation of the sinus node following electrical cardioversion of persistent atrial fibrillation: relation with early recurrence. Int J Cardiol 2005;102:219-223.

13. Kanoupakis EM, Manios EG, Mavrakis HE, Kaleboubas MD, Parthenakis FI, Vardas PE. Relation of autonomic modulation to recurrence of atrial fibrillation following cardioversion. Am J Cardiol 2000;86:954-958.

14. Fuster V, Ryden LE, Cannom DS, Crijns HJ, Curtis AB, Ellenbogen KA, Halperin JL, Le Heuzey JY, Kay GN, Lowe JE, Olsson SB, Prystowsky EN, Tamargo JL, Wann S, Smith SC Jr, Jacobs AK, Adams CD, Anderson $\mathrm{JL}$, Antman EM, Halperin JL, Hunt SA, Nishimura R, Ornato JP, Page RL, Riegel B, Priori SG, Blanc JJ, Budaj A, Camm AJ, Dean V, Deckers JW, Despres C, Dickstein K, Lekakis J, McGregor K, Metra M, Morais J, Osterspey A, Tamargo JL, Zamorano JL. ACC/AHA/ESC 2006 Guidelines for the management of patients with atrial fibrillation: a report of the American College of Cardiology/American Heart Association Task Force on Practice Guidelines and the European Society of Cardiology Committee for Practice Guidelines (Writing Committee to Revise the 2001 Guidelines for the Management of Patients With Atrial Fibrillation): developed in collaboration with the European Heart Rhythm Association and the Heart Rhythm Society. Circulation 2006;114:e257-e354.

15. Nieuwlaat R, Capucci A, Camm AJ, Olsson SB, Andresen D, Davies DW, Cobbe S, Breithardt G, Le Heuzey JY, Prins MH, Levy S, Crijns HJ. Atrial fibrillation management: a prospective survey in ESC member countries: the Euro Heart Survey on Atrial Fibrillation. Eur Heart J 2005;26:2422-2434.

16. Allessie M, Ausma J, Schotten U. Electrical, contractile and structural remodeling during atrial fibrillation. Cardiovasc Res 2002;54:230-246.

17. Olshansky B. Interrelationships between the autonomic nervous system and atrial fibrillation. Prog Cardiovasc Dis 2005;48:57-78.

18. van den Berg MP, Crijns HJ, Haaksma J, Brouwer J, Lie KI. Analysis of vagal effects on ventricular rhythm in patients with atrial fibrillation. Clin Sci (Lond) 1994;86:531-535. 


\section{Chapter 3}

Progression from paroxysmal to persistent atrial fibrillation

Clinical correlates and prognosis

CB de Vos, R Pisters, R Nieuwlaat, MH Prins, RG Tieleman, R-JS Coelen, AC van den Heijkant, MA Allessie, HJGM Crijns

J Am Coll Cardiol 2010;55:725-731 


\section{Abstract}

Objectives

We investigated clinical correlates of atrial fibrillation (AF) progression and evaluated the prognosis of patients demonstrating AF progression in a large population.

\section{Background}

Progression of paroxysmal AF to more sustained forms is frequently seen. However, not all patients will progress to persistent AF.

\section{Methods}

We included 1,219 patients with paroxysmal AF who participated in the Euro Heart Survey on AF and had a known rhythm status at follow-up. Patients who experienced AF progression after 1 year of follow-up were identified.

\section{Results}

Progression of AF occurred in 178 (15\%) patients. Multivariate analysis showed that heart failure, age, previous transient ischemic attack or stroke, chronic obstructive pulmonary disease, and hypertension were the only independent predictors of AF progression. Using the regression coefficient as a benchmark, we calculated the HATCH score. Nearly $50 \%$ of the patients with a $\mathrm{HATCH}$ score $>5$ progressed to persistent AF compared with only $6 \%$ of the patients with a $\mathrm{HATCH}$ score of 0 . During follow-up, patients with AF progression were more often admitted to the hospital and had more major adverse cardiovascular events.

\section{Conclusions}

A substantial number of patients progress to sustained AF within 1 year. The clinical outcome of these patients regarding hospital admissions and major adverse cardiovascular events was worse compared with patients demonstrating no AF progression. Factors known to cause atrial structural remodeling (age and underlying heart disease) were independent predictors of AF progression. The HATCH score may help to identify patients who are likely to progress to sustained forms of AF in the near future. 


\section{Introduction}

Atrial fibrillation (AF) is the most common sustained cardiac arrhythmia in clinical practice. The arrhythmia is associated with increased morbidity and mortality, mainly as a result of 2 complications: stroke and heart failure. ${ }^{1}$ In clinical practice, one should distinguish between the clinical AF type (paroxysmal AF, episodes of the arrhythmia that terminate spontaneously) and persistent AF (episodes that are sustained longer than 7 days and are not selfterminating). ${ }^{2}$ The latter will affect the individual treatment strategy for each patient. Important differences were found between the clinical subsets of AF. ${ }^{3}$ Underlying heart disease occurs more frequently in patients with sustained AF. Patients with paroxysmal AF are more often treated with antiarrhythmic drugs, whereas patients with chronic AF receive more rate control therapy. In the CARAF (Canadian Registry of Atrial Fibrillation) study, investigators evaluated determinants of AF progression. ${ }^{4}$ The investigators found that underlying heart disease and age were independently associated with progression of AF. The Euro Heart Survey (EHS) on AF presents a unique overview of AF management in a large group of patients in several European countries. Nieuwlaat et al. ${ }^{5}$ previously reported the influence of underlying heart disease on the progression of AF in the EHS. However, in this univariate analysis, no correction for possible confounders was performed, and the contribution of each factor to AF progression was not studied.

The present study is the largest study to investigate the clinical correlates of arrhythmia progression in patients with paroxysmal AF. In addition, we evaluated the prognosis of patients with AF progression and validated a risk stratification rule to assess the probability of AF progression.

\section{Methods}

A detailed description of the methods, data collection, validation, and the first results of the EHS on AF were presented by Nieuwlaat et al. ${ }^{6}$ In 2003 and 2004, 5,333 AF patients were enrolled in this survey. These patients were enrolled at 182 hospitals in 35 different member countries of the European Society of Cardiology. Inclusion criteria were age older than 18 years and $\mathrm{AF}$ on an electrocardiogram or Holter recording in the previous 12 months or at the time of inclusion. Enrollment of consecutive patients took place at several sites within the cardiology departments.

$A F$ was classified into 5 categories. The clinical AF type was first detected AF in 978 patients, paroxysmal AF in 1,517 patients, persistent AF in 1,167 patients, permanent $A F$ in 1,541 patients, and unknown type of $A F$ in 130 patients. In the present study, only the records for patients with paroxysmal AF and first detected AF in whom sinus rhythm restored spontaneously or after pharmacological treatment during admission were evaluated, leaving a study population of 1,219 patients with a known rhythm status at 1-year follow-up. We did not include patients who underwent 
electrical cardioversion to sinus rhythm because one cannot be sure that those patients have self-terminating AF. In addition, we did not take persistent AF as a separate entity to evaluate progression to permanent AF because the classification permanent $A F$ is physician driven and does not depend on the pathophysiology or clinical characteristics of the arrhythmia and therefore precludes proper assessment of progression. $^{2}$

In the EHS on AF, data were collected from medical records and medical information systems or entered by the attending physician. Progression of AF was defined as follows: paroxysmal AF at baseline becoming persistent or permanent AF at 1-year follow-up or first detected $A F$ at baseline with spontaneous conversion to sinus rhythm during admission becoming persistent or permanent $A F$ at 1-year follow-up. We also determined the CHADS 2 score. ${ }^{7}$ This acronym stands for congestive heart failure, hypertension, age (75 years and older), diabetes mellitus, and a history of stroke/transient ischemic attack (TIA) (2 points). This scoring system allows instant classification of the relative thromboembolic risk in patients with $A F$ and is incorporated in the latest guidelines on the management of AF.

\section{Statistical analysis}

Data analysis was performed with SPSS statistical software (version 15.0, SPSS Inc., Chicago, Illinois). Continuous variables are reported as mean \pm SD and categorical variables as observed number of patients (percentage). When comparing patients with AF progression and no AF progression regarding baseline characteristics, treatment, or outcome, we used an independent $t$ test for continuous variables and the Fisher exact test for categorical variables. The $P$ values resulting from these analyses are reported in Tables 3.1, 3.2, and 3.3. All baseline characteristics showing a significant univariate relationship with $\mathrm{AF}$ progression at follow-up were included in a logistic regression model (heart failure in history, chronic obstructive pulmonary disease [COPD] in history, left atrial size on echocardiogram, age, regular physical activity, hypertension, coronary artery disease, valve disease, previous stroke or TIA, renal failure). We did not include the variables lone AF or CHADS2 score in the model because they were derived from other variables included in the model. Model reduction was performed by stepwise excluding variables from the model with a $P$ value $<0.10$. All variables that were independently associated with AF progression were tested for interactions. To develop a convenient score, the regression coefficients of the final logistic regression model were used to estimate the contribution of each variable to the risk estimation of AF progression. This resulted in the attribution of 1 or 2 points for each variable included in the score.

The predictive accuracy of the known predictors of AF progression and the HATCH score was reported using a receiver-operator characteristic curve. To compare the discriminative power of the HATCH score (acronym stands for hypertension, age [75 years and older], transient ischemic attack or stroke (2 points), chronic obstructive 
pulmonary disease and heart failure ( 2 points); this scoring system allows instant classification of the risk of progression to persistent or permanent AF in patients with paroxysmal AF) and the CHADS2 score, we applied the Delong, Delong, Clarke-Pearson method using Analyse-it 2.20 statistical software (Leeds, United Kingdom). All tests performed were 2 sided. Overall, a P value of $<0.05$ was considered to be statistically significant.

\section{Results}

The age of the 1,219 patients included in the present study was $64 \pm 13$ years. Progression of AF to more sustained forms occurred in 178 patients (15\%). Table 3.1 shows the baseline characteristics of patients with and without AF progression. Patients who experienced AF progression were older and performed less regular physical activity. In addition, these patients had more underlying heart disease.

Table 3.1 Baseline characteristics.

\begin{tabular}{|c|c|c|c|c|}
\hline & All patients & No AF progression & AF progression & $P$-value \\
\hline $\mathrm{N}$ & 1219 & $1041(85 \%)$ & $178(15 \%)$ & \\
\hline Age (years) & $64 \pm 13$ & $63 \pm 13$ & $68 \pm 11$ & $<0.001$ \\
\hline Female & $524(43 \%)$ & 439 (42\%) & 85 (49\%) & 0.165 \\
\hline Body Mass Index $\left(\mathrm{kg} / \mathrm{m}^{2}\right)$ & $27 \pm 4$ & $27 \pm 4$ & $28 \pm 5$ & 0.246 \\
\hline Symptoms (admission) & $913(75 \%)$ & $773(74 \%)$ & $140(79 \%)$ & 0.261 \\
\hline Regular physical activity & $415(34 \%)$ & $370(36 \%)$ & $45(25 \%)$ & 0.010 \\
\hline \multicolumn{5}{|l|}{ Echo and ECG characteristics } \\
\hline Left atrial size on echo $(\mathrm{mm})$ & $43 \pm 8$ & $43 \pm 8$ & $45 \pm 8$ & $<0.001$ \\
\hline Ventricular rate (when sinus rhythm) & $70 \pm 15$ & $70 \pm 15$ & $72 \pm 19$ & 0.195 \\
\hline Ventricular rate (when AF) & $109 \pm 30$ & $109 \pm 31$ & $110 \pm 30$ & 0.712 \\
\hline \multicolumn{5}{|l|}{ AF-type } \\
\hline $1^{\text {st }}$ detected & $165(14 \%)$ & $140(13 \%)$ & $25(14 \%)$ & \\
\hline Paroxysmal & $1054(86 \%)$ & $901(87 \%)$ & $153(86 \%)$ & \\
\hline \multicolumn{5}{|l|}{ Underlying diseases } \\
\hline Hypertension & 752 (62\%) & $626(60 \%)$ & $126(71 \%)$ & 0.007 \\
\hline Coronary artery disease & $392(32 \%)$ & $321(31 \%)$ & $71(40 \%)$ & 0.024 \\
\hline Diabetes mellitus & $182(15 \%)$ & $148(14 \%)$ & $34(19 \%)$ & 0.110 \\
\hline Valve disease & $233(19 \%)$ & $188(18 \%)$ & $45(25 \%)$ & 0.030 \\
\hline Heart failure & 247 (21\%) & $181(18 \%)$ & $66(38 \%)$ & $<0.001$ \\
\hline Chronic obstructive pulmonary disease & $137(11 \%)$ & $104(10 \%)$ & $33(19 \%)$ & 0.002 \\
\hline Hyperthyroidism & $60(5 \%)$ & $52(5 \%)$ & $8(5 \%)$ & 0.853 \\
\hline Stroke or TIA in history & $105(9 \%)$ & $77(8 \%)$ & $28(16 \%)$ & 0.001 \\
\hline Malignancy & $56(5 \%)$ & 47 (5\%) & $9(5 \%)$ & 0.699 \\
\hline Peripheral vascular disease & $74(6 \%)$ & $58(6 \%)$ & $16(9 \%)$ & 0.089 \\
\hline Renal failure & $56(5 \%)$ & $41(4 \%)$ & $15(9 \%)$ & 0.018 \\
\hline Lone AF & $203(17 \%)$ & 189 (19\%) & $14(8 \%)$ & $<0.001$ \\
\hline $\mathrm{CHADS}_{2}$ score & $1,3 \pm 1,2$ & $1,2 \pm 1,1$ & $1,9 \pm 1,3$ & $<0.001$ \\
\hline
\end{tabular}

ECG=electrocardiogram; TIA=transient ischemic attack 
Hypertension, coronary artery disease, valve disease, heart failure, COPD, stroke or TIA, and renal failure occurred more frequently in patients with AF progression. This is reflected by the higher mean $\mathrm{CHADS}_{2}$ score $(1.9 \pm 1.3$ vs. $1.2 \pm 1.1, P<0.001)$ and lower percentage of lone AF ( $8 \%$ vs. $19 \%, P<0.001)$ in patients with AF progression compared with patients whose AF remained paroxysmal after 1 year. No significant difference was found between the percentage of patients with diabetes demonstrating AF progression and patients who remained in sinus rhythm. On the echocardiogram obtained at baseline, patients with AF progression had a larger left atrium.

Medication use at baseline is presented in Table 3.2. Understandably, all drugs associated with heart failure were used more frequently in patients with AF progression: digitalis, angiotensin-converting enzyme inhibitors, and diuretics. Furthermore, patients experiencing worsening of their AF used more oral anticoagulation, which likely is the result of a higher mean CHADS 2 score in this group. Patients with AF progression used angiotensin II receptor blockers (7\% vs. $13 \%$, $P=0.023$ ) less frequently. Beta-blockers were prescribed in $56 \%$ of patients with heart failure and in $65 \%$ of patients with coronary artery disease.

Table $3.2 \quad$ Medication use at baseline.

\begin{tabular}{lcccc}
\hline & All patients & No AF progression & AF progression & $P$-value \\
\hline $\mathrm{N}$ & 1219 & $1041(85 \%)$ & $178(15 \%)$ & \\
Oral anticoagulation & $594(50 \%)$ & $490(49 \%)$ & $104(60 \%)$ & 0.007 \\
Aspirin & $437(37 \%)$ & $376(37 \%)$ & $61(35 \%)$ & 0.611 \\
Beta-blocker & $495(42 \%)$ & $418(41 \%)$ & $77(44 \%)$ & 0.506 \\
Diltiazem & $36(3 \%)$ & $29(3 \%)$ & $7(4 \%)$ & 0.468 \\
Verapamil & $60(5 \%)$ & $48(5 \%)$ & $12(7 \%)$ & 0.257 \\
Digitalis & $136(11 \%)$ & $108(11 \%)$ & $28(16 \%)$ & 0.039 \\
Any antiarrhythmic drug & $627(52 \%)$ & $541(52 \%)$ & $86(49 \%)$ & 0.415 \\
- Flecainide & $89(7 \%)$ & $80(8 \%)$ & $9(5 \%)$ & 0.274 \\
- Disopyramide & $6(1 \%)$ & $6(1 \%)$ & 0 & 0.601 \\
- Propafenone & $111(9 \%)$ & $101(10 \%)$ & $10(6 \%)$ & 0.090 \\
- Sotalol & $145(12 \%)$ & $128(12 \%)$ & $17(10 \%)$ & 0.379 \\
- Amiodarone & $288(24 \%)$ & $237(23 \%)$ & $51(29 \%)$ & 0.086 \\
Angiotensin-converting enzyme inhibitor & $518(44 \%)$ & $411(41 \%)$ & $107(62 \%)$ & $<0.001$ \\
Angiotensin-II receptor blocker & $142(12 \%)$ & $130(13 \%)$ & $12(7 \%)$ & 0.023 \\
Diuretics & $428(36 \%)$ & $339(34 \%)$ & $89(51 \%)$ & $<0.001$ \\
\hline
\end{tabular}

During follow-up, in patients with AF progression, either persistent (46\%) or permanent (54\%) AF developed (Table 3.3). The patients with progression were more often symptomatic compared with patients without AF progression. Patients without AF progression had either first detected AF (10\%) or paroxysmal AF $(83 \%)$, and nearly $7 \%$ of the patients were considered cured by their physician. Finally, patients who progressed to more sustained forms of AF underwent more electrical cardioversions, were more often admitted to the hospital for a cardiovascular problem, and had more often a stroke or TIA during the 1 year of follow-up. We found no significant differences in pharmacological cardioversions between both groups. 
Table 3.3 Characteristics at one year follow-up.

\begin{tabular}{|c|c|c|c|c|}
\hline & All patients & No AF progression & AF progression & $P$-value \\
\hline $\mathrm{N}$ & 1219 & $1041(85 \%)$ & $178(15 \%)$ & \\
\hline Symptoms & $366(32 \%)$ & $280(29 \%)$ & $86(52 \%)$ & $<0.001$ \\
\hline Death & $22(2 \%)$ & $16(2 \%)$ & $6(3 \%)$ & 0.118 \\
\hline \multicolumn{5}{|l|}{ Type of AF } \\
\hline -First detected & $107(9 \%)$ & $107(10 \%)$ & 0 & \\
\hline -Paroxysmal & $860(71 \%)$ & $860(83 \%)$ & 0 & \\
\hline -Persistent & $81(7 \%)$ & 0 & $81(46 \%)$ & \\
\hline -Permanent & $97(8 \%)$ & 0 & $97(54 \%)$ & \\
\hline -Considered cured & $74(5 \%)$ & $74(7 \%)$ & 0 & \\
\hline \multicolumn{5}{|l|}{ Hospital admissions during 1 year } \\
\hline Cardiovascular admissions & $523(53 \%)$ & $419(50 \%)$ & $104(71 \%)$ & $<0.001$ \\
\hline Pharmacological cardioversion & $255(23 \%)$ & $217(22 \%)$ & $38(24 \%)$ & 0.534 \\
\hline $\begin{array}{l}\text { Number of pharmacological } \\
\text { cardioversions }\end{array}$ & $0.4 \pm 1.3$ & $0.4 \pm 1.3$ & $0.5 \pm 1.0$ & 0.847 \\
\hline Electrical cardioversion & $161(15 \%)$ & $122(13 \%)$ & $39(26 \%)$ & $<0.001$ \\
\hline Number of electrical cardioversions & $0.2 \pm 0.7$ & $0.2 \pm 0.7$ & $0.4 \pm 0.8$ & 0.009 \\
\hline Catheter ablation & $61(5 \%)$ & $57(6 \%)$ & $4(2 \%)$ & 0.065 \\
\hline \multicolumn{5}{|l|}{ Major adverse Cardiovascular events } \\
\hline Coronary artery disease & $72(6 \%)$ & $57(6 \%)$ & $15(8 \%)$ & 0.168 \\
\hline - Myocardial Infarction & $17(1 \%)$ & $12(1 \%)$ & $5(3 \%)$ & 0.091 \\
\hline - Unstable Angina & $44(4 \%)$ & $34(3 \%)$ & $10(6 \%)$ & 0.130 \\
\hline Ischemic stroke or TIA & $31(3 \%)$ & $20(2 \%)$ & $11(6 \%)$ & 0.003 \\
\hline - Ischemic stroke & $20(2 \%)$ & $12(1 \%)$ & $8(5 \%)$ & 0.005 \\
\hline- TIA & $11(1 \%)$ & $8(1 \%)$ & $3(2 \%)$ & 0.212 \\
\hline Combined survival/stroke & $40(3 \%)$ & $27(3 \%)$ & $13(7 \%)$ & 0.005 \\
\hline
\end{tabular}

The multivariate logistic regression regarding factors associated with AF progression after 1 year of follow-up is presented in Table 3.4. A history of heart failure, hypertension, COPD, and stroke or TIA and age older than 75 years were the only independent factors associated with AF progression. No significant interactions were found between these variables. Using the regression coefficient as a benchmark, we determined the relative contribution of each factor to the prediction of AF progression. This resulted in the HATCH score rule: $1 \times$ (hypertension) $+1 \times$ (age $>75$ years) $+2 \times$ (stroke or TIA) $+1 \times($ COPD) $+2 \times$ (heart failure).

Because of its plausible preventive effect on AF progression, we repeated the logistic regression including antiarrhythmic drugs. However, antiarrhythmic drugs were not present in the final logistic regression model resulting from this analysis. The final model contained the same variables as the initial analysis excluding antiarrhythmic drugs (data not shown). We also excluded first-detected AF patients who underwent a pharmacological cardioversion in a separate analysis (data not shown) because these patients could have a more advanced electrophysiological substrate than pure paroxysmal AF patients. However, this did not alter the results significantly. 
Table 3.4 Independent predictors of AF progression resulting from multivariate logistic regression analysis.

\begin{tabular}{lccccc}
\hline & OR & OR 95\%Cl & $\begin{array}{c}\text { Regression } \\
\text { coefficient }\end{array}$ & $P$-value & Score \\
\hline Heart Failure in history & 2.22 & $1.54-3.22$ & 0.80 & $<0.001$ & 2 \\
Hypertension & 1.52 & $1.05-2.20$ & 0.42 & 0.024 & 1 \\
Chronic obstructive pulmonary disease & 1.51 & $0.95-2.39$ & 0.41 & 0.088 & 1 \\
Stroke or TIA in history & 2.02 & $1.24-3.31$ & 0.71 & 0.007 & 2 \\
Age $>75$ years & 1.57 & $1.07-2.30$ & 0.45 & 0.024 & 1 \\
\hline
\end{tabular}

$\mathrm{OR}=$ odds ratio; $\mathrm{Cl}=$ confidence interval; $\mathrm{TIA}=$ transient ischemic attack

Nearly $50 \%$ of the patients with paroxysmal AF and a HATCH score of 6 or 7 had AF progression after 1 year compared with only $6 \%$ of the patients with a HATCH score of 0 . The percentages of AF progression in patients with a HATCH score of 0 through 7 are presented in Figure 3.1. With increasing $\mathrm{HATCH}$ score, the proportion of patients with AF progression during follow-up increases.

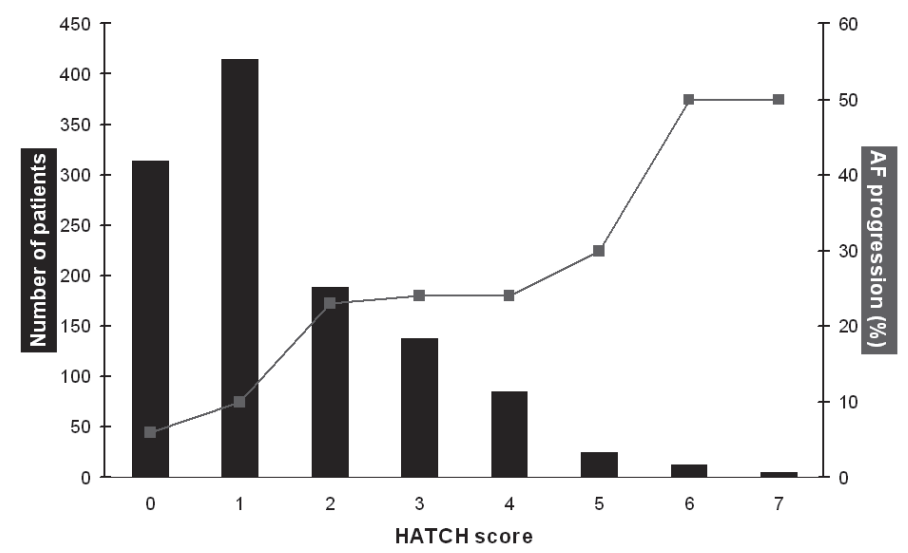

Figure 3.1 Prevalence of the different HATCH scores and incidence of progression.

The number of patients for each HATCH score is represented by the black bars. The percentage of atrial fibrillation (AF) progression after 1 year of follow-up per HATCH score is represented by the grey line.

The receiver-operator characteristic curve to discriminate individuals who will or will not have AF progression during follow-up based on their HATCH score is shown in Figure 3.2. The area under the curve (AUC) is 0.675 (95\% confidence interval: 0.632 to $0.718, P<0.001)$. The predictive value of the $\mathrm{HATCH}$ score is higher than all other independent predictors of $A F$ progression individually: heart failure ( $A \cup C=0.599$ ), hypertension ( $A \cup C=0.564$ ), COPD ( $A \cup C=0.542)$, stroke or TIA ( $A \cup C=0.545)$, and age (AUC=0.561). The AUC of the HATCH score was slightly higher compared with the CHADS2 score (difference: 0.02 (95\% confidence interval: 0.00 to 0.04 ); $P=0.0576$ ). 


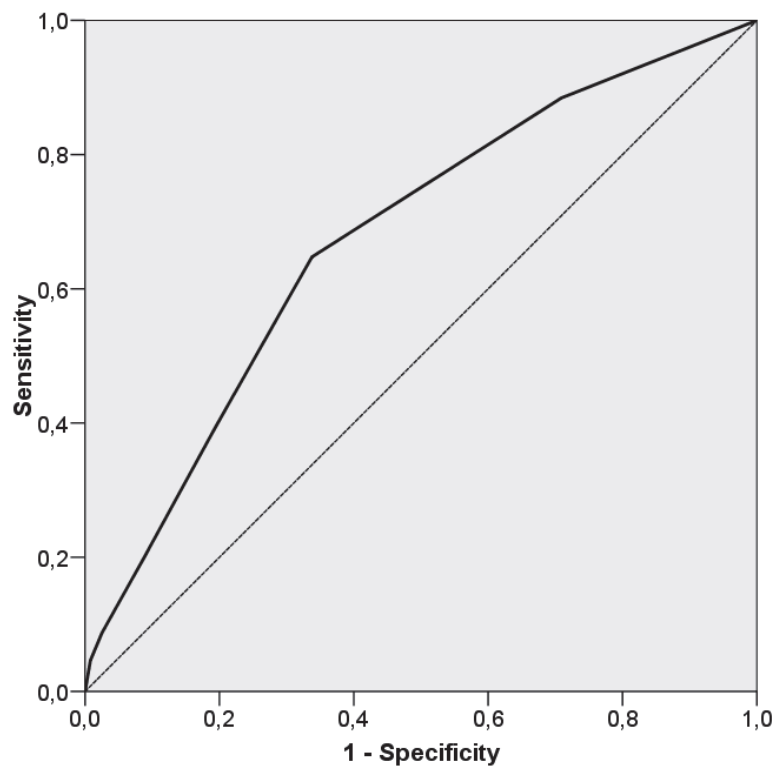

Figure 3.2 Predictive ability of the HATCH Score

The receiver-operator characteristic curve for the prediction of clinical atrial fibrillation type progression using the HATCH score.

We classified patients into 4 groups based on their HATCH score. The percentages of AF progression for each group are presented in Figure 3.3. This figure demonstrates that with increasing score, the percentage of AF progression during follow-up increases as well.

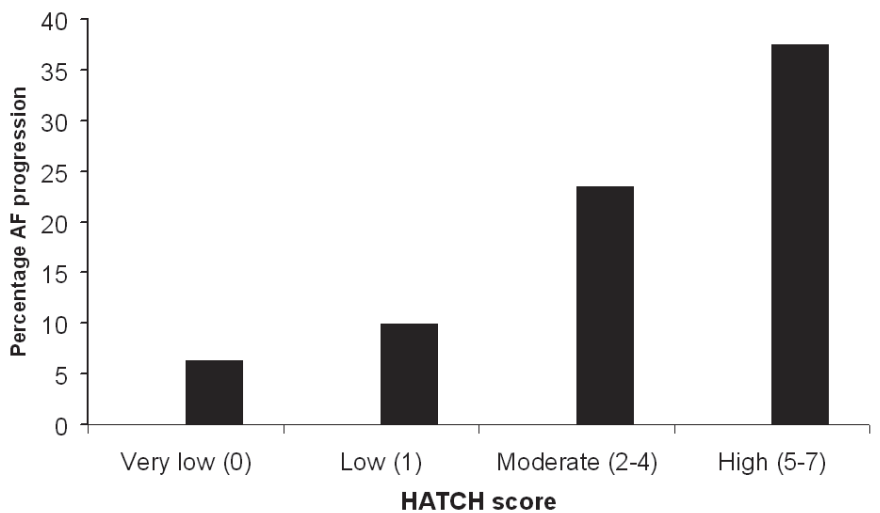

Figure 3.3 Incidence of AF progression.

The 1-year incidence of atrial fibrillation (AF) progression per HATCH score. The HATCH score is divided into 4 categories that could be clinically relevant. 


\section{Discussion}

The present study is the largest study evaluating clinical correlates of AF progression. It provides a unique insight into the characteristics and prognosis of patients with progression from paroxysmal to more sustained forms of AF. Nearly $15 \%$ of the patients with paroxysmal AF included in this study progressed to persistent or permanent AF after 1 year of follow-up, despite the fact that more effort was made to obtain sinus rhythm in this group. In addition, patients with progression had more adverse cardiovascular events and were more often admitted in the hospital. Heart failure, previous stroke or TIA, COPD, hypertension, and age were independent predictors of AF progression. Considering the nature of these factors and in view of the fact that they are associated with future cardiovascular events, one may conjecture that structural rather than electrical remodeling of the atria is involved in AF progression. Underlying diseases might cause chronic stretch and atrial dilation, which seem to be important stimuli for chronic atrial structural remodeling (cellular hypertrophy, fibroblast proliferation, and tissue fibrosis), which enables maintenance of $A F .^{8}$ It is likely that structural atrial remodeling leading to atrial pathology enables the development of cardiovascular events, which might explain the relatively high stroke rate among the patients with AF progression in our survey. In addition, recent studies showed that patients with a higher AF burden, which is the case in patients demonstrating AF progression, are more prone to have a stroke. ${ }^{9}$

Based on the predictors of AF progression, we developed a risk stratification rule to estimate the probability of AF progression in patients with paroxysmal AF: the HATCH score. This score enables the detection of patients in whom more sustained forms of AF are likely to develop in the near future. Previous studies showed that the presence of underlying heart disease is associated with poor outcome of rhythm control therapy. ${ }^{10}$ However, these patients are more likely to have AF progression. In the same way, our data suggest that the potential preventive effect of antiarrhythmic drugs on AF progression was outperformed by the promoting effect of underlying heart disease and age, as represented by the HATCH parameters. Therefore, it seems very important to identify patients that are likely to progress to persistent AF beforehand to avoid needless rhythm control therapy. This holds even more because AF progression may be associated with major events that are easily enhanced by rhythm control drugs known for their potential to induce proarrhythmia, heart failure, and atrioventricular block. In our study, relatively low numbers of beta-blockers were prescribed in patients with heart failure and coronary artery disease. We hypothesized that this is probably the result of the use antiarrhythmic drugs in our patients. Many antiarrhythmic drugs such as amiodarone, sotalol, and propafenone have beta-blocking properties. Bradycardia might result when these antiarrhythmic drugs are prescribed together with a beta-blocker. Our results suggest that if a high HATCH score is found, clinicians should focus on rate control and upstream therapy rather than rhythm control therapy. Several studies investigating AF progression have been published in the 
past. ${ }^{5,11-13}$ The rate of AF progression described in these studies varied between $8 \%{ }^{4}$ and $22 \%{ }^{14}$ after 1 year of follow-up, depending on the rhythm-monitoring methods used. Various factors were associated with AF progression: valvular disease, alcohol consumption, age, left atrial dimension and amount of atrial enlargement over time, stroke, and heart failure. However, correction for possible confounders was not always performed, and the currently available risk stratification parameters resulting from these studies have limited predictive value in individual patients. Our findings suggest that combining several independent predictors of AF progression into a balanced rule outperforms all the previously known predictors for the development of sustained AF.

\section{Clinical implications}

The HATCH score in daily practice could guide the physician in the clinical decisionmaking process. First, patients with a high HATCH score should be monitored more frequently because they are prone to the development of cardiovascular events. In addition, one could hypothesize that the HATCH score may be used for early selection of patients for rhythm control therapy in an effort to prevent disease progression. Conversely, potentially harmful drugs and interventions including cardioversion and ablation may be avoided in patients with a high HATCH score. Obviously, further studies are needed to confirm these hypotheses and show the clinical value of the HATCH score when implemented in clinical practice.

\section{Study limitations}

We performed a subgroup analysis of the EHS. As a result, our data should be interpreted with care. Follow-up regarding rhythm status was unavailable for approximately $31 \%$ of the patients with first detected or paroxysmal AF at baseline. Patients with unknown rhythm status had more often underlying heart disease and a higher HATCH score (1.8 vs. 1.5) compared with patients with a known rhythm status at follow-up (additional data not shown). This may have led to an underestimation of the incidence of AF progression. Conversely, this does not, in our view, reduce the predictive capacity of the HATCH score.

Considering the relatively low use of beta-blockers, ACE inhibitors, and angiotensinreceptor blockers, the patients included in the present analysis may have been undertreated, especially the patients concomitantly having coronary artery disease and heart failure. ${ }^{15}$ Future studies may show that progression factors other than the HATCH score are important in AF patients fully managed according to all the guidelines pertinent to their various underlying diseases. The definition of AF progression that we selected is arbitrary. In clinical practice, it is extremely difficult to robustly determine the progression from persistent to permanent AF because a firm end point is lacking. However, we believe that our definition reflects the pathophysiological stage of AF severity. This is supported by the direct or indirect relationship between AF 
progression as defined and clinical outcomes such as hospital admissions and major adverse cardiovascular events.

The predictive value of the HATCH score was not flawless. In addition, the score should be validated in another population of patients with AF before it can be applied in clinical practice.

\section{Conclusions}

This is the largest study exploring the characteristics and outcome of patients with AF progression. A substantial number of patients progress to sustained AF within 1 year. The clinical outcome of these patients with regard to hospital admissions and major adverse cardiovascular events was worse compared with patients demonstrating no AF progression. Heart failure, previous stroke or TIA, COPD, hypertension, and age were independent predictors of AF progression. Based on these parameters, we developed the HATCH score, which enhances detection of patients in whom more sustained forms of AF are likely to develop in the near future. 


\section{References}

1. Kannel WB, Abbott RD, Savage DD, McNamara PM. Epidemiologic features of chronic atrial fibrillation: the Framingham study. N Engl J Med 1982;306:1018-1022.

2. Fuster V, Rydén LE, Cannom DS, Crijns HJ, Curtis AB, Ellenbogen KA, Halperin JL, Le Heuzey JY, Kay GN, Lowe JE, Olsson SB, Prystowsky EN, Tamargo JL, Wann S, Smith SC Jr, Jacobs AK, Adams CD, Anderson JL, Antman EM, Hunt SA, Nishimura R, Ornato JP, Page RL, Riegel B, Priori SG, Blanc JJ, Budaj A, Camm AJ, Dean V, Deckers JW, Despres C, Dickstein K, Lekakis J, McGregor K, Metra M, Morais J, Osterspey A, Zamorano JL ACC/AHA/ESC 2006 guidelines for the management of patients with atrial fibrillationexecutive summary: a report of the American College of Cardiology/American Heart Association Task Force on Practice Guidelines and the European Society of Cardiology Committee for Practice Guidelines (Writing Committee to Revise the 2001 Guidelines for the Management of Patients With Atrial Fibrillation). J Am Coll Cardiol 2006;48:854-906.

3. Lévy S, Maarek M, Coumel P, Guize L, Lekieffre J, Medvedowsky JL, Sebaoun A. Characterization of different subsets of atrial fibrillation in general practice in France: the ALFA study. The College of French Cardiologists. Circulation 1999;99: 3028-3035.

4. Kerr CR, Humphries KH, Talajic M, Klein GJ, Connolly SJ, Green M, Boone J, Sheldon R, Dorian P, Newman D. Progression to chronic atrial fibrillation after the initial diagnosis of paroxysmal atrial fibrillation: results from the Canadian Registry of Atrial Fibrillation. Am Heart J 2005;149:489-496.

5. Nieuwlaat R, Prins MH, Le Heuzey JY, Vardas PE, Aliot E, Santini M, Cobbe SM, Widdershoven JW, Baur LH, Lévy S, Crijns HJ. Prognosis, disease progression, and treatment of atrial fibrillation patients during 1 year: follow-up of the Euro Heart Survey on atrial fibrillation. Eur Heart J 2008;29:1181-1189.

6. Nieuwlaat R, Capucci A, Camm AJ, Olsson SB, Andresen D, Davies DW, Cobbe S, Breithardt G, Le Heuzey JY, Prins MH, Lévy S, Crijns HJ; European Heart Survey Investigators. Atrial fibrillation management: a prospective survey in ESC member countries: the Euro Heart Survey on Atrial Fibrillation. Eur Heart J 2005;26:2422-2434.

7. Gage BF, Waterman AD, Shannon W, Boechler M, Rich MW, Radford MJ. Validation of clinical classification schemes for predicting stroke: results from the National Registry of Atrial Fibrillation. JAMA 2001;285:2864-2870.

8. Eckstein J, Verheule S, de Groot NM, Allessie M, Schotten U. Mechanisms of perpetuation of atrial fibrillation in chronically dilated atria. Prog Biophyss Mol Biol 2008;97:435-451.

9. Botto GL, Padeletti L, Santini M, Capucci A, Gulizia M, Zolezzi F, Favale S, Molon G, Ricci R, Biffi M, Russo G, Vimercati M, Corbucci G, Boriani G. Presence and duration of atrial fibrillation detected by continuous monitoring: crucial implications for the risk of thromboembolic events. J Cardiovasc Electrophysiol 2009;20:241-248.

10. Shah AN, Mittal S, Sichrovsky TC, Cotiga D, Arshad A, Maleki K, Pierce WJ, Steinberg JS. Long-term outcome following successful pulmonary vein isolation: pattern and prediction of very late recurrence. J Cardiovasc Electrophysiol 2008;19:661-667.

11. Ruigomez A, Johansson S, Wallander MA, Garcia Rodriguez LA. Predictors and prognosis of paroxysmal atrial fibrillation in general practice in the UK. BMC Cardiovasc Disord 2005;5:20.

12. Parkash R, Green MS, Kerr CR, Connolly SJ, Klein GJ, Sheldon R, Talajic M, Dorian P, Humphries KH; Canadian Registry of Atrial Fibrillation. The association of left atrial size and occurrence of atrial fibrillation: a prospective cohort study from the Canadian Registry of Atrial Fibrillation. Am Heart $J$ 2004;148:649-654.

13. Kato T, Yamashita T, Sagara K, linuma H, Fu LT. Progressive nature of paroxysmal atrial fibrillation. Observations from a 14-year follow-up study. Circ J 2004;68:568-572.

14. Gianfranchi L, Brignole M, Menozzi C, Lolli G, Bottoni N. Determinants of development of permanent atrial fibrillation and its treatment. Europace 1999;1:35-39.

15. Nieuwlaat R, Eurlings LW, Cleland JG, Cobbe SM, Vardas PE, Capucci A, López-Sendòn JL, Meeder JG, Pinto YM, Crijns HJ. Atrial fibrillation and heart failure in cardiology practice: reciprocal impact and combined management from the perspective of atrial fibrillation: results of the Euro Heart Survey on atrial fibrillation. J Am Coll Cardiol 2009;53:1690-1698. 


\title{
Editorial comment
}

\section{Progression of Paroxysmal to Persistent Atrial Fibrillation}

\author{
Factors Promoting the HATCH Score
}

A Jahangir , S Murarka

J Am Coll Cardiol. 2010;55:732-734

With a lifetime 1 in 4 risk of its development, ${ }^{1}$ atrial fibrillation (AF) continues to be the most common cardiac arrhythmia that impairs quality of life and contributes to increased susceptibility to heart failure, hospitalization, stroke, and mortality, costing society more than $\$ 15$ billion annually. ${ }^{2,3}$ With the rapid increase in the number of elderly patients ${ }^{4}$ and cardiovascular comorbidities ${ }^{5}$, a 6 -fold increase in the prevalence of $\mathrm{AF}$ (from 2.3 million to 15.9 million) is projected, ${ }^{6}$ highlighting the magnitude of the problem and the far-reaching implications that the epidemic of AF will have on the health and economics of the country. Thus, an urgent need exists to better understand clinical factors and the basic biology that predispose to AF and its progression and associated complications so that effective preventive strategies can be implemented to reduce the burden of AF on society. AF is a heterogeneous disorder with variable etiology, clinical profile, and natural history. ${ }^{2}$. From a clinical perspective, AF has been broadly classified as paroxysmal, persistent (or long-lasting), and permanent, depending on the duration of symptoms and its propensity to terminate by itself, terminate with electrical or pharmacological intervention, or not terminate at all. ${ }^{2,7}$ The electrophysiological basis for the initiation and/or maintenance of AF varies depending on age, the presence of underlying heart disease, and other modulating factors. In the majority of patients, AF occurs in the setting of structural heart disease, with only a small percentage exhibiting $A F$ as a primarily electrical disorder. ${ }^{2,8}$ Changes in hemodynamic, mechanical, neurohumoral, metabolic, and inflammatory factors that accompany aging or agingassociated diseases, ${ }^{9}$ such as heart failure, valvular heart disease, hypertension, myocardial infarction, pulmonary disease, and diabetes contribute to the development of $A F$, yet the common mechanistic link between these factors and the development of the substrate for AF or its progression is not fully understood. ${ }^{10}$

In this issue of the Journal, de Vos et al. ${ }^{11}$ report the results of their investigation on the clinical correlates of AF progression and prognosis in patients enrolled in the Euro Heart Survey of AF. The Euro Heart Survey enrolled 5,333 adult patients between 2003 and 2004 in 182 hospitals among 35 different European countries and represents a unique overview of real-life AF management within cardiology practices across Europe. ${ }^{12}$ Their report is on 1,219 patients with paroxysmal or first detected AF in whom sinus rhythm restored spontaneously or after pharmacological treatment during 
admission and who had a known rhythm status at 1-year follow-up. Progression of AF to persistent or long-lasting forms occurred in 178 (15\%) patients. These patients were older and had more underlying cardiovascular disease and other comorbidities. On multivariate analysis, HATCH (hypertension, age older than 75 years, previous transient ischemic attack or stroke, chronic obstructive pulmonary disease, and heart failure) were identified as independent predictors of AF progression. Using the regression coefficient as a benchmark, the investigators came up with the HATCH score to predict the probability of progression of AF. With an increasing HATCH score, the proportion of patients in whom AF progressed to longlasting forms was significantly higher with a greater number of hospital admissions and major adverse cardiovascular events compared with those with fewer of these risk factors.

The strength of this study is the provision of information about AF management and progression in patients in 35 European countries in real-life situations and the development of a risk prediction system for progression of paroxysmal or first detected AF. The major limitation is that information is provided only on $<50 \%$ of patients $(1,219$ of 2,495$)$ who were initially included in the survey with a first episode of AF or paroxysmal AF. ${ }^{12}$ The patients who were not included could have gone either way (i.e. AF progressed or remained paroxysmal), and, hence, the reported results could under- or overestimate the true progression rate. In a population of AF patients referred to cardiology practices within university (majority of patients) and nonuniversity settings in 35 different (western, central, and Mediterranean) European countries with variable facilities and management left to the usual local institutional practices, the interpretation of the data and generalizability to AF patients in the community become difficult. This, combined with the short follow-up period and definition of paroxysmal AF used ${ }^{12}$ diminishes the robustness of the conclusion. The authors included a significant number of patients with AF who required pharmacological cardioversion for restoration of sinus rhythm in paroxysmal AF, which, by standard definition, would have been classified as persistent AF. ${ }^{2}$ These patients could have a different electrophysiological substrate or natural history from those who spontaneously converted to sinus rhythm and thus may have substantially influenced progression analysis. Differences in the definitions used and misclassification of AF subtype at enrollment, as previously reported, ${ }^{12}$ also make comparison with other studies difficult. No information about the date of onset and duration of AF before enrollment is provided. A population with new-onset or recently diagnosed AF could have provided more useful information on progression to longlasting AF. In addition, the use of beta-blockers and other cardiac medicines seems to be low, considering the substantial number of patients with coronary artery disease, hypertension, and heart failure who were included, ${ }^{13}$ raising the concern that these patients may have been undertreated, thus complicating the differentiation of atrial substrate progression due to coronary artery disease, heart failure, or remodeling solely caused by rhythm disturbance or uncontrolled ventricular rate response. 
Although no new insights into the mechanisms of AF or risk predictions are reported, the proposed HATCH scheme for AF progression seems to be a useful scoring system and is the major strength of the article. The striking similarity to $\mathrm{CHADS}_{2}$ (congestive heart failure, hypertension, age [75 years and older], diabetes mellitus, and a history of stroke or transient ischemic attack) score for risk of thromboembolic events ${ }^{14}$ is interesting. Both reflect the advanced age of the AF population and comorbidities, such as the presence of heart failure, hypertension, previous stroke/transient ischemic attack, chronic obstructive pulmonary disease (for progression vs. diabetes mellitus for thromboembolic risk), highlighting factors associated with an advanced substrate for AF progression and its complications. The HATCH score may help to identify patients who are at high risk of progression and hence may be followed more closely than they otherwise would be. The authors suggest that the HATCH score may also identify the population in which the rate versus rhythm control approach should be used, because antiarrhythmic agents were unable to prevent progression of AF in their population. In the absence of randomization to specific treatment strategies and treatment decisions left to the preference of the attending cardiologist, ${ }^{12}$ the conclusion about the lack of effectiveness of antiarrhythmic agents in preventing progression needs to be made with caution. The HATCH score may help, but may not be the sole determinant of the decision for initiating antiarrhythmic therapy, as the treatment for paroxysmal AF needs to be individualized based on the presence of symptoms associated with frequent recurrences. ${ }^{2}$ The findings of the study again reinforce previous recommendations regarding frequent monitoring ${ }^{15}$ for the development and treatment of comorbidities ${ }^{2}$ that may accelerate AF progression and predispose to its complications.

In summary, this study validates the risk factors reported previously for AF progression $^{2}$ in a referral population of cardiology practices within a widely diverse geopolitical area in Europe. The HATCH score seems to be a useful tool to predict the progression of AF but should be validated in other populations with a longer follow-up period before it can be applied in clinical practice. The major challenge raised by this and other studies identifying risk factors for the development and progression of AF is to focus our efforts on identification of common mechanistic links between these factors and the molecular substrate that promotes the development of AF and its progression, so that effective strategies can be developed to prevent $A F$ and its associated complications. 


\section{References}

1. Lloyd-Jones DM, Wang TJ, Leip EP, Larson MG, Levy D, Vasan RS, D'Agostino RB, Massaro JM, Beiser A, Wolf PA, Benjamin EJ. Lifetime risk for development of atrial fibrillation: the Framingham Heart Study. Circulation 2004;110:1042-1046.

2. Fuster V, Ryden LE, Cannom DS, et al. ACC/AHA/ESC 2006 guidelines for the management of patients with atrial fibrillation: a report of the American College of Cardiology/American Heart Association Task Force on Practice Guidelines and the European Society of Cardiology Committee for Practice Guidelines (Writing Committee to Revise the 2001 Guidelines for the Management of Patients With Atrial Fibrillation). J Am Coll Cardiol 2006;48:e149-246.

3. Wu EQ, Birnbaum HG, Mareva M, Tuttle E, Castor AR, Jackman W, Ruskin J. Economic burden and comorbidities of atrial fibrillation in a privately insured population. Curr Med Res Opin 2005;21:16931699.

4. Jahangir A, Sattiaraju S, Shen WK. Senescence and arrhythmogenesis. In: Gussak I AC, editor. Electrical Disease of the Heart: Genetics, Mechanisms, Treatment, and Prevention. London: Springer, 2008: 247-260.

5. Lloyd-Jones D, Adams R, Carnethon M, De Simone G, Ferguson TB, Flegal K, Ford E, Furie K, Go A, Greenlund K, Haase N, Hailpern S, Ho M, Howard V, Kissela B, Kittner S, Lackland D, Lisabeth L, Marelli A, McDermott M, Meigs J, Mozaffarian D, Nichol G, O'Donnell C, Roger V, Rosamond W, Sacco R, Sorlie P, Stafford R, Steinberger J, Thom T, Wasserthiel-Smoller S, Wong N, Wylie-Rosett J, Hong Y. Heart disease and stroke statistics-2009 update: a report from the American Heart Association Statistics Committee and Stroke Statistics Subcommittee. Circulation 2009;119:480-486.

6. Miyasaka Y, Barnes ME, Gersh BJ, Cha SS, Bailey KR, Abhayaratna WP, Seward JB, Tsang TS. Secular trends in incidence of atrial fibrillation in Olmsted County, Minnesota, 1980 to 2000, and implications on the projections for future prevalence. Circulation 2006;114:119-125.

7. Calkins H, Brugada J, Packer DL, Cappato R, Chen SA, Crijns HJ, Damiano RJ Jr, Davies DW, Haines DE, Haissaguerre $M$, lesaka $Y$, Jackman $W$, Jais $P$, Kottkamp $H$, Kuck KH, Lindsay BD, Marchlinski FE, McCarthy PM, Mont JL, Morady F, Nademanee K, Natale A, Pappone C, Prystowsky E, Raviele A, Ruskin JN, Shemin RJ. HRS/EHRA/ECAS expert consensus statement on catheter and surgical ablation of atrial fibrillation: recommendations for personnel, policy, procedures and followup. A report of the Heart Rhythm Society (HRS) Task Force on catheter and surgical ablation of atrial fibrillation. Heart Rhythm 2007;4:816-861.

8. Andalib A, Brugada R, Nattel S. Atrial fibrillation: evidence for genetically determined disease. Curr Opin Cardiol 2008;23:176-183.

9. Liu X, Jahangir A, Shen W. Dysrhythmias in older adults. In: Halter JB, Ouslander JG, Tinetti ME, Studenski S, High KP, Asthana S, editors. Hazzard's Geriatric Medicine and Gerontology. 6th edition. New York, NY: McGraw-Hill, 2009:951-965.

10. Eckstein J, Verheule S, de Groot NM, Allessie M, Schotten U. Mechanisms of perpetuation of atrial fibrillation in chronically dilated atria. Prog Biophys Mol Biol 2008;97:435-451.

11. de Vos CB, Pisters R, Nieuwlaat R, Prins MH, Tieleman RG, Coelen RJ, van den Heijkant AC, Allessie MA, Crijns HJ. Progression from paroxysmal to persistent atrial fibrillation: clinical correlates and prognosis. J Am Coll Cardiol 2010;55:725-731.

12. Nieuwlaat R, Capucci A, Camm AJ, Olsson SB, Andresen D, Davies DW, Cobbe S, Breithardt G, Le Heuzey JY, Prins $M H$, Lévy S, Crijns HJ; European Heart Survey Investigators. Atrial fibrillation management: a prospective survey in ESC member countries: the Euro Heart Survey on Atrial Fibrillation. Eur Heart J 2005;26:2422-2434.

13. Nieuwlaat R, Eurlings LW, Cleland JG, Cobbe SM, Vardas PE, Capucci A, López-Sendòn JL, Meeder JG, Pinto YM, Crijns HJ. Atrial fibrillation and heart failure in cardiology practice: reciprocal impact and combined management from the perspective of atrial fibrillation: results of the Euro Heart Survey on atrial fibrillation. J Am Coll Cardiol 2009;53:1690-1698.

14. Gage BF, Waterman AD, Shannon W, Boechler M, Rich MW, Radford MJ. Validation of clinical classification schemes for predicting stroke: results from the National Registry of Atrial Fibrillation. JAMA 2001;285:2864-2870. 
15. Jahangir A, Lee V, Friedman PA, Trusty JM, Hodge DO, Kopecky SL, Packer DL, Hammill SC, Shen WK, Gersh BJ.Long-term progression and outcomes with aging in patients with lone atrial fibrillation: a 30year follow-up study. Circulation 2007;115:3050-3056. 


\section{Chapter 4}

Progression of atrial fibrillation in the REgistry on Cardiac rhythm disORDers assessing the control of Atrial Fibrillation cohort: Clinical correlates and the effect of rhythm-control therapy

CB De Vos, G Breithardt, AJ Camm, P Dorian, PR Kowey, J-Y Le Heuzey, L Naditch-Brûlé, EN Prystowsky, PJ Schwartz, C Torp-Pedersen, WS Weintraub, HJ Crijns

Am Heart J 2012;163:887-893 


\begin{abstract}
Introduction

Paroxysmal atrial fibrillation (AF) may progress to persistent AF. We studied the clinical correlates and the effect of rhythm-control strategy on AF progression.
\end{abstract}

Methods

RecordAF was a worldwide prospective survey of AF management. Consecutive eligible patients with recent-onset $A F$ were included and allocated to rate or rhythm control according to patient/physician choice. A total of 2,137 patients were followed up for 12 months. Atrial fibrillation progression was defined as a change from paroxysmal to persistent/permanent AF.

\title{
Results
}

Progression of AF occurred in 318 patients (15\%) after 1 year. Patients with AF progression were older; had a higher diastolic blood pressure; and more often had a history of coronary artery disease, stroke or transient ischemic attack, hypertension, or heart failure. Patients treated with rhythm control were less likely to show progression than those treated only with rate control (164/1542 [11\%] vs. 154/595 [26\%], $P<0.001$ ). Multivariable analysis showed that history of heart failure (odds ratio [OR] $2.2,95 \% \mathrm{Cl} 1.7-2.9, P<0.0001$ ), history of hypertension (OR 1.5, 95\% Cl 1.1-2.0, $P=0.01$ ), and rate control rather than rhythm control (OR 3.2, 95\% Cl 2.5-4.1, $P<0.0001$ ) were independent predictors of AF progression. The propensity score-adjusted OR of AF progression in patients with rate rather than rhythm control was 3.3 (95\% Cl 2.4-4.6, $P<0.0001)$.

Conclusions

Although heart failure and hypertension are associated with AF progression, rhythm control is associated with lower risk of AF progression. 


\section{Introduction}

Atrial fibrillation (AF) is the most common sustained cardiac arrhythmia in clinical practice. ${ }^{1}$ Paroxysmal, that is, self-terminating, AF often progresses to persistent AF, which may complicate rhythm control. ${ }^{2,3}$ To determine the preferred treatment strategy in paroxysmal AF, it is appropriate to consider risk factors for AF progression. ${ }^{4}$ However, few data are available on the progression of paroxysmal AF to more sustained forms. Kerr et al. ${ }^{2}$ evaluated determinants of AF progression in the Canadian Registry of Atrial Fibrillation (CARAF) study. They found that underlying heart disease and age are independently associated with progression of AF. More recently, de Vos et al. $^{3}$ studied the clinical correlates of arrhythmia progression in patients with paroxysmal AF and evaluated the prognosis of patients with AF progression, introducing a risk stratification rule to assess the probability of AF progression. They found that heart failure, age, previous transient ischemic attack (TIA) or stroke, chronic obstructive pulmonary disease, and hypertension are independent predictors of AF progression. The clinical outcome of patients demonstrating AF progression regarding hospital admissions and major adverse cardiovascular events was worse compared with patients without progression. A recent report provides an overview of all established and emerging factors for incident AF and AF progression. ${ }^{5}$ The RecordAF is the first worldwide, 1-year observational, longitudinal study of the management of AF in recently diagnosed patients. ${ }^{6}$ In the present study, we evaluated AF progression in the RecordAF cohort.

\section{Methods}

RecordAF is an international (Europe, North and South America, and Asia), observational, prospective, 1-year longitudinal cohort study of patients with AF. A detailed description of the methods, data collection, and initial results of the RecordAF has been published previously. ${ }^{6}$ The study included 5,604 patients and was conducted at 532 sites in 21 countries. Institutional review board approval was obtained at all sites. Recruitment started in May 2007 and was completed in April 2008. The study was conducted in accordance with the Helsinki principles. Patients were included when aged $\geq 18$ years with AF discovered at the inclusion visit or AF diagnosed $\leq 1$ year from inclusion. Atrial fibrillation was diagnosed by electrocardiogram or Holter registration. Rate- or rhythm-control therapy was decided by the patient and the physician according to their standard practice. Exclusion criteria were AF resulting from a transient cause, post-cardiac surgery AF, life expectancy of $<1$ year owing to a severe disease; mental disability; a pacemaker or an implantable cardioverter/defibrillator; scheduled pulmonary vein isolation, atrioventricular node/His bundle ablation, or pacemaker implantation; participation in an AF clinical trial in the previous 3 months; or pregnancy or breastfeeding. Eligible patients included those who met the inclusion 
criteria regardless of the purpose of the visit to the cardiologist or the hospitalization. A total of 10 to 30 consecutive patients were enrolled at each site. The patients gave written informed consent to participate in the study. All patients were evaluated at baseline, after 6 months, and after 12 months during routine follow-up visits.

In the present study, only the records for patients with paroxysmal AF and firstdetected AF in whom sinus rhythm restored spontaneously or after pharmacologic treatment during admission were evaluated, leaving a study population of 2,137. Atrial fibrillation progression was defined as a change from self-terminating or paroxysmal $\mathrm{AF}$ at baseline to non-selfterminating $\mathrm{AF}$, that is, persistent or permanent $\mathrm{AF}$ after 1 year of follow-up. Atrial fibrillation type was determined according to the clinical judgment of the attending physician.

\section{Statistical analysis}

Data analysis was performed with SAS statistical software version 9.1 (SAS Institute, Cary, NC). Continuous variables are reported as mean $\pm S D$, and categorical variables, as observed number of patients and percentage. When comparing patients with "AF progression" and "no AF progression" regarding baseline characteristics, treatment, or outcome, we used an independent $t$ test for continuous variables and $\chi_{2}$ or Fisher exact test for categorical variables. We calculated a derivate of the HATCH score (not including chronic obstructive pulmonary disease [COPD]). $\mathrm{HATCH}$ is an acronym for hypertension, age $>75$ years, TIA or stroke, COPD, and heart failure, which has been proposed as a simple prediction rule for AF progression. ${ }^{3}$ Unfortunately, we were unable to validate the HATCH score in the present study because a history of COPD was not included in the study case record form. We also calculated the $\mathrm{CHADS}_{2}$ (congestive heart failure, hypertension, age $\geq 75$ years, diabetes mellitus, stroke or, TIA) score, a scoring system allowing classification of the relative thromboembolic risk in patients with AF. ${ }^{7}$ All baseline characteristics with a $P$ value $>0.2$ resulting from the univariate comparison between "no AF progression" and "AF progression at follow-up" and all variables having a plausible or historical association with AF progression were included in a logistic regression model to predict progression: age; family history of AF; gender; diabetes; dyslipidemia; hypertension; body mass index; family history of premature cardiovascular disease, coronary artery disease, heart failure, myocardial infarction, stroke, or TIA; valvular heart disease; smoking status; pulse pressure; and AF treatment strategy at baseline. Model construction was performed by a stepwise procedure, with a $P$ value of 0.20 required for entering and of 0.05 for retaining the variable in the model. Odds ratios (ORs) and associated $95 \% \mathrm{Cls}$ were calculated. To adjust for variables that could be associated with treatment strategy, we calculated a propensity score: a stepwise logistic regression was used to estimate the score for each patient based on a wide list of covariates that could possibly be associated with treatment strategy selection. In addition to the variables listed above, ethnicity, carotid stenosis, thyroid disease, renal disease, duration of $A F$, symptoms, 
antithrombotic treatment, antihypertensive treatment, antidiabetic treatment, and country were included. All covariates associated with treatment strategy with a $P$ value $<0.5$ were kept in the model. The patient population was divided into strata defined by the quintiles of propensity score. In each stratum, the main patient characteristics were comparable between rate-control and rhythm-control strategy. Effect of strategy on AF progression was tested across propensity score strata. Overall, $P<0.05$ was considered to be statistically significant.

The registry was funded by Sanofi, Paris, France. The authors are solely responsible for the design and conduct of this study, all study analyses, the drafting and editing of the manuscript, and its final contents.

\section{Results}

We assessed 2,137 patients with paroxysmal AF at study entry and after 12 months of follow-up. The mean age in our population was $65 \pm 12$ years. Progression to persistent AF occurred in 318 patients (15\%) after 1 year. Table 4.1 shows the baseline characteristics. In our population, patients with AF progression were older; had a higher diastolic blood pressure; and were more likely to have a history of coronary artery disease, stroke or TIA, hypertension, or heart failure. As a result, these patients less frequently had "lone AF." Patients with a higher CHADS2 score showed more AF progression: $19 \%$ progression when $\mathrm{CHADS}_{2}>1$ versus $14 \%$ progression when $\mathrm{CHADS}_{2}$ is 1 and 9\% progression when CHADS2 is $0(P<0.0001)$. Patients treated with rhythm control showed less progression than those treated with rate control: $11 \%$ versus $26 \%$; $P<0.001$.

Atrial fibrillation-related medication used at baseline is presented in Figure 4.1. The use of class Ic antiarrhythmic drugs was associated with less AF progression, whereas the use of cardiac glycosides was associated with more AF progression at 1-year follow-up. Regarding non-AF-related medication, $46 \%$ used diuretics, $24 \%$ used dihydropyridine calcium-channel blockers, $83 \%$ used angiotensin-converting enzyme inhibitors or angiotensin receptor blockers, $7 \%$ used nitrates, and $41 \%$ used lipidlowering drugs. No significant differences were found regarding prescription of these medications between patients with and without AF progression. Table 4.2 shows the electrocardiographic parameters of patients with versus without AF progression. The baseline characteristics of patients treated with a rate-control strategy versus those treated with a rhythm-control strategy are presented in Table 4.3. Patients receiving rhythm control were younger and had less valvular heart disease. On the other hand, they had more hypertension and heart failure. However, the left ventricular ejection fraction was nearly the same in both groups. 
Table 4.1 Baseline characteristics.

\begin{tabular}{|c|c|c|c|c|}
\hline Characteristic & Total & Progression & No progression & $P$ value \\
\hline $\mathrm{N}$ & 2137 & 318 & 1819 & \\
\hline Age, years $\pm S D$ & $65.1 \pm 12$ & $67.2 \pm 11$ & $64.7 \pm 12$ & 0.0011 \\
\hline Female sex, $\mathrm{n}(\%)$ & $1013(47)$ & $151(47)$ & $862(47)$ & 0.9749 \\
\hline Ethnicity (except in French arm of study) & & & & 0.2177 \\
\hline White & $1818(86)$ & $268(85)$ & $1550(87)$ & \\
\hline Black & $28(1)$ & $3(1)$ & $25(1)$ & \\
\hline Asian & $170(8)$ & $34(11)$ & $136(8)$ & \\
\hline Other & $88(4)$ & $10(3)$ & $78(4)$ & \\
\hline Body mass index, $\mathrm{kg} / \mathrm{m}^{2}$ & $28.2 \pm 5$ & $28.2 \pm 5$ & $28.2 \pm 5$ & 0.7581 \\
\hline Systolic BP, mm Hg & $133.7 \pm 19$ & $134.8 \pm 21$ & $133.6 \pm 19$ & 0.3938 \\
\hline Diastolic BP, mm Hg & $79.2 \pm 11$ & $80.5 \pm 12$ & $78.9 \pm 11$ & 0.0252 \\
\hline Pulse pressure, $\mathrm{mm} \mathrm{Hg}$ & $54.6 \pm 15$ & $54.3 \pm 16$ & $54.6 \pm 15$ & 0.4713 \\
\hline Family history of premature CVD, $\mathrm{n}(\%)$ & $402(21)$ & $46(17)$ & $356(21)$ & 0.0893 \\
\hline Family history of $A F, n(\%)$ & $228(11)$ & $24(8)$ & $204(11)$ & 0.0527 \\
\hline Smoking status, n (\%) & & & & 0.4014 \\
\hline Never & $1189(57)$ & $186(61)$ & $1003(57)$ & \\
\hline Current & $285(14)$ & $36(12)$ & $249(14)$ & \\
\hline Former & $593(29)$ & $85(28)$ & $508(29)$ & \\
\hline \multicolumn{5}{|l|}{ Cardiovascular disease, $\mathrm{n}(\%)$} \\
\hline Coronary artery disease & 381 (19) & $72(24)$ & $309(18)$ & 0.0213 \\
\hline Myocardial infarction & $175(8)$ & $34(11)$ & $141(8)$ & 0.0770 \\
\hline Stroke or TIA & $165(8)$ & $34(11)$ & $131(7)$ & 0.0283 \\
\hline Arterial hypertension & $1499(70)$ & $247(78)$ & $1252(69)$ & 0.0015 \\
\hline Heart failure & $437(20)$ & $103(32)$ & $334(18)$ & $<0.0001$ \\
\hline Dyslipidemia & $986(46)$ & $136(43)$ & $850(47)$ & 0.1954 \\
\hline Valvular heart disease & $351(17)$ & 60 (19) & $291(16)$ & 0.1932 \\
\hline Diabetes & $321(15)$ & $54(17)$ & $267(15)$ & 0.2926 \\
\hline Arrhythmia other than $\mathrm{AF}$ & $337(16)$ & $39(12)$ & $298(17)$ & 0.0571 \\
\hline Lone AF & $436(20)$ & $35(11)$ & $401(22)$ & $<0.0001$ \\
\hline \multicolumn{5}{|l|}{ Other disease, $\mathrm{n}(\%)$} \\
\hline Thyroid disease & $218(10)$ & $28(9)$ & $190(11)$ & 0.3909 \\
\hline Renal disease & $124(6)$ & $23(7)$ & $101(6)$ & 0.2192 \\
\hline Strategy at baseline, $\mathrm{n}(\%)$ & & & & $<0.0001$ \\
\hline Rhythm control & $1542(72)$ & $164(52)$ & $1378(76)$ & \\
\hline Rate control & $595(28)$ & $154(48)$ & $441(24)$ & \\
\hline
\end{tabular}

$B P$ : blood pressure; $C V D$ : cardiovascular disease; $S D$ : standard deviation

At follow-up, $61 \%$ of the patients with AF progression had developed permanent AF and $39 \%$ persistent AF. Patients with progression more often underwent electrical and pharmacologic cardioversion (Table 4.4). In addition, they more often had a myocardial infarction, stroke, or TIA and were more frequently admitted for cardiovascular events during the year of observation. 


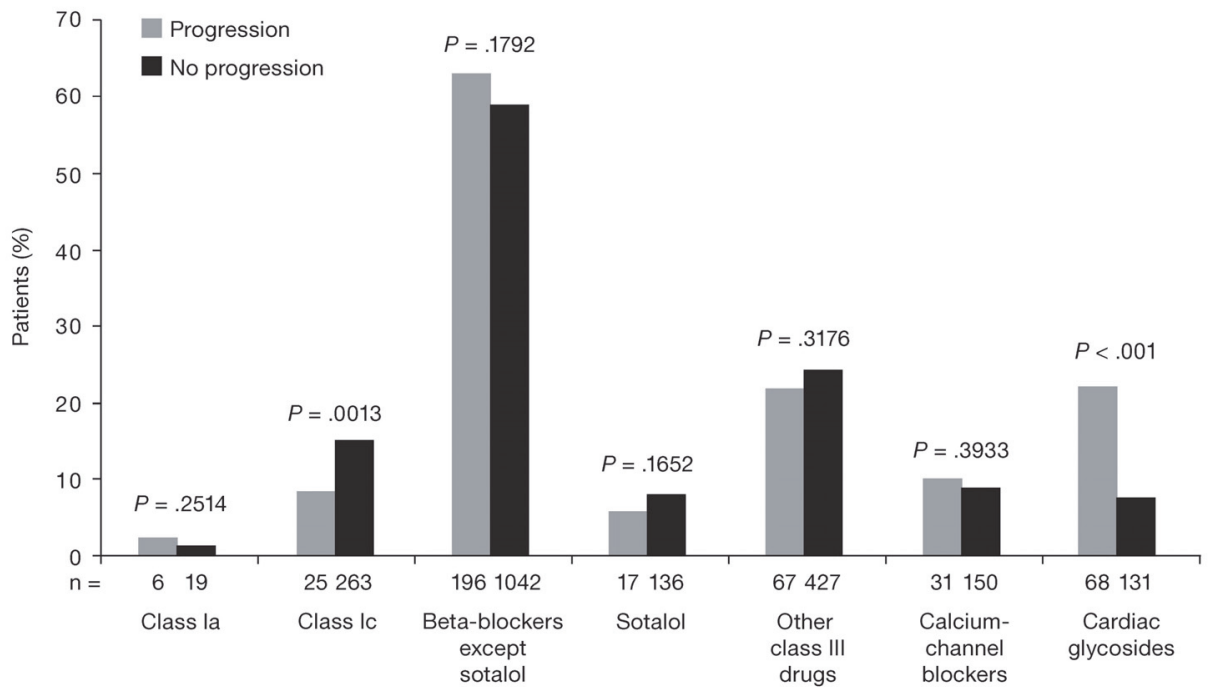

Figure 4.1 Use of AF-related drugs at baseline according to AF status at 1 year.

Table 4.2 Electrocardiogram at baseline (when in sinus rhythm).

\begin{tabular}{lcccc}
\hline Characteristics & Total & Progression & No progression & $P$ value \\
\hline Number of patients & 1445 & 131 & 1314 & \\
PR (ms) & $172.0 \pm 33$ & $175.0 \pm 34$ & $171.6 \pm 33$ & 0.4654 \\
QT (ms) & $395.6 \pm 47$ & $395.8 \pm 48$ & $395.6 \pm 47$ & 0.3710 \\
QRS complex (ms) & $92.9 \pm 18$ & $91.2 \pm 18$ & $93.1 \pm 18$ & 0.3701 \\
T-wave abnormalities & $275(18)$ & $41(29)$ & $234(17)$ & 0.0004 \\
\hline
\end{tabular}

The multivariate logistic regression for factors associated with AF progression after 1-year follow-up showed that a history of heart failure $(\mathrm{OR} 2.2,95 \% \mathrm{Cl} 1.7-2.9$, $P<0.0001$ ), history of hypertension (OR $1.5,95 \% \mathrm{Cl} 1.1-2.0, P=0.0108)$, and rate control rather than rhythm control (OR 3.2, 95\% Cl 2.5-4.1, $P<0.0001$ ) were independent predictors of AF progression. The propensity score-adjusted OR of AF progression in patients with rate rather than rhythm control was $3.3,95 \% \mathrm{Cl} 2.4$ to $4.6, P<0.0001$. The progression rate according to the $\mathrm{HATCH}$ score (without COPD) is presented in Figure 4.2. In the subgroup of patients with a rate-control strategy, predictive factors for AF progression were heart failure (OR 2.9, 95\% Cl 1.8-4.5, $P<0.0001)$ and heart rate (OR $1.02 \mathrm{per}$ beat/min, $95 \% \mathrm{Cl} 1.01-1.03, P<0.0001)$. In the subgroup of patients with a rhythm-control strategy, predictive factors of AF progression were heart failure (OR 2.0, 95\% Cl 1.4-2.8, $P=0.0002$ ), hypertension (OR 1.8, 95\% Cl 1.2-2.7, $P=0.0064$ ), and heart rate (OR 1.01 per beat $/ \mathrm{min}, 95 \% \mathrm{Cl} 1.02, P=0.0003$ ). 
Table 4.3 Baseline characteristics according to strategy AF at baseline.

\begin{tabular}{|c|c|c|c|}
\hline Characteristic & Rate-control strategy & Rhythm-control strategy & $P$ value \\
\hline $\mathrm{N}$ & 595 & 1542 & \\
\hline Age, years \pm SD & $67.8 \pm 11$ & $64.0 \pm 12$ & $<0.0001$ \\
\hline Female sex, $\mathrm{n}(\%)$ & $280(47.1)$ & $733(47.5)$ & 0.8431 \\
\hline Body mass index, $\mathrm{kg} / \mathrm{m}^{2}$ & $28.1 \pm 6$ & $28.2 \pm 5$ & 0.6925 \\
\hline Systolic BP, mm Hg & $132.0 \pm 20$ & $134.4 \pm 19$ & 0.0112 \\
\hline Diastolic BP, mm Hg & $78.0 \pm 11$ & $79.6 \pm 11$ & 0.0017 \\
\hline LVEF available, n (\%) & $476(82.4)$ & $1235(82.2)$ & \\
\hline LVEF by Classes, n (\%) & & & 0.1935 \\
\hline$<30 \%$ & $9(1.9)$ & $9(0.7)$ & \\
\hline 30 to $35 \%$ & $7(1.5)$ & $16(1.3)$ & \\
\hline 36 to $40 \%$ & $8(1.7)$ & $26(2.1)$ & \\
\hline 41 to $50 \%$ & $39(8.2)$ & $83(6.7)$ & \\
\hline$>50 \%$ & $412(86.7)$ & $1099(89.1)$ & \\
\hline Family history of premature CVD, $\mathrm{n}(\%)$ & $103(19.7)$ & $299(21.3)$ & 0.4569 \\
\hline Family history of AF, n (\%) & $60(10.1)$ & 168 (10.9) & 0.5868 \\
\hline \multicolumn{4}{|l|}{ Cardiovascular disease, n (\%)5 (\%) } \\
\hline Coronary artery disease & $112(19.6)$ & $269(19.1)$ & 0.7891 \\
\hline Myocardial infarction & $50(8.5)$ & $125(8.2)$ & 0.8257 \\
\hline Stroke or TIA & $49(8.3)$ & $116(7.6)$ & 0.5660 \\
\hline Arterial hypertension & $411(69.1)$ & $1088(70.6)$ & 0.4890 \\
\hline Heart failure & $104(17.5)$ & $333(21.6)$ & 0.0353 \\
\hline Dyslipidemia & $279(47)$ & 707 (45.9) & 0.6451 \\
\hline Valvular heart disease & $124(21.2)$ & $227(14.8)$ & 0.0004 \\
\hline Diabetes & $100(16.8)$ & $221(14.4)$ & 0.1546 \\
\hline Arrhythmia other than AF & $94(16.1)$ & $243(16.2)$ & 0.9463 \\
\hline Lone AF & $122(20.6 \%)$ & $314(20.4 \%)$ & 0.9357 \\
\hline \multicolumn{4}{|l|}{ Other disease, n (\%) } \\
\hline Thyroid disease & $61(10.4)$ & $157(10.4)$ & 0.9707 \\
\hline Renal disease & $38(6.5)$ & $86(5.6)$ & 0.4362 \\
\hline
\end{tabular}

BP: blood pressure; CVD: cardiovascular disease; LVEF: left ventricular ejection fraction; SD: standard deviation.

Table 4.4 Characteristics at 1-year follow-up.

\begin{tabular}{lcccc}
\hline Characteristic & Total & Progression & No progression & $P$ value \\
\hline $\mathrm{N}$ & 2137 & 318 & 1819 & \\
Cardiovascular intervention, $\mathrm{n}(\%)$ & & & & \\
$\quad$ Pharmacologic conversion & $243(11)$ & $47(15)$ & $196(11)$ & 0.0267 \\
$\quad$ Electrical conversion & $88(4)$ & $34(11)$ & $54(3)$ & $<0.0001$ \\
Catheter ablation & $34(2)$ & $4(1)$ & $30(2)$ & 0.8086 \\
$\quad$ Surgical AF therapy & $7(<1)$ & $2(1)$ & $5(<1)$ & 0.2723 \\
Cardiovascular event & & & & \\
$\quad$ Myocardial infarction & $13(1)$ & $6(2)$ & $7(<1)$ & 0.0065 \\
Stroke/TIA & $40(2)$ & $11(3)$ & $29(2)$ & 0.0204 \\
Hospitalization for cardiovascular event & $342(16)$ & $78(25)$ & $264(15)$ & $<0.0001$ \\
New arrhythmia & $116(6)$ & $20(7)$ & $96(5)$ & 0.3802 \\
$\quad$ Atrial flutter & $29(1)$ & $8(3)$ & $21(1)$ & 0.0579 \\
$\quad$ Other atrial arrhythmia & $26(1)$ & $4(1)$ & $22(1)$ & 0.7826 \\
\hline
\end{tabular}




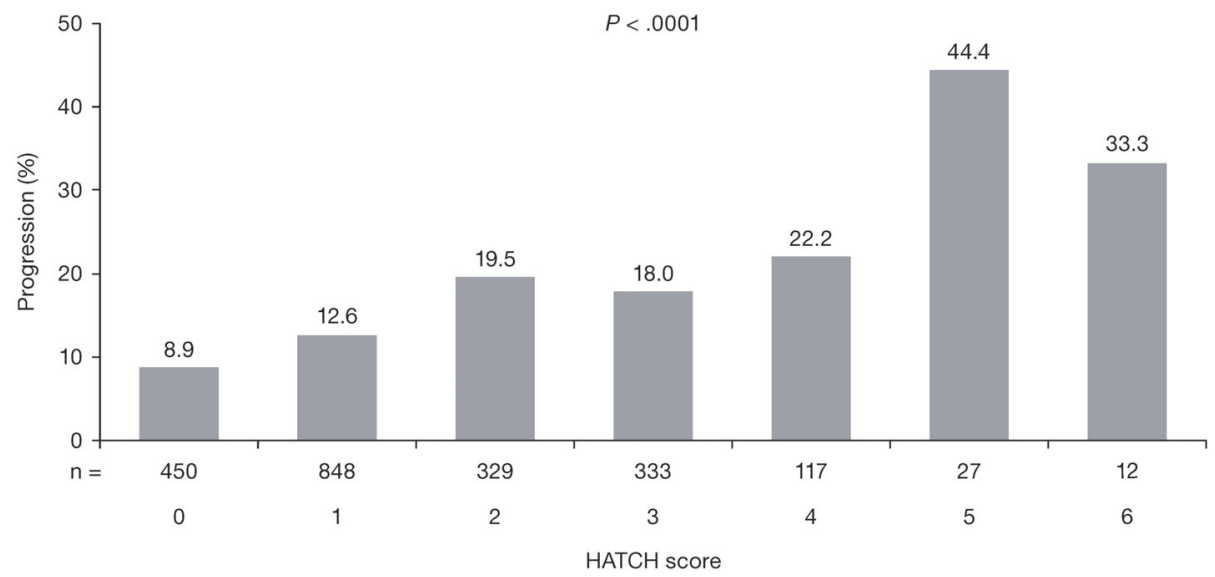

Figure 4.2 Rate of AF progression by HATCH score (without COPD).

\section{Discussion}

The present investigation is a large observational study evaluating clinical correlates and outcome parameters of AF progression in patients with recently diagnosed AF. We found that $15 \%$ of the patients with paroxysmal AF showed AF progression within 1 year of follow-up. Previous studies showed that AF progression is associated with underlying heart disease and structural remodeling. ${ }^{2,3,8-13}$ Factors causing $A F$ progression overlap largely with factors leading to the development of new-onset AF. ${ }^{5}$ Our findings are in line with these studies. A history of heart failure or hypertension and rate-control rather than rhythm-control strategy was independently associated with AF progression in our population. The first 2 factors (hypertension and heart failure) are known to induce structural remodeling of the atria. Both cause chronic stretch and atrial dilatation, which may activate signaling pathways leading to cellular hypertrophy, fibroblast proliferation, and tissue fibrosis. In addition, atrial fibrosis may lead to disruption of the electrical side-to-side junctions between muscle bundles, ${ }^{14,15}$ which may promote and sustain reentry. In addition, pacemaker studies revealed that patients with underlying disease are more prone to sustaining prolonged or multiple atrial tachycardias that result in $A F{ }^{16}$ This is also reflected by an-on the wholeincreased AF progression rate with increasing $\mathrm{HATCH}$ scores. Unfortunately, we were unable to validate the HATCH score in the present study because a history of COPD was not included in the study case record form. The third factor that we found to be associated with AF progression was rate control rather than rhythm control. This could suggest that rhythm control prevents AF progression. One could hypothesize that an aggressive rhythm-control strategy stops electrical remodeling. This is supported by 
the goat studies performed by Wijffels et al., ${ }^{17}$ who demonstrate that artificial maintenance of AF leads to a marked shortening of atrial refractory period, which enhances the inducibility and stability of AF. In addition, clinical data suggest that catheter ablation seems beneficial in reducing recurrences and delaying arrhythmia progression. ${ }^{18}$ On the other hand, "AF treatment strategy" was purely physician driven in the present study. It is possible that the treating physician only chose a rhythmcontrol strategy for the patients with less underlying disease, in whom the greatest probability of maintaining sinus rhythm was expected, and to avoid unnecessary exposure of patients to the adverse effects of rhythm-control drugs. Previous studies showed that a history of heart failure and valvular disease as well as advanced age was associated with a choice of rate control. ${ }^{6}$ Nevertheless, in the present study, univariate analysis showed that patients treated with rhythm control seem to have slightly more hypertension and heart failure. On the other hand, they were younger and had less valvular disease. We attempted to correct for the potential influence of these variables using propensity score models and found similar results. We identified some significant differences in the use of AF medication between patients with and without AF progression. Class Ic drugs could prevent electrical remodeling by reducing the number of AF recurrences. Then again, the physician chose which medication was administered to each patient. The use of class Ic drugs is contraindicated in many forms of underlying heart disease. Therefore, the patients using class Ic drugs probably have less underlying heart disease. In contrast, cardiac glycosides are often administered to patients with heart failure.

The 2 most important studies evaluating the outcome of treatment strategy in patients with AF (AFFIRM and RACE) did not study AF progression. ${ }^{19,20}$ AFFIRM classified "high risk AF patients" in first episode or recurrent AF, and RACE only studied patients with persistent AF. The study design did not enable to evaluate AF progression. More recently, the AF-CHF trial studied the effect of treatment strategy on mortality in patients with $\mathrm{AF}$ and systolic heart failure. ${ }^{21}$ All these studies demonstrate that a rhythm-control strategy is not associated with improved survival. Therefore, one could question the relevance of a rhythm-control strategy. On the other hand, knowing the factors that enhance (or prevent) AF progression might be very relevant in symptomatic AF patients.

A previous study showed a strong and graded link between body mass index and AF progression. $^{22}$ However, in our study, there was no univariate nor multivariate association between obesity and AF progression. This could be explained by the difference in cohorts. In the study by Tsang et al., ${ }^{22}$ only Olmsted County residents were included, whereas in our study, we included patients from 21 countries in different continents. One could hypothesize that the etiology of obesity and the unhealthy behavior associated with obesity might be different according to the local lifestyle. 
Finally, patients demonstrating AF progression had a worse prognosis, with more cardiovascular events and admissions. It remains unclear whether achieving rhythm control would have prevented these events in our population.

\section{Limitations}

We performed a subgroup analysis of the RecordAF study. As a result, our findings should be interpreted with caution because there may be confounding factors that are beyond those tested here. Patients were not randomized into a rate- or rhythmcontrol strategy. Therefore, the choice between rhythm and rate control was per se influential regarding long-term outcome (and possibly not a consequence of the actual treatment). We want to stress that the observed association found in the present study between rate control and AF progression is hypothesis generating rather than conclusive evidence. Other studies show that $\mathrm{P}$-wave dispersion might predict transition from paroxysmal to persistent $A F .^{23}$ We did not have data available in our cohort to verify this hypothesis. Unfortunately, we have no data on AF burden and left atrial size in the present cohort. Both were associated with AF progression in earlier publications. ${ }^{2,16}$ In our analyses, we corrected for many variables. The patient numbers of the cohorts that we compared (318 vs. 1819) were probably too low to adequately correct for that many variables. However, we believe that all these variables should be taken into account when trying to reduce the effect of potential confounders.

\section{Conclusions}

In this large AF population, $15 \%$ of patients who were recently diagnosed with $\mathrm{AF}$ progressed to persistent or permanent AF within 1 year. Heart failure, hypertension, and rate-control rather than rhythm-control strategy were independently associated with AF progression. The clinical outcome of patients demonstrating AF progression is worse compared with patients demonstrating no AF progression. The observed associations found in the present study are hypothesis generating rather than conclusive evidence. Further studies are needed to evaluate the hypothesis that a rhythm-control strategy prevents AF progression. 


\section{References}

1. Kannel WB, Abbott RD, Savage DD, McNamara PM. Epidemiologic features of chronic atrial fibrillation: the Framingham study. N Engl J Med 1982;306:1018-1022.

2. Kerr CR, Humphries KH, Talajic M, Klein GJ, Connolly SJ, Green M, Boone J, Sheldon R, Dorian P, Newman D. Progression to chronic atrial fibrillation after the initial diagnosis of paroxysmal atrial fibrillation: results from the Canadian Registry of Atrial Fibrillation. Am Heart J 2005;149:489-496.

3. de Vos CB, Pisters R, Nieuwlaat R, Prins MH, Tieleman RG, Coelen RJ, van den Heijkant AC, Allessie MA, Crijns HJ. Progression from paroxysmal to persistent atrial fibrillation clinical correlates and prognosis. J Am Coll Cardiol 2010;55:725-731.

4. Camm AJ, Kirchhof P, Lip GY, Schotten U, Savelieva I, Ernst S, Van Gelder IC, Al-Attar N, Hindricks G, Prendergast B, Heidbuchel H, Alfieri O, Angelini A, Atar D, Colonna P, De Caterina R, De Sutter J, Goette A, Gorenek B, Heldal M, Hohloser SH, Kolh P, Le Heuzey JY, Ponikowski P, Rutten FH. Guidelines for the management of atrial fibrillation: the Task Force for the Management of Atrial Fibrillation of the European Society of Cardiology (ESC). Eur Heart J 2009;31:2369-2429.

5. Kirchhof P, Lip GY, Van Gelder IC, Bax J, Hylek E, Kaab S, Schotten U, Wegscheider K, Boriani G, Brandes A, Ezekowitz M, Diener H, Haegeli L, Heidbuchel H, Lane D, Mont L, Willems S, Dorian P, Aunes-Jansson M, Blomstrom-Lundqvist C, Borentain M, Breitenstein S, Brueckmann M, Cater N, Clemens A, Dobrev D, Dubner S, Edvardsson NG, Friberg L, Goette A, Gulizia M, Hatala R, Horwood J, Szumowski L, Kappenberger L, Kautzner J, Leute A, Lobban T, Meyer R, Millerhagen J, Morgan J, Muenzel F, Nabauer M, Baertels C, Oeff M, Paar D, Polifka J, Ravens U, Rosin L, Stegink W, Steinbeck G, Vardas P, Vincent A, Walter M, Breithardt G, Camm AJ. Comprehensive risk reduction in patients with atrial fibrillation: emerging diagnostic and therapeutic options-a report from the 3rd Atrial Fibrillation Competence NETwork/European Heart Rhythm Association consensus conference. Europace 2012;14:8-27.

6. Le Heuzey JY, Breithardt G, Camm J, Crijns H, Dorian P, Kowey PR, Merioua I, Prystowsky EN, Schwartz PJ, Torp-Pedersen C, Weintraub W. The RecordAF study: design, baseline data, and profile of patients according to chosen treatment strategy for atrial fibrillation. Am J Cardiol 2010;105:687-693.

7. Gage BF1, Waterman AD, Shannon W, Boechler M, Rich MW, Radford MJ. Validation of clinical classification schemes for predicting stroke: results from the National Registry of Atrial Fibrillation. JAMA 2001;285:2864-2870.

8. Ruigómez A, Johansson S, Wallander MA, García Rodríguez LA. Predictors and prognosis of paroxysmal atrial fibrillation in general practice in the UK. BMC Cardiovasc Disord 2005;5:20.

9. Nieuwlaat R, Prins MH, Le Heuzey JY, Vardas PE, Aliot E, Santini M, Cobbe SM, Widdershoven JW, Baur LH, Lévy S, Crijns HJ. Prognosis, disease progression, and treatment of atrial fibrillation patients during 1 year: follow-up of the Euro Heart Survey on atrial fibrillation. Eur Heart $J$ 2008;29:1181-1189.

10. Parkash R, Green MS, Kerr CR, Connolly SJ, Klein GJ, Sheldon R, Talajic M, Dorian P, Humphries KH; Canadian Registry of Atrial Fibrillation. The association of left atrial size and occurrence of atrial fibrillation: a prospective cohort study from the Canadian Registry of Atrial Fibrillation. Am Heart $J$ 2004;148:649-654.

11. Kato T, Yamashita T, Sagara K, linuma H, Fu LT. Progressive nature of paroxysmal atrial fibrillation. Observations from a 14-year follow-up study. Circ J 2004;68:568-572.

12. Gianfranchi L, Brignole M, Menozzi C, Lolli G, Bottoni N. Determinants of development of permanent atrial fibrillation and its treatment. Europace 1999;1:35-39.

13. Nabauer M, Gerth A, Limbourg T, Schneider S, Oeff M, Kirchhof P, Goette A, Lewalter T, Ravens U, Meinertz T, Breithardt G, Steinbeck G. The Registry of the German Competence NETwork on Atrial Fibrillation: patient characteristics and initial management. Europace 2009;11:423-434.

14. Eckstein J, Verheule S, de Groot NM, Allessie M, Schotten U. Mechanisms of perpetuation of atrial fibrillation in chronically dilated atria. Prog Biophys Mol Biol 2008;97:435-451.

15. Schotten U, Verheule S, Kirchhof P, Goette A. Pathophysiological mechanisms of atrial fibrillation: a translational appraisal. Physiol Rev 2011;91:265-325.

16. Saksena S, Hettrick DA, Koehler JL, Grammatico A, Padeletti L. Progression of paroxysmal atrial fibrillation to persistent atrial fibrillation in patients with bradyarrhythmias. Am Heart J 2007;154: 884-892. 
17. Wijffels MC, Kirchhof CJ, Dorland R, Allessie MA. Atrial fibrillation begets atrial fibrillation. A study in awake chronically instrumented goats. Circulation 1995;92:1954-1968.

18. Pappone C, Radinovic A, Manguso F, Vicedomini G, Ciconte G, Sacchi S, Mazzone P, Paglino G, Gulletta $\mathrm{S}$, Sala S, Santinelli V. Atrial fibrillation progression and management: a 5-year prospective follow-up study. Heart Rhythm 2008;5:1501-1507.

19. Wyse DG, Waldo AL, DiMarco JP, Domanski MJ, Rosenberg Y, Schron EB, Kellen JC, Greene HL, Mickel MC, Dalquist JE, Corley SD; Atrial Fibrillation Follow-up Investigation of Rhythm Management (AFFIRM) Investigators. A comparison of rate control and rhythm control in patients with atrial fibrillation. $N$ Engl J Med 2002;347:1825-1833.

20. Van Gelder IC, Hagens VE, Bosker HA, Kingma JH, Kamp O, Kingma T, Said SA, Darmanata JI, Timmermans AJ, Tijssen JG, Crijns HJ; Rate Control versus Electrical Cardioversion for Persistent Atrial Fibrillation Study Group. A comparison of rate control and rhythm control in patients with recurrent persistent atrial fibrillation. N Engl J Med 2002;347:1834-1840.

21. Roy D, Talajic M, Nattel S, Wyse DG, Dorian P, Lee KL, Bourassa MG, Arnold JM, Buxton AE, Camm AJ, Connolly SJ, Dubuc M, Ducharme A, Guerra PG, Hohnloser SH, Lambert J, Le Heuzey JY, O'Hara G, Pedersen OD, Rouleau JL, Singh BN, Stevenson LW, Stevenson WG, Thibault B, Waldo AL; Atrial Fibrillation and Congestive Heart Failure Investigators. Rhythm control versus rate control for atrial fibrillation and heart failure. N Engl J Med 2008;358:2667-2677.

22. Tsang TS, Barnes ME, Miyasaka Y, Cha SS, Bailey KR, Verzosa GC, Seward JB, Gersh BJ. Obesity as a risk factor for the progression of paroxysmal to permanent atrial fibrillation: a longitudinal cohort study of 21 years. Eur Heart J 2008;29:2227-2233.

23. Koide $Y$, Yotsukura M, Ando H, Aoki S, Suzuki T, Sakata K, Ootomo E, Yoshino H. Usefulness of P-wave dispersion in standard twelve-lead electrocardiography to predict transition from paroxysmal to persistent atrial fibrillation. Am J Cardiol 2008;102:573-577. 


\section{Part II}

Echo-electrocardiography to identify the substrate for atrial fibrillation during sinus rhythm 


\section{Chapter 5}

Atrial activation time determined by transthoracic Doppler tissue imaging can be used as an estimate of the total duration of atrial electrical activation

KL Merckx, CB De Vos, A Palmans, J Habets, EC Cheriex, HJGM Crijns, RG Tieleman J Am Soc Echocardiogr 2005;18:940-944 


\begin{abstract}
Background

Currently, the total atrial activation time, as indicated by the P-wave duration using signal-averaged (SA) electrocardiogram (ECG) (SAECG), is the most powerful predictor of atrial fibrillation. However, because of practical limitations, this technique is not used in clinical routine. In this study we evaluated several alternative techniques to measure the total atrial activation time, including a new parameter that uses atrial Doppler tissue imaging (TDI).
\end{abstract}

Methods

For 30 patients who were in sinus rhythm and underwent a transthoracic echocardiogram, we determined the P-wave duration on surface ECG and SA-ECG, and the interval from the onset of the $P$ wave (lead II) until the onset of the echocardiographic flow Doppler A wave over the mitral valve. In addition, using pulsed wave TDI in the 4-chamber view, we measured the interval of time from initiation of the ECG P wave (lead II) until the peak of the local lateral left atrial (LA) TDI signal. Correlation between the SA-ECG, surface ECG, and echocardiographic parameters were evaluated by Spearman correlation tests.

Results

All parameters that were used to estimate total atrial activation time showed a significant correlation with the SA-ECG P-wave duration. Although the interval of time from initiation of the ECG $P$ wave until the peak of the local lateral LA TDI signal was significantly longer than the SA-ECG P-wave duration $(151.12 \pm 19.4$ vs. $128.4 \pm 15.8$ milliseconds, respectively, $P<0.01)$, it showed the highest correlation $(R=0.91$, $P<0.001)$. There was no significant correlation between the SA-ECG and routine echocardiographic parameters such as LA, right atrial, or total atrial size. Measurement of the interval of time from initiation of the ECG $P$ wave until the peak of the local lateral LA TDI signal added $1 \pm 0.5$ minutes to a routine echocardiographic evaluation, whereas measurement of the SA-ECG P-wave duration took $20 \pm 5$ minutes $(P<0.01)$.

\title{
Conclusions
}

LA TDI is an easy, fast, and reliable method to estimate the total atrial electrical activation time, and may be useful in the identification of those prone to develop atrial fibrillation. 


\section{Introduction}

Atrial fibrillation (AF) is the most common sustained cardiac arrhythmia in clinical practice. ${ }^{1}$ With increasing age of the population, the numbers of patients with AF will grow tremendously, creating the need for primary prevention. ${ }^{2}$ To enable prevention, we need a better way to predict who will develop AF in the future. Currently, risk stratification for AF is based on clinical and echocardiographic parameters that are derived from population-based observational studies such as the Framingham Heart Study and the Manitoba Follow-up Study. ${ }^{3-6}$ For the individual patient, the currently available risk stratification parameters are of limited value for prediction of AF. ${ }^{7}$

Factors that facilitate AF are atrial dilatation and depressed intra-atrial conduction. Together, they determine the total time required for atrial electrical activation, the total atrial conduction time (TACT), with the maximal P-wave duration as an equivalent on the 12-lead surface electrocardiogram (ECG). The gold standard for determination of the P-wave duration is the signal-averaged (SA) ECG (SA-ECG) technique. This has been used to determine the total duration of atrial activation and has a reasonable predictive power for the development of AF. ${ }^{8-11}$ However, P-wave determination by SA-ECG has not found its way into clinical practice, possibly because it requires special hardware and is a time-consuming technique.

Recently, Fuenmayor et al. ${ }^{12}$ described an alternative technique to estimate TACT. They measured the time from the onset of the ECG P wave (lead II) until the onset of the A wave as determined by flow Doppler echocardiography over the mitral valve (PA$\mathrm{mv}$ ). They demonstrated a significant correlation with invasively determined TACT. However, this technique is not able to detect left atrial (LA) late activation and, thereby, theoretically underestimates TACT.

We hypothesized that the duration of atrial electrical activation can be estimated more accurately by a novel echocardiographic technique using Doppler tissue imaging (TDI) of the local LA wall motion. Therefore, we compared transthoracic pulsed wave TDI of the local lateral LA wall motion with current techniques to estimate TACT.

\section{Methods}

We included 30 consecutive patients in normal sinus rhythm who were referred to our department of cardiology for a routine transthoracic echocardiogram. The examination consisted of a standard 2-dimensional echocardiogram, including M-mode and Doppler echocardiography (Sonos 5500, Philips Medical Systems, Andover, Mass). To estimate TACT, we determined PA-mv interval (average of 3 cycles). In addition, in the 4chamber apical view, the time from initiation of the ECG P wave (lead II) to the onset or the peak of the local lateral LA TDI signal (PA-TDI) was measured using pulsed wave TDI, with the sample placed at the lateral wall of the LA just above the mitral valve (average of 3 cycles) (Figure 5.1). 


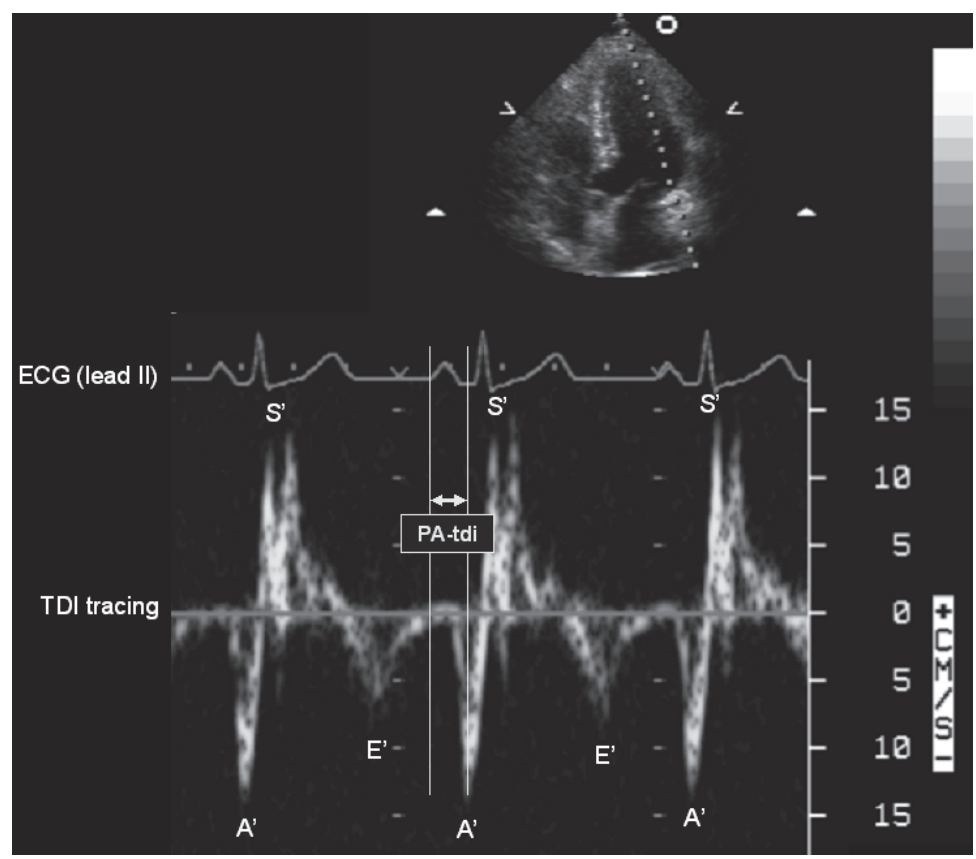

Figure 5.1 Example of measurement of time from initiation of electrocardiographic P wave (lead II) to peak of local lateral left atrial Doppler tissue signal.

After echocardiography, a 12-lead surface ECG was recorded in each patient using an ECG system (MAC 5000, Marquette Medical Systems, Milwaukee, Wis). All 12-lead ECGs were obtained in the supine position. The measurement of the maximum $P$ wave was done manually by an independent observer who was unaware of the results from the other tests. To improve accuracy, measurements were performed with calipers and magnifying glass. The onset of the $P$ wave was defined as the junction between the isoelectric line and the beginning of the P-wave deflection and the offset of the $P$ wave as the junction between the end of the P-wave deflection and the isoelectric line. $^{13,14}$

Finally, P-wave SA-ECG was recorded from X-, Y-, and Z-lead system using the ECG system (MAC 5000, Marquette Medical Systems). All recordings were performed in a quiet atmosphere to reduce ambient noise. $P$ waves were recorded until a target noise level of less than $0.3 \mu \mathrm{V}$ was achieved in the TP segment of the ECG, and until at least 500 beats were analyzed. Before SA, a P-wave template was created and measured P waves were correlated with that template. Unless a match of more than $95 \%$ was present, $\mathrm{P}$ waves were rejected to exclude atrial premature beats. P-wave filtering with a bandwidth of 40 to $250 \mathrm{~Hz}$ was applied to the averaged $P$ wave. 
The times needed for recording and analysis of the PA-mv and PA-TDI intervals, and measurement of the P-wave duration on either surface ECG or using SA-ECG, were recorded.

Patient characteristics, including arrhythmia history, were derived from the chart and the electronic ECG database, which consists of all ECGs that are made in our hospital.

\section{Statistical analysis}

Results are expressed as the mean \pm SD. Correlation between the echocardiographic and ECG variables was evaluated by the Spearman correlation test. Alpha value was set at 0.05 and confidence intervals at $95 \%$. All analyses were performed using statistical software (SPSS 11.0, SPSS Inc, Chicago, III).

\section{Results}

Table 5.1 shows the characteristics of the patients included in this validation study. Figure 5.2, A, demonstrates that there was a significant, but poor correlation between the SA-ECG P-wave duration and the P-wave duration from the surface ECG $(R=0.60$, $P=0.001)$. The average value of the PA-mv interval $(128.9 \pm 20.1$ milliseconds) closely resembled the average value of the SA-ECG P-wave duration (128.4 \pm 25.8 milliseconds), and the correlation between the two parameters $(R=0.76, P=0.001)$ (Figure 5.2, B) was better than between SA-ECG and surface ECG P-wave duration. TACT as estimated by TDI (PA-TDI) (151.1 \pm 19.4 milliseconds) was significantly longer than the SA-ECG P-wave duration. However, the PA-TDI interval showed the highest correlation with the SAECG. $(R=0.91, P=0.001$ ) (Figure 5.2, C). This was true only for the PA-TDI interval until the peak of the atrial velocity curve, not for the interval until the onset of the atrial tissue velocity deflection $(R=0.54, P=0.002)$. The correlation was similar for patients with or without a history of AF (Figure 5.2). In this study, there was no difference in atrial activation time between patients with or without a history of $A F$, as indicated by SA-ECG (156.2 \pm 20.5 vs. $148.8 \pm 18.9$ milliseconds, respectively, $P=$ not significant) or PATDI (131.4 \pm 18.1 vs. $126.9 \pm 14.8$ milliseconds, respectively, $P=$ not significant). However, the current study was not designed for this purpose and the number of included patients may have been too low to reveal a significant difference.

There was no significant correlation between the SA-ECG and other echocardiographic parameters, such as LA, right atrial, or total atrial size. Measurement of the PA-mv and PA-TDI intervals both prolonged a routine echocardiographic examination by $1 \pm 0.5$ minutes, which was significantly shorter than measurement of TACT by SA-ECG, which took $20 \pm 5$ minutes $(P<0.01)$. Determination of the maximum $P$-wave duration took $2 \pm 1$ minutes. 
Table 5.1 Patient characteristics.

\begin{tabular}{|c|c|}
\hline $\mathrm{N}$ & 30 \\
\hline Age & 60 \\
\hline Men & 16 \\
\hline \multicolumn{2}{|l|}{ Cardiovascular disease } \\
\hline Hypertension & $5(17 \%)$ \\
\hline Coronary artery disease & 15 (50\%) \\
\hline Congestive heart failure & $5(16.7 \%)$ \\
\hline \multicolumn{2}{|l|}{ Medication } \\
\hline Nitrates & $10(33 \%)$ \\
\hline Beta-blockers & $12(40 \%)$ \\
\hline Calcium-channel blocker & $3(10 \%)$ \\
\hline \multicolumn{2}{|l|}{ AAD } \\
\hline Sotalol & $3(10 \%)$ \\
\hline Flecainide & $2(6.7 \%)$ \\
\hline Amiodarone & $2(6.7 \%)$ \\
\hline Diuretics & $5(16.7 \%)$ \\
\hline ACE inhibitors & $10(33 \%)$ \\
\hline \multicolumn{2}{|l|}{ Echocardiographic parameters } \\
\hline LA size, $\mathrm{mm}$ & $40.4 \pm 7$ \\
\hline LVEDD, mm & $50.4 \pm 6.4$ \\
\hline LVESD, mm & $35.1 \pm 7.3$ \\
\hline IVSEDWT, mm & $8.7 \pm 1.8$ \\
\hline PWEDWT, mm & $8.4 \pm 1.2$ \\
\hline LVEF, \% & $55.4 \pm 13.4$ \\
\hline$P A-m v, m s$ & $128.9 \pm 20.1$ \\
\hline PA-TDI start, ms & $91.4 \pm 26.6$ \\
\hline PA-TDI peak, ms & $151.2 \pm 19.4$ \\
\hline \multicolumn{2}{|l|}{ Electrocardiographic parameters } \\
\hline $\mathrm{HR}$, beats/min & $64 \pm 3$ \\
\hline Maximum $\mathrm{P}$-wave duration, $\mathrm{ms}$ & $113 \pm 14$ \\
\hline $\mathrm{PQ}, \mathrm{ms}$ & $172 \pm 26$ \\
\hline QRS, ms & $98 \pm 17$ \\
\hline QTc, ms & $419 \pm 24$ \\
\hline SA-ECG P-wave duration, ms & $128.4 \pm 15.8$ \\
\hline
\end{tabular}

AAD: Antiarrhythmic drugs; ACE: angiotensin-converting enzyme; HR: heart rate; IVSEDWT: interventricular septum end-diastolic wall thickness; LA: left atrial; LVEDD: left ventricular end-diastolic diameter; LVEF: left ventricular ejection fraction; LVESD: left ventricular end-systolic diameter; PA-TDI: onset or peak of the local lateral LA TDI; PA-mv: onset of the A wave as determined by flow Doppler Echocardiography over the mitral valve; PWEDWT: posterior wall end-diastolic wall thickness; SA-ECG: signal averaged ECG. 
A

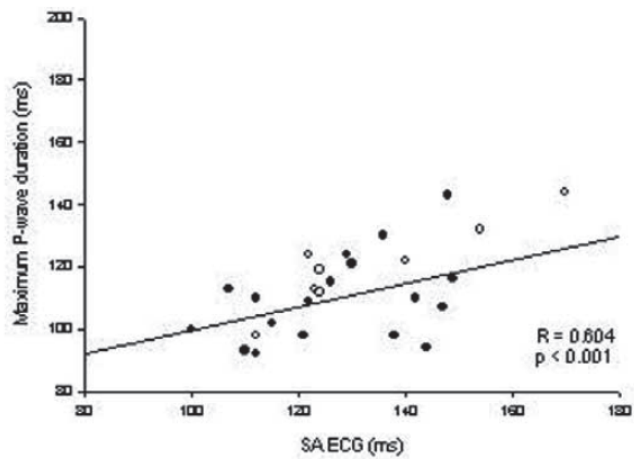

B

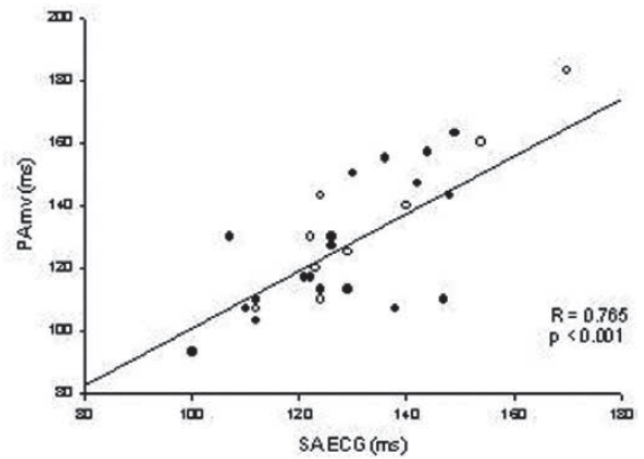

C

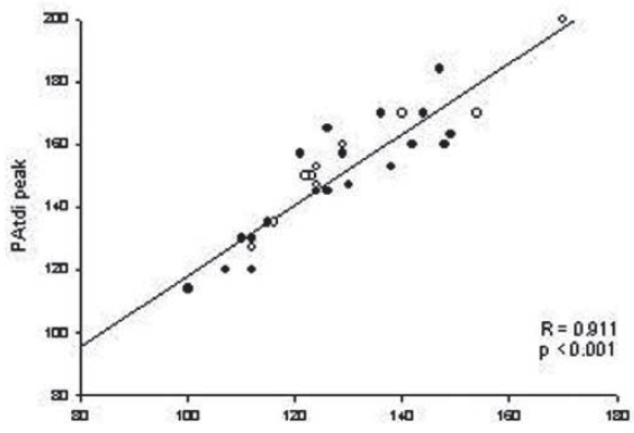

Figure 5.2 Correlation between signal-averaged electrocardiogram (ECG) and P-wave duration on surface ECG (A), time from onset of ECG P wave (lead II) until onset of A wave as determined by flow Doppler echocardiography over mitral valve (B), and time from initiation of ECG P wave (lead II) to peak of local lateral left atrial Doppler tissue signal (C). Open circles, Patients with history of atrial fibrillation. 


\section{Discussion}

\section{Mechanisms of AF}

In their multiple wavelet theory, $\mathrm{Moe}^{15}$ postulated the existence of independent wandering wavelets as the basis for AF. Many studies have supported the hypothesis that $\mathrm{AF}$ results from multiple re-entrant circuits, with areas of delayed conduction to initiate and maintain the arrhythmia. ${ }^{15-18}$ It has been demonstrated that the atria should be able to harbor a critical number of wavelets to develop and sustain AF. ${ }^{17}$ The number of wavelets that fit into the atria depends on the atrial mass, the conduction velocity, and the atrial refractory period.

\section{Characterization of AF vulnerability}

The vulnerability for AF development could be evaluated by means of an electrophysiologic study by programmed electrical stimulation or burst pacing. However, this is impractical for the evaluation of large patient groups. A noninvasive alternative is measurement of TACT, which is the time elapsed between the initiation of atrial depolarization (usually in the region of the sinus node) and the last depolarization (usually in the lateral LA wall) of the same activation front. TACT prolongs in case of increased atrial size or decreased conduction velocity. Therefore, theoretically, a prolonged TACT should correlate with vulnerability for AF.

\section{Determination of TACT}

The simplest way to determine TACT is by measuring P-wave duration on the 12-lead surface ECG. A prolonged $\mathrm{P}$-wave duration may reflect slow intra-atrial conduction or an increase in atrial size. A prolonged $\mathrm{P}$-wave duration predicts postoperative $\mathrm{AF} .{ }^{19}$

Based on the same principle, the improved method of measuring P-wave duration by SA-ECG was shown to be of superior value for the prediction of AF. ${ }^{9}$ Although it allows more precise measurement of the $P$-wave duration, it requires special (SA-ECG) hardware and software that is only available in a limited number of hospitals.

An alternative approach to determine TACT is invasive measurement of the time elapsed between activation at the high right atrium (near the superior vena cava) and the inferior and lateral aspect of the LA at the coronary sinus during an electrophysiologic study. Recently, Fuenmayor et al. ${ }^{12}$ proposed a new noninvasive way to estimate the TACT by measuring the PA-mv interval. They demonstrated a significant correlation between the PA-mv interval and TACT as determined by invasive electrophysiology. Although this is an easy, inexpensive, and fast technique, theoretically it gives an underestimation of the TACT because transmitral blood flow starts well before activation and contraction of the LA is completed. A further improvement of this technique, based on the same principle, was put forward by Kinay 
et $\mathrm{al}^{20}$ who measured the time from the start of the P wave (lead II) to the onset of the LA appendage ejection flow by means of transesophageal echocardiography. It was demonstrated that this is an effective predictor of recurrent AF. Major disadvantages of this method are that TEE is an unpleasant examination for the patient and it requires special skills of the examiner, which makes this technique impractical for examination of large patient groups, as is required during risk stratification to perform primary prevention of AF.

The current study examined the value of a new technique to estimate TACT by pulsed wave TDI. The principle is similar to the technique used by Kinay et al. ${ }^{20}$ but now transthoracic pulsed wave TDI reveals the local movement of the LA wall, which is usually activated last during in sinus rhythm. ${ }^{21}$

We were able to demonstrate that this noninvasive technique had the best correlation with the gold standard P-wave duration as determined by SA-ECG, in comparison with surface ECG P-wave duration and PA-mv interval. The PA-TDI interval using the onset of the a wave was significantly shorter than the $P$ wave until the peak of the TDI time velocity curve. Also, the correlation between SA-ECG P-wave duration and PA-TDI peak was much better than with the PA-TDI onset, which may be significantly affected by neighboring LA cells, thus, representing overall LA activation.

The obvious advantage of the PA-TDI (peak) method is that it does not require special skills or devices, other than standard echocardiography machines that are used for routine echocardiograms. Furthermore, measuring the PA-TDI interval is fast and easy to perform.

\section{Conclusion}

The results of our study demonstrate that LA TDI is an easy, fast, and reliable method to estimate the total atrial activation time, and may be of value for the identification of patients with an atrial substrate vulnerable for AF.

\section{Study limitations}

Total atrial activation time is defined as the time elapsed between the initiation of atrial depolarization (usually in the region of the sinus node) and the last depolarization of the same activation front. It should be kept in mind that the PA-TDI interval includes both the time required for the propagation of impulses from the sinus node to the LA, and the time required for the electromechanical coupling in the LA. Therefore, the PA-TDI interval overestimates the total atrial activation time. Fortunately, the time required for excitation-contraction coupling appears to be rather constant. The PA-TDI interval prolonged the SA-ECG interval by $22.8 \pm 8.2$ milliseconds. This resulted in a high correlation with the SA-ECG P-wave duration, which may make the PA-TDI a suitable parameter for the identification of an atrial substrate vulnerable for (future development of) AF. 


\section{References}

1. Feinberg WM, Blackshear JL, Laupacis A, Kronmal R, Hart RG. Prevalence, age distribution, and gender of patients with atrial fibrillation: analysis and implications. Arch Intern Med 1995;155:469-473.

2. Wattigney WA, Mensah GA, Croft JB. Increasing trends in hospitalization for atrial fibrillation in the United States, 1985 through 1999: implications for primary prevention. Circulation 2003;108:711-716.

3. Kannel WB, Abbott RD, Savage DD, McNamara PM. Epidemiologic features of chronic atrial fibrillation: the Framingham study. N Engl J Med 1982;306:1018-1022.

4. Brand FN, Abbott RD, Kannel WB, Wolf PA. Characteristics and prognosis of lone atrial fibrillation: 30year follow-up in the Framingham study. JAMA 1985;254:3449-3453.

5. Wolf PA, Abbott RD, Kannel WB. Atrial fibrillation: a major contributor to stroke in the elderly; the Framingham study. Arch Intern Med 1987;147:1561-1564.

6. Wolf PA, Abbott RD, Kannel WB. Atrial fibrillation as an independent risk factor for stroke: the Framingham study. Stroke 1991;22:983-988.

7. Furberg CD, Psaty BM, Manolio TA, Gardin JM, Smith VE, Rautaharju PM. Prevalence of atrial fibrillation in elderly subjects (the cardiovascular health study). Am J Cardiol 1994;74:236-241.

8. Fukunami M, Yamada T, Ohmori M, Kumagai K, Umemoto K, Sakai A, Kondoh N, Minamino T, Hoki N. Detection of patients at risk for paroxysmal atrial fibrillation during sinus rhythm by $\mathrm{P}$ wave-triggered signal-averaged electrocardiogram. Circulation 1991;83: 162-169.

9. Guidera SA, Steinberg JS. The signal-averaged $\mathrm{P}$ wave duration: a rapid and noninvasive marker of risk of atrial fibrillation. J Am Coll Cardiol 1993;21:1645-1651.

10. Rosenheck S. Signal-averaged $\mathrm{P}$ wave in patients with paroxysmal atrial fibrillation. Pacing Clin Electrophysiol 1997;20:2577-2586.

11. Ishimoto N, Ito M, Kinoshita M. Signal-averaged P-wave abnormalities and atrial size in patients with and without idiopathic paroxysmal atrial fibrillation. Am Heart J 2000;139:684-689.

12. Fuenmayor AJ, Ramirez L, Fuenmayor AM. Validation of inter-atrial conduction time measurement by means of echo-Doppler. Arch Cardiol Mex 2002;72:125-128.

13. Dilaveris $P$, Batchvarov V, Gialafos J, Malik M. Comparison of different methods for manual $P$ wave duration measurement in 12-lead electrocardiograms. Pacing Clin Electrophysiol 1999;22:1532-1538.

14. Dilaveris PE, Andrikopoulos GK, Metaxas G, Richter DJ, Avgeropoulou CK, Androulakis AM, Gialafos EJ, Michaelides AP, Toutouzas PK, Gialafos JE. Effects of ischemia oil P wave dispersion and maximum $\mathrm{P}$ wave duration during spontaneous anginal episodes. Pacing Clin Electrophysiol 1999;22:1640-1647.

15. Moe G. On the multiple wavelet hypothesis of atrial fibrillation. Arch Int Pharmacodyn Ther 1962;140:183-188.

16. Smeets JL, Allessie MA, Lammers WJ, Bonke FI, Hollen J. The wavelength of the cardiac impulse and reentrant arrhythmias in isolated rabbit atrium: the role of heart rate, autonomic transmitters, temperature, and potassium. Circ Res 1986;58:96-108.

17. Rensma PL, Allessie MA, Lammers WJ, Bonke FI, Schalij MJ. Length of excitation wave and susceptibility to reentrant atrial arrhythmias in normal conscious dogs. Circ Res 1988;62:395-410.

18. Allessie MA, Konings K, Kirchhof CJ, Wijffels M. Electrophysiologic mechanisms of perpetuation of atrial fibrillation. Am J Cardiol 1996;77:10-23A.

19. Buxton $\mathrm{AE}$, Josephson $\mathrm{ME}$. The role of $\mathrm{P}$ wave duration as a predictor of postoperative atrial arrhythmias. Chest 1981;80:68-73.

20. Kinay O, Nazli C, Ergene O, Dogan A, Gedikli O, Hoscan Y, Acar G, Altinbas A. Time interval from the initiation of the electrocardiographic $P$ wave to the start of left atrial appendage ejection flow: a novel method for predicting atrial fibrillation recurrence. J Am Soc Echocardiogr 2002;15:1479-1484.

21. De PR, Ho SY, Salerno-Uriarte JA, Tritto M, Spadacini G. Electroanatomic analysis of sinus impulse propagation in normal human atria. J Cardiovasc Electrophysiol 2002;13:1-10. 


\section{Chapter 6}

Clinical and echocardiographic correlates of intra-atrial conduction delay

B Weijs* and CB de Vos*, RG Tieleman, R Pisters, EC Cheriex, MH Prins, HJGM Crijns

* Both authors contributed equally

Europace. 2011;13:1681-1687 


\section{Abstract}

Aims

The total atrial conduction time (TACT) is an important electrophysiological parameter. We developed a new transthoracic echocardiographic tool (PA-TDI). The PA-TDI interval is a reflection of the TACT. In the present study, we evaluated the clinical and echocardiographic correlates of intra-atrial conduction delay.

Methods and results

We studied 427 patients without class I anti-arrhythmic agents or amiodarone. All patients underwent an echocardiogram and the PA-TDI interval was measured. Patient characteristics were recorded. The mean PA-TDI was $157 \pm 22$ ms. Multivariate linear regression analysis revealed that atrial fibrillation (AF) in history $(B=9.7 ; 95 \% \mathrm{Cl}$ 5.7-13.8; $P<0.001)$, hypertension $(B=5.5 ; 95 \% C l 1.4-9.8 ; P=0.01)$, clinically relevant valve disease $(B=5.7 ; 95 \% \mathrm{Cl} 0.5-10.8 ; P=0.03)$, age $(B=5 ; 95 \% \mathrm{Cl} 3.3-6.6 ; P<0.001)$, and body mass index ( $\mathrm{BMI} ; \mathrm{B}=2.6 ; 95 \% \mathrm{Cl} 0.3-4.9 ; \mathrm{P}=0.026$ ) were independently associated with the PA-TDI interval. On the echocardiogram: the aortic diameter $(B=0.7 ; 95 \% \mathrm{Cl}$ 0.2-1.2; $P=0.009)$, left atrial dimension $(B=0.9 ; 95 \% C l 0.5-1.3 ; P<0.001)$, mitral valve E-wave deceleration time $(B=0.1 ; 95 \% \mathrm{Cl} 0.1-0.1 ; P<0.001)$, aortic incompetence $(B=13$; 95\% $\mathrm{Cl} 3.3-22.6 ; P=0.008)$, and mitral incompetence $(\mathrm{B}=11 ; 95 \% \mathrm{Cl} 3.6-17.5 ; P<0.003)$ were independently associated with the PA-TDI interval.

\section{Conclusions}

This study is the largest to investigate the relation between the atrial conduction time, underlying heart diseases, and echocardiographic parameters. We found that the PA-TDI was independently prolonged in patients with a history of AF, hypertension, valve disease, higher age, and a higher BMI. Signs of diastolic dysfunction, valve incompetence, and enlarged atrium or aortic root on the echocardiogram were associated with a prolonged PA-TDI. This suggests that early and aggressive treatment of hypertension, diastolic dysfunction, and obesity could prevent intra-atrial conduction delay. 


\section{Introduction}

The total atrial conduction time (TACT) is an important electrophysiological parameter that can be determined during an electrophysiological study. ${ }^{1} \mathrm{~A}$ delay of atrial conduction is strongly associated with underlying diseases affecting the atria directly or indirectly. ${ }^{2-5}$ Delayed conduction is one of the requirements for the initiation of reentry and the development of atrial fibrillation (AF). ${ }^{6}$ This implies that prevention or amelioration of atrial conduction delay may prevent the development of atrial arrhythmias such as AF. Indeed, previous studies suggest that the TACT may be a useful target of therapy. ${ }^{7-10}$ We validated a novel noninvasive echocardiographic technique using atrial tissue Doppler imaging (PA-TDI or atrial electromechanical interval) that strongly correlates with TACT. ${ }^{11}$ In previous studies, we showed that a prolonged PA-TDI is the most important predictor of new-onset $A F .^{11,12}$ Other investigators confirmed our findings in different populations. ${ }^{13,14} \mathrm{~A}$ prolonged PA-TDI interval is also associated with recurrence of AF after catheter ablation. ${ }^{15}$ Knowing the conditions that prolong the TACT is essential in order to develop therapies or strategies for prevention of AF. However, the clinical determinants of a prolonged TACT were never studied before in a large population. In this report, we used the echocardiographic PA-TDI to study the clinical and echocardiographic correlates of intra-atrial conduction delay in a large group of patients.

\section{Methods}

\section{Study population}

We studied 522 outpatient clinic patients referred to the Maastricht University Medical Centre for a standard transthoracic echocardiographic examination for various medical conditions (including AF in 273 patients). Patients were included between January 2003 and February 2007. Patients were enrolled if they were 18 years or older and had sinus rhythm during the echocardiogram. Exclusion criteria were previous pacemaker implantation, an implantable cardioverter-defibrillator and the use of class I anti-arrhythmic agents or amiodarone. The 249 patients without previous AF have been reported in a separate paper on the role of PA-TDI in the prediction of AF. ${ }^{12}$

\section{Echocardiographic examination}

The echocardiographic examination consisted of a standard twodimensional echocardiogram, including M-mode and Doppler echocardiography (Sonos 5500, Philips Medical Systems, Andover, MA, USA) during continuous electrocardiogram (ECG) monitoring according to the recommendations as described in the American Society of Echocardiography guidelines. Left atrial volume was obtained from the 
singleplane area-length of the apical four-chamber view, just prior to mitral valve opening, and with the patient in the left-lateral decubitus position. Additionally, we determined the PA-TDI interval. ${ }^{11}$ In the apical fourchamber view, the pulsed-wave tissue Doppler sample was placed on the lateral wall of the left atrium just above the mitral annulus. The PA-TDI interval, defined as the time-interval from initiation of the electrocardiographic $P$-wave recorded by the echo machine (lead II) to the peak of the $A^{\prime}$-wave of the atrial tissue Doppler tracing (Figure 6.1), was measured in three cardiac cycles and averaged.

The investigator who performed the echocardiographic measurements (including PA-TDI interval) was an independent observer blinded for other patient characteristics.

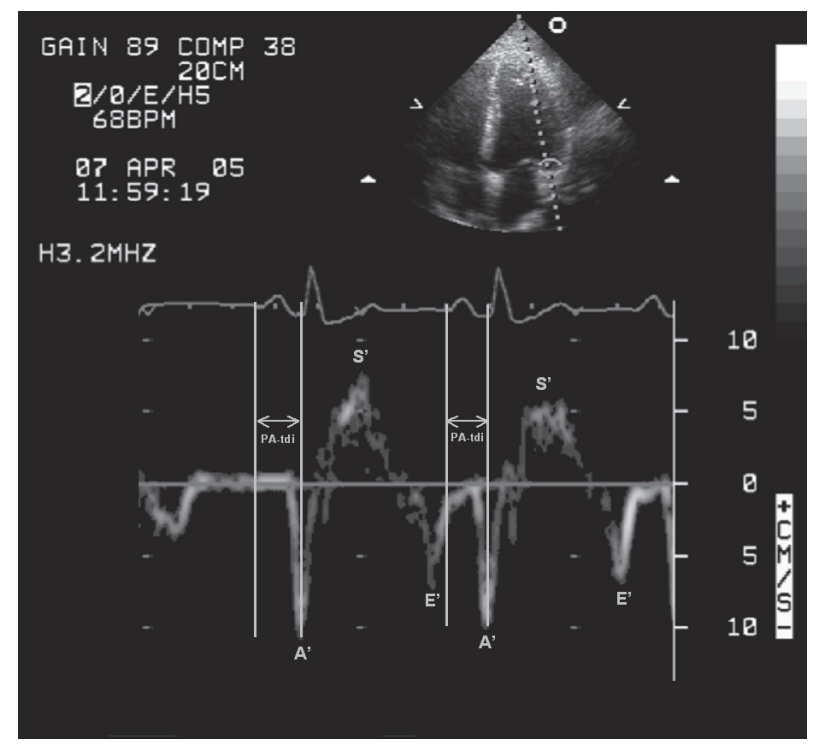

Figure 6.1 Example of PA-TDI measurement. PA-TDI is defined as the time interval between the onset of electrocardiographic $P$ wave in lead II and the top of the $A^{\prime}$-wave on the atrial tissue Doppler velocity curve from the left atrial wall.

\section{Data collection}

Patient characteristics, including medication, (arrhythmia) history, and ECGs at the time of echocardiography were collected. Data were derived from the patient charts and electronic medical records. A diagnosis of AF in history was defined as a documented episode of AF lasting $30 \mathrm{~s}$ or more. 'Valve disease' was defined as clinically relevant valve disease at discretion of the treating physician. The study complies with the Declaration of Helsinki. Patient informed consent was obtained and the Institutional Review Board approved the study. 


\section{Statistical analysis}

Continuous variables are presented as mean and standard deviation, categorical variables as observed number of patients and percentages. We used an independent t-test after performing Levene's test for equality of variances to compare all continuous variables. Categorical variables were tested with Fisher's exact test. Tables 6.1 and 6.2 show the $P$-values resulting from multiple uncorrected t-tests for continuous variables and Fisher's exact tests for categorical variables. This allowed us to identify parameters to feed into the linear regression analysis. Therefore, these tables are not presenting the ultimate results of the analysis. All parameters with a $P$ value $<0.1$ resulting from the univariate comparisons in Tables 6.1 and 6.2 were included in the linear regression models presented in Table 6.3. We did not include medication in the multivariate analysis presented in Table 6.3 since it is a reflection of the underlying diseases already included in the model. Model reduction was performed by stepwise exclusion of variables from the model with a $P$-value $<0.1$. For all continuous variables in the final regression analysis model, we determined their correlation with PA-TDI using Pearson's correlation test. Statistical analysis was performed with SPSS statistical software (SPSS Inc. release 16.0) and statistical significance was assumed for $P<0.05$. All tests performed were two sided.

\section{Results}

From the initial population of 522 patients, 95 patients were excluded because of use of conduction slowing class I antiarrhythmic agents or amiodarone leaving a final study population of 427 . The mean PA-TDI was $157 \pm 22 \mathrm{~ms}$. The shortest PA-TDI interval we measured was $103 \mathrm{~ms}$ and longest was $230 \mathrm{~ms}$. Baseline characteristics of all patients in relation to the mean PA-TDI interval in our population are shown in Table 6.1. Patients with a prolonged PA-TDI duration ( $\geq 157 \mathrm{~ms}$ ) were older and more often suffered from AF, hypertension, coronary artery disease, clinically relevant valve disease, and more often used oral anticoagulation, beta-blockers, nitrates, angiotensinconverting enzyme (ACE)-inhibitors and diuretics. Patients with a shorter PA-TDI interval used more aspirin. Figure 6.2 shows the mean PA-TDI interval according to age in tertiles and hypertension in patients with and without AF. 
Table 6.1 Baseline characteristics in relation to the mean PA-TDI duration in our population - univariate analysis.

\begin{tabular}{|c|c|c|c|}
\hline & $\begin{array}{c}\mathrm{PA}-\mathrm{TDI}<157 \mathrm{~ms} \\
(\mathrm{n}=222)\end{array}$ & $\begin{array}{c}P A-T D I \geq 157 \mathrm{~ms} \\
(n=205)\end{array}$ & $P$-value \\
\hline Age (years)* & $60 \pm 13$ & $67 \pm 11$ & $<0.001$ \\
\hline Female, $\mathrm{n}(\%)$ & $121(45)$ & $97(47)$ & 0.147 \\
\hline Body mass index $\left(\mathrm{kg} / \mathrm{m}^{2}\right)^{*}$ & $27 \pm 4$ & $28 \pm 4$ & 0.081 \\
\hline \multicolumn{4}{|l|}{ Underlying Risk Factors and Cardiovascular Disease } \\
\hline AF in history, $\mathrm{n}(\%)$ & $74(33)$ & $114(55)$ & $<0.001$ \\
\hline Hypertension, $\mathrm{n}(\%)$ & $122(55)$ & $132(64)$ & 0.049 \\
\hline Coronary artery disease, $\mathrm{n}(\%)$ & $22(10)$ & $34(17)$ & 0.045 \\
\hline Diabetes mellitus, $\mathrm{n}(\%)$ & $29(13)$ & $22(11)$ & 0.551 \\
\hline Valve disease, $\mathrm{n}(\%)$ & $30(14)$ & $50(24)$ & 0.004 \\
\hline Heart failure, $\mathrm{n}(\%)$ & $14(6)$ & $20(10)$ & 0.213 \\
\hline Thyroid disease, n (\%) & $15(7)$ & $12(6)$ & 0.843 \\
\hline Chronic obstructive pulmonary disease, $\mathrm{n}(\%)$ & $14(6)$ & $15(7)$ & 0.704 \\
\hline \multicolumn{4}{|l|}{ Medication } \\
\hline Oral anticoagulation, $\mathrm{n}(\%)$ & $39(18)$ & $85(42)$ & $<0.001$ \\
\hline Aspirin, $\mathrm{n}(\%)$ & $70(32)$ & $42(21)$ & 0.011 \\
\hline Beta-blocker, n (\%) & $63(28)$ & $104(51)$ & $<0.001$ \\
\hline Sotalol, n (\%) & $28(13)$ & $40(20)$ & 0.064 \\
\hline Verapamil, n (\%) & $18(8)$ & $19(9)$ & 0.732 \\
\hline Digitalis, n (\%) & $10(5)$ & $14(7)$ & 0.401 \\
\hline Nitrates, $\mathrm{n}(\%)$ & $8(4)$ & $22(11)$ & 0.004 \\
\hline Angiotensin-converting enzyme inhibitor, $\mathrm{n}(\%)$ & $37(17)$ & $61(30)$ & 0.002 \\
\hline Angiotensin-II receptor blocker, n (\%) & $49(22)$ & $44(22)$ & 0.907 \\
\hline Diuretics, n (\%) & $33(15)$ & $56(27)$ & 0.002 \\
\hline Statins, $\mathrm{n}(\%)$ & $64(29)$ & $54(26)$ & 0.589 \\
\hline Alpha-blocker, n (\%) & $7(3)$ & $5(3)$ & 0.774 \\
\hline Dihydropyridin calcium channel blocker, $\mathrm{n}(\%)$ & $27(12)$ & $36(18)$ & 0.133 \\
\hline
\end{tabular}

* average (standard deviation)

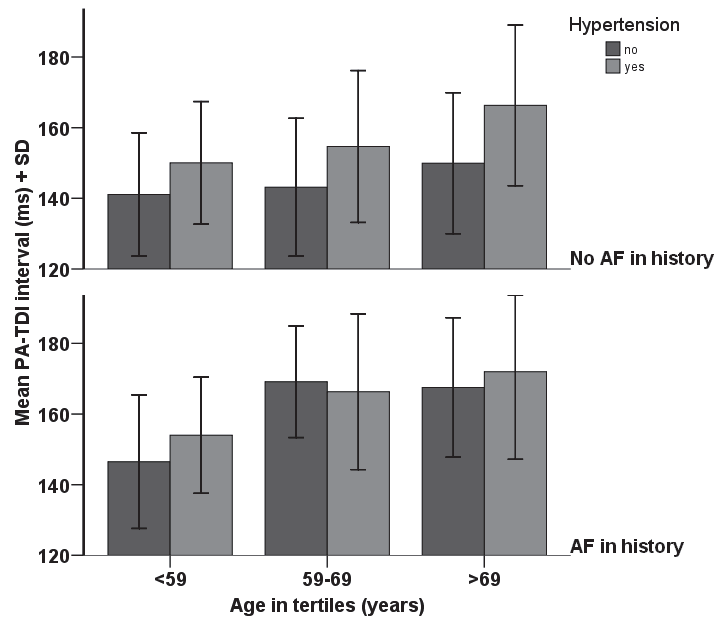

Figure 6.2 Clinical parameters affecting the PA-TDI interval.

Mean PA-TDI interval \pm standard deviation according to age in tertiles and hypertensive patients (grey bars) versus nonhypertensive patients (dark grey bars). The upper panel shows patients without a history of atrial fibrillation and the lower panel patients with a history of atrial fibrillation. 
A history of AF was present in 188 (44\%) patients. Atrial fibrillation was paroxysmal and self-terminating in 165 (88\%) patients and persistent and previously terminated by electrical or chemical cardioversion in $23(12 \%)$ patients.

Echocardiographic differences according to PA-TDI duration are shown in Table 6.2. Patients with a longer PA-TDI interval have an increased aortic width, increased atrial dimensions, and a larger and thicker left ventricle. The E-wave deceleration slope is decreased and the E-wave deceleration time is increased in the patients with a longer PA-TDI interval. Patients with a prolonged PA-TDI interval had more aortic valve incompetence and mitral valve incompetence. Figure 6.3 shows the mean PA-TDI interval according to mitral valve E-wave deceleration time and left atrial dimension.

Table 6.2 Echocardiographic parameters in relation to the mean PA-TDI duration in our population univariate analysis.

\begin{tabular}{|c|c|c|c|}
\hline & $\begin{array}{c}\mathrm{PA}-\mathrm{TDI}<157 \mathrm{~ms} \\
(\mathrm{n}=222)\end{array}$ & $\begin{array}{c}\text { PA-TDI } \geq 157 \mathrm{~ms} \\
(n=205)\end{array}$ & $P$-value \\
\hline \multicolumn{4}{|l|}{ Dimensions: } \\
\hline Ao Diameter (mm) & $33.6 \pm 4$ & $35.1 \pm 4$ & $<0.001$ \\
\hline Left atrial dimension (mm) & $39 \pm 5$ & $42 \pm 5$ & $<0.001$ \\
\hline Left atrial volume (cc) & $51 \pm 20$ & $57 \pm 25$ & 0.012 \\
\hline Right atrial volume $(\mathrm{cc})$ & $42 \pm 14$ & $46 \pm 16$ & 0.049 \\
\hline Left ventricular end diastolic dimension ( $\mathrm{mm}$ ) & $48 \pm 5$ & $50 \pm 5$ & $<0.001$ \\
\hline Left ventricular end systolic dimension (mm) & $32 \pm 6$ & $34 \pm 6$ & 0.002 \\
\hline Interventricular septum width (mm) & $9.1 \pm 1.1$ & $9.9 \pm 5.8$ & 0.025 \\
\hline Posterior wall width (mm) & $8.7 \pm 0.9$ & $9.1 \pm 1.1$ & 0.002 \\
\hline Left ventricular mass $(\mathrm{g})$ & $185 \pm 44$ & $209 \pm 54$ & $<0.001$ \\
\hline Left ventricular end diastolic volume (cc) & $109 \pm 28$ & $120 \pm 35$ & 0.001 \\
\hline Left ventricular end systolic volume (cc) & $42 \pm 21$ & $49 \pm 27$ & 0.006 \\
\hline Caval vein $(\mathrm{mm})$ & $17 \pm 4$ & $17 \pm 4$ & 0.256 \\
\hline Right ventricular systolic pressure (mmHg) & $30 \pm 6$ & $32 \pm 8$ & 0.182 \\
\hline \multicolumn{4}{|l|}{ Left ventricular function: } \\
\hline Left ventricular ejection fraction (\%) & $61 \pm 9$ & $60 \pm 9$ & 0.072 \\
\hline \multicolumn{4}{|l|}{ Mitral valve Doppler: } \\
\hline Maximal E-wave velocity (cm/sec) & $75 \pm 17$ & $73 \pm 20$ & 0.292 \\
\hline E-wave deceleration slope $\left(\mathrm{m} / \mathrm{sec}^{2}\right)$ & $396 \pm 145$ & $355 \pm 157$ & 0.006 \\
\hline E-wave deceleration time (ms) & $196 \pm 44$ & $218 \pm 62$ & $<0.001$ \\
\hline Maximal A-wave velocity (cm/sec) & $76 \pm 20$ & $75 \pm 21$ & 0.462 \\
\hline E/A ratio & $1.04 \pm 0.4$ & $1.06 \pm 0.6$ & 0.603 \\
\hline \multicolumn{4}{|l|}{ Valve disease: } \\
\hline Aortic incompetence (>grade 1) & $4(2 \%)$ & $18(9 \%)$ & 0.002 \\
\hline Mitral incompetence (>grade 1 ) & $9(4 \%)$ & $28(14 \%)$ & $<0.001$ \\
\hline Tricuspid incompetence (>grade 1) & $14(6 \%)$ & $17(8 \%)$ & 0.460 \\
\hline Mitral valve stenosis & 0 & $2(1 \%)$ & 0.230 \\
\hline Aortic stenosis & $8(4 \%)$ & $8(4 \%)$ & 1.000 \\
\hline Systolic right ventricular pressure $(\mathrm{mm} \mathrm{Hg})$ & $30 \pm 6$ & $32 \pm 8$ & 0.182 \\
\hline
\end{tabular}




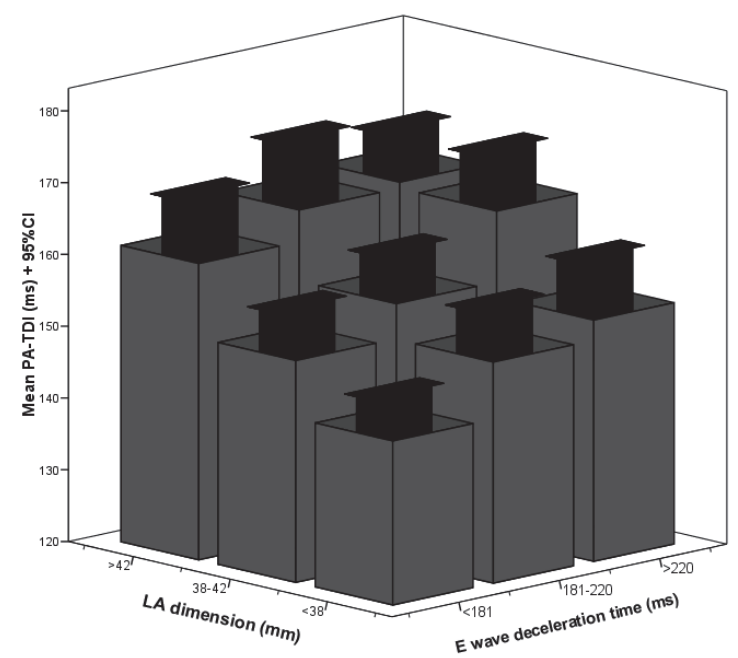

Figure 6.3 Echocardiographic parameters affecting the PA-TDI interval. Mean PA-TDI interval and 95\% confidence intervals according to mitral valve E-wave deceleration time and left atrial dimension, both in tertiles.

Multivariable linear regression analysis revealed that AF in history, hypertension, clinically relevant valve disease, age, and $\mathrm{BMI}$ were independently associated with the PA-TDI interval (Table 6.3). When excluding patients with $A F$ in history, hypertension $(B=10, P<0.001)$, age $(B=5$ per 10 years increase of age, $P<0.001)$, and $B M I(B=4$ per 5 points increase of $\mathrm{BMI}, \mathrm{P}=0.011$ ) remained significantly associated with a prolonged PA-TDI interval.

Table 6.3 Multivariate linear regression analysis: clinical and echocardiographic parameters that independently prolong the PA-TDI interval and correlation coefficients of all continuous variables resulting from the correlation with PA-TDI.

\begin{tabular}{lccc|cc}
\hline & $\mathrm{B}(\mathrm{ms})$ & $95 \% \mathrm{Cl}$ for $(\mathrm{B})$ & $P$-value & $\mathrm{R}^{2}$ & $P$-value \\
\hline Demographic and clinical parameters & & & & & \\
AF in history & 9.7 & $5.7-13.8$ & $<0.001$ & & \\
Hypertension & 5.5 & $1.4-9.8$ & 0.010 & & \\
Valve disease & 5.7 & $0.5-10.8$ & 0.030 & & \\
Age (per 10 years) & 5 & $3.3-6.6$ & $<0.001$ & 0.34 & $<0.001$ \\
BMI (per 5 kg/m ${ }^{2}$ ) & 2.6 & $0.3-4.9$ & 0.026 & 0.13 & 0.008 \\
Echocardiographic parameters & & & & & \\
Aorta diameter (per mm) & 0.7 & $0.2-1.2$ & 0.009 & 0.22 & $<0.001$ \\
Left atrial dimension (per mm) & 0.9 & $0.5-1.3$ & $<0.001$ & 0.34 & $<0.001$ \\
Aortic incompetence (>grade 1) & 13 & $3.3-22.6$ & 0.008 & & \\
Mitral incompetence (>grade 1) & 11 & $3.6-17.5$ & 0.003 & & \\
Mitral valve E-wave deceleration time (per ms) & 0.076 & $0.039-0.113$ & $<0.001$ & 0.25 & $<0.001$ \\
\hline
\end{tabular}


Regarding the echocardiographic parameters: the aortic diameter, left atrial dimension, mitral valve E-wave deceleration time, aortic incompetence, and mitral incompetence were independently associated with the PA-TDI interval in our population (Table 6.3). When excluding patients with a history of AF, the clinical parameters hypertension, age and BMI remained independently associated with the PA-TDI interval. The echocardiographic parameters aorta diameter, left atrial dimension, aortic incompetence, and mitral valve E-wave deceleration time remained independently associated with PA-TDI interval when performing multivariate linear regression analysis in patients without a history of $A F$.

\section{Discussion}

The present study is the largest to investigate the relationship between PA-TDI, underlying cardiovascular diseases and echocardiographic parameters. We used the PA-TDI interval-a relatively new echocardiographic parameter ${ }^{11}$-to estimate the TACT.

\section{Clinical correlates of intra-atrial conduction delay}

In this study, PA-TDI was independently prolonged in patients with a history of AF, hypertension, clinically relevant valve disease, higher age, and a higher BMI. We found that after correcting for possible confounders, a history of AF increases PA-TDI by +/$10 \mathrm{~ms}$, a history of hypertension by $5 \mathrm{~ms}$ and clinically relevant valve disease by $6 \mathrm{~ms}$. Each additional 10 years of age increases PA-TDI with +/- $5 \mathrm{~ms}$ and each additional $5 \mathrm{~kg} / \mathrm{m}^{2}$ of BMI increases PA-TDI with $3 \mathrm{~ms}$. The strong association between prolonged atrial conduction time and $A F$ is not surprising since on one hand long conduction times are a prerequisite for the development of AF and on the other hand, AF itself may induce remodelling and hence contribute to lengthening of conduction through the atria. ${ }^{6,16}$ As has been suggested previously, prevention of AF may ameliorate atrial structural remodelling and prevent further AF episodes. Since it is unlikely that available therapies reduce atrial conduction time, preventive therapy might focus especially on suppression of AF in the subset with still normal conduction. Ageing is a recognized determinant of atrial size and fibrosis but unfortunately non-modifiable with respect to prevention of conduction abnormalities. Hypertension and valve disease are associated with diastolic dysfunction inducing intermittent pressure rises and dilatation of the atria and hence atrial fibrosis. ${ }^{17,18}$ In turn, this prolongs the TACT because of 'detour conduction' in larger atria. Although BMI relates to hypertension we showed an independent impact on TACT. From our data we cannot tell whether high BMI effected an increase in TACT through obstructive sleep apnea which was recently described as being associated with atrial conduction slowing. ${ }^{2}$ On the other hand, the pericardial fat that overlies the cardiac surface including the inter- and intra- 
atrial conduction system might be responsible for atrial conduction delays. Recent studies demonstrate a relation between pericardial fat and atrial conduction delay. ${ }^{19}$ Reducing body weight may ameliorate the atrial conduction time. Indeed, the effect of a high BMI on atrial conduction is likely to be reversible since obesity studies demonstrate that substantial weight loss is associated with improvement in atrial repolarization abnormalities on the ECG in obese subjects. ${ }^{20}$ Patients with a prolonged PA-TDI interval more often used oral anticoagulation, beta-blockers, nitrates, ACEinhibitors, and diuretics. It is difficult to interpret the relation between PA-TDI and the use of medication in the present study. The univariate analysis showed that in patients with a long PA-TDI interval AF, hypertension, and coronary artery disease occurred more frequently. Oral anticoagulation is typically prescribed in patients with AF, betablockers in patients with coronary artery but also in patients with hypertension and AF, nitrates are frequently applied in patients with coronary artery disease, and ACEinhibitors and diuretics are usually prescribed in patients with hypertension. Therefore, one could hypothesize that the differences found in medication use according to the length of the PA-TDI interval are the result of underlying heart disease. On the other hand, one could imagine that some medication directly influences the PA-TDI interval. Unfortunately, the present study does not provide an answer to this question.

\section{Echocardiographic correlates of intra-atrial conduction delay}

We also investigated echocardiographic parameters that were associated with PA-TDI. We found that increased left atrium (LA) dimension, increased aortic diameter, aortic, and mitral valve incompetence and a longer E-wave deceleration time are independently associated with a prolonged PA-TDI interval. The latter probably reflects mild diastolic dysfunction since it might be a sign of an impaired relaxation of the left ventricle. However, other parameters necessary to confirm this finding such as the pulmonary vein flow and $E / e^{\prime \prime}$ were not available in all patients. However, smaller studies using the signal averaged ECG to assess atrial conduction also demonstrate increased left atrial pressure and impaired LV relaxation in patients with delayed atrial conduction. $^{21}$ The increased aortic diameter could be a reflection of the presence of aortic incompetence. However, our data show an independent relation between aortic diameter and PA-TDI. Another explanation could be inadequate management of hypertension. Since hypertension in history is also one of the clinical parameters, which was independently associated with a delay of the PA-TDI interval in this study, lowering the blood pressure is probably crucial to prevent prolongation of the TACT. An increased LA dimension could be the reflection of intermittent left atrial pressure rises typically seen in diastolic left ventricular dysfunction. ${ }^{22}$

\section{Future perspectives}

Since recent studies suggest that a prolonged PA-TDI is associated with the development of new-onset AF and poor outcome of rhythm control, ${ }^{10,12-15}$ one could 
hypothesize that reducing the duration of PA-TDI (or preventing its lengthening) improves primary and secondary prevention of AF. Our study suggests that early and aggressive treatment of hypertension, diastolic dysfunction, and obesity could prevent an increased PA-TDI. This was also suggested in smaller clinical studies. ${ }^{23}$ In addition, recent laboratory studies affirm that upstream therapy might enhance atrial conduction by reducing atrial fibrosis. ${ }^{7,23}$ PA-TDI could be used to select appropriate candidates for upstream therapy and evaluating its effect.

\section{Limitations}

The PA-TDI interval overestimates the total atrial activation time since it includes both the time required for the propagation of impulses from the sinus node area to the left atrium and the time required for the electromechanical coupling in the left atrium. Furthermore, there seems to be a minor delay in ECG processing on all echo machines. In our study, this delay amounts to a maximum of $5 \mathrm{~ms}$ (unpublished technical information by Philips Medical Systems, Andover, MA, USA). Fortunately, this delay is consistent and therefore unlikely to have affected our results.

Some of the parameters in Table 6.2 showed only a small difference but still a significant univariate $\mathrm{P}$ value, which may relate to the large sample size. Obviously, these differences may be of limited clinical relevance because they were at times smaller than the error in individual measurements. However, it should be noted that Tables 6.1 and 6.2 concerned univariate analyses used to identify parameters to feed the regression analysis. All our patients were included in a cardiology outpatient clinic. As a result, the population we studied may not be representative of the general population. On the other hand, PA-TDI is intended for patients with cardiovascular diseases. The investigator who included the patients (R.G.T.) is a general cardiologist with a special interest in electrophysiology. For that reason, many patients included in the present study had a history of AF. However, we verified our main findings in a group of patients excluding those with a history of AF and found similar results.

\section{Conclusions}

The present study is the largest clinical study to investigate the relation between the atrial conduction times, underlying heart diseases, and echocardiographic parameters. We found that PA-TDI was prolonged in patients with a history of AF, hypertension, clinically relevant valve disease, higher age, and a higher BMI. On the echocardiogram, a larger left atrium, a larger aortic diameter, a longer E-wave deceleration time, and aortic and mitral incompetence were also associated with a prolonged PA-TDI interval. Since recent studies suggest that atrial conduction delay is associated with the development of new-onset AF and poor outcome of rhythm control, one could hypothesize that reducing atrial conduction time (or preventing its lengthening) improves primary and secondary prevention of AF. Based on our results, one could 
hypothesize that early and aggressive treatment of hypertension, diastolic dysfunction, and obesity could prevent atrial conduction delay. 


\section{References}

1. Shimizu A, Centurion OA. Electrophysiological properties of the human atrium in atrial fibrillation. Cardiovasc Res 2002;54:302-314.

2. Yagmur J, Yetkin O, Cansel M, Acikgoz N, Ermis N, Karakus Y, Tasolar H. Assessment of atrial electromechanical delay and influential factors in patients with obstructive sleep apnea. Sleep Breath 2012;16:83-88.

3. Dogdu O, Yarlioglues M, Kaya MG, Ardic I, Kilinc Y, Elcik D, Kelesoglu S, Akpek M, Sahin O, Cosgun S, Oguzhan N, Oguzhan A. Assessment of atrial conduction time in patients with systemic lupus erythematosus. J Investig Med 2011;59:281-286.

4. Buyukoglan H, Kaya MG, Ardic I, Yarlioglues M, Dogdu O, Bol C, Sahin O, Kanbay A, Koç F, Ozdogru I. Assessment of atrial conduction time in patients with sarcoidosis. J Investig Med 2011;59:15-21.

5. Van Beeumen K, Duytschaever M, Tavernier R, Van de Veire N, De Sutter J. Intra and interatrial asynchrony in patients with heart failure. Am J Cardiol 2007;99:79-83.

6. Pytkowski M, Jankowska A, Maciag A, Kowalik I, Sterlinski M, Szwed H, Saumarez RC. Paroxysmal atrial fibrillation is associated with increased intra-atrial conduction delay. Europace 2008;10:1415-1420.

7. Matsuyama N, Tsutsumi T, Kubota N, Nakajima T, Suzuki H, Takeyama Y. Direct action of an angiotensin II receptor blocker on angiotensin II-induced left atrial conduction delay in spontaneously hypertensive rats. Hypertens Res 2009;32:721-726.

8. Verlato R, Zanon F, Bertaglia E, Turrini P, Baccillieri MS, Baracca E, Bongiorni MG, Zampiero A, Zonzin P, Pascotto $P$, Venturini $D$, Corbucci $G$. Prevalence of conduction delay of the right atrium in patients with SSS: implications for pacing site selection. J Cardiovasc Med (Hagerstown) 2007;8:706-712.

9. Lewicka-Nowak E, Kutarski A, Dabrowska-Kugacka A, Rucinski P, Zagozdzon P, Raczak G. A novel method of multisite atrial pacing, incorporating Bachmann's bundle area and coronary sinus ostium, for electrical atrial resynchronization in patients with recurrent atrial fibrillation. Europace 2007;9:805-811.

10. Buck S, Rienstra M, Maass AH, Nieuwland W, Van Veldhuisen DJ, Van Gelder IC. Cardiac resynchronization therapy in patients with heart failure and atrial fibrillation: importance of new-onset atrial fibrillation and total atrial conduction time. Europace 2008;10:558-565.

11. Merckx KL, De Vos CB, Palmans A, Habets J, Cheriex EC, Crijns HJ, Tieleman RG. Atrial activation time determined by transthoracic Doppler tissue imaging can be used as an estimate of the total duration of atrial electrical activation. J Am Soc Echocardiogr 2005;18:940-944.

12. De Vos CB, Weijs B, Crijns HJ, Cheriex EC, Palmans A, Habets J, Prins MH, Pisters R, Nieuwlaat R, Tieleman RG. Atrial tissue Doppler imaging for prediction of new-onset atrial fibrillation. Heart 2009;95:835-840.

13. Antoni ML, Bertini M, Atary JZ, Delgado V, ten Brinke EA, Boersma E, Holman ER, van der Wall EE, Schalij MJ, Bax JJ, van de Veire NR. Predictive value of total atrial conduction time estimated with tissue Doppler imaging for the development of new-onset atrial fibrillation after acute myocardial infarction. Am J Cardiol 2010;106:198-203.

14. Bertini M1, Borleffs CJ, Delgado V, Ng AC, Piers SR, Shanks M, Antoni ML, Biffi M, Boriani G, Schalij MJ, Bax JJ, Van de Veire NR.. Prediction of atrial fibrillation in patients with an implantable cardioverterdefibrillator and heart failure. Eur J Heart Fail 2010;12:1101-1110.

15. Chao TF1, Sung SH, Wang KL, Lin YJ, Chang SL, Lo LW, Hu YF, Tuan TC, Suenari K, Li CH, Ueng KC, Wu TJ, Chen SA. Associations between the atrial electromechanical interval, atrial remodelling and outcome of catheter ablation in paroxysmal atrial fibrillation. Heart 2011;97:225-230.

16. Wijffels MC, Kirchhof CJ, Dorland R, Allessie MA. Atrial fibrillation begets atrial fibrillation. A study in awake chronically instrumented goats. Circulation 1995;92:1954-1968.

17. Daccarett M, Badger TJ, Akoum N, Burgon NS, Mahnkopf C, Vergara G, Kholmovski E, McGann CJ, Parker D, Brachmann J, Macleod RS, Marrouche NF Association of left atrial fibrosis detected by delayed-enhancement magnetic resonance imaging and the risk of stroke in patients with atrial fibrillation. J Am Coll Cardiol 2011;57:831-838.

18. Anné $W$, Willems R, Roskams $T$, Sergeant $P$, Herijgers $P$, Holemans $P$, Ector $H$, Heidbüchel $H$. Matrix metalloproteinases and atrial remodeling in patients with mitral valve disease and atrial fibrillation. Cardiovasc Res 2005;67:655-666. 
19. Babcock MJ, Soliman EZ, Ding J, Kronmal RA, Goff DC Jr. Pericardial fat and atrial conduction abnormalities in the Multiethnic Study of Atherosclerosis (MESA). Obesity 2011;19:179-184.

20. Duru M, Seyfeli E, Kuvandik G, Kaya H, Yalcin F. Effect of weight loss on $P$ wave dispersion in obese subjects. Obesity 2006;14:1378-1382.

21. Vranka I, Penz P, Dukat A. Atrial conduction delay and its association with left atrial dimension, left atrial pressure and left ventricular diastolic dysfunction in patients at risk of atrial fibrillation. Exp Clin Cardiol 2007;12:197-201.

22. Kojodjojo P, Peters NS, Davies DW, Kanagaratnam P. Characterization of the electroanatomical substrate in human atrial fibrillation: the relationship between changes in atrial volume, refractoriness, wavefront propagation velocities, and AF burden. J Cardiovasc Electrophysiol 2007;18:269-75.

23. Fuenmayor AJ, Moreno G, Landaeta A, Fuenmayor AM. Inter-atrial conduction time shortens after blood pressure control in hypertensive patients with left ventricular hypertrophy. Int J Cardiol 2005;102:443-6. 


\section{Editorial comment}

\section{Atrial electromechanical function}

Michael Y. Henein

Europace 2011;13:1665-1666

As one of the four cardiac pumps, the left atrium abides by the natural properties of myocardial function, i.e. electrical stimulation, irrespective of the conduction pattern, followed by mechanical muscle contraction then stroke volume ejection. While failure of native ventricular electrical stimulation is not compatible with life, that of the atrium is tolerable and many patients may live a completely normal life in atrial fibrillation. In fact, recent evidence supports the notion that rate-controlled atrial fibrillation has a clinical outcome similar to the rhythm-controlled one. ${ }^{1}$ Patients with severe left ventricular disease, however, may respond differently and develop fast worsening symptoms with atrial fibrillation, because of the loss of the component of stroke volume pumped by the left atrium.

Full understanding of left atrial function requires critical appreciation of its detailed anatomy as well as myocardial fibre architecture. Anatomically, the left atrium is the functional opponent to the left ventricle, with reciprocal shortening and lengthening relationship between the two. The dominant myocardial fibres of the left atrium are longitudinally orientated, originating from the back of the atrium and inserting around the circumference of the mitral annulus. A smaller group of fibres run transversely around the base of the left atrium, although not covering its full circumference. ${ }^{2}$ Thus, the main axis of the left atrial cavity shortening is longitudinal with the mitral annulus moving back towards the rear of the atrium after the P-wave and during the PR interval and returning to its resting position at the time of the first heart sound, marking end-diastole. It is worth mentioning that not only does this pattern of function mirror that of the left ventricle, although in the opposite direction, but the atrium also does not function in isolation of the ventricle. Myocardial development studies have shown close relationship between age-related changes in the function of the atrium and the ventricle which themselves are closely related. As left ventricular lengthening velocities reduce with age, those of left atrial shortening reciprocally increase in order to secure normal stroke volume entering the left ventricle. ${ }^{3}$ Conventional measurements of the left atrial size rely on longitudinal and transverse diameters as well as its area measurements. Segmental left atrial myocardial function is easily assessed from the longitudinal motion amplitude and velocity of the lateral, septal, and posterior segments as shown by the mitral annulus excursion during atrial systole. This is easily achieved using tissue Doppler or speckle tracking techniques. The amplitude of left atrial longitudinal motion is also assessed by the same techniques or by conventional M-mode. 
Similar to the left ventricle, the main determinant of left atrial contractile function is its intrinsic myocardial function, which has its well-established maturation course, between foetal life and adolescence. ${ }^{4}$ As the atrium gets large in size due to various pathologies, with the commonest secondary to left ventricular and valve diseases, its overall contractile function falls and eventually pump failure and atrial fibrillation. Even in patients with paroxysmal atrial fibrillation and only small increase in atrial size we have shown significant reduction in segmental left atrial function particularly in areas adjacent to the pulmonary veins. ${ }^{5}$ Critical investigation of atrial function shows that such pathophysiological course is not that simple. We and others have previously shown that atrial flutter and fibrillation are commonly preceded by progressive prolongation of P-wave duration which itself proved a good predictor for the occurrence of atrial arrhythmias. ${ }^{6,7}$ This is explained on the basis of progressive atrial enlargement and myocardial stretching, which increase its surface area and hence the prolonged depolarization time. Such behaviour is similar to that occurring in dilated left ventricles with prolonged depolarization time and broad QRS duration.

Another important component of left atrial function is its electromechanical delay, similar to that seen in the left ventricle. This can easily be studied by the same Doppler echocardiographic techniques mentioned above and left atrial motion measured with reference to the onset of its electrical depolarization, the P-wave. Studies have used the onset of segmental left atrial shortening (excursion) or peak shortening velocity as two possible landmarks for electromechanical delay. Normal values for the two measurements have been determined and well documented. Normally, the three left atrial segments shorten in a synchronous fashion with no more than few milliseconds time difference between them, again a finding similar to that seen in the left ventricle. We have previously shown that such measurement is significantly abnormal and its relationship with that of the right atrium is disturbed in patients who develop atrial flutter. ${ }^{8}$ Furthermore, within the same atrium there is emerging evidence suggesting the presence of segmental left atrial dyssynchrony in patients with right heart disease, with some segments contracting significantly later than the others (unpublished data from Umea University) in response to the increase in right atrial pressures. Although left atrial contractile contribution to the stroke volume is relative to its wall thickness, it remains functioning as a pump with a need to behave in a satisfactory synchronous manner.

In this issue Weijs B et al. ${ }^{9}$ report an interesting measure of delayed atrial contraction as shown by the time interval between the onset of the P-wave and peak atrial systolic velocity. Interestingly, the authors report a number of clinical findings predicted by such measure, namely history of atrial fibrillation, hypertension, relevant valve disease, age, and body mass index. In addition, echocardiographic evidence of dilated aortic diameter, left atrial dimension, E-wave deceleration time, and aortic and mitral regurgitation were also independently associated with prolonged intra-atrial conduction. It seems that most of those conditions and functional disturbances result in various degrees of raised left atrial pressure. Age and long-standing hypertension 
are associated with the development of stiff left ventricle and raised left atrial pressure, a known substrate for atrial fibrillation. This can clearly be manifested in the form of short E-wave deceleration time, which reflects raised left ventricular enddiastolic pressure. Significant mitral and aortic valve disease, as mentioned above increase the overload on the left ventricle, again resulting into a similar pattern of pathophysiology, and increased left atrial pressure. Finally, aortic dilatation seems to represent an external left atrial wall stress which destabilizes its function and hence atrial arrhythmia, although this finding is not well documented in the literature. The reported index seems to reflect atrial electromechanical delay in a very simple and feasible way. The onset of the P-wave is easily measured on the superimposed electrocardiogram and the peak atrial shortening velocity should adequately be obtained by tissue Doppler or speckle tracking techniques, making such measure highly reproducible. Finally, to the clear scientific mind such an index of atrial electromechanical delay should be seen to encompass the prolonged P-wave as a reflection of delayed atrial depolarization in addition to the pure delay in the atrial mechanical function, if it exists. 


\section{References}

1. Fuster V, Rydén LE, Cannom DS, Crijns HJ, Curtis AB, Ellenbogen KA et al. 2011 ACCF/AHA/HRS focused updates incorporated into the ACC/AHA/ESC 2006 Guidelines for the management of patients with atrial fibrillation: a report of the American College of Cardiology Foundation/American Heart Association Task Force on Practice Guidelines developed in partnership with the European Society of Cardiology and in collaboration with the European Heart Rhythm Association and the Heart Rhythm Society. J Am Coll Cardiol 2011;57:e101-98.

2. Wang K, Ho SY, Gibson DG, Anderson RH. Architecture of atrial musculature in humans. Br Heart $J$ 1995;73:559-65.

3. Henein $M$, Lindqvist $P$, Francis D, Mörner S, Waldenström A, Kazzam E. Tissue Doppler analysis of agedependency in diastolic ventricular behaviour and filling: a cross-sectional study of healthy hearts (the Umea $^{\circ}$ General Population Heart Study). Eur Heart J 2002;23:162-71.

4. Gardiner HM, Pasquini L, Wolfenden J, Barlow A, Li W, Kulinskaya E et al. Myocardial tissue Doppler and long axis function in the fetal heart. Int J Cardiol 2006;113:39-47.

5. Henein M Jr, Lindqvist P, Mörner S, Henein M. Effect of raised left atrial pressure on its regional and segmental chamber function: the role of speckle tracking. Scandinavian Cardiovasc J 2009;43:28.

6. Li W, Xiao HB, Henein MY, Somerville J, Gibson DG. Progressive ECG changes before the onset of atrial flutter in adult congenital heart disease patients. Heart 2001;85:703.

7. Dilaveris PE, Gialafos EJ, Sideris SK, Theopistou AM, Andrikopoulos GK, Kyriakidis M et al. Simple electrocardiographic markers for the prediction of paroxysmal idiopathic atrial fibrillation. Am Heart J 1998;135:733-8.

8. Li W, Somerville J, Gibson DG, Henein MY. Disturbed atrioventricular electromechanical function long after Mustard operation for transposition of great arteries: a potential contributing factor to atrial flutter. J Am Soc Echocardiogr 2001;14:1088-93.

9. Weijs B, de Vos CB, Tieleman RG, Pisters R, Cheriex EC, Prins MH, Crijns HJGM. Clinical and echocardiographic correlates of intra-atrial conduction delay. Europace 2011;13:1681-7. 
Chapter 7

Atrial tissue Doppler imaging for prediction of new-onset atrial fibrillation

CB De Vos, B Weijs, HJGM Crijns, EC Cheriex, A Palmans, J Habets, M Prins, R Pisters, R Nieuwlaat, RG Tieleman

Heart 2009;95:835-840 


\section{Abstract}

\section{Background}

The total atrial conduction time (TACT) is an independent predictor of atrial fibrillation (AF). A new transthoracic echocardiographic tool to determine TACT by tissue Doppler imaging (PA-TDI (the time from the initiation of the P wave on the ECG (lead II) to the $A^{\prime}$ wave on the lateral left atrial tissue Doppler tracing)) has been developed recently.

\section{Objective}

To test the hypothesis that measurement of PA-TDI enables prediction of new-onset AF.

\section{Methods}

249 Patients without a history of AF were studied. All patients underwent an echocardiogram and the PA-TDI interval was measured. Patient characteristics and rhythm at follow-up were recorded.

Results

During a mean (SD) follow-up of 680 (290) days, 15 patients (6\%) developed new-onset AF. These patients had a longer PA-TDI interval than patients who remained in sinus rhythm (172 (25) ms vs. 150 (20) ms, P=0.001). Furthermore, the patients developing AF were older, more often had a history of heart failure or chronic obstructive pulmonary disease, more often used $\alpha$ blockers, had enlarged left atria and more frequently mitral incompetence on the echocardiogram. After adjusting for potential confounders, Cox regression showed that PA-TDI was independently associated with new-onset $A F(O R=1.375 ; 95 \% \mathrm{Cl} 1.037$ to $1.823 ; P=0.027)$. The 2-year incidence of $A F$ was $33 \%$ in patients with a PA-TDI interval $>190$ ms versus $0 \%$ in patients with a PA-TDI interval $<130 \mathrm{~ms}(P=0.002)$.

\section{Conclusions}

A prolonged PA-TDI interval may predict the development of new-onset AF. This measure may be used to identify patients at risk in future strategies to prevent the development or complications of AF. 


\section{Introduction}

Atrial fibrillation (AF) is the most common sustained cardiac arrhythmia and may result in life-threatening complications such as stroke and heart failure. ${ }^{1}$ Unfortunately, treatment often comes too late-for example, when stroke is the first manifestation of AF. ${ }^{2}$ Therefore, prediction and prevention of $\mathrm{AF}$ and its complications is essential. There has been an increase in the number of admissions to hospital for AF in recent years, demonstrating the need for primary prevention of new-onset AF. ${ }^{3}$ To enable primary prevention strategies, we have to identify which patients are at increased risk for the development of AF. Observational population studies resulted in the discovery of clinical and echocardiographic parameters that are associated with the development of $\mathrm{AF}^{4-7}$ However, the currently available risk stratification parameters have limited predictive value in the individual patient. ${ }^{8}$

Age or underlying heart disease may result in atrial dilatation or a depressed intraatrial conduction. ${ }^{9-11}$ This will lead to an increased total atrial conduction time (TACT) and facilitate AF. Recently, we validated a new non-invasive echocardiographic method to determine the TACT, using transthoracic tissue Doppler imaging of the atria (the PA-TDI interval). ${ }^{12}$ We demonstrated that PA-TDI is an easy, fast and reliable method to estimate the TACT. This study was designed to test the hypothesis that non-invasive measurement of the TACT facilitates the identification of subjects at risk for development of $A F$ in patients with no prior history of atrial arrhythmias.

\section{Methods}

We prospectively studied a total of 249 consecutive patients in sinus rhythm. We included all consecutive patients from the outpatient clinic of one of our cardiologists (RGT) who were referred for a standard echocardiographic examination for various cardiovascular diseases. Patient-informed consent was obtained and the study was approved by our institutional review board. Exclusion criteria were a history of AF, atrial flutter, atrial tachycardia, age ,18 years, previous pacemaker implantation or an implantable cardioverter-defibrillator.

\section{The echocardiogram}

An independent observer blinded for the history of the patients performed the echocardiogram while subjects were lying in the left lateral decubitus position. All patients underwent standard twodimensional transthoracic echocardiography, including M mode, and Doppler echocardiography (Sonos 5500, Philips Medical Systems, Andover, Massachusetts, USA). Recordings were made in the standard projections (subcostal, parasternal long-axis, parasternal short-axis, four-chamber apical long-axis and two-chamber apical long-axis views). Aortic diameter, atrial 
volumes, ventricular wall thickness, left ventricular dimensions, left ventricular mass, left ventricular ejection fraction, caval vein width and collapse index, valve disorders, wall motion disorders and Doppler flow patterns of the mitral valve (E wave, $A$ wave) were determined in all patients according to the recommendations of the American Society of Echocardiography.

Additionally, we determined the TACT with tissue Doppler imaging as described previously. ${ }^{12}$ In the apical four-chamber view, the pulsed-wave tissue Doppler sample was placed on the lateral wall of the left atrium just above the mitral annulus. The PA-TDI interval, defined as the time-interval from initiation of the electrocardiographic $P$ wave recorded by the echo machine (lead II) to the peak of the $A^{\prime}$ wave of the atrial tissue Doppler tracing (Figure 7.1), was measured in three cardiac cycles and averaged.

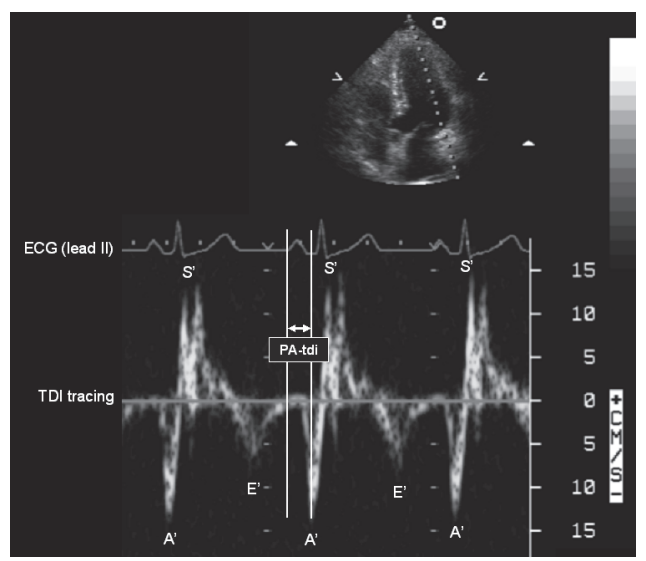

Figure 7.1 Example measurement of the PA-TDI interval.

\section{The electrocardiogram}

At the time of inclusion, all patients underwent 12-lead ECG recording obtained in the supine position using an ECG system (MAC 5000, Marquette Medical Systems, Milwaukee, Wisconsin, USA). Previous studies have shown that the surface ECG $\mathrm{P}$-wave duration, also an estimate of the TACT, is a predictor for new-onset AF after cardiac surgery. ${ }^{13}$ Therefore, an independent observer who was unaware of the results from the other examinations or the patients' history did a manual P-wave duration measurement. The onset of the $P$ wave was defined as the junction between the isoelectric line and the beginning of the P-wave deflection, and the offset of the $\mathrm{P}$-wave as the junction between the end of the P-wave deflection and the isoelectric line. To improve accuracy, a digital calliper and magnifying glass were used to perform the measurements. 


\section{Data collection}

Patient characteristics, medical history and medication at the time of echocardiography were collected. Furthermore, we verified the absence of atrial arrhythmias by examining the patient charts and our electronic medical records and an electronic ECG database which stores all ECGs and Holter recordings performed in our hospital. In all patients a virtual CHADS2 score was calculated. This acronym stands for Congestive heart failure, Hypertension, Age (75 years and older), Diabetes mellitus and a history of Stroke/transient ischaemic attack ( 2 points). This scoring system allows instant classification of the relative thromboembolic risk in patients with $A F$, and is incorporated in the latest guidelines on the management of $A F .^{14}$ During follow-up, patients were seen at 6-month intervals in our outpatient department. During every visit, symptoms of AF were thoroughly verified and an ECG was obtained. When in doubt about the rhythm status of the patient, a Holter recording was performed. As soon as patients were admitted to the first aid department with cardiac complaints, the rhythm was verified by one of our cardiologists and the presence of AF was recorded in the digital charts of our cardiology department. Since the University Hospital Maastricht has a strong regional community care function, none of the patients were lost to follow-up.

\section{Statistical analysis}

Data analysis was performed with SPSS statistical software V.15.0. Continuous variables are reported as mean (SD) and categorical variables as observed number of patients (percentage). Since our survival data were partly censored, we performed a Cox regression univariate analysis when comparing patients who developed AF during follow-up with patients who did not. When comparing 2-year incidences of AF we used $\chi^{2}$ to evaluate three or more groups and Fisher's exact test when comparing two groups. Given the limited number of events, we first determined an odds ratio (OR) for PA-TDI alone to predict AF during follow-up using Cox regression analysis. Later, we adjusted the OR for potential confounders. All parameters showing a significant univariate relation with the occurrence of new-onset $A F$ during follow-up were included in a Cox regression model (heart failure in history, mitral incompetence on echo, chronic obstructive pulmonary disease in history, $\alpha$-blocker use, left atrial size on echocardiogram and age). We did not include the CHADS2 score in the model since it was derived from other variables included in the model (age and history of heart failure). The predictive accuracy of PA-TDI was reported using a receiver operating characteristic (ROC) curve. All tests performed were two sided. Overall, a $P$-value of $<0.05$ was considered to be significant. 


\section{Results}

We included 249 patients in our study. The PA-TDI interval ranged between $103 \mathrm{~ms}$ and 223 ms. The mean (SD) age of our cohort was 62 (13) years. Many patients had underlying cardiovascular disease. The most common disease was hypertension which occurred in $61 \%$ of our patients. Table 7.1 presents the other baseline and electrocardiographic characteristics of our cohort. The body mass index and underlying heart disease of our cohort were in line with previous large cohort studies evaluating echocardiographic predictors of AF. ${ }^{7,15}$ Therefore, we believe that our population is representative of general cardiac outpatient clinics.

During a mean (SD) follow-up of 680 (290) days, 15 (6\%) patients developed new-onset AF. Of all patients developing AF, two (13\%) had one episode of paroxysmal AF, 12 (80\%) had recurrent episodes of paroxysmal AF and one (7\%) had permanent AF. The patients who developed AF during follow-up were older (70 (13) years vs. 61 (13) years, $P=0.01$ ) and more often had a history of heart failure and chronic obstructive pulmonary disease. $\alpha$ Blockers were used more frequently in the patients who developed AF during the follow-up period. As a result, the mean CHADS2 score was higher in these patients. No other differences were seen in baseline characteristics between the patients who demonstrated AF during follow-up and those who did not.

The echocardiogram of the patients who developed AF showed a longer mean (SD) PA-TDI interval at baseline than patients who remained in sinus rhythm (172 (25) ms vs. 150 (20) ms, $P=0.001$ ). The standard echocardiographic examination demonstrated enlarged left atrial size and more mitral incompetence in the patient with new-onset AF during followup (Table 7.1).

Table 7.1 Patient characteristics.

\begin{tabular}{lcccc}
\hline & All patients & $\begin{array}{c}\text { No AF } \\
\text { during FU* }\end{array}$ & $\begin{array}{c}\text { AF } \\
\text { during FU* }\end{array}$ & $P$-value \\
\hline $\mathrm{N}$ & 249 & 234 & 15 & \\
Age (years) & $62 \pm 13$ & $61 \pm 13$ & $70 \pm 13$ & 0.009 \\
Female & $135(54 \%)$ & $127(54 \%)$ & $8(53 \%)$ & 0.987 \\
Body Mass Index (kg/m ${ }^{2}$ ) & $27 \pm 4$ & $27 \pm 4$ & $27 \pm 4$ & 0.755 \\
Underlying Heart Disease: & & & & \\
Hypertension & $153(61 \%)$ & $142(61 \%)$ & $11(73 \%)$ & 0.643 \\
Coronary artery disease & $26(10 \%)$ & $24(10 \%)$ & $2(13 \%)$ & 0.527 \\
Diabetes mellitus & $29(12 \%)$ & $27(12 \%)$ & $2(13 \%)$ & 0.686 \\
Thromboembolic events & $9(4 \%)$ & $9(4 \%)$ & 0 & 0.633 \\
Valve disease & $49(20 \%)$ & $44(19 \%)$ & $5(33 \%)$ & 0.091 \\
Heart failure & $22(9 \%)$ & $17(7 \%)$ & $5(33 \%)$ & 0.007 \\
Stroke or transient ischemic attack & $47(19 \%)$ & $44(19 \%)$ & $3(20 \%)$ & 0.534 \\
Electrophysiology study/ablation & $11(4 \%)$ & $10(4 \%)$ & $1(7 \%)$ & 0.670 \\
Chronic obstructive pulmonary disease & $17(7 \%)$ & $13(6 \%)$ & $4(27 \%)$ & 0.014 \\
Thyroid disease & $12(5 \%)$ & $11(5 \%)$ & $1(7 \%)$ & 0.662 \\
Virtual CHADS2 score (mean) & $1,37 \pm 1,23$ & $1,32 \pm 1,17$ & $2,21 \pm 1,72$ & 0.007 \\
Virtual CHADS2 score (median, range) & $1(6)$ & $1(5)$ & $2(6)$ & 0.007 \\
\hline
\end{tabular}


Table 7.1 Patients characteristics (continued).

\begin{tabular}{|c|c|c|c|c|}
\hline & All Patients & $\begin{array}{c}\text { No AF } \\
\text { during FU* }\end{array}$ & $\begin{array}{c}\mathrm{AF} \\
\text { during } \mathrm{FU}\end{array}$ & P-value $\neq$ \\
\hline $\mathrm{N}$ & 249 & 234 & 15 & \\
\hline \multicolumn{5}{|l|}{ Medication: } \\
\hline Oral anticoagulation & $18(7 \%)$ & $16(7 \%)$ & $2(13 \%)$ & 0.279 \\
\hline Aspirin & $63(25 \%)$ & $58(25 \%)$ & $5(33 \%)$ & 0.551 \\
\hline Sotalol & $9(4 \%)$ & $8(3 \%)$ & $1(7 \%)$ & 0.562 \\
\hline Beta-blocker & $90(36 \%)$ & $82(36 \%)$ & $8(53 \%)$ & 0.204 \\
\hline Verapamil & $14(6 \%)$ & $13(6 \%)$ & $1(7 \%)$ & 0.776 \\
\hline Digitalis & $5(2 \%)$ & $4(2 \%)$ & $1(7 \%)$ & 0.115 \\
\hline Nitrates & $18(7 \%)$ & $18(8 \%)$ & 0 & 0.520 \\
\hline Angiotensin-converting enzyme inhibitor & $57(23 \%)$ & $52(23 \%)$ & $5(33 \%)$ & 0.902 \\
\hline Angiotensin-II receptor blocker & $53(21 \%)$ & $51(22 \%)$ & $2(13 \%)$ & 0.487 \\
\hline Diuretics & $58(23 \%)$ & $52(23 \%)$ & $6(40 \%)$ & 0.256 \\
\hline Statins & $69(28 \%)$ & $64(28 \%)$ & $5(33 \%)$ & 0.637 \\
\hline Dihydropyridin calcium channel blocker & $48(19 \%)$ & $44(19 \%)$ & $4(27 \%)$ & 0.827 \\
\hline Alpha-blocker & $6(2 \%)$ & $4(2 \%)$ & $2(13 \%)$ & 0.004 \\
\hline Number of cardiovascular drugs (mean): & $1,96 \pm 1,94$ & $1,92 \pm 1,69$ & $2,60 \pm 2,29$ & 0.272 \\
\hline Number of cardiovascular drugs (median, range): & $2(7)$ & $2(7)$ & $2(7)$ & 0.272 \\
\hline \multicolumn{5}{|l|}{ Electrocardiogram: } \\
\hline Heart rate $(\mathrm{bpm}+)$ & $71 \pm 13$ & $71 \pm 14$ & $71 \pm 11$ & 0.977 \\
\hline P-wave duration (ms) & $89 \pm 22$ & $89 \pm 21$ & $97 \pm 33$ & 0.669 \\
\hline PQ-interval (ms) & $158 \pm 29$ & $157 \pm 27$ & $170 \pm 53$ & 0.066 \\
\hline QRS duration (ms) & $93 \pm 17$ & $93 \pm 17$ & $99 \pm 22$ & 0.112 \\
\hline \multicolumn{5}{|l|}{ Tissue Doppler imaging: } \\
\hline PA-TDI duration (ms) & $152 \pm 21$ & $150 \pm 20$ & $172 \pm 25$ & 0.001 \\
\hline Maximal A'-wave velocity $(\mathrm{cm} / \mathrm{sec})$ & $16 \pm 5$ & $16 \pm 5$ & $14 \pm 4$ & 0.215 \\
\hline \multicolumn{5}{|l|}{ Dimensions: } \\
\hline Aorta diameter (mm) & $34 \pm 4$ & $34 \pm 4$ & $34 \pm 4$ & 0.806 \\
\hline Left atrial dimension $(\mathrm{mm})$ & $40 \pm 5$ & $40 \pm 5$ & $43 \pm 7$ & 0.018 \\
\hline Left ventricular end-diastolic diameter (mm) & $49 \pm 6$ & $49 \pm 6$ & $49 \pm 7$ & 0.775 \\
\hline Left ventricular end-systolic diameter (mm) & $33 \pm 7$ & $33 \pm 7$ & $35 \pm 10$ & 0.223 \\
\hline Interventricular septum width (mm) & $9 \pm 1$ & $9 \pm 1$ & $10 \pm 2$ & 0.689 \\
\hline Posterior wall width $(\mathrm{mm})$ & $9 \pm 1$ & $9 \pm 1$ & $9 \pm 2$ & 0.894 \\
\hline Left ventricular mass (g) & $197 \pm 52$ & $196 \pm 51$ & $203 \pm 64$ & 0.586 \\
\hline End diastolic volume (cc) & $112 \pm 34$ & $112 \pm 35$ & $103 \pm 19$ & 0.282 \\
\hline End systolic volume (cc) & $45 \pm 29$ & $45 \pm 29$ & $39 \pm 9$ & 0.370 \\
\hline Caval vein $(\mathrm{mm})$ & $17 \pm 4$ & $17 \pm 4$ & $18 \pm 5$ & 0.985 \\
\hline \multicolumn{5}{|l|}{ Left ventricular function: } \\
\hline Left ventricular ejection fraction (\%) & $60 \pm 10$ & $61 \pm 9$ & $56 \pm 14$ & 0.095 \\
\hline Hypokinesia & $42(17 \%)$ & $38(16 \%)$ & $4(27 \%)$ & 0.480 \\
\hline \multicolumn{5}{|l|}{ Mitral valve Doppler assessments: } \\
\hline Maximal E-wave velocity (cm/sec) & $74 \pm 18$ & $74 \pm 18$ & $78 \pm 15$ & 0.410 \\
\hline E-wave deceleration slope $\left(\mathrm{m} / \mathrm{sec}^{2}\right)$ & $383 \pm 155$ & $379 \pm 150$ & $453 \pm 216$ & 0.301 \\
\hline E-wave deceleration time (ms) & $203 \pm 51$ & $204 \pm 50$ & $185 \pm 60$ & 0.524 \\
\hline Maximal A-wave velocity $(\mathrm{cm} / \mathrm{sec})$ & $82 \pm 42$ & $82 \pm 43$ & $77 \pm 19$ & 0.882 \\
\hline E/A ratio & $0.98 \pm 0.32$ & $0.97 \pm 0.33$ & $1.03 \pm 0.22$ & 0.870 \\
\hline \multicolumn{5}{|l|}{ Valvular disorders: } \\
\hline Aortic incompetence & $13(5 \%)$ & $12(5 \%)$ & $1(7 \%)$ & 0.749 \\
\hline Mitral incompetence & $17(7 \%)$ & $13(6 \%)$ & $4(27 \%)$ & 0.009 \\
\hline Tricuspid incompetence & $14(6 \%)$ & $12(5 \%)$ & $2(13 \%)$ & 0.118 \\
\hline Aortic stenosis & $10(4 \%)$ & $9(4 \%)$ & $1(7 \%)$ & 0.421 \\
\hline Mitral valve stenosis & $1(1 \%)$ & $1(1 \%)$ & 0 & 0.868 \\
\hline Systolic right ventricular pressure $(\mathrm{mmHg})$ & $31 \pm 7$ & $30 \pm 6$ & $33 \pm 11$ & 0.126 \\
\hline
\end{tabular}

*Follow-up; †Beats per minute; †P-value resulting from comparison "no AF during FU" versus "AF during FU" 


\section{Prediction of atrial fibrillation during follow-up}

Cox regression analysis showed that the echocardiographic PA-TDI interval was associated with the development of AF during follow-up (per $10 \mathrm{~ms} ; \mathrm{OR}=1.520 ; 95 \% \mathrm{Cl}$ 1.195 to $1.933 ; P=0.001)$. When adjusting for possible confounders as defined in the statistical section, we found an OR of $1.375(95 \% \mathrm{Cl} 1.037$ to $1.823 ; P=0.027)$ (Table 7.2).

Table 7.2 Cox regression analysis: risk of new-onset AF during follow-up in patients without a history of AF corrected for possible confounders.

\begin{tabular}{llc}
\hline & OR (95\%Cl) & P-value \\
\hline PA-TDI (per 10 ms increase) & $1.375(1.037-1.823)$ & 0.027 \\
Heart failure in history & $1.929(0.400-9.307)$ & 0.413 \\
Mitral incompetence on echo & $2.866(0.666-12.342)$ & 0.158 \\
Chronic obstructive pulmonary disease in history & $3.383(0.827-13.848)$ & 0.090 \\
Alpha-blocker use & $6.800(0.933-49.568)$ & 0.059 \\
Left atrial size on echocardiogram (per mm) & $0.991(0.880-1.115)$ & 0.875 \\
Age (per year) & $1.016(0.956-1.081)$ & 0.606 \\
\hline
\end{tabular}

Figure 7.2 shows the ROC curve to discriminate between people who will or will not develop new-onset AF during follow-up based on the PA-TDI. The area under the curve was $0.740(95 \% \mathrm{Cl} 0.608$ to $0.871 ; P=0.002)$. Using the ROC curve of PA-TDI, we determined the optimal cut-off value for PA-TDI to predict the occurrence of atrial fibrillation: $165 \mathrm{~ms}$ (sensitivity 67\%; specificity 77\%). A lower cut-off point (i.e. $150 \mathrm{~ms}$ ) would result in a higher sensitivity $(80 \%)$ and a lower specificity $(50 \%)$, implying that many patients would be wrongly identified as patients developing new-onset AF.

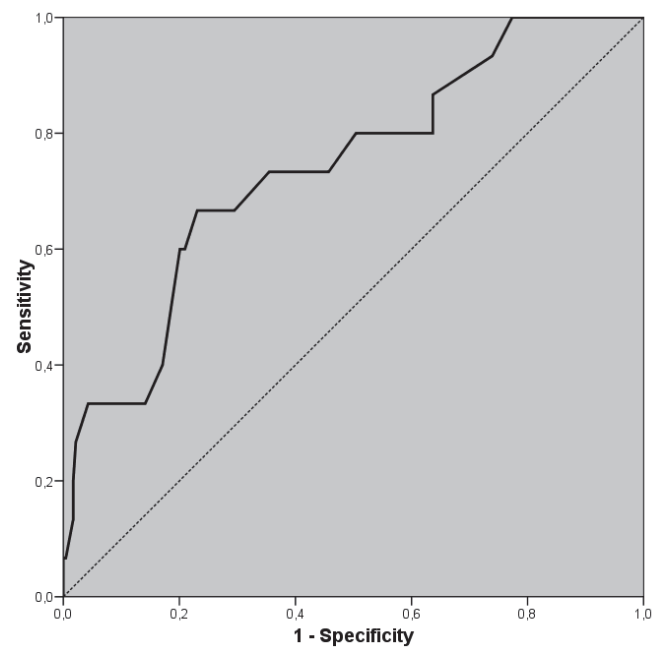

Figure 7.2 ROC curve of PA-TDI to predict the development of atrial fibrillation. 
The Kaplan-Meier 2-year cumulative risk for the development of AF was significantly increased for patients with a baseline PA-TDI interval >165 ms (Figure 7.3).

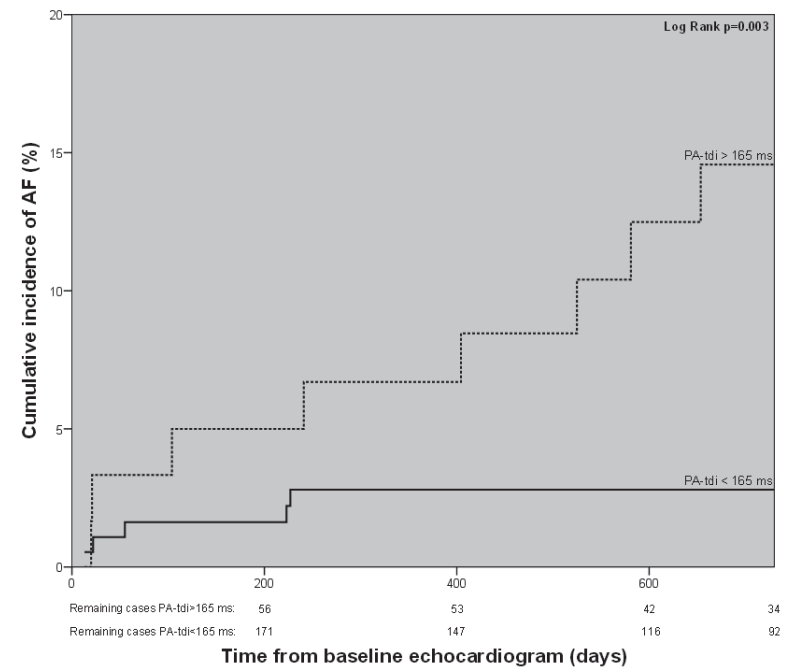

Figure 7.3 Kaplan-Meier cumulative incidence of the first occurrence of atrial fibrillation (AF).

We divided the patients into four groups according to the PA-TDI interval measured at baseline (for each $30 \mathrm{~ms}$ increase). The 2-year incidence of AF was 33\% in patients with a PA-TDI interval $>190 \mathrm{~ms}$ vs. $0 \%$ in patients with a PA-TDI interval $<130 \mathrm{~ms}(P=0.002)$ (Figure 7.4).

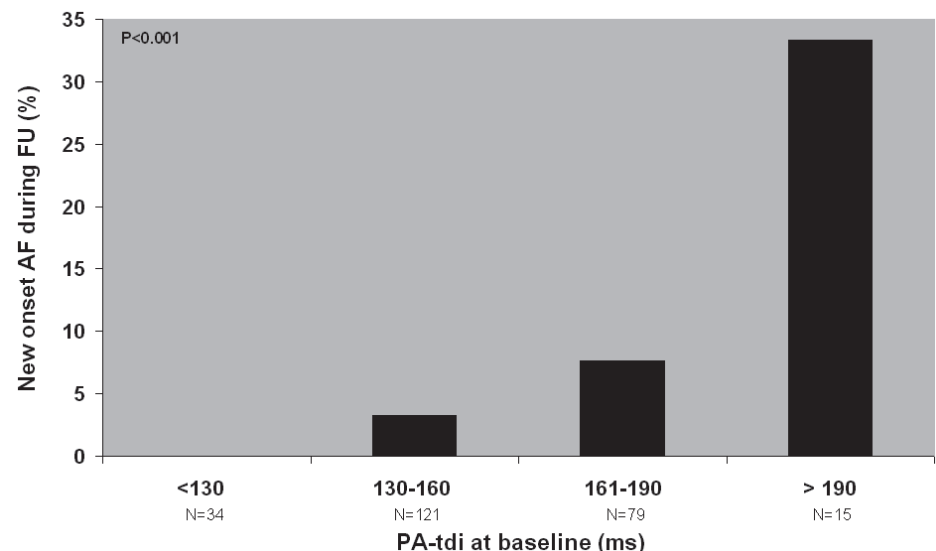

Figure 7.4 2-Year incidence of new-onset atrial fibrillation (AF) in patients classified according to the PA-TDI interval measured at baseline. 


\section{Discussion}

This study demonstrates that the TACT as determined by tissue Doppler imaging may help to identify patients with a substrate vulnerable for AF. After correcting for possible confounders, the PA-TDI interval remains the most important predictor of new-onset AF. The longer the PA-TDI interval, the higher the incidence of new-onset AF. In fact, each $10 \mathrm{~ms}$ increase of PA-TDI is associated with an increased risk of developing $A F$ of $37-52 \%$ in the next 2 years. Therefore, the PA-TDI interval may become a useful measure for risk stratification to improve efficiency of primary prevention of $A F$.

\section{Importance of predicting atrial fibrillation}

AF can result in life-threatening complications such as stroke and heart failure. Therefore, the application of adequate individual treatment is essential. ${ }^{16,17}$ Unfortunately, many patients have silent $A F .{ }^{18}$ As a result, treatment may come too late. In this study, the virtual CHADS2 score in the group of patients who developed AF indicates that most of our patients do have an indication for oral anticoagulation once they develop AF. Adequate administration of oral anticoagulation will reduce the risk of thromboembolic complications by $60 \% .{ }^{19}$ Therefore, one could imagine that prophylactic anticoagulation could be applied in patients with a high CHADS2 score and a long PA-TDI interval. However, this hypothesis needs to be confirmed in prospective randomised trials. Recent studies demonstrated that new-onset AF and associated stroke were significantly reduced by losartan. ${ }^{20,21}$ In our study, these "upstream" drugs did not prevent AF. However, drug treatment was not randomised, and the trend towards an increased number of cardiovascular drugs may in fact reflect the presence of more severe underlying heart disease.

In our study, we demonstrate that a short PA-TDI interval ( $<130 \mathrm{~ms})$ seems to prevent patients from developing AF. Therefore, one could hypothesise that these patients are not candidates for primary prevention. Patients with a PA-TDI interval >165 ms have a reasonable chance of developing $A F$ and could be candidates for primary prevention using "upstream" cardiovascular drugs. A PA-TDI interval >190 ms makes patients very vulnerable for the development of AF. These patients could be treated with prophylactic anticoagulation, especially when they have a high CHADS2 score.

In summary, the use of a simple echocardiographic measure enhances identification of patients at increased risk for AF, which may make primary prevention more cost effective by reducing the numbers needed to treat.

\section{Classic predictors of atrial fibrillation}

Observational population studies such as the Framingham Heart study, the Manitoba Follow-up study and the Cardiovascular Health study reported several clinical and 
echocardiographic parameters that are associated with the development of new-onset AF. ${ }^{4-7,22,23}$ The clinical factors associated with new-onset AF are higher age, male sex, the presence of diabetes, hypertension, congestive heart failure, valve disease and coronary artery disease. Left atrial enlargement, increased left ventricular wall thickness, left ventricular diastolic dysfunction and a reduced left ventricular fractional shortening are predictive echocardiographic parameters for new-onset AF. ${ }^{15,24}$

However, these currently available risk stratification measures have limited predictive value in the individual patient. $^{8}$ This study showed that the PA-TDI interval outperformed all the previously known predictors of AF. This is possibly because the pathophysiological mechanisms by which ageing and the above-mentioned conditions leading to AF have a final common pathway, which result in prolongation of the TACT. ${ }^{9}$

\section{Role of the total atrial conduction time in the prediction of atrial fibrillation}

The multiple wavelet re-entry theory postulated the existence of multiple spatially discrete activation fronts (wavelets) resulting in re-entry at changing locations as the basis for AF. ${ }^{25,26} \mathrm{~A}$ decreased conduction velocity, leads to a shorter wavelength of the re-entrant wave fronts. An increased atrial size can harbour more wave fronts of a certain size at the same time. Both will favour AF. An increased TACT, which is the time elapsed between the initiation of atrial depolarisation and the last depolarisation of the same activation front, ${ }^{27}$ incorporates both conduction slowing and atrial dilatation, and may therefore reflect the existence of a substrate vulnerable for AF. Determination of the TACT may therefore be better than the classical predictors of AF since it might not only demonstrate the presence of underlying disease but also its severity. P-wave duration on the 12-lead ECG and PA-mv using the mitral Doppler flow signal $^{28,29}$ provide estimates of the TACT. However, PA-TDI determined by transthoracic tissue Doppler imaging had the best correlation with the "gold standard" (SA-ECG P-wave duration). ${ }^{12}$ Previous studies presented a similar parameter measuring the interval between the onset of the $P$ wave on the ECG till the onset of the $A^{\prime}$ wave of the left atrial lateral wall instead of the peak of the $A^{\prime}$ wave (atrial electromechanical interval or AEMI). ${ }^{30,31}$ Post hoc analysis of our data showed similar results using both methods (data not shown).

\section{Study limitations}

The PA-TDI interval overestimates the total atrial activation time since it includes both the time required for the propagation of impulses from the sinus node area to the left atrium, and the time required for the electromechanical coupling in the left atrium. However, in a recent validation study, this electromechanical coupling appeared to be constant. $^{12}$ Furthermore, there seems to be a minor delay in ECG processing on all echo machines. In our study, this delay amounts to a maximum of 5 ms (unpublished 
technical information by Philips Medical Systems, Andover, Massachusetts, USA). Fortunately, this delay is consistent and therefore unlikely to affect our results.

This study was of limited size. As a result, the exact cut-off values need to be confirmed in a larger study with a longer follow-up. This would allow a study of the contribution of PA-TDI to a prediction model including "classical" predictors of newonset AF. Nevertheless, it seems reasonable to state that a larger PA-TDI interval is related to an increased incidence of AF.

All our patients were included in a cardiology outpatient clinic. As a result, the population we studied may not be representative of the general population. On the other hand, PA-TDI is intended for patients with cardiovascular diseases. The investigator who included the patients (RGT) is a general cardiologist with a special interest in electrophysiology. For that reason, one might hypothesise that this led to a selection bias. On the other hand, all patients with a history of atrial arrhythmias, a pacemaker or an implantable cardioverter-defibrillator were excluded from our study and the patient characteristics of our population are representative of a general cardiac outpatient clinic.

Finally, AF incidence was derived from partly symptom-driven ECG and Holter recordings. This may have led to an underestimation of the AF incidence, since a large number of AF episodes are known to be asymptomatic.

\section{Conclusion}

The total atrial conduction time as determined by tissue Doppler imaging is a feasible, non-invasive tool for the identification of patients with a substrate vulnerable for AF. A long PA-TDI interval is associated with the development of new-onset AF. Therefore, PA-TDI has the potential to become a valuable measure for risk stratification to enable primary prevention of AF and its complications.

The exact cut-off values found in this study need to be confirmed in a second study. Studying the role of PA-TDI to predict new-onset AF in a general population would require a large number of patients and a long follow-up owing to the relatively low incidence of AF in this group. Alternative study designs (a selected study group) should result in a more feasible study. 


\section{References}

1. Chugh SS, Blackshear JL, Shen WK, Hammill SC, Gersh BJ. Epidemiology and natural history of atrial fibrillation: clinical implications. J Am Coll Cardiol 2001;37:371-378.

2. Wolf PA, Kannel WB, McGee DL, Meeks SL, Bharucha NE, McNamara PM. Duration of atrial fibrillation and imminence of stroke: the Framingham study. Stroke 1983;14:664-667.

3. Wattigney WA, Mensah GA, Croft JB. Increasing trends in hospitalization for atrial fibrillation in the United States, 1985 through 1999: implications for primary prevention. Circulation 2003;108:711-716.

4. Benjamin EJ, Levy D, Vaziri SM, D'Agostino RB, Belanger AJ, Wolf PA. Independent risk factors for atrial fibrillation in a population-based cohort. The Framingham Heart Study. JAMA 1994;271:840-844.

5. Kannel WB, Wolf PA, Benjamin EJ, Levy D. Prevalence, incidence, prognosis, and predisposing conditions for atrial fibrillation: population-based estimates. Am J Cardiol 1998;82:2N-9N.

6. Krahn AD, Manfreda J, Tate RB, Mathewson FA, Cuddy TE. The natural history of atrial fibrillation: incidence, risk factors, and prognosis in the Manitoba Follow-Up Study. Am J Med 1995;98:476-484.

7. Vaziri SM, Larson MG, Benjamin EJ, Levy D. Echocardiographic predictors of nonrheumatic atrial fibrillation. The Framingham Heart Study. Circulation 1994;89:724-730.

8. Furberg CD, Psaty BM, Manolio TA, Gardin JM, Smith VE, Rautaharju PM. Prevalence of atrial fibrillation in elderly subjects (the Cardiovascular Health Study). Am J Cardiol 1994;74:236-241.

9. Simpson RJ Jr, Foster JR, Gettes LS. Atrial excitability and conduction in patients with interatrial conduction defects. Am J Cardiol 1982;50:1331-1337.

10. Omori I, Inoue D, Shirayama T, Asayama J, Katsume H, Nakagawa M. Prolonged atrial activity due to delayed conduction in the atrium of patients with paroxysmal atrial fibrillation. Heart Vessels 1991;6:224-228.

11. Kuhlkamp V, Haasis R, Seipel L. Atrial vulnerability and electrophysiology determined in patients with and without paroxysmal atrial fibrillation. Pacing Clin Electrophysiol 1992;15:71-80.

12. Merckx KL, De Vos CB, Palmans A, Habets J, Cheriex EC, Crijns HJ, Tieleman RG. Atrial activation time determined by transthoracic Doppler tissue imaging can be used as an estimate of the total duration of atrial electrical activation. J Am Soc Echocardiogr 2005;18:940-944.

13. Buxton $\mathrm{AE}$, Josephson $\mathrm{ME}$. The role of $\mathrm{P}$ wave duration as a predictor of postoperative atrial arrhythmias. Chest 1981;80:68-73.

14. Gage BF, Waterman AD, Shannon W, Boechler M, Rich MW, Radford MJ. Validation of clinical classification schemes for predicting stroke: results from the National Registry of Atrial Fibrillation. JAMA 2001;285:2864-2870.

15. Tsang TS, Barnes ME, Bailey KR, Leibson CL, Montgomery SC, Takemoto Y, Diamond PM, Marra MA, Gersh BJ, Wiebers DO, Petty GW, Seward JB. Left atrial volume: important risk marker of incident atrial fibrillation in 1655 older men and women. Mayo Clin Proc 2001;76:467-475.

16. Wyse DG, Waldo AL, DiMarco JP, Domanski MJ, Rosenberg Y, Schron EB, Kellen JC, Greene HL, Mickel MC, Dalquist JE, Corley SD; Atrial Fibrillation Follow-up Investigation of Rhythm Management (AFFIRM) Investigators. A comparison of rate control and rhythm control in patients with atrial fibrillation. $N$ Engl J Med 2002;347:1825-1833.

17. Van Gelder IC, Hagens VE, Bosker HA, Kingma JH, Kamp O, Kingma T, Said SA, Darmanata JI, Timmermans AJ, Tijssen JG, Crijns HJ; Rate Control versus Electrical Cardioversion for Persistent Atrial Fibrillation Study Group. A comparison of rate control and rhythm control in patients with recurrent persistent atrial fibrillation. N Engl J Med 2002;347:1834-1840.

18. Nieuwlaat R, Capucci A, Camm AJ, Olsson SB, Andresen D, Davies DW, Cobbe S, Breithardt G, Le Heuzey JY, Prins MH, Lévy S, Crijns HJ; European Heart Survey Investigators. Atrial fibrillation management: a prospective survey in ESC member countries: the Euro Heart Survey on Atrial Fibrillation. Eur Heart J 2005;26:2422-2434.

19. Hart RG, Benavente O, McBride R, Pearce LA. Antithrombotic therapy to prevent stroke in patients with atrial fibrillation: a meta-analysis. Ann Intern Med 1999;131:492-501.

20. Wachtell K, Lehto M, Gerdts E, Olsen MH, Hornestam B, Dahlöf B, Ibsen H, Julius S, Kjeldsen SE, Lindholm LH, Nieminen MS, Devereux RB. Angiotensin II receptor blockade reduces new-onset atrial fibrillation and subsequent stroke compared to atenolol: the Losartan Intervention For End Point Reduction in Hypertension (LIFE) study. J Am Coll Cardiol 2005;45:712-719. 
21. Okin PM, Wachtell K, Devereux RB, Harris KE, Jern S, Kjeldsen SE, Julius S, Lindholm LH, Nieminen MS, Edelman JM, Hille DA, Dahlöf B. Regression of electrocardiographic left ventricular hypertrophy and decreased incidence of new-onset atrial fibrillation in patients with hypertension. JAMA 2006; 296:1242-1248.

22. Brand FN, Abbott RD, Kannel WB, Wolf PA. Characteristics and prognosis of lone atrial fibrillation. 30Year follow-up in the Framingham Study. JAMA 1985;254:3449-3453.

23. Psaty BM, Manolio TA, Kuller LH, Kronmal RA, Cushman M, Fried LP, White R, Furberg CD, Rautaharju PM. Incidence of and risk factors for atrial fibrillation in older adults. Circulation 1997;96:2455-2461.

24. Tsang TS, Gersh BJ, Appleton CP, Tajik AJ, Barnes ME, Bailey KR, Oh JK, Leibson C, Montgomery SC, Seward JB. Left ventricular diastolic dysfunction as a predictor of the first diagnosed nonvalvular atrial fibrillation in 840 elderly men and women. J Am Coll Cardiol 2002;40:1636-1644.

25. Abildskov JA. Additions to the wavelet hypothesis of cardiac fibrillation. J Cardiovasc Electrophysiol 1994;5:553-559.

26. Moe GK, Rheinboldt WC, Abildskov JA. A computer model of atrial fibrillation. Am Heart J 1964;67:200-220

27. De PR, Ho SY, Salerno-Uriarte JA, Tritto M, Spadacini G. Electroanatomic analysis of sinus impulse propagation in normal human atria. J Cardiovasc Electrophysiol 2002;13:1-10.

28. Fuenmayor AJ, Ramirez L, Fuenmayor AM. Validation of inter-atrial conduction time measurement by means of echo-Doppler. Arch Cardiol Mex 2002;72:125-128.

29. Kinay O, Nazli C, Ergene O, Dogan A, Gedikli O, Hoscan Y, Acar G, Altinbas A. Time interval from the initiation of the electrocardiographic $P$ wave to the start of left atrial appendage ejection flow: a novel method for predicting atrial fibrillation recurrence. J Am Soc Echocardiogr 2002;15:1479-1484.

30. Omi W, Nagai H, Takamura M, Okura S, Okajima M, Furusho H, Maruyama M, Sakagami S, Takata S, Kaneko S. Doppler tissue analysis of atrial electromechanicl coupling in paroxysmal atrial fibrillation. $J$ Am Soc Echocardiogr 2005;18:39-44.

31. Roshanali F1, Mandegar MH, Yousefnia MA, Rayatzadeh H, Alaeddini F, Amouzadeh F. Prediction of atrial fibrillation via atrial electromechanical interval after coronary artery bypass grafting. Circulation 2007;116:2012-2017. 
Part III

Echo-electrocardiography to characterize the atrial substrate during atrial fibrillation 


\section{Chapter 8}

The fibrillating atrial myocardium visualized: An unexploited source of information

CB de Vos, HJGM Crijns, RG Tieleman

Heart Rhythm. 2009;6:1247-1248 
Chapter 8 
Atrial fibrillation (AF) is the most common sustained cardiac arrhythmia in clinical practice. ${ }^{1}$ The arrhythmia results in contractile dysfunction of both atria of the heart. In the past, physicians assumed that the atria were immobile during AF. However, during cardiothoracic surgery, one observed that the atria were actually fibrillating. This interesting finding has remained unexploited in clinical practice.

Tissue velocity imaging (TVI) is a relatively new echocardiographic technique used for noninvasive quantification and timing of local myocardial wall motion. ${ }^{2}$ It may be used to observe atrial myocardial movement during AF at multiple sites in the atria, providing evidence of general and regional contraction disturbances that may relate to stroke and hemodynamic atrial failure. In addition, TVI of the atrial wall may uncover electrophysiological information. Recent studies found a strong temporal correlation between atrial mechanical contraction assessed by tissue Doppler imaging (TDI) and the electrical fibrillatory cycle length assessed by the intracardiac electrogram. ${ }^{3}$ However, no attention has been paid to the amplitude or velocity information in the TDI recordings.

We performed TVI echocardiography in two patients with AF undergoing a His bundle ablation. The first patient had a nonremodeled left atrium (paroxysmal AF, electrophysiological type $1 \mathrm{AF},{ }^{4}$ left atrial volume normalized for body surface area $36 \mathrm{ml} / \mathrm{m}^{2}$ ). The other patient had a remodeled atrium (permanent $A F$, electrophysiological type $2 \mathrm{AF},{ }^{4}$ left atrial volume normalized for body surface area $74 \mathrm{ml} / \mathrm{m}^{2}$, and a history of heart failure).

After the ablation, TVI images were recorded in the apical four-chamber view. The sample volume was obtained in the lateral left atrium just superior to the mitral annulus. The TVI tracings of the atrial wall revealed the fibrillating myocardium as a substitute of the atrial contraction $\left(A^{\prime}\right)$ observed during sinus rhythm (Figure 8.1A). These direct recordings of the AF wall movements showed a 4 times lower velocity in the remodeled compared with the nonremodeled left atrium, which may relate to atrial contractile failure and/or higher atrial afterload (Figure 8.1B and 8.1C). Furthermore, the frequency of the fibrillating myocardium $(f)$ was higher in the remodeled atrium, which reflects a shorter atrial refractory period, and therefore this atrium may well harbor permanent $\mathrm{AF} .^{3}$

We believe that TVI of the fibrillating atrial myocardium itself provides essential information on atrial cardiomyopathy, stroke risk, and electrical remodeling. The recordings presented herein illustrate that the fibrillating atrial myocardium may harbor heretofore largely unexploited information that deserves further study. 

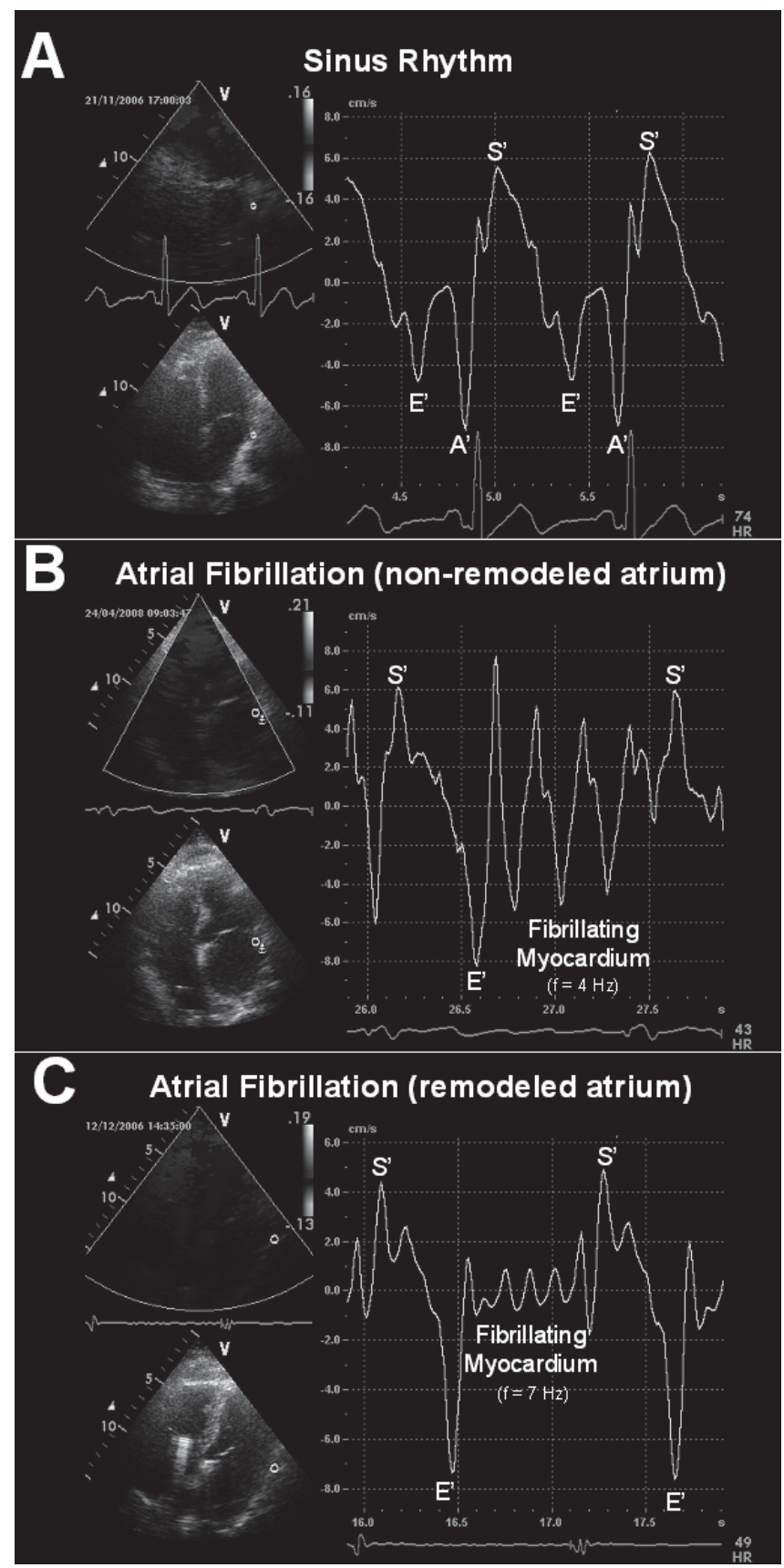

Figure 8.1 


\section{References}

1. Chugh SS, Blackshear JL, Shen WK, Hammill SC, Gersh BJ. Epidemiology and natural history of atrial fibrillation: clinical implications. J Am Coll Cardiol 2001;37:371-378.

2. Abraham TP, Dimaano VL, Liang HY. Role of tissue Doppler and strain echocardiography in current clinical practice. Circulation 2007;116:2597-2609.

3. Duytschaever M, Heyse A, de Sutter J, Crijns H, Gillebert T, Tavernier R, Tieleman R. Transthoracic tissue Doppler imaging of the atria: a novel method to determine the atrial fibrillation cycle length. $J$ Cardiovasc Electrophysiol 2006;17: 1202-1209.

4. Wells JL Jr, Karp RB, Kouchoukos NT, MacLean WA, James TN, Waldo AL. Characterization of atrial fibrillation in man: studies following open heart surgery. Pacing Clin Electrophysiol 1978;1:426-438. 


\section{Chapter 9}

Atrial fibrillatory wall motion and degree of atrial remodeling in patients with atrial fibrillation:

A tissue velocity imaging study

CB De Vos, L Pison, R Pisters, U Schotten, EC Cheriex, MH Prins, T Delhaas, HJGM Crijns, RG Tieleman

J Cardiovasc Electrophysiol 2009;20:1374-1381 


\begin{abstract}
Introduction

The atrial fibrillation cycle length (AFCL) and the intracardiac atrial electrogram morphology may be used to characterize atrial fibrillation (AF). However, assessment of these parameters requires an invasive electrophysiological study. We assessed clinical and electrophysiological correlates of noninvasive tissue velocity imaging (TVI) of the right and left atrial myocardial fibrillatory wall motion.
\end{abstract}

Methods and results

We performed an electrophysiological study in 12 patients with AF referred for His bundle ablation. Using atrial electrograms, we determined the AFCL (AFCL-egm) and electro-physiological AF type. Simultaneously, transthoracic echocardiography was performed. We used the TVI traces to determine the cycle length of the atrial fibrillatory wall motion (AFCL-tvi) and atrial fibrillatory wall velocities (AFV-tvi). AFCLtvi matched very well with AFCL-egm $\left(r^{2}=0.98 ; P<0.001\right)$, both in the left and right atrium. Patients with permanent AF had shorter AFCL-tvi (155 \pm 15 ms vs. $216 \pm 23$ ms; $P<0.001)$, higher AFCL-tvi variability, and lower AFV-tvi compared to patients with paroxysmal AF. Three electrophysiological AF types were found based on the morphology of the electrograms and these related to specific TVI patterns.

\title{
Conclusion
}

TVI of the atrial fibrillatory wall motion may enhance noninvasive characterization of atrial remodeling in patients with atrial fibrillation. 


\section{Introduction}

Atrial fibrillation (AF) is the most common sustained cardiac arrhythmia in clinical practice. ${ }^{1}$ The arrhythmia is associated with shortening of atrial refractoriness ${ }^{2}$ as represented by a reduced atrial fibrillation cycle length $(\mathrm{AFCL}){ }^{3,4}$ In addition, $A F$ is linked with increased dispersion of refractoriness ${ }^{5}$ as well as heterogeneity of conduction, prolonged conduction times, and fractionation of intracardiac atrial electrograms. ${ }^{6,7}$ Evaluation of these parameters, which represent atrial remodeling, may help predict arrhythmia prognosis and response to therapy. However, this requires an invasive procedure. Noninvasive assessment of these parameters may appear useful in clinical practice. Recently, we demonstrated that there is a correlation between the mechanical atrial fibrillatory wall motion and the electrophysiological AFCL in the left atrium. ${ }^{8}$ In addition, there is evidence that tissue velocity imaging (TVI) of the fibrillating atrial myocardium enables visualization of atrial remodeling. ${ }^{9}$ In this study, we assessed clinical and electrophysiological correlates of noninvasive TVI of the right and left atrial myocardial fibrillatory wall motion.

\section{Methods}

We studied 12 consecutive patients with symptomatic paroxysmal or permanent AF who were referred to our electrophysiology laboratory for His bundle ablation. The only exclusion criterion was age $<18$ years. All patients were implanted with a VVIR or DDDR (depending on the clinical AF type) pacemaker at least 2 weeks before the procedure. The study was approved by the Institutional Review Board and all patients gave informed consent for participation in the study.

\section{Data acquisition}

Patients were instrumented with an RF-ablation catheter (Celsius ${ }^{\mathrm{TM}}$ DS electrophysiology catheter, Biosense Webster, Johnson\&Johnson, bipolar, interelectrode spacing $0.5 \mathrm{~cm}$ ) and an electrophysiology catheter (Supreme electrophysiology catheter, St. Jude Medical, bipolar, interelectrode spacing $0.5 \mathrm{~cm}$ ). Filter settings were high pass $30 \mathrm{~Hz}$ and low pass $400 \mathrm{~Hz}$. All patients underwent successful His bundle ablation. After ablation the implanted pacemaker was temporarily programmed at $40 \mathrm{bpm}$. We recorded local atrial activation at the lateral wall of the right atrium and the coronary sinus in close proximity of the mitral valve annulus in order to establish the right and left AFCL from the intracardiac electrogram (AFCL-egm). When patients were in sinus rhythm during the procedure, AF was induced by pacing in the coronary sinus for 10 seconds at a short cycle length (<300 ms), resulting in 1:1 atrial capture. When AF was induced, the electro-physiological and echocardiographic measurements were performed at least 3 minutes after induction of the arrhythmia. ${ }^{10,11}$ 
During the electrophysiological procedure, transthoracic echocardiography (apical 4-chamber view) was performed using a Vivid 7 ultrasound system (GE Healthcare, Milwaukee, WI, USA) with $3.5 \mathrm{MHz}$ cardiac transducer. Patients were in supine position and the TVI images were made in the apical 4-chamber view during the end-expiratory phase in order to avoid respiratory artifacts. The narrowest image sector angle possible enabling imaging of both atrial lateral walls was used to attain the maximum frame rate possible $(>100 \mathrm{~Hz})$.

Before the procedure, left ventricular end diastolic diameter, left ventricular end systolic diameter, interventricular end diastolic width, posterior wall end diastolic width, left ventricular ejection fraction and systolic right ventricular pressure were determined according to the recommendations of the American Society of Echocardiography. Atrial volumes were measured using the biplane Simpson rule. The investigational clocks on the echo-machine and electrophysiology system were synchronized and the start of the echocardiographic measurement was labeled on the electrophysiology recording.

\section{Data analysis}

Two independent observers (RT and LP) unaware of clinical type of AF classified the electrograms into 3 categories according to their morphology as previously described by the group of Waldo (Figure 9.1). ${ }^{12}$ Type I: discrete atrial complexes separated by an isoelectric line free of perturbations; Type II: discrete atrial complexes separated by an isoelectric line with perturbations; Type III: discrete atrial complexes are mostly absent and the isoelectric line contains perturbations. When 2 electrophysiological AF types were present in the same tracing, the observers were asked to report the dominant type. Subsequently, AFCLs were measured manually using Bard Electrophysiology (Lowell, MA, USA) software (AFCL-egm). To have acceptable rates of error, we studied electrograms of a sufficiently long duration. ${ }^{13}$ Approximately 100 AFCLs were measured in both left and right atrium (LA, RA). We also evaluated the mean AFCL of the $5 \%$ shortest (P5) and $5 \%$ longest (P95) fibrillation intervals. The variability was then calculated by subtracting the P5 from the P95.

Using commercially available software (Q-analysis, GE Healthcare) we evaluated TVI traces during the late diastole (between the end of $E^{\prime}$ wave and start of $S^{\prime}$ wave). Care was taken to obtain the TVI sample from the electrode catheter recording sites. However, in some patients the catheters could not be visualized in the 4-chamber view. In that case, we used standardized locations to obtain our tracings. Regarding the left atrial data: the distal ablation catheter was placed in the CS in close proximity to the point where it crosses the mitral valve annulus. This location corresponds to the lateral wall of the left atrium near the mitral valve annulus in the apical 4-chamber view and is easy to identify. Regarding the right atrial data, the electrophysiology catheter was placed against the mid right atrial wall. This location corresponds to the midlateral wall of the right atrium in the apical 4-chamber view. 


\section{TYPE I}

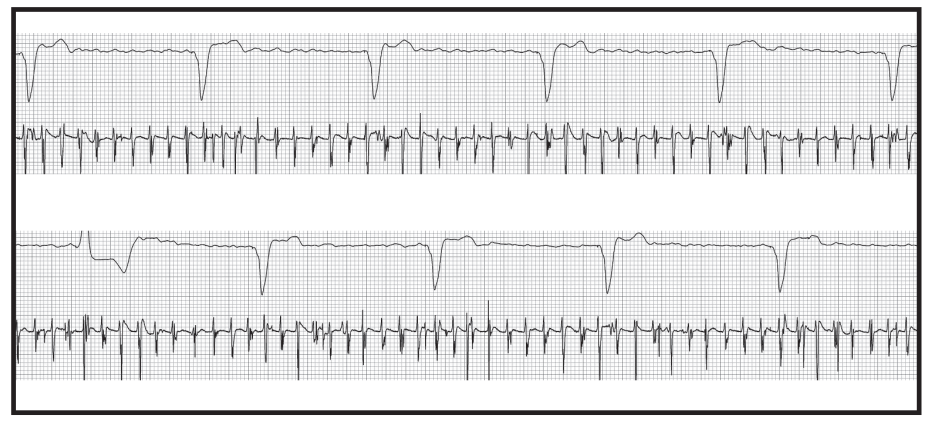

TYPE ||

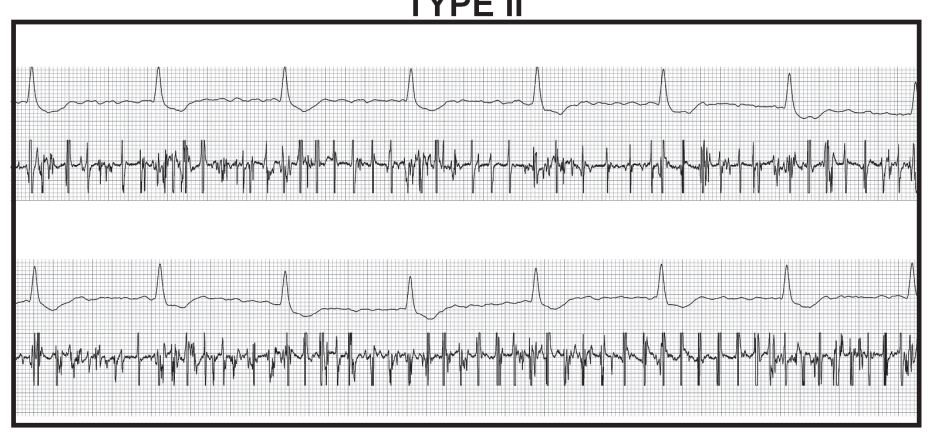

TYPE III

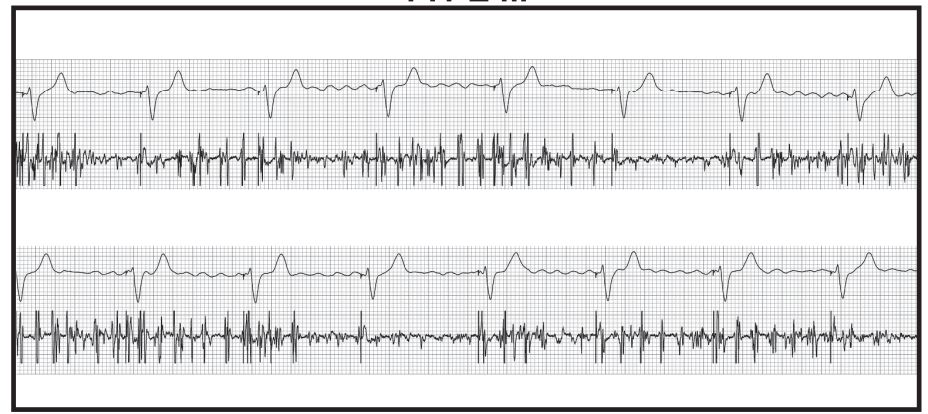

Figure 9.1 Examples of intracardiac electrograms in for each electrophysiological AF type and measurement of the AFCL-egm. Type I: patient number 3, left atrial location; Type 2: patient number 10, right atrial location; Type III: patient number 11, right atrial location. (speed $25 \mathrm{~mm} / \mathrm{sec})$.

One hundred cycle lengths of the atrial fibrillatory wall motion (AFCL-tvi) were measured at both atrial sites from the TVI traces. AFCL-tvi was defined as the time interval between 2 consecutive deflections of the late diastolic atrial tissue velocity curve (Figure 9.2).We evaluated the P5 and P95 of the AFCL-tvi and its variability as indicated above. AF wall motion velocity (AFV-tvi) was defined as the mean amplitude of 100 atrial fibrillatory deflections. 


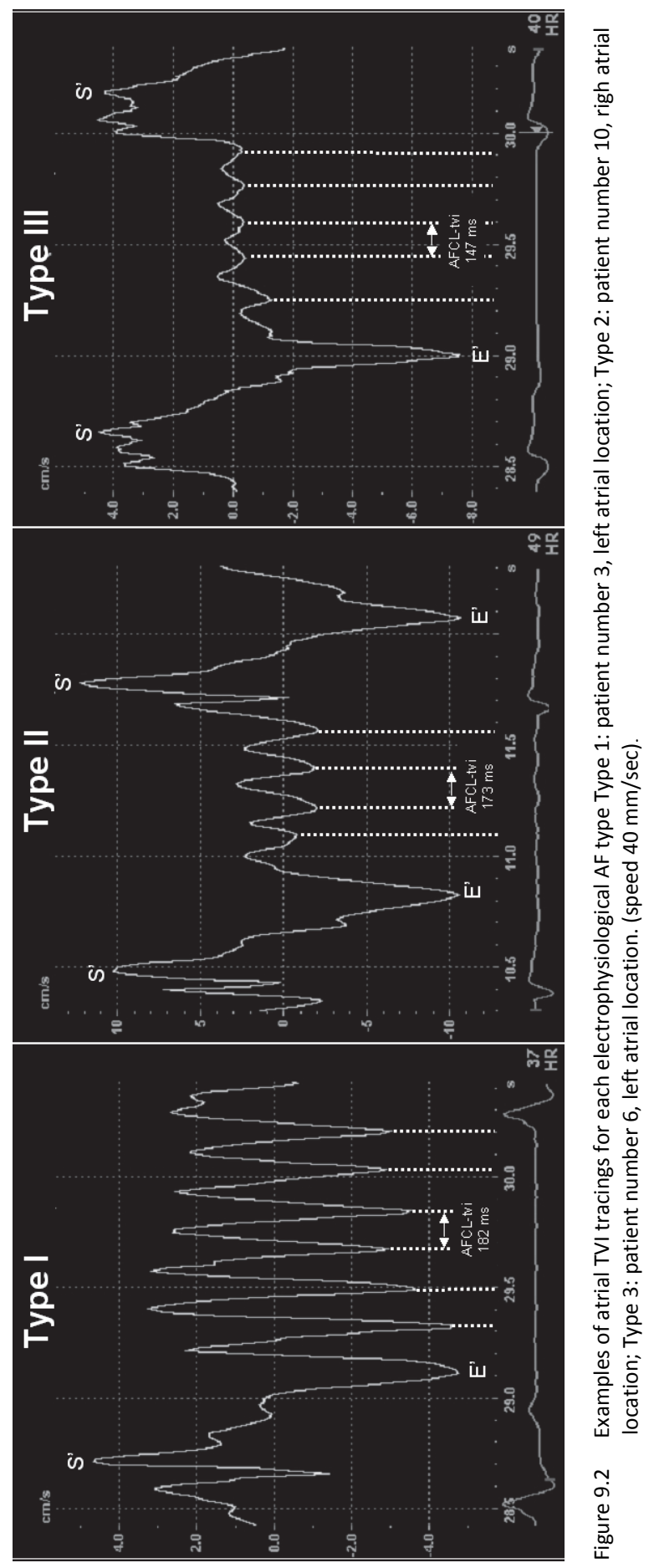




\section{Statistical analysis}

Data analysis was performed with SPSS statistical software (SPSS, Inc., release 15.0, Chicago, Illinois, USA). Continuous variables are reported as mean \pm standard deviation or median with interquartile range and categorical variables as observed number of patients (percentage). We performed Levene's test for equality of variances in all continuous variables before testing differences with an independent $t$-test when comparing 2 groups or with ANOVA when comparing 3 or more groups. Categorical variables were tested with Fisher's exact test. Correlations were evaluated by Spearman correlation tests. Additionally, the relationship between mean AFCL-egm and mean AFCL-tvi was evaluated using Bland-Altman bias analysis. The difference between the measurements was plotted against their average. Two standard deviations around the mean difference represented the upper and lower limits of agreement. All tests performed were 2-sided. Overall, a $P$-value of $<0.05$ was considered to be statistically significant.

\section{Results}

\section{Patient characteristics}

Five patients (42\%) had paroxysmal AF and 7 patients (58\%) had permanent AF. The mean total duration of the AF history among our patients was $9 \pm 6$ years and the median duration of the last episode was 123 days (interquartile range: 2-444). The majority of patients had some form of underlying heart disease (hypertension; coronary artery disease; diabetes mellitus; heart failure; clinically significant valvular heart disease). Nearly all patients were treated with rate-control and 3 patients received antiarrhythmic drugs (sotalol or flecaïnide). Table 9.1 shows other baseline characteristics. Typical electrophysiological findings included shortest AFCL-egm in permanent AF. In addition, paroxysmal AF patients mostly showed electrophysiological AF type I (70\% of all recordings in paroxysmal AF patients) and no type III AF, whereas type I occurred in only $23 \%$ and type III in $46 \%$ in permanent AF patients.

\section{Correlation Between AFCL-tvi and AFCL-egm}

AFCL-tvi could be identified in all patients on the echocardiographic TVI tracings at both left and right atrial locations. In 1 patient, we did not obtain an intracardiac electrogram of the left atrium since the coronary sinus was inaccessible (Table 9.1). A significant correlation was found between the mean AFCL-tvi and AFCL-egm in the LA $\left(r^{2}=0.99 ; P<0.001\right)$ and RA $\left(r^{2}=0.97 ; P<0.001\right)$. The overall correlation between the mean AFCL-tvi and AFCL-egm measured at the 2 atrial locations is presented in Figure 9.3A $\left(r^{2}=0.98 ; P<0.001\right)$. The mean AFCL-egm and mean AFCL-tvi for all patients 
measured at both atrial sites were compared in a Bland-Altman plot. The mean difference (AFCL-egm-AFCL-tvi) was $0.99 \mathrm{~ms}$, and the $95 \%$ limit of agreement $( \pm 1.96$ $\mathrm{SD}$ ) was $\pm 7.07 \mathrm{~ms}$. We also found a significant correlation between P5 of the AFCL-egm and AFCL-tvi $\left(r^{2}=0.67 ; P=0.003\right)$ and the P95 of both measurements $\left(r^{2}=0.77 ; P<0.001\right)$ (Figure 9.3B and 9.3C, respectively). Figure 9.4 shows the distribution of $100 \mathrm{AFCL}$-egm and $100 \mathrm{AFCL}$-tvi in patient number 10 in the LA and RA. No significant correlations were found between LA volume as determined by echocardiography and AFCL-tvi measured in the LA $\left(r^{2}=0.182 ; P=0.59\right)$ and between RA volume and AFCL-tvi measured in the RA $\left(r^{2}=0.48 ; P=0.12\right)$.

\section{Relation between the clinical AF type, AFCL-tvi, and AFV-tvi}

Patients with paroxysmal AF had a significantly longer AFCL-tvi than patients with permanent AF $(216 \pm 23$ ms vs. $155 \pm 15 \mathrm{~ms} ; P<0.001)$. The P5 and P95 of the AFCL-tvi were also longer in patients with paroxysmal AF compared to permanent AF (Table 9.2). Furthermore, the AFV-tvi was higher in patients with paroxysmal AF compared to permanent AF.

\section{Relation between electrophysiological AF type, AFCL-tvi, and AFV-tvi}

The mean AFCL-tvi and the mean AFV-tvi were highest in electrophysiological type I AF, intermediate in type II and lowest in type III (Figures 9.2 and 9.5). In addition, a significant difference of AFCL-tvi variability was found between type I (lowest) and type III AF (highest). Table 9.3 presents TVI parameters according to electrophysiological AF type. 


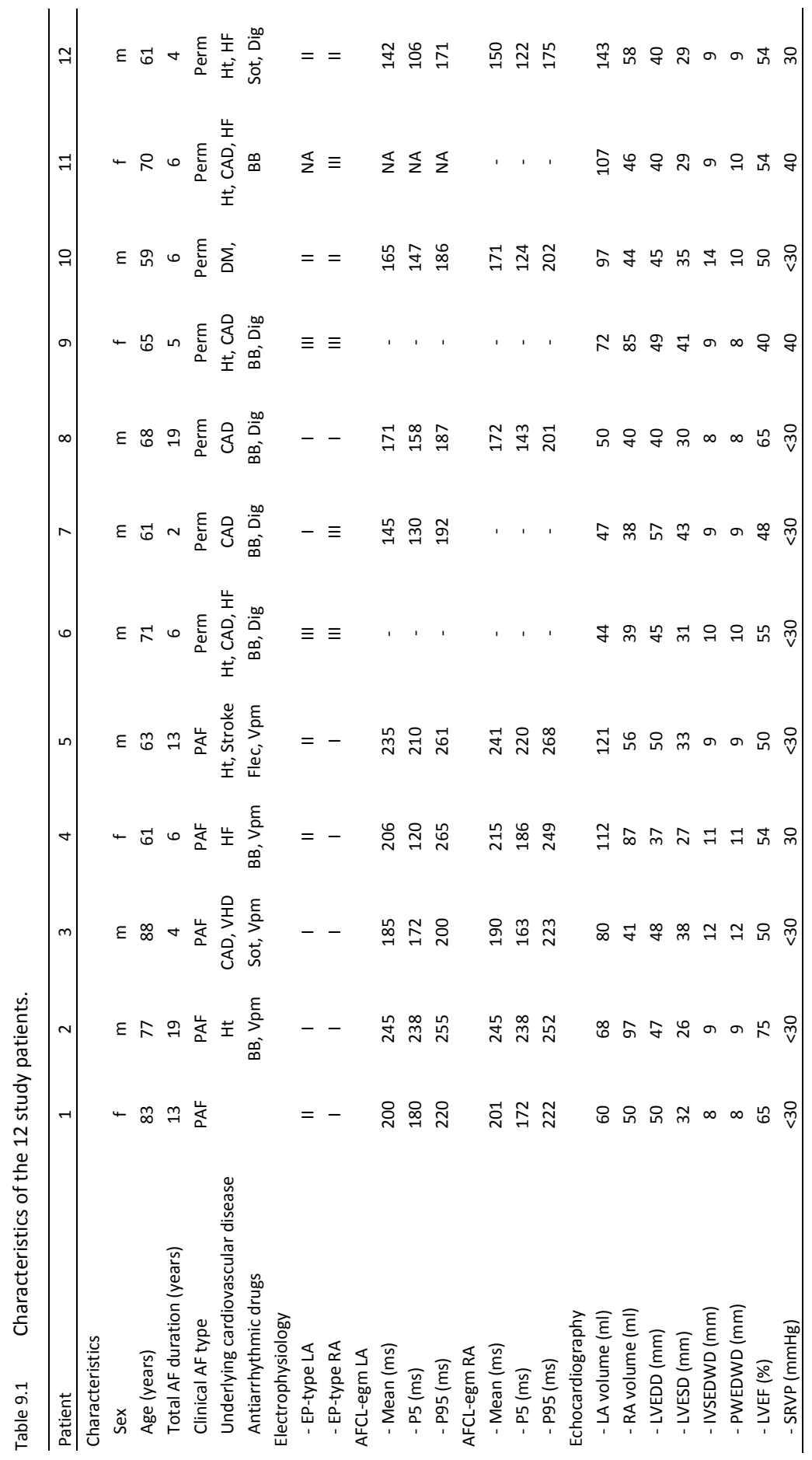




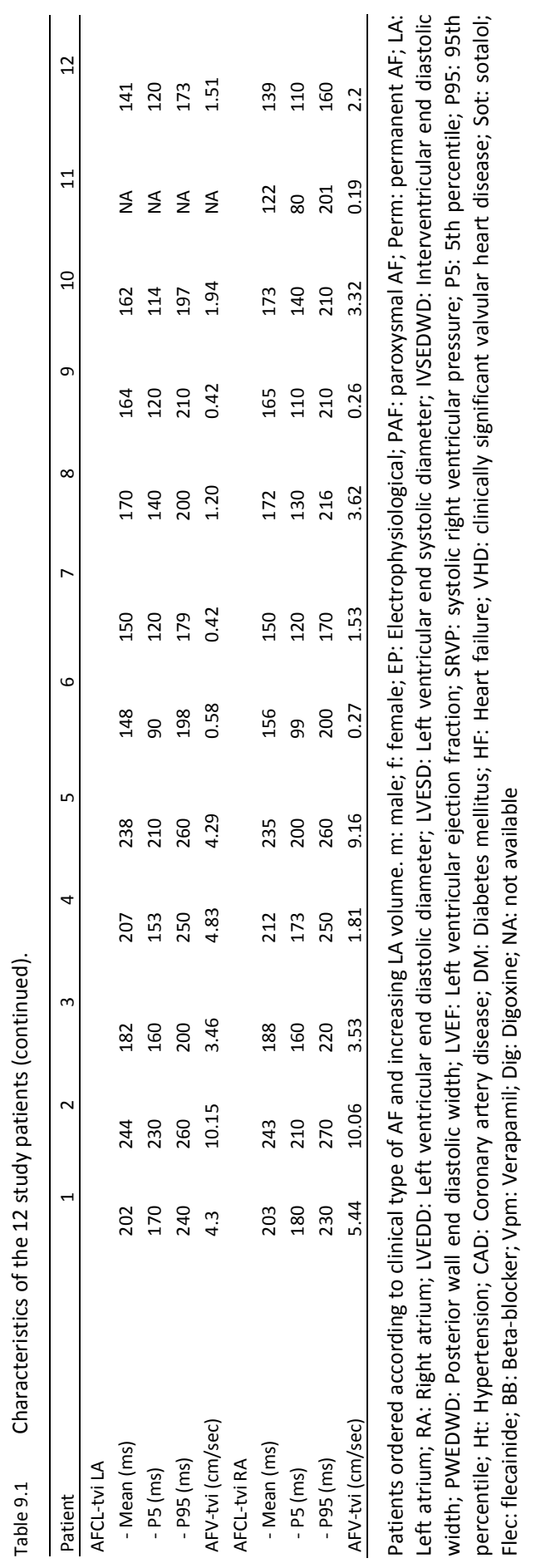



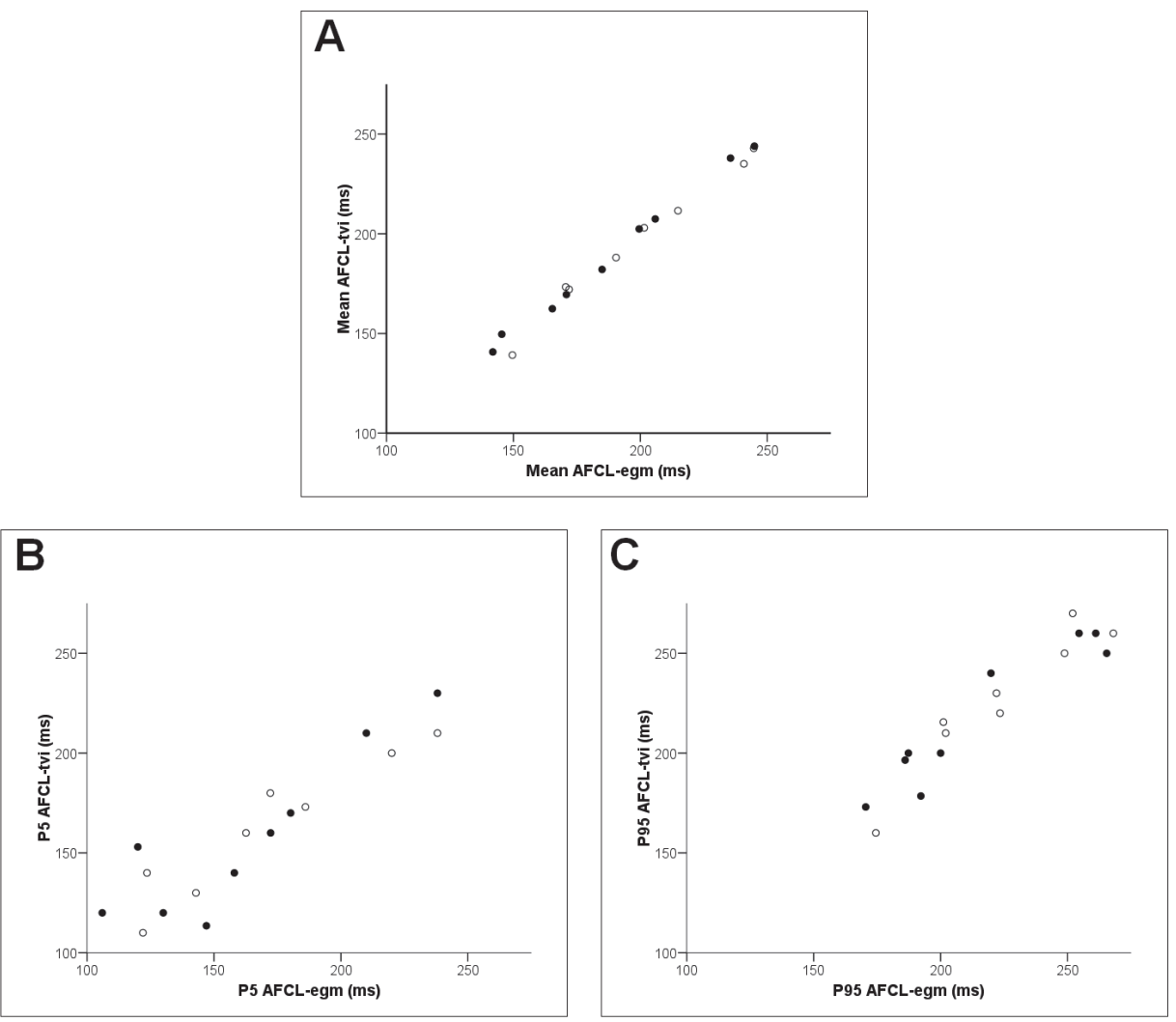

Figure 9.3 Correlation between AFCL-tvi and AFCL-egm measured at left (black dots) and right atrial (open dots) locations. (A): Correlation between mean AFCL-tvi and mean AFCL-egm; (B): Correlation between P5 AFCL-tvi and P5 AFCL-egm; (C): Correlation between P95 AFCL-tvi and P95 AFCL-egm. 

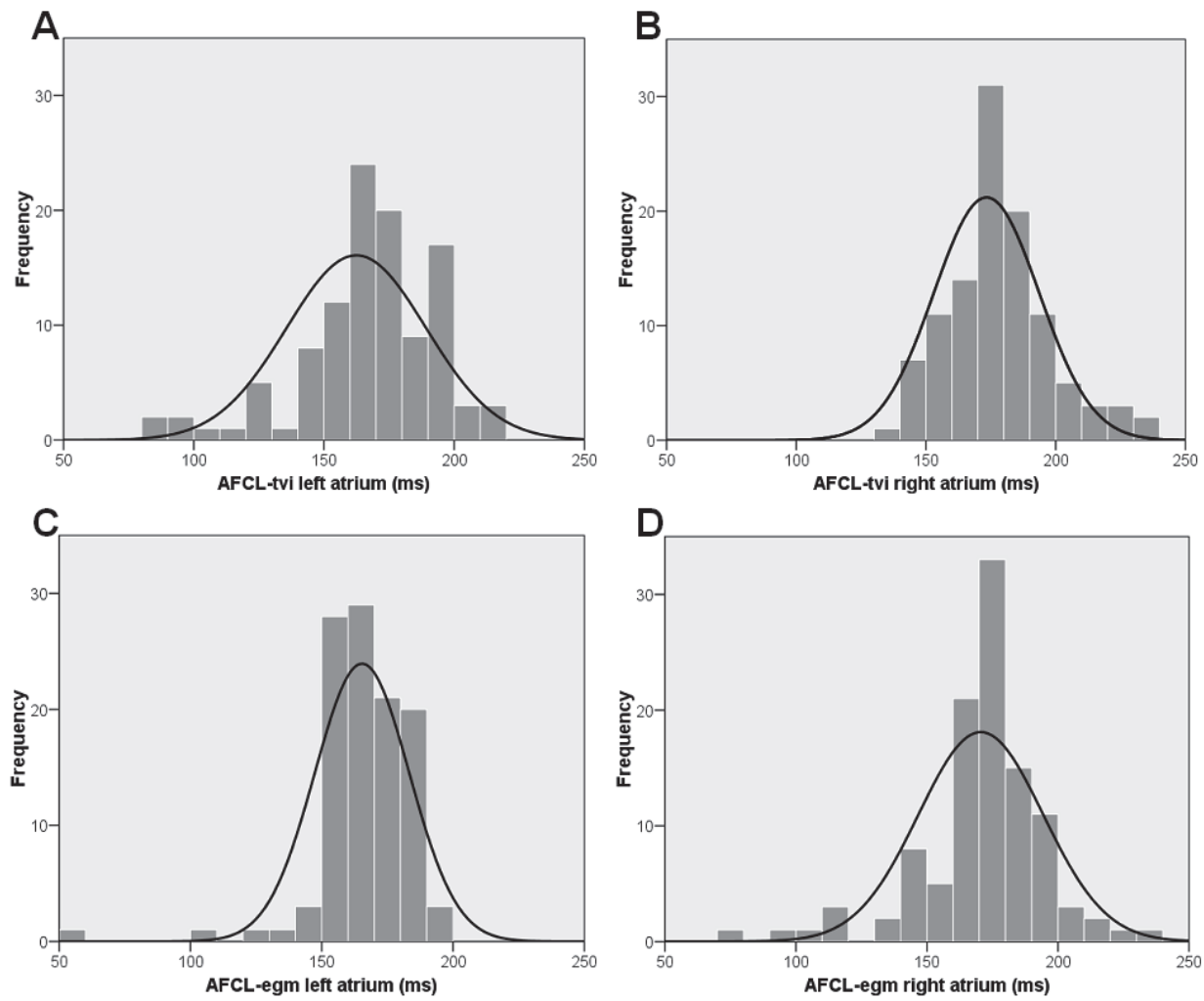

Figure 9.4 Example of the distribution of $100 \mathrm{AFCLs}$ in patient number 10 with permanent $\mathrm{AF}$ using both the intracardiac electrogram and TVI at two atrial locations. (A) Distribution of AFCL-tvi measured in the left atrium; (B) Distribution of AFCL-tvi measured in the right atrium; (C) Distribution of AFCL-egm measured in the left atrium; (D) Distribution of AFCL-egm measured in the right atrium.

Table 9.2 Local atrial TVI characteristics according to clinical AF type.

\begin{tabular}{lccc}
\hline & \multicolumn{3}{c}{ Clinical AF type } \\
\cline { 2 - 4 } & Paroxysmal & Permanent & P-value \\
\hline N & 10 & 13 & \\
Mean AFCL-tvi (ms) & $216 \pm 23$ & $155 \pm 15$ & $<0.001$ \\
P5 AFCL-tvi (ms) & $185 \pm 26$ & $115 \pm 18$ & $<0.001$ \\
P95 AFCL-tvi (ms) & $244 \pm 22$ & $194 \pm 18$ & $<0.001$ \\
Difference P95-P5 (ms) & $59 \pm 19$ & $79 \pm 24$ & 0.044 \\
AFV-tvi (cm/sec) & $5.7 \pm 3.0$ & $1.3 \pm 1.2$ & $<0.001$ \\
\hline
\end{tabular}


Table 9.3 Local atrial TVI characteristics according to electrophysiological AF type.

\begin{tabular}{lcccc}
\hline & \multicolumn{4}{c}{ Electrophysiological AF type } \\
\cline { 2 - 5 } & Type I & Type II & Type III & P-value \\
\hline N & 10 & 7 & 6 & \\
Mean AFCL-tvi (ms) & $200 \pm 33$ & $180 \pm 37$ & $151 \pm 16$ & 0.021 \\
P5 AFCL-tvi (ms) & $170 \pm 36$ & $145 \pm 36$ & $103 \pm 16$ & 0.002 \\
P95 AFCL-tvi (ms) & $228 \pm 31$ & $213 \pm 39$ & $198 \pm 15$ & 0.176 \\
Difference P95-P5 AFCL-tvi (ms) & $58 \pm 16$ & $68 \pm 18$ & $95 \pm 24$ & 0.004 \\
AFV-tvi (cm/sec) & $4.9 \pm 3.7$ & $3.2 \pm 1.3$ & $0.5 \pm 0.5$ & 0.014 \\
\hline
\end{tabular}

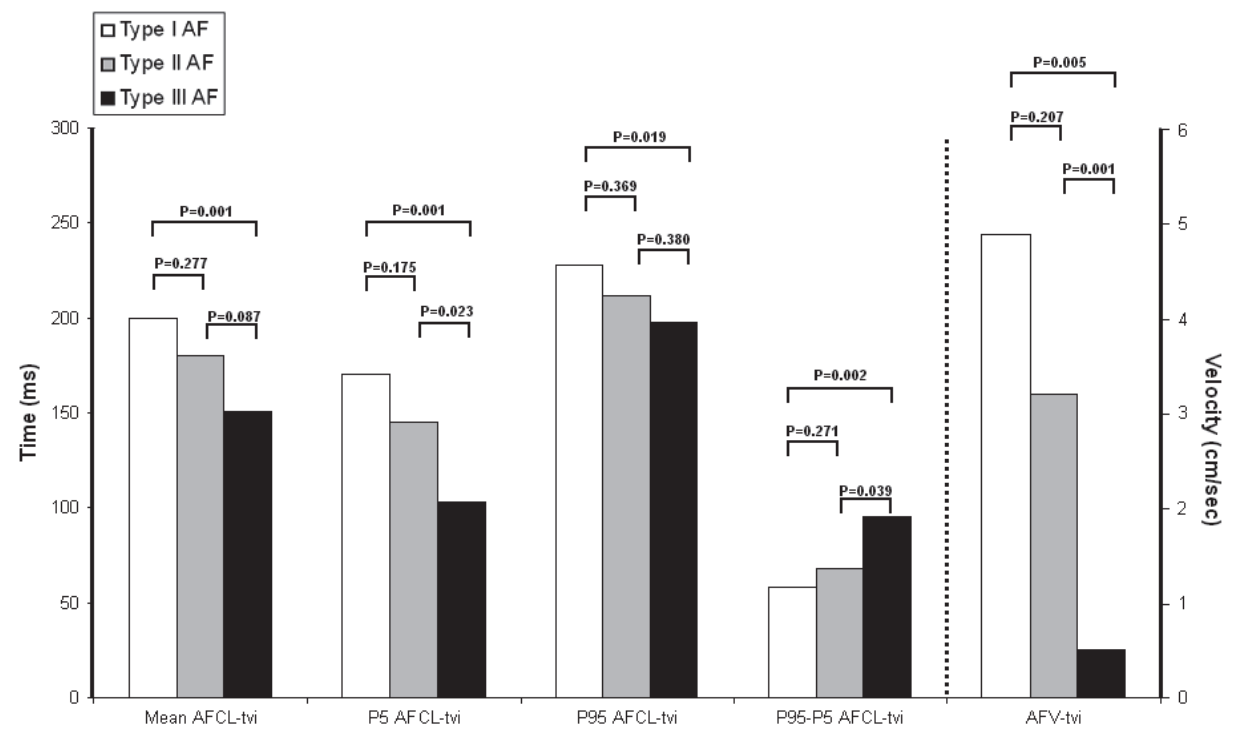

Figure 9.5 Atrial TVI parameters according to electrophysiological AF type. (P5: fifth percentile; P95: ninety-fifth percentile).

\section{Discussion}

This study shows that echocardiographic TVI of the left and right atrial fibrillatory wall motion may correspond to several electrophysiological parameters during AF. First, a strong correlation was found between the mean AFCL-tvi and the mean AFCL-egm. In addition, there was a significant correlation between the electrophysiological and echocardiographic P5 and P95 of the AFCL. The former relationship suggests that AFCLtvi may reflect the functional atrial refractory period, the latter relationship denotes that AFCL-tvi may indicate temporal dispersion of conduction. These notions are further supported by the finding that electrophysiological AF type was associated with 
specific TVI patterns. With increasing electrophysiological complexity, the AFCL-tvi shortened, the AFCL-tvi variability increased and the AFV-tvi decreased. Finally, atrial TVI findings correlated with the clinical type of AF since patients with permanent AF had shorter mean AFCL-tvi and higher AFCL-tvi variability compared to patients with paroxysmal AF. In addition, AFV-tvi was lower in permanent AF suggesting more advanced structural remodeling and compromised atrial contractile function in these patients. Taken together, our findings suggest that TVI of the atrial fibrillatory wall motion may be used to noninvasively characterize remodeling in AF.

\section{Relation between the clinical AF type and the atrial fibrillatory wall motion determined with TVI}

The functional atrial refractory period is represented by the AFCL as measured during AF. ${ }^{4,5}$ Atrial refractoriness and its spatial dispersion play an important role in the development and maintenance of AF. Prolongation of refractoriness enhances self termination of AF whereas shortening is associated with persistence of AF. In our study, we found that patients with paroxysmal-self-terminating-AF had longer AFCLtvi compared to patients with permanent AF. These findings are in line with previous electrophysiological studies..$^{14}$ Increased variability of cycle length has been reported before in patients with induced AF and seems to relate to complex patterns of atrial conduction suggesting advanced remodeling. ${ }^{15}$ In this respect it is noteworthy that the largest variability was seen in patients with permanent AF. Furthermore, permanent AF was linked to low atrial wall velocities on TVI, again suggesting advanced structural remodeling as expected in these patients.

\section{Relation between electrophysiological AF type and the atrial fibrillatory wall motion determined with TVI}

Paroxysmal AF was associated with noncomplex electrophysiological AF types (types I and II) ${ }^{12}$ with long average $A F C L$, whereas the complex type III electrograms with short $A F C L$, high $A F C L$ variability and electrogram fragmentation were mainly seen in permanent AF patients. Not only the higher AF burden in permanent AF but also the higher accumulated number of associated cardiac conditions may have caused electrogram fragmentation in permanent rather than paroxysmal AF. Fragmentation represents structural and electrical remodeling and is associated with fibrosis, cellular and myofibril uncoupling and disarray and local detour conduction. ${ }^{16}$ The association of fragmentation and low atrial fibrillatory velocities seems obvious since the same pathologic factors causing fragmentation mentioned above may cause decreased atrial contractility. ${ }^{17,18}$ In addition, atrial motility results from the sum of contractions from the individual atrial cells. In case of type III AF, the disorganized atrial activation, as represented by fragmented electrograms, results in disorganized contractions, with a reduced overall velocity of atrial motion, if any at all. 
There was no clear relation between right or left atrial volume and type of AF. Usually, larger atria harbor structural pathology of the atrial wall. Absence of a relationship suggests that the other factors like AF burden are more important. Alternatively, the low number of observations may have precluded a firm conclusion in this respect.

\section{The value of $A F C L$ and electrophysiological AF type in clinical practice}

The morphology of the atrial electrograms and duration of the AFCL provides valuable information in patients with AF. ${ }^{19}$ The distribution and the duration of the AFCL can be useful to identify sites of high-frequency activity during AF. These sites play an important role in the maintenance of $A F$ since ablation targeting these sites may result in prolongation of the AFCL and termination of AF. ${ }^{20-25}$ Moreover, measurement of the atrial fibrillatory frequency might predict short- and long-term success of catheter ablation. $^{26,27}$ In addition, heterogeneity of AFCL is associated with recurrence of AF after electrical cardioversion. ${ }^{28}$ Antiarrhythmic drugs could restore homogeneity of the $\mathrm{AFCL}^{29}$ and increase the $\mathrm{AFCL}{ }^{30}$ which is associated with termination of $\mathrm{AF} .{ }^{31}$

Considering the above, AFCL and electrophysiological AF type may play an important role in clinical management of patients with AF. However, up till now the invasive nature of electrophysiology studies precludes a wide scale use in clinical practice. We strongly believe that TVI of the atrial fibrillatory wall movement will encourage the use of AFCL in clinical practice. Better selection of patients for drug prophylaxis, cardioversion, and catheter ablation are among the possibilities in addition to monitoring of those treatments and predicting their outcome. This avoids unnecessary exposure of patients to the risks of therapy and enhances "tailored treatment."

\section{Alternative noninvasive methods to determine the $\mathrm{AFCL}$}

The local AFCL is presently measured during an electrophysiological study. This procedure is invasive and timeconsuming and therefore not extensively used in clinical practice. Husser et al. described electrocardiographic methods to estimate the AFCL. ${ }^{32}$ Although this technique provides valuable information, it requires special software and it only provides global estimation of the right atrial AFCL. Therefore, this technique is less suitable to evaluate the homogeneity of the $\mathrm{AFCL}$ distribution at several atrial sites. Recently, our research group developed a noninvasive way to determine the $\mathrm{AFCL}$ by means of pulsed wave tissue Doppler echocardiography (AFCL-tdi). ${ }^{8}$ In contrast, TVI has the advantage of simultaneous multisite imaging, which theoretically enables fast assessment of homogeneity of AFCL distribution. Furthermore, the information on mean atrial fibrillatory wall motion velocity as determined by TVI (AFVtvi) gives an extra dimension to the electrical measurements. Future development of automated analysis software will improve the clinical application of this technique. 


\section{Limitations}

We included patients who were referred for a His bundle ablation. These patients probably did not respond to the conventional therapies of AF. As a result, our findings need to be confirmed in a more "healthy" AF population. We determined the AFCL at 2 atrial sites. Lower tissue velocities were observed at the atrial site that is firmly attached to the rest of the body (the pulmonary vein area) implying that analysis of the atrial fibrillatory wall motion at these locations could be challenging. Furthermore, the echocardiographic examination was performed in supine position due to the risk of catheter dislocation that might have resulted in lower image quality. The current method needs a long diastole to avoid artifacts by interference with ventricular motion that occurs during the first phase of diastole. Currently, we are developing a method allowing TVI measurements during higher heart rates in patients with AF. This study was of limited size. Therefore, our results and its clinical impact need to be confirmed in a larger study aiming at the relation between the fibrillatory wall motion and outcome parameters. Manual measurement of AFCL-tvi and AFV-tvi is rather timeconsuming. Future development of automated analysis software will improve the clinical application of this technique. As a final point, the usual limitations inherent to TVI regarding the angle of insonation and loading conditions of the heart also apply in this study. To limit the influence of these potential confounders, we selected patients who were hemodynamically stable and care was taken to align the ultrasound beam with the direction of the myocardium studied.

\section{Conclusions}

We found a strong correlation between the velocity and cycle length of the local atrial fibrillatory wall motion on TVI and the local AFCL and AF type determined during electrophysiology studies. Therefore, TVI of the fibrillating atrial myocardium may enhance noninvasive characterization of remodeling in patients with atrial fibrillation. Nevertheless, more studies are needed to confirm our findings and establish its clinical impact. 


\section{References}

1. Chugh SS, Blackshear JL, ShenWK, Hammill SC, Gersh BJ: Epidemiology and natural history of atrial fibrillation: Clinical implications. J Am Coll Cardiol 2001;37:371-378.

2. Attuel P, Childers R, Cauchemez B, Poveda J, Mugica J, Coumel P: Failure in the rate adaptation of the atrial refractory period: Its relationship to vulnerability. Int J Cardiol 1982;2:179-197.

3. Wijffels MC, Kirchhof CJ, Dorland R, Allessie MA: Atrial fibrillation begets atrial fibrillation. A study in awake chronically instrumented goats. Circulation 1995;92:1954-1968.

4. Capucci A, Biffi M, Boriani G, Ravelli F, Nollo G, Sabbatani P, Orsi C, Magnani B: Dynamic electrophysiological behavior of human atria during paroxysmal atrial fibrillation. Circulation 1995;92: 1193-1202.

5. Misier AR, Opthof T, van Hemel NM, Defauw JJ, de Bakker JM, Janse MJ, van Capelle FJ: Increased dispersion of "refractoriness" in patients with idiopathic paroxysmal atrial fibrillation. J Am Coll Cardiol 1992;19:1531-1535.

6. Sanders P, Morton JB, Davidson NC, Spence SJ, Vohra JK, Sparks PB, Kalman JM: Electrical remodeling of the atria in congestive heart failure: Electrophysiological and electroanatomic mapping in humans. Circulation 2003;108:1461-1468.

7. Li D, Fareh S, Leung TK, Nattel S: Promotion of atrial fibrillation by heart failure in dogs: Atrial remodeling of a different sort. Circulation 1999;100:87-95.

8. Duytschaever M, Heyse A, de Sutter J, Crijns H, Gillebert T, Tavernier R, Tieleman R: Transthoracic tissue Doppler imaging of the atria: A novel method to determine the atrial fibrillation cycle length. $J$ Cardiovasc Electrophysiol 2006;17:1202-1209.

9. De Vos CB, Crijns HJ, Tieleman RG: The fibrillating atrial myocardium visualized: An unexploited source of information. Heart Rhythm 2009;6:1247-1248.

10. Ravelli F, Mase M, Del Greco M, Faes L, Disertori M: Deterioration of organization in the first minutes of atrial fibrillation: A beat-to-beat analysis of cycle length and wave similarity. J Cardiovasc Electrophysiol 2007;18:60-65.

11. Daoud EG, Bogun F, Goyal R, Harvey M, Man KC, Strickberger SA, Morady F: Effect of atrial fibrillation on atrial refractoriness in humans. Circulation 1996;94:1600-1606.

12. Wells JL Jr, Karp RB, Kouchoukos NT, MacLean WA, James TN, Waldo AL: Characterization of atrial fibrillation in man: Studies following open heart surgery. Pacing Clin Electrophysiol 1978;1:426-438.

13. Stiles MK, Brooks AG, John B, Wilson L, Kuklik P, Dimitri H, Lau DH, Roberts-Thomson RL, Mackenzie L, Willoughby S, Young GD, Sanders P: The effect of electrogram duration on quantification of complex fractionated atrial electrograms and dominant frequency. J Cardiovasc Electrophysiol 2008;19: 252-258.

14. Stiles MK, Brooks AG, Kuklik P, John B, Dimitri H, Lau DH, Wilson L, Dhar S, Roberts-Thomson RL, Mackenzie L, Young GD, Sanders P: High-density mapping of atrial fibrillation in humans: Relationship between high-frequency activation and electrogram fractionation. J Cardiovasc Electrophysiol 2008;19:1245-1253.

15. Konings KT, Kirchhof CJ, Smeets JR, Wellens HJ, Penn OC, Allessie MA: High-density mapping of electrically induced atrial fibrillation in humans. Circulation 1994;89:1665-1680.

16. Allessie M, Ausma J, Schotten U: Electrical, contractile and structural remodeling during atrial fibrillation. Cardiovasc Res 2002;54:230-246.

17. Morillo CA, Klein GJ, Jones DL, Guiraudon CM: Chronic rapid atrial pacing. Structural, functional, and electrophysiological characteristics of a new model of sustained atrial fibrillation. Circulation 1995;91:1588-1595.

18. Schotten U, Duytschaever M, Ausma J, Eijsbouts S, Neuberger HR, Allessie M: Electrical and contractile remodeling during the first days of atrial fibrillation go hand in hand. Circulation 2003;107:1433-1439.

19. Haissaguerre $M$, Lim KT, Jacquemet V, Rotter M, Dang L, Hocini M, Matsuo S, Knecht S, Jais P, Virag N: Atrial fibrillatory cycle length: Computer simulation and potential clinical importance. Europace 2007;9(Suppl 6):vi64-vi70.

20. Porter M, Spear W, Akar JG, Helms R, Brysiewicz N, Santucci P, Wilber DJ: Prospective study of atrial fibrillation termination during ablation guided by automated detection of fractionated electrograms. $J$ Cardiovasc Electrophysiol 2008;19:613-620. 
21. Haissaguerre $M$, Hocini $M$, Takahashi $Y, O^{\prime}$ Neill MD, Pernat $A$, Sanders $P$, Jonsson $A$, Rotter $M$, Sacher F, Rostock T, Matsuo S, Arantes L, Teng Lim K, Knecht S, Bordachar P, Laborderie J, Jais P, Klein G, Clementy J: Impact of catheter ablation of the coronary sinus on paroxysmal or persistent atrial fibrillation. J Cardiovasc Electrophysiol 2007;18:378-386.

22. Sanders $P$, Berenfeld $O$, Hocini M, Jais $P$, Vaidyanathan R, Hsu LF, Garrigue S, Takahashi $Y$, Rotter M, Sacher F, Scavee C, Ploutz-Snyder R, Jalife J, Haissaguerre M: Spectral analysis identifies sites of highfrequency activity maintaining atrial fibrillation in humans. Circulation 2005;112:789-797.

23. Takahashi $Y, O^{\prime}$ Neill MD, Hocini M, Dubois R, Matsuo S, Knecht S, Mahapatra S, Lim KT, Jais P, Jonsson A, Sacher F, Sanders P, Rostock T, Bordachar P, Clementy J, Klein GJ, Haissaguerre M: Characterization of electrograms associated with termination of chronic atrial fibrillation by catheter ablation. J Am Coll Cardiol 2008;51:1003-1010.

24. Verma A, Novak P, Macle L, Whaley B, Beardsall M, Wulffhart Z, Khaykin Y: A prospective, multicenter evaluation of ablating complex fractionated electrograms (CFEs) during atrial fibrillation (AF) identified by an automated mapping algorithm: Acute effects on AF and efficacy as an adjuvant strategy. Heart Rhythm 2008;5:198-205.

25. Haissaguerre M, Sanders P, Hocini M, Hsu LF, Shah DC, Scavee C, Takahashi Y, Rotter M, Pasquie JL, Garrigue $\mathrm{S}$, Clementy J, Jais $\mathrm{P}$ : Changes in atrial fibrillation cycle length and inducibility during catheter ablation and their relation to outcome. Circulation 2004;109:3007-3013.

26. Lo LW, Tai CT, Lin YJ, Chang SL, Udyavar AR, Hu YF, Ueng KC, Tsai WC, Tuan TC, Chang CJ, Kao T, TsaoHM,Wongcharoen W, Higa S, Chen SA: Predicting factors for atrial fibrillation acute termination during catheter ablation procedures: Implications for catheter ablation strategy and long-term outcome. Heart Rhythm 2009;6:311-318.

27. Atienza F, Almendral J, Jalife J, Zlochiver S, Ploutz-Snyder R, Torrecilla EG, Arenal A, Kalifa J, FernandezAviles F, Berenfeld O: Realtime dominant frequency mapping and ablation of dominant frequency sites in atrial fibrillation with left-to-right frequency gradients predicts long-term maintenance of sinus rhythm. Heart Rhythm 2009;6:33-40.

28. Fynn SP, Todd DM, Hobbs WJ, Armstrong KL, Garratt CJ: Role of dispersion of atrial refractoriness in the recurrence of clinical atrial fibrillation; a manifestation of atrial electrical remodelling in humans? Eur Heart J 2001;22:1822-1834.

29. Fynn SP, Todd DM, Hobbs WJ, Armstrong KL, Fitzpatrick AP, Garratt CJ: Effect of amiodarone on dispersion of atrial refractoriness and cycle length in patients with atrial fibrillation. $J$ Cardiovasc Electrophysiol 2003;14:485-491.

30. Sticherling C, Hsu W, Tada H, Bares AC, Oral H, Pelosi F, Knight BP, Strickberger SA, Morady F: Effects of verapamil and ibutilide on atrial fibrillation and postfibrillation atrial refractoriness. $J$ Cardiovasc Electrophysiol 2002;13:151-157.

31. Boahene KA, Klein GJ, Yee R, Sharma AD, Fujimura O: Termination of acute atrial fibrillation in the Wolff-Parkinson-White syndrome by procainamide and propafenone: Importance of atrial fibrillatory cycle length. J Am Coll Cardiol 1990;16:1408-1414.

32. Husser D, Stridh M, Cannom DS, Bhandari AK, Girsky MJ, Kang S, Sornmo L, Bertil Olsson S, Bollmann A: Validation and clinical application of time-frequency analysis of atrial fibrillation electrocardiograms. $J$ Cardiovasc Electrophysiol 2007;18:41-46. 


\section{Chapter 10}

The mechanical fibrillation pattern of the atrial myocardium is associated with acute and long-term success of electrical cardioversion in patients with persistent atrial fibrillation

CB De Vos* and I Limantoro*, R Pisters, T Delhaas, U Schotten, EC Cheriex, RG Tieleman, HJGM Crijns *both authors contributed equally Heart Rhythm. 2014;11:1514-1521 


\section{Abstract}

\section{Background}

Electrophysiological studies demonstrate that a short atrial fibrillation cycle length (AFCL) is related with poor outcome of electrical cardioversion (ECV) of atrial fibrillation (AF). We found previously that the mechanical AFCL (AFCL-tvi) and atrial fibrillatory velocity (AFV-tvi) may be determined non-invasively using color tissue velocity imaging and closely relates to the electrophysiological AFCL.

\section{Objective}

In the present study, we evaluated the relation between AFCL-tvi, AFV-tvi and success of ECV in patients with AF.

\section{Methods}

We prospectively studied 133 patients with persistent AF by performing an echocardiogram before ECV and measured the AFCL-tvi and AFV-tvi in the right atrium (RA) and left atrium (LA). Recurrent AF was monitored.

\section{Results}

Nineteen patients had failure of ECV, 42 remained in sinus rhythm after one year follow-up and 72 had a recurrence of persistent AF. Patients with immediate ECV failure had a lower median right atrial AFV-tvi compared to patients with a successful ECV: $0.7(0.2-1.0)$ versus $1.7(0.9-2.8) \mathrm{cm} / \mathrm{sec}, P=0.008$. Patients with maintenance of sinus rhythm after one year had a longer AFCL-tvi measured in the left atrium compared to patients with recurrence of AF (150 versus $137 \mathrm{~ms} ; P=0.017)$ and higher AFV-tvi in both atria (1.4 versus $0.9 \mathrm{~cm} / \mathrm{sec}$ in LA; $P=0.013$ and 2.2 versus $1.4 \mathrm{~cm} / \mathrm{sec}$ in RA; $P=0.011$ ). Multivariate analyses showed that all atrial TVI parameters were independently associated with maintenance of sinus rhythm after one year.

\section{Conclusions}

Higher atrial fibrillatory wall velocities and longer AFCLs determined by echocardiography are associated with acute and long-term success of ECV. 


\section{Introduction}

Atrial fibrillation (AF) is the most common sustained cardiac arrhythmia in clinical practice. ${ }^{1}$ Most symptomatic patients undergo pharmacological or electrical cardioversion (ECV) to restore normal sinus rhythm. Unfortunately, ECV is not always successful. $^{2}$ In addition, $40-70 \%$ of the patients have recurrence of AF within 2 years after a successful ECV. ${ }^{3}$ Identification of patients in whom ECV is likely to be successful will avoid unnecessary exposure of expected non-responders to complications of ECV. Factors that facilitate AF are depressed intra-atrial conduction as well as shortening of the atrial refractory period. The former factor relates to atrial structural remodeling, the latter is represented by the atrial fibrillation cycle length (AFCL). ${ }^{4}$ Electrophysiological studies demonstrated that AFCL is associated with maintenance of sinus rhythm. ${ }^{5-7}$ In previous studies we showed that, as an alternative to the invasive electrophysiological studies, color tissue velocity imaging (TVI) is a reliable noninvasive tool to assess the mechanical atrial fibrillatory frequency which is closely related to the electrophysiological $A F C L$ and hence atrial refractoriness. ${ }^{8-11}$ In addition, the velocity of the atrial fibrillatory wall motion as assessed by TVI (AFV-tvi) is inversely associated with the extent of arrhythmogenic structural atrial remodeling. ${ }^{10,11}$ In the present study we evaluate the relation between these electrophysiology-based echocardiographic tools and success of ECV and recurrences of persistent AF after ECV.

\section{Methods}

This study was approved by the Institutional Review Board for human research. We studied 133 consecutive patients referred for an ECV with symptomatic persistent AF. All patients were included in our outpatient clinic and had AF lasting $>1$ month which was verified by serial ECGs. Informed consent was obtained from all patients. Patients using class I or III anti-arrhythmic drugs were excluded. Other exclusion criteria were age $<18$ years, atrial flutter, and secondary AF. The decision of ECV referral and pretreatment with anti-arrhythmic drugs was made by the treating physician.

\section{Echocardiogram}

Before ECV ( $<1$ hour), trans-thoracic echocardiography including color TVI in the apical 4-chamber view was performed with a Vivid 7 ultrasound system (GE Healthcare). Patients were in supine position and the color TVI images were made during the endexpiratory phase in order to avoid respiratory artifacts. The frame rate was set above $100 \mathrm{~Hz}$. Offline, we studied TVI curves obtained from late diastole from the lateral wall of the left atrium just above the mitral annulus and from the lateral wall of the right atrium just above the tricuspid valve. At these specific atrial locations, the intrinsic motility of the myocardium is generally the highest. Moreover, these anatomical spots 
near the atrioventricular annulus are easy to identify which enhances the reproducibility of the measurements. We tried to avoid ventricular artifacts as much as possible by performing our measurements in the late diastolic phase when the ventricular contraction and relaxation are completed. Finally, the atrial sites where we measured AFCL were previously validated by comparing the AFCL-TVI with the electrophysiological AFCL on the electrogram. ${ }^{11}$

The atrial fibrillatory cycle length (AFCL-tvi) and atrial fibrillatory velocity (AFV-tvi) were measured at both atrial sites using the color TVI curves (Figure 10.1). AFCL-tvi was defined as the mean time interval between two consecutive negative deflections of the late diastolic atrial tissue velocity curve and AFV-tvi was defined as the mean difference in velocity of negative and positive deflections of the late diastolic atrial tissue velocity curve. From at least 3 cycles, AFCL-tvi and AFV-tvi were measured and averaged by one of the investigators (CDV) who was blinded for the result of the ECV. In order to evaluate the inter-observer variability of the TVI measurements, a second investigator (IL) repeated these measurements in 14 randomly selected patients.

According to the recommendations of the American Society of Echocardiography the left ventricular global systolic function was evaluated by LV ejection fraction, mitral flow velocity was assessed by pulsed-wave Doppler from the apical 4-chamber view and left atrial volumes were measured using the biplane Simpson rule.

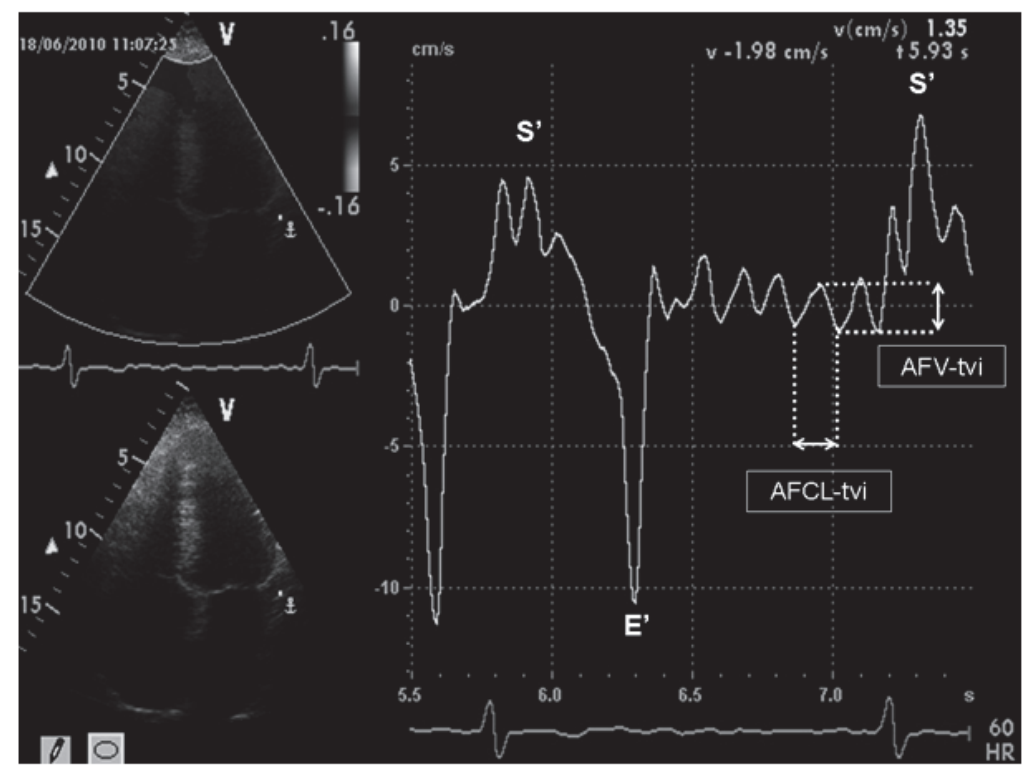

Figure 10.1 Example of a Tissue Velocity Imaging (TVI) tracing of the left atrial lateral wall in a patient with atrial fibrillation and measurement of Atrial Fibrillation Cycle Length (AFCL-tvi) and velocity of the atrial fibrillatory wall motion (AFV-tvi). 


\section{Electrical cardioversion}

Using a biphasic Lifepak $^{\circledR}$ defibrillator (Medtronic) electrical cardioversion was performed with paddles placed in an antero-lateral position using 100 Joules followed by 200 , and 360 Joules until sinus rhythm was obtained or until failure to convert with 360 Joules. Continuous ECG monitoring was performed during 3 hours after the procedure. Failure of ECV was defined as total shock failure or immediate recurrence of AF (recurrence within 2 minutes after ECV). We did not perform a separate analysis of total shock failure patients. This would have been interesting from a pathophysiological point of view. However, the patient numbers in the "failure of ECV" group were too low to split this group.

\section{Follow-up}

All our patients were seen within one month after ECV at our outpatient clinic, and subsequently at regular intervals. Within the first year of follow-up most patients were seen at least at three moments in time depending on the treating physician and symptoms of the patients. All patients were followed-up for at least one year. During every visit, symptoms of AF were evaluated and a 12-lead ECG was made. When in doubt about the rhythm status of the patient, a Holter recording was performed. If patients were admitted to the emergency department with cardiac complaints, the rhythm was verified by one of our cardiologists and the presence of AF was recorded in the digital charts of our cardiology department. None of the patients were lost to follow-up. Recurrence of persistent AF was defined as AF on a follow-up 12-lead ECG and subsequently documented as continuous AF on 24 hour Holter.

\section{Statistical analysis}

Data analysis was performed with SPSS statistical software (SPSS, Inc., release 20.0). Continuous variables were tested for normal distribution using the KolmogorovSmirnov test. Since most of these variables were not normally distributed, we reported continuous variables as "median $\left(25^{\text {th }}\right.$ percentile $-75^{\text {th }}$ percentile)". Categorical variables were reported as "observed number of patients (percentage)". Differences between variables that were not normally distributed were tested with the MannWhitney $U$ test when comparing two groups and the Kruskal-Wallis test when comparing three groups. Categorical variables were tested with Fisher's exact test when comparing two groups and Chi-square when comparing three groups. The predictive accuracy of our new tissue velocity parameters were reported using Receiver-operator characteristics (ROC). Differences in AF-free survival were determined using Kaplan-Meier curves (log-rank test). The interobserver variability of AFCL-tvi and AFV-tvi was evaluated using Spearman correlation tests. All baseline characteristics showing a significant univariate relationship with persistent $A F$ recurrence at follow-up and all variables known to be associated with outcome of ECV 
were included in a logistic regression model (hypertension, heart failure, left atrial dimensions, age, AF duration). Because of the risk of interaction, all TVI parameters were included separately to the model. Model reduction was performed by stepwise excluding variables from the model with a $P$ value $>0.10$. We evaluated model accuracy and discrimination by integrated discrimination improvement (IDI). ${ }^{12}$ The clinical model includes age, duration of AF episode and LA diameter. We included all consecutive patients in the univariate analysis which might give a better representation of the variables associated with success of ECV. The multivariate analyses and Kaplan-Meier analyses were limited only to patients in whom the TVI parameters were obtained. All tests performed were two-sided. Overall, a $P$-value of $<0.05$ was considered to be statistically significant.

\section{Results}

We included 133 consecutive patients before ECV. In nineteen patients (14\%) ECV failed to restore sinus rhythm and $114(86 \%)$ had a successful ECV. Of all patients in whom sinus rhythm was obtained, 42 (37\%) remained in sinus rhythm and 72 (63\%) had a recurrence of AF during one year follow-up.

The median AFCL-tvi was 140 (129-156) ms when measured in the left atrium and 155 (140-170) ms when measured in the right atrium. The median AFV-tvi was 1.0 (0.6-1.7) $\mathrm{cm} / \mathrm{sec}$ measured in the left atrium and $1.5(0.8-2.6) \mathrm{cm} / \mathrm{sec}$ in the right atrium. The clinical and echocardiographic baseline characteristics of the study population according to immediate success of ECV are presented in Table 10.1. Except for the TVI parameters, no significant differences were found. Table 10.2 shows the characteristics of our population according to overall maintenance of sinus rhythm during one year follow up. Significant differences were only found for the TVI parameters. In addition, there was a trend for longer AF duration and less hypertension in patients with AF recurrence during follow-up. The medication used by the patients is presented in Table 10.3.

Measurement of the AFCL-tvi was feasible in 91 (68\%) patients in the left atrium and in $85(64 \%)$ patients in the right atrium. The AFV-tvi could be determined for 101 (76\%) patients in the left atrium and for 94 (71\%) patients in the right atrium. We compared the characteristics in patients in whom the TVI parameters could be obtained with the patients in whom they could not be obtained as an attempt to exclude any forms of bias and found no significant differences. 
Table 10.1 Clinical and echocardiographic characteristics of the study population according to immediate success of electrical cardioversion.

\begin{tabular}{|c|c|c|c|c|}
\hline & All patients & $\begin{array}{c}\text { Failure of electrical } \\
\text { cardioversion }\end{array}$ & $\begin{array}{c}\text { Success of electrical } \\
\text { cardioversion }\end{array}$ & $P$-value* \\
\hline $\mathrm{N}$ & 133 & $19(14 \%)$ & $114(86 \%)$ & \\
\hline Age (years) & $67(59-74)$ & $66(52-73)$ & $67(59-74)$ & 0.792 \\
\hline Female & $39(29 \%)$ & $8(42 \%)$ & $31(27 \%)$ & 0.275 \\
\hline Total AF duration (months) & $7(3-40)$ & $8(3-29)$ & $6(3-40)$ & 0.615 \\
\hline AF duration current episode (days) & $101(57-84)$ & $107(64-231)$ & $97(56-172)$ & 0.357 \\
\hline Ventricular rate $(\mathrm{bpm})$ & $82(73-96)$ & $82(69-100)$ & $82(73-96)$ & 0.872 \\
\hline \multicolumn{5}{|l|}{ Underlying diseases } \\
\hline Hypertension & $75(56 \%)$ & $11(58 \%)$ & $64(56 \%)$ & 1.000 \\
\hline Coronary artery disease & $35(26 \%)$ & $3(16 \%)$ & $32(28 \%)$ & 0.399 \\
\hline Valvular heart diasese & $24(18 \%)$ & $2(11 \%)$ & $22(19 \%)$ & 0.524 \\
\hline Heart failure & $38(29 \%)$ & $7(37 \%)$ & $31(27 \%)$ & 0.417 \\
\hline \multicolumn{5}{|l|}{ Echography } \\
\hline Left atrial size $(\mathrm{mm})$ & $46(42-50)$ & $44(42-51)$ & $46(42-50)$ & 0.927 \\
\hline Left Atrial volume (ml) & 87 (66-109) & $101(75-115)$ & $84(66-108)$ & 0.190 \\
\hline Right atrial volume (ml) & $74(55-96)$ & $81(62-104)$ & $74(54-96)$ & 0.270 \\
\hline Ejection fraction (\%) & $52(43-60)$ & $55(43-62)$ & $51(44-60)$ & 0.465 \\
\hline \multicolumn{5}{|l|}{ TVI echography } \\
\hline AFCL-tvi LA (ms) n=91 & $140(129-156)$ & $133(105-148)$ & $140(130-160)$ & 0.072 \\
\hline AFCL-tvi RA (ms) n=85 & $155(140-170)$ & $130(115-169)$ & $155(140-170)$ & 0.081 \\
\hline AFV-tvi LA (cm/sec) n=101 & $1.0(0.6-1.7)$ & $0.8(0.1-1.6)$ & $1.0(0.6-1.7)$ & 0.174 \\
\hline AFC-tvi RA $(\mathrm{cm} / \mathrm{sec}) \mathrm{n}=88$ & $1.5(0.8-2.6$ & $0.7(0.2-1.0)$ & $1.7(0.9-2.8)$ & 0.008 \\
\hline
\end{tabular}

* $P$-value resulting from the comparison "failure of electrical cardioversion" versus "success of electrical cardioversion". AF: atrial fibrillation; FU: follow-up; AFCL: atrial fibrillation cycle length; AFV: atrial fibrillation velocity; LA: left atrium; RA: right atrium.

\section{Immediate failure of ECV}

We found a trend towards a shorter median AFCL-tvi in patients with a failed ECV compared to patients with a successful ECV: 133 versus $140 \mathrm{~ms}$ in the left atrium and $130 \mathrm{~ms}$ versus $155 \mathrm{~ms}$ in the right atrium. See Table 10.1 for details. The atrial fibrillatory wall velocity in the left atrium did not significantly differ between ECV failure and ECV success. However, in the right atrium, a significant difference of AFV-tvi was found between patients with a successful ECV $(1.7 \mathrm{~cm} / \mathrm{sec})$ versus patients with a failed ECV $(0.7 \mathrm{~cm} / \mathrm{sec})$.

Next, we studied the predictive ability of AFCL-tvi and AFV-tvi regarding acute success of ECV by creating ROC-curves. AFV-tvi measured in the right atrium significantly predicted immediate success of ECV: AUC 0.74, $P=0.018$. AFV-tvi measured in the left atrium (AUC 0.62; $P=0.174$ ) and AFCL-tvi measured in the left ( $A \cup C 0.69 ; P=0.073$ ) or right atrium (AUC 0.68; $P=0.081$ ) did not significantly predict immediate success of ECV. We calculated the IDI by comparing the clinical model for prediction of successful cardioversion with the new model (clinical model + AFV-tvi of the right atrium). The IDI showed that the discrimination slope of the new model was $14 \%$ higher than the clinical model itself. 
Table 10.2 Clinical and echocardiographic characteristics of the study population according to overall maintenance of sinus rhythm during follow-up.

\begin{tabular}{|c|c|c|c|c|}
\hline & All patients & $\begin{array}{c}\text { Failure of ECV or } \\
\text { recurrence of AF } \\
\text { during FU }\end{array}$ & $\begin{array}{l}\text { Overall maintenance } \\
\text { of sinus rhythm }\end{array}$ & $P$-value* \\
\hline $\mathrm{N}$ & 133 & $91(68 \%)$ & $42(32 \%)$ & \\
\hline Age (years) & $67(59-74)$ & $68(59-73)$ & $67(59-75)$ & 0.697 \\
\hline Female & $39(29 \%)$ & $29(32 \%)$ & $10(24 \%)$ & 0.415 \\
\hline Total AF duration (months) & $7(3-40)$ & $7(3-41)$ & $5(3-35)$ & 0.144 \\
\hline AF duration current episode (days) & $101(57-84)$ & $108(64-199)$ & $80(46-152)$ & 0.076 \\
\hline Ventricular rate $(\mathrm{bpm})$ & $82(73-96)$ & $82(73-96)$ & $84(73-97)$ & 0.875 \\
\hline \multicolumn{5}{|l|}{ Underlying diseases } \\
\hline Hypertension & $75(56 \%)$ & $46(51 \%)$ & $29(69 \%)$ & 0.060 \\
\hline Coronary artery disease & $35(26 \%)$ & $22(24 \%)$ & $13(31 \%)$ & 0.407 \\
\hline Valvular heart diasese & $24(18 \%)$ & $19(21 \%)$ & $5(12 \%)$ & 0.237 \\
\hline Heart failure & $38(29 \%)$ & $30(33 \%)$ & $8(19 \%)$ & 0.148 \\
\hline \multicolumn{5}{|l|}{ Echography } \\
\hline Left atrial size (mm) & $46(42-50)$ & $45(42-50)$ & $47(44-51)$ & 0.292 \\
\hline Left Atrial volume (ml) & 87 (66-109) & $86(66-109)$ & 91 (67-109) & 0.815 \\
\hline Right atrial volume (ml) & $74(55-96)$ & $74(58-100)$ & $75(52-95)$ & 0.479 \\
\hline Ejection fraction (\%) & $52(43-60)$ & $52(41-60)$ & $54(48-60)$ & 0.185 \\
\hline \multicolumn{5}{|l|}{ TVI echography } \\
\hline AFCL-tvi LA (ms) n=91 & $140(129-156)$ & $137(123-151)$ & $150(134-170)$ & 0.017 \\
\hline AFCL-tvi RA (ms) n=85 & $155(140-170)$ & $150(135-170)$ & $156(144-177)$ & 0.216 \\
\hline AFV-tvi LA (cm/sec) n=101 & $1.0(0.6-1.7)$ & $0.9(0.5-1.6)$ & $1.4(0.8-2.4)$ & 0.013 \\
\hline AFC-tvi RA $(\mathrm{cm} / \mathrm{sec}) \mathrm{n}=88$ & $1.5(0.8-2.6$ & $1.3(0.7-2.3)$ & $2.2(1.4-3.1)$ & 0.011 \\
\hline
\end{tabular}

* $P$-value resulting from the comparison "Failure of ECV or recurrence of AF during FU" versus "Overall maintenance of sinus rhythm". AF: atrial fibrillation; FU: follow-up; AFCL: atrial fibrillation cycle length; AFV: atrial fibrillation velocity; LA: left atrium; RA: right atrium.

\section{Overall recurrence of persistent AF within one year after ECV}

Left atrial AFCL-tvi was longer in patients who remained in sinus rhythm during followup compared to patients with recurrent AF: 150 ms versus 137; $P=0.017$. See Table 10.2 for details. In the right atrium, AFCL-tvi did not differ between patients with long term sinus rhythm and those with recurrent AF. However, for both atria AFV-tvi was higher in the patients that maintained sinus rhythm: $1.4 \mathrm{~cm} / \mathrm{sec}$ versus $0.9 \mathrm{~cm} / \mathrm{sec}$ in the left atrium; $P=0.013$ and $2.2 \mathrm{~cm} / \mathrm{sec}$ versus $1.3 \mathrm{~cm} / \mathrm{sec}$ in the right atrium; $P=0.011$. Next we performed ROC analyses to study the predictive ability of AFCL-tvi and AFV-tvi regarding recurrence of $A F$ within one year after $E C V$. AFV-tvi measured in the right atrium (AUC 0.67, P=0.01), AFV-tvi of the left atrium (AUC 0.66, $P=0.01$ ) and AFCL-tvi measured in the left atrium ( $A \cup C 0.66, P=0.02$ ) were significant predictors of $A F$ recurrence. 
Table 10.3 Medication used at baseline.

\begin{tabular}{|c|c|c|c|c|c|}
\hline & All patients & $\begin{array}{c}\text { Failure of } \\
\text { electrical } \\
\text { cardioversion }\end{array}$ & $\begin{array}{c}\text { Recurrence } \\
\text { of AF during } \\
\text { FU }\end{array}$ & $\begin{array}{l}\text { Maintenance } \\
\text { of sinus } \\
\text { rhythm }\end{array}$ & $P$-value* \\
\hline $\mathrm{N}$ & 133 & $19(14 \%)$ & 72 (54\%) & $42(32 \%)$ & \\
\hline \multicolumn{6}{|l|}{ Rate-control drugs } \\
\hline Beta-blockers & $96(71 \%)$ & $14(74 \%)$ & $48(67 \%)$ & $33(79 \%)$ & 0.39 \\
\hline Digoxine & $35(26 \%)$ & $4(21 \%)$ & $21(67 \%)$ & $10(24 \%)$ & 0.70 \\
\hline $\begin{array}{l}\text { Non-dihydropyridine calcium channel } \\
\text { blockers }\end{array}$ & $16(12 \%)$ & $4(21 \%)$ & $6(8 \%)$ & $6(14 \%)$ & 0.27 \\
\hline \multicolumn{6}{|l|}{ Other medication } \\
\hline Diuretics & $47(35 \%)$ & $7(37 \%)$ & $23(32 \%)$ & $17(41 \%)$ & 0.65 \\
\hline Angiotensin converting enzyme inhibitors & $48(36 \%)$ & $8(42 \%)$ & $30(42 \%)$ & $10(24 \%)$ & 0.13 \\
\hline Angiotensin receptor blockers & $48(36 \%)$ & $8(42 \%)$ & $20(28 \%)$ & $20(48 \%)$ & 0.09 \\
\hline Statins & $60(45 \%)$ & $8(42 \%)$ & $27(38 \%)$ & $25(60 \%)$ & 0.07 \\
\hline Calcium channel blockers & $11(8 \%)$ & $1(5 \%)$ & 7 (10\%) & $6(14 \%)$ & 0.78 \\
\hline Nitrates & $14(11 \%)$ & $1(5 \%)$ & $7(10 \%$ & $6(14 \%)$ & 0.52 \\
\hline
\end{tabular}

* $P$-value resulting from the comparison "failure of electrical cardioversion" versus "recurrence of AF during FU" versus "maintenance of sinus rhythm". AF: atrial fibrillation; FU: follow-up.

Multivariable analyses show that absence of hypertension, AFCL-tvi measured in the left atrium, AFCL-tvi measured in the right atrium, AFV-tvi measured in the left atrium and AFV-tvi of the right atrium were all independently associated with recurrence of AF within one year after ECV (Table 10.4). We calculated the IDI by comparing the clinical model for prediction of maintenance of sinus rhythm after 1 year with the new model (clinical model + AFV-tvi in the right atrium). The IDI showed that the discrimination slope of the new model was $4 \%$ higher than the clinical model itself. Finally, we created an AF-tvi score combining TVI parameters to determine the KaplanMeier 1-year AF-free survival. (Figure 10.2).

Table 10.4 Independent predictors of persistent AF at one year resulting from the multivariable analysis (each TVI parameter added to the model separately).

\begin{tabular}{lccc}
\hline & OR & Cl & P-value* \\
\hline & \multicolumn{3}{c}{ Model including AFCL-tvi LA } \\
AFCL-tvi LA (per ms) & 0.97 & $0.96-.099$ & 0.01 \\
Hypertension & 0.30 & $0.11-0.84$ & 0.01 \\
\hline \multicolumn{3}{l}{0.98} & Model including AFCL-tvi RA \\
\hline AFCL-tvi RA (per mes) & $0.97-0.99$ & 0.03 \\
Hypertension & $0.09-0.85$ & 0.02 \\
\hline \multicolumn{2}{l}{0.62} & $0.39-1.00$ & 0.04 \\
\hline AFV-tvi LA (per cm/sec) & 0.39 & $0.15-1.02$ & 0.05 \\
\hline Hypertension & \multicolumn{3}{c}{ Model including AFV-tvi RA } \\
\hline AVF-tvi RA (per cm/sec) & 0.74 & $0.55-1.00$ & 0.04 \\
\hline
\end{tabular}

AFCL: atrial fibrillation cycle lenght; AFV: atrial fibrillatory velocity; LA: left atrium; RA: right atrium; Cl: confidence interval; OR: odds ratio 


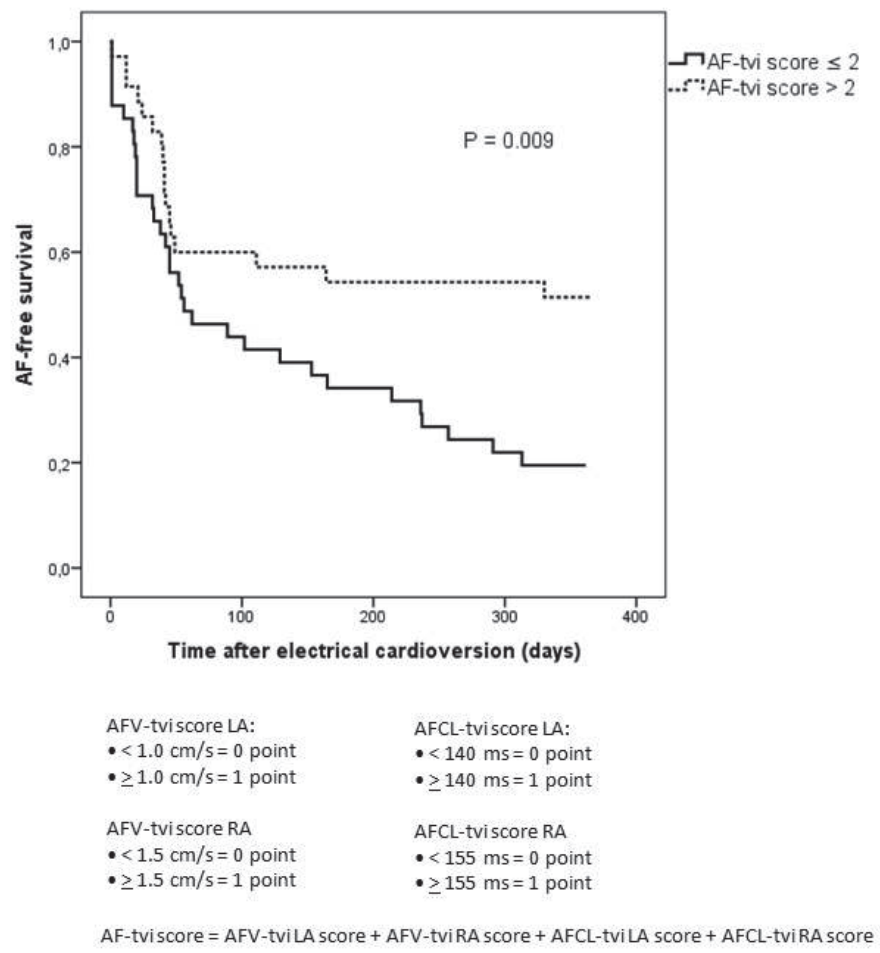

Figure 10.2 Kaplan-Meier one-year AF-free survival according to the AF-tvi score.

\section{Interobserver variability}

Twenty-eight repeated measurements were performed (left and right atrium in 14 patients). We evaluated the correlation between the measurements performed by two independent observers. For the measurement of AFCL-tvi, the correlation coefficient was $0.830(P<0.001)$ and for the measurement of AFV-tvi, the correlation was $0.813(P<0.001)$.

\section{Discussion}

\section{New TVI parameters to characterize patients with AF}

In the presence of a short excitable gap (as present during AF with functional reentry), the duration of the atrial refractory period is related to the $A F C L$ as measured during AF. ${ }^{4}$ Duytschaever et al. found a strong correlation between atrial mechanical fibrillatory wall motion assessed by tissue Doppler imaging (TDI) and the electrical 
fibrillatory cycle length assessed by the intracardiac electrogram. ${ }^{8}$ The AFCL is inversely associated with the number of wavelets participating in AF maintenance. ${ }^{13}$ Conversion to sinus rhythm may be hampered by a short AFCL. In addition, a short refractory period sets the stage for a supervulnerable phase immediately after applying a DC countershock to convert persistent AF. ${ }^{14}$ Considering the above, it is plausible that AFCL-tvi is associated with maintenance of sinus rhythm after ECV.

Atrial contractile dysfunction is strongly related to electrical remodeling. ${ }^{15}$ In addition, atrial dilatation due to heart disease results in loss of atrial contractility. Besides, structural heart disease results in atrial tissue fibrosis which is an important hallmark of atrial arrhythmogenicity. In our study, lower atrial fibrillatory wall velocity signals were associated with worse outcome. TVI echocardiography may demonstrate differences in contractile and, hence, structural remodeling and arrhythmogenicity among persistent AF patients. ${ }^{10,11}$

Although, we found in the present study that AFV-tvi measured in the left atrium was longer in patients with immediate success of ECV compared to immediate failure of $E C V$, this difference was not statistically significant. AFV-tvi was significantly longer in patients with successful cardioversion when measured in the right atrium. We found that the overall AFV-tvi was lower in the left atrium compared to the right atrium. In addition to that, the variation of AFV-tvi was much smaller in the left compared to the right atrium. Therefore, we believe that AFV-tvi measured in the right atrium has the highest intrinsic predictive power regarding immediate success of ECV.

\section{Predicting success of electrical cardioversion in patients with AF}

The most consistent clinical predictors of successful ECV were a short duration of the AF episode, younger age, a small atrial size and the use of anti-arrhythmic drugs or beta-blockers. ${ }^{16-20}$ There is increasing evidence that AF is associated with inflammation which might be reduced by statins. ${ }^{21}$ Inhibition of the RAAS can possibly reduce atrial structural remodeling by decreasing fibrosis which can result in a decrease in the incidence of $A F^{22}$ The predictive value of valvular disease is less evident. ${ }^{19,23}$ Other clinical parameters associated with unsuccessful ECV are a history of coronary artery disease, female sex, weight, hypertension, and sleep apnea syndrome. ${ }^{20,24,25}$ However, the predictive value of the parameters evaluated is low. ${ }^{26}$ Echocardiographic parameters predicting ECV success were left atrial appendage (LAA) peak bloodflow velocity, pulmonary vein blood flow patterns and mitral Doppler peak A-wave velocity. ${ }^{27-29}$ P-wave duration during sinus rhythm and global right atrial fibrillatory frequency during AF are electrocardiographic parameters that are associated with maintenance of sinus rhythm after ECV. ${ }^{30}$

Basically, all clinical and echocardiographic "predictors" described above, primarily relate to structural remodeling whereas the electrocardiographic predictors described previously also seem to reflect the global amount of electrical remodeling. 


\section{Limitations}

The current TVI method needs a long diastole to avoid artifacts by interference with ventricular motion. As a result, measurement of AFCL-tvi and AFV-tvi was not feasible in patients with a too high ventricular rate. In some patients we could not measure AFCL-tvi despite a long diastole because the velocity of the signal was too low. However, these signals could be a manifestation of advanced structural remodeling and may identify patients with potential ECV failure as reflected by the low AFV-tvi. In addition to that, we do not have data regarding the temporal intra-patient variability since we only performed one echocardiographic recording in each patient. However, a previous publication studying longer recordings shows little temporal intra-patient variability. ${ }^{11}$ The predictive power of our technique is too low to categorically exclude patients from an ECV attempt. This might be the result of a somewhat underpowered sample size. On the other hand, we found a strong and independent relation between AFCL-TVI, AFV-TVI and outcome of ECV in persistent AF patients. We believe that this might guide the physician in the management of patients with AF. Taken together, patients with a short AFCL-TVI and/or low AFV-TVI could be candidates for pretreatment with anti-arrhythmic drugs to enhance the short- and long-term success rate of ECV. In addition, we believe that further developments in echocardiography (especially regarding temporal and spatial resolution) may improve the accuracy of our measurements. Not all co-variates described in the past which could influence the success of ECV were included in the present analysis. However all patients in whom AF was thought to be secondary to underlying disease were not included in our study. We did not change the paddle position in case of ECV failure, which could have increased immediate success of ECV. However, our ECV protocol represent standard practice and therefore we feel our results are valid for such practice. Finally, the usual limitations inherent to TVI regarding the angle of insonation and loading conditions of the heart also apply in this study.

\section{Conclusions}

In the present study, we evaluated the relation between the mechanical fibrillatory wall motion during AF and outcome of ECV. Two echocardiographic TVI parameters, AFCL-tvi and AFV-tvi, closely reflecting electrical and structural remodeling of the atrial walls, appear to be independently associated with success or failure of rhythm control by electrical cardioversion in persistent AF. Long AFCL-tvi and high AFV-tvi are associated with long term maintenance of sinus rhythm in patients undergoing cardioversion for persistent AF. We believe that non-invasive imaging of local electrophysiological and structural atrial changes may trigger a shift of paradigm in diagnosis and management of AF patients. Obviously, more and larger studies are needed to show that these conclusions remain true in different populations such as patients on anti-arrhythmic drugs or ablated patients. 


\section{References}

1. Chugh SS, Blackshear JL, Shen WK, Hammill SC, Gersh BJ. Epidemiology and natural history of atrial fibrillation: clinical implications. J Am Coll Cardiol 2001; 37:371-378.

2. McCarthy C, Varghese PJ, Barritt DW. Prognosis of atrial arrhythmias treated by electrical counter shock therapy. A three-year follow-up. Br Heart J 1969; 31:496-500.

3. Crijns HJ, Van Gelder IC, Van Gilst WH, Hillege H, Gosselink AM, Lie KI. Serial antiarrhythmic drug treatment to maintain sinus rhythm after electrical cardioversion for chronic atrial fibrillation or atrial flutter. Am J Cardiol 1991; 68:335-341.

4. Capucci A, Biffi M, Boriani G, Ravelli F, Nollo G, Sabbatani P, Orsi C, Magnani B. Dynamic electrophysiological behavior of human atria during paroxysmal atrial fibrillation. Circulation 1995; 92:1193-1202.

5. Fynn SP, Todd DM, Hobbs WJ, Armstrong KL, Garratt CJ. Role of dispersion of atrial refractoriness in the recurrence of clinical atrial fibrillation; a manifestation of atrial electrical remodelling in humans? Eur Heart J 2001; 22:1822-1834.

6. Hunter RJ, Diab I, Tayebjee M, Richmond L, Sporton S, Earley MJ, Schilling RJ. Characterization of fractionated atrial electrograms critical for maintenance of atrial fibrillation: a randomized, controlled trial of ablation strategies (the CFAE AF trial). Circ Arrhythm Electrophysiol 2011;4:622-629.

7. Rostock T1, Salukhe TV, Steven D, Drewitz I, Hoffmann BA, Bock K, Servatius H, Müllerleile K, Sultan A, Gosau N, Meinertz T, Wegscheider K, Willems S. Long-term single- and multiple-procedure outcome and predictors of success after catheter ablation for persistent atrial fibrillation. Heart Rhythm 2011; 8:1391-1397.

8. Duytschaever M, Heyse A, de Sutter J, Crijns H, Gillebert T, Tavernier R, Tieleman R. Transthoracic tissue Doppler imaging of the atria: a novel method to determine the atrial fibrillation cycle length. $J$ Cardiovasc Electrophysiol 2006; 17:1202-1209.

9. De Vos CB, Weijs B, Crijns HJ, Cheriex EC, Palmans A, Habets J, Prins MH, Pisters R, Nieuwlaat R, Tieleman RG. Atrial tissue Doppler imaging for prediction of new-onset atrial fibrillation. Heart 2009; 95:835-840.

10. De Vos CB, Crijns HJ, Tieleman RG. The fibrillating atrial myocardium visualized: An unexploited source of information. Heart Rhythm 2009; 6:1247-1248.

11. De Vos CB1, Pison L, Pisters R, Schotten U, Cheriex EC, Prins MH, Delhaas T, Crijns HJ, Tieleman RG. Atrial fibrillatory wall motion and degree of atrial remodeling in patients with atrial fibrillation: a tissue velocity imaging study. J Cardiovasc Electrophysiol 2009; 20:1374-1381.

12. Pencina MJ, D'Agostino RB, Sr., D'Agostino RB, Jr., Vasan RS. Evaluating the added predictive ability of a new marker: from area under the ROC curve to reclassification and beyond. Stat Med 2008; 27:157172; discussion 207-212.

13. Allessie M, Ausma J, Schotten U. Electrical, contractile and structural remodeling during atrial fibrillation. Cardiovasc Res 2002; 54:230-246.

14. Duytschaever M, Danse $P$, Allessie M. Supervulnerable phase immediately after termination of atrial fibrillation. J Cardiovasc Electrophysiol 2002; 13:267-275.

15. Schotten U, Duytschaever M, Ausma J, Eijsbouts S, Neuberger HR, Allessie M. Electrical and contractile remodeling during the first days of atrial fibrillation go hand in hand. Circulation 2003; 107:1433-1439.

16. Dittrich HC, Erickson JS, Schneiderman T, Blacky AR, Savides T, Nicod PH. Echocardiographic and clinical predictors for outcome of elective cardioversion of atrial fibrillation. Am J Cardiol 1989; 63:193197.

17. Duytschaever M, Haerynck F, Tavernier R, Jordaens L. Factors influencing long term persistence of sinus rhythm after a first electrical cardioversion for atrial fibrillation. Pacing Clin Electrophysiol 1998; 21:284-287.

18. Frick M, Frykman V, Jensen-Urstad M, Ostergren J, Rosenqvist M. Factors predicting success rate and recurrence of atrial fibrillation after first electrical cardioversion in patients with persistent atrial fibrillation. Clin Cardiol 2001; 24:238-244.

19. Brodsky MA, Allen BJ, Capparelli EV, Luckett CR, Morton R, Henry WL. Factors determining maintenance of sinus rhythm after chronic atrial fibrillation with left atrial dilatation. Am J Cardiol 1989; 63:1065-1068. 
20. Pisters R, Nieuwlaat R, Prins MH, Le Heuzey JY, Maggioni AP, Camm AJ, Crijns HJ; Euro Heart Survey Investigators. Clinical correlates of immediate success and outcome at 1-year follow-up of real-world cardioversion of atrial fibrillation: the Euro Heart Survey. Europace 2012; 14:666-674.

21. Loffredo L, Angelico F, Perri L, Violi F. Upstream therapy with statin and recurrence of atrial fibrillation after electrical cardioversion. Review of the literature and meta-analysis. BMC Cardiovasc Disord 2012; 12:107.

22. Healey JS, Baranchuk A, Crystal E, Morillo CA, Garfinkle M, Yusuf S, Connolly SJ. Prevention of atrial fibrillation with angiotensin-converting enzyme inhibitors and angiotensin receptor blockers: a metaanalysis. J Am Coll Cardiol 2005; 45: 1832-1839.

23. Van Gelder IC, Crijns HJ, Van Gilst WH, Verwer R, Lie KI. Prediction of uneventful cardioversion and maintenance of sinus rhythm from direct-current electrical cardioversion of chronic atrial fibrillation and flutter. Am J Cardiol 1991; 68:41-46.

24. Suttorp MJ, Kingma JH, Koomen EM, van 't Hof A, Tijssen JG, Lie KI. Recurrence of paroxysmal atrial fibrillation or flutter after successful cardioversion in patients with normal left ventricular function. $A m$ J Cardiol 1993; 71: 710-713.

25. Mazza A, Bendini MG, Cristofori M, Nardi S, Leggio M, De Cristofaro R, Giordano A, Cozzari L, Giordano G, Cappato R. Baseline apnoea/hypopnoea index and high-sensitivity C-reactive protein for the risk of recurrence of atrial fibrillation after successful electrical cardioversion: a predictive model based upon the multiple effects of significant variables. Europace 2009;11:902-909.

26. Raitt MH, Volgman AS, Zoble RG, Charbonneau L, Padder FA, O'Hara GE, Kerr D; AFFIRM Investigators. Prediction of the recurrence of atrial fibrillation after cardioversion in the Atrial Fibrillation Follow-up Investigation of Rhythm Management (AFFIRM) study. Am Heart J 2006; 151:390-396.

27. Verhorst PM, Kamp O, Welling RC, Van Eenige MJ, Visser CA. Transesophageal echocardiographic predictors for maintenance of sinus rhythm after electrical cardioversion of atrial fibrillation. Am J Cardiol 1997; 79:1355-1359.

28. Paraskevaidis IA, Theodorakis GN, Katritsis DG, Tsiapras DP, Livanis EG, Kremastinos DT. Pulmonary vein flow analysis by transoesophageal echocardiogr phy in patients with chronic atrial fibrillation; 1 year follow-up after cardioversion. Eur Heart J 1999; 20:375-385.

29. Spiecker M, Böhm S, Börgel J, Grote J, Görlitz S, Huesing A, Mügge A. Doppler echocardiographic prediction of recurrent atrial fibrillation following cardioversion. Int J Cardiol 2006; 113:161-166.

30. Holmqvist F, Stridh M, Waktare JE, Sörnmo L, Olsson SB, Meurling CJ. Atrial fibrillatory rate and sinus rhythm maintenance in patients undergoing cardioversion of persistent atrial fibrillation. Eur Heart $J$ 2006; 27:2201-2207. 


\section{Chapter 11}

General discussion 
Chapter 11 


\section{General discussion}

Atrial fibrillation (AF) may lead to significant morbidity and mortality. ${ }^{1}$ It is expected that the number of patients with AF will increase tremendously within the next decades which will have an important socioeconomic impact. ${ }^{2,3}$ This thesis aims to contribute to a better identification of patients at risk for the development of the arrhythmia and prediction of response to therapy. We evaluated the role of clinical parameters and explored new electrophysiology-derived echocardiographic parameters to characterize the atrial substrate in patients with AF.

\section{Clinical parameters to characterize patients with atrial fibrillation}

In the first part of this thesis, we evaluated the role of clinical parameters to characterize AF. A better characterization of AF using clinical parameters may improve treatment of the arrhythmia.

In chapter 2, we studied the clinical characteristics and management of patients with paroxysmal AF associated with autonomic triggers among the patients in the Euro Heart Survey. ${ }^{4}$ Coumel et al. were the first to describe an autonomic origin of atrial fibrillation. ${ }^{5}$ Electrophysiology studies show that activation of the cardiac autonomic nervous system - mostly by vagal stimulation - enhance inducibility of AF by pulmonary vein ectopy and may cause shortening of the atrial effective refractory period and atrial fibrillation cycle length ( $A F C L$ ), regional conduction delays, heterogeneous changes in the atrial fibrillatory cycle length and complex fractionated electrograms that may maintain the arrhythmia. ${ }^{6-9}$ Ablation of ganglionated plexi can suppress pulmonary vein potentials and reduce complex fractionated atrial electrograms, and thereby control atrial fibrillation. ${ }^{10}$ We found that an autonomic trigger pattern (adrenergic, vagal or mixed) was present in $33 \%$ of all patients with paroxysmal $A F$ in the Euro Heart Survey. It is important to classify these patients correctly since successful management of autonomic AF may depend on its recognition. ${ }^{11}$ Beta-blocking drugs, sotalol, digitalis and propafenone are considered unsuitable in vagal AF since they may exacerbate the episodes of vagal induced AF, whereas in adrenergic AF drugs with beta-blocking properties are thought to be beneficial. However, these guidelines derived recommendations are based on empirical evidence and expert opinion since controlled studies on the effect of different drugs in autonomic induced AF are lacking. ${ }^{5}$ Our observations are among the first to add information to the knowledge base concerning the broad management of autonomic AF. Our data suggest that autonomic AF may be recognized using straightforward history taking. Further, we found that in patients with vagal AF, prescription of non-recommended treatment may be detrimental because of aggravation of the arrhythmia pattern. Our observational data are not underpinned by physiologic measurements of autonomic function in the various patient profiles as 
found by simple history taking. Nevertheless, considering the above the autonomic patterns identified appeared clinically meaningful. Further studies may lead to a refinement of the clinical assessment especially if supported by autonomic function testing. This may contribute to a better treatment of atrial fibrillation.

In Chapters $\mathbf{3}$ and $\mathbf{4}$ we characterized patients with AF progression in two cohorts: the Euro Heart Survey population ${ }^{12}$ and the RecordAF population ${ }^{13}$ respectively. In clinical practice, one can discriminate three clinical AF types: paroxysmal AF (the episodes of the arrhythmia terminate spontaneously), persistent AF (the episodes are not selfterminating), and permanent AF (the physician decides that further attempts to restore normal sinus rhythm are useless). ${ }^{11}$ Several previous studies investigated AF progression. ${ }^{14-18}$ We explored the possibility to predict $A F$ progression using clinical parameters and found that heart failure, previous stroke or TIA, COPD, hypertension and age were independent predictors of AF progression in the Euro Heart survey. ${ }^{19}$ We developed a new simple prediction rule to estimate the probability of AF progression in patients with paroxysmal AF: the HATCH score.

Why is the HATCH score so important for clinicians? First, factors united in $\mathrm{HATCH}$ are known to induce structural remodeling of the atria causing chronic stretch and atrial dilatation leading to atrial fibrosis. This may lead to disturbance of the electrical junctions between muscle bundles inducing reentry. ${ }^{20,21}$ This explains why the potential preventive effect of antiarrhythmic drugs was annulled by the promoting effect of underlying heart disease and age as represented by HATCH. Secondly, HATCH represents not only arrhythmia progression but is also associated with cardiovascular events during follow-up. Since antiarrhythmic drugs may result in lethal complications and AF progression is associated with more adverse cardiovascular events that could be enhanced by antiarrhythmic drugs, we believe prediction of AF progression could contribute to a safer and more rational treatment by avoiding antiarrhythmic therapy in patients with a high risk of AF progression. As pointed out by Drs Jahangir and Murarka in their editorial comment accompanying our JACC paper on progression, the similarity of the HATCH score to the $\mathrm{CHADS}_{2}$ score is striking. ${ }^{22}$ This suggests that the same parameters leading to AF progression, also induce thromboembolic complications in patients with AF. In their editorial, the authors deplore that no information about the duration of AF before enrollment is provided. Obviously all patients included had paroxysmal forms of AF. Unfortunately, information regarding the total AF duration was not available in all patients in this cohort. However, in the RecordAF cohort AF duration was not an independent predictor of AF progression. In addition, the same authors noticed that the fact that antiarrhythmic drugs were not preventing AF progression in the Euro Heart Survey population might be due to the absence of randomization to specific treatment strategies. Despite the fact that no randomization was performed, in the RecordAF population, we studied AF progression in a slightly different population of patients with recent-onset AF only. In this study the decision whether patients were treated with rate or rhythm control was made at 
inclusion which enabled us to study the effect of treatment strategy more consistently. However, we could not appraise all confounders related to the physician's choice for either rate or rhythm control therapy. In RecordAF the same AF progression rate at one year follow-up was found as in the Euro Heart Survey (15\%). Besides heart failure and hypertension, treatment strategy (rate- versus rhythm-control) was found to be an independent predictor of AF progression in the RecordAF population. This suggests that rhythm control prevents electrical remodeling and maybe also structural remodeling. These notions are supported by the goat studies that demonstrate that artificial maintenance of AF shortens the atrial refractory period which promotes inducibility and maintenance of $A F^{23}$ Furthermore, this notion is supported by the observation in the ATHENA trial showing that dronedarone is associated with less AF progression and at the same time with fewer major adverse events. ${ }^{24}$ Unfortunately, we were unable to validate the HATCH score in RecordAF because a history of chronic obstructive pulmonary disease was not included in the RecordAF case record form.

\section{Echo-electrocardiography to identify the substrate for atrial fibrillation during sinus rhythm}

In the second part of this thesis we studied new, non-invasive, electrophysiologyderived echocardiographic parameters to identify patients vulnerable for the development of AF. AF is associated with complications such as stroke and heart failure resulting in considerable morbidity and mortality. ${ }^{25,26}$ Unfortunately, preventive treatment comes too late when stroke is the first manifestation of AF. We believe that prediction of new-onset $A F$ enables to start adequate therapy on time reducing the development of AF-related complications.

The total atrial conduction time or TACT (the total time required for atrial electrical activation) is an important electrophysiological parameter. ${ }^{27}$. The longer TACT is, the higher the risk of developing AF. This relates to the fact that conduction slowing is an important determinant of reentry and at the same time an expression of atrial remodeling including fibrosis, amyloidosis, fat accumulation and other changes related to an arrhythmogenic atrial substrate. TACT can be determined using the signalaveraged ECG $p$-wave or the maximal $p$-wave duration on the 12-lead surface ECG. ${ }^{28}$ However, $p$-wave measurement on the 12-lead ECG has a lower predictive value compared to the other techniques and $p$-wave analysis by signal averaged ECG has not found its way into clinical practice, possibly because it requires special hardware whilst it is rather time-consuming. In chapter $\mathbf{5}$ we validated a new echocardiographic technique to estimate the TACT using pulsed-wave tissue Doppler echocardiography, namely PA-TDI. ${ }^{29}$ Echocardiography is the diagnostic working horse of cardiology and therefore measurement of PA-TDI may find its way much more easily into clinical practice compared to signal-averaged $p$-wave duration. We found that PA-TDI was highly correlated with the signal averaged $p$-wave duration and was easy to perform. 
In chapter 6, we studied the clinical determinants of a prolonged TACT using PA-TDI. ${ }^{30}$ Multivariate linear regression analysis revealed that AF in history, hypertension, clinically relevant valve disease, age, and body mass were independently associated with the PA-TDI interval. The independent association between a prolonged TACT and AF could be explained by the fact that long conduction times are a condition for the development of $\mathrm{AF}$ and - on the other hand - AF itself may induce electrical remodeling. ${ }^{23,31}$ A decreased conduction velocity, leads to a shorter wavelength of the reentrant wave fronts. An increased atrial size can harbour more wave fronts of a certain size at the same time. Both will favor AF. ${ }^{32,33}$ Age, valve disease and hypertension are known to induce atrial fibrosis which prolongs the TACT because of "detour conduction". Regarding the independent relation between TACT and body mass index, we hypothesized that this might be the result of obstructive sleep apnea which frequently occurs in obese patients or pericardial fat that alters inter- and intraatrial conduction. $^{34,35}$ The aortic diameter, left atrial dimension, mitral valve E-wave deceleration time, aortic incompetence, and mitral incompetence were the echocardiographic parameters that were independently associated with the PA-TDI interval. We theorized that this might be a reflection of (insufficiently treated) hypertension, raised left atrial pressure and diastolic left ventricular dysfunction. In the editorial comment accompanying our paper, $\mathrm{Dr}$ Henein is in favour of such interpretation by suggesting that the common denominator of a prolonged TACT seems to be a raised left atrial pressure. ${ }^{36}$

In chapter 7 we evaluated the role of PA-TDI to identify subjects at risk for development of new-onset $A F^{37}$ We found that patients who will develop $A F$ in the future have a longer PA-TDI interval at baseline compared to patients who remain in sinus rhythm. After adjusting for other clinical and echocardiographic parameters known predictors of AF - PA-TDI was the strongest predictor of new-onset AF in the studied population. The longer the PA-TDI interval, the higher the incidence of newonset AF. Table 11.1 shows a possible clinical application of the PA-TDI tool for primary prevention of AF. We found that patients with a PA-TDI interval $<130$ ms are unlikely to develop AF. Therefore, we hypothesized that these patients are not candidates for primary prevention. If PA-TDI $<130 \mathrm{~ms}$ and associated cardiovascular disease is mostly absent, further management could consist of repeating PA-TDI measurement in 5 years. However, if associated cardiovascular disease is present, the risk of developing $\mathrm{AF}$ is moderate and upstream therapy is warranted focusing on the underlying cardiovascular disease. Typically, treatment would include angiotensin receptor blocker and if coronary or other vascular disease plays a role, also aspirin and a statin. One may in addition, consider repeating PA-TDI measurement in 2 years. Patients with a PA-TDI interval between 130-160 ms have a reasonable chance of developing AF and could benefit from primary prevention using "upstream" cardiovascular drugs irrespective of the presence of underlying heart disease. In this group PA-TDI should be monitored more frequently. In patients with very long PA-TDI (>190 ms), the risk of developing $A F$ is very high and since such long PA-TDI usually is a harbinger of 
advanced associated cardiovascular disease, one should in addition to optimizing upstream therapy also consider installing prophylactic antithrombotic treatment certainly if the virtual $\mathrm{CHADS}_{2}$ score is 2 or higher. Post-hoc analyses showed that PATDI significantly increased with increasing $\mathrm{CHA}_{2} \mathrm{DS}_{2}$-VASc score. However, in the Cox regression analysis, PA-TDI outperformed $\mathrm{CHA}_{2} \mathrm{DS}_{2}$-VASc score to predict new-onset AF. For patients 'in the middle' (PA-TDI 160-190 ms) a midstream management is advocated. Obviously, future studies should evaluate the cost-benefit and costeffectiveness of such an approach.

Table 11.1 Hypothetical clinical application of PA-TDI for primary prevention of AF.

\begin{tabular}{|c|c|c|c|}
\hline PA-TDI & UHD* & Risk of AF & Strategy \\
\hline$<130 \mathrm{~ms}$ & No & Low & - Re-measure PA-TDI in 5 years \\
\hline & Yes & Moderate & $\begin{array}{l}\text { - Re-measure PA-TDI in } 2 \text { years } \\
\text { - Start upstream therapy }{ }^{\#}\end{array}$ \\
\hline $130-160 \mathrm{~ms}$ & Yes* & Moderate & $\begin{array}{l}\text { - Re-measure PA-TDI in } 1 \text { year } \\
\text { - Start upstream therapy }\end{array}$ \\
\hline $160-190 \mathrm{~ms}$ & Yes* & High & $\begin{array}{l}\text { - Start upstream therapy } \\
\text { - OAC if virtual CHADS2 }>3 \\
\text { - Frequent ECG and Holter monitoring }\end{array}$ \\
\hline$>190 \mathrm{~ms}$ & Yes* & Very High & $\begin{array}{l}\text { - Start upstream therapy } \\
\text { - OAC if virtual CHADS2 }>2 \text { or consider subcutaneous loop recorder } \\
\text { - Frequent ECG and Holter monitoring }\end{array}$ \\
\hline
\end{tabular}

UHD=underlying heart disease; ${ }^{\#}$ start, continue or intensify upstream therapy; * if PA-TDI>130 ms, underlying $\mathrm{CV}$ disease unavoidable; $\mathrm{OAC}=$ oral anticoagulation

Other investigators confirmed our findings regarding the ability of PA-TDI to predict the development of AF in different populations. ${ }^{38-40}$ Several studies showed that a prolonged PA-TDI interval is also associated with recurrence of AF after catheter ablation. $^{41,42}$

Since all these recent studies suggest that a prolonged PA-TDI is associated with the development of new-onset AF and poor outcome of rhythm control, one could hypothesize that reducing the duration of PA-TDI (or preventing its lengthening) improves primary and secondary prevention of AF. Our findings in chapter 6 suggest that early and aggressive treatment of hypertension, diastolic dysfunction, and obesity could prevent an increased PA-TDI. This hypothesis is plausible since previous studies showed that aggressive treatment of hypertension results in a reduction of the TACT. (Figure 11.1) (3,44 $^{4}$ 


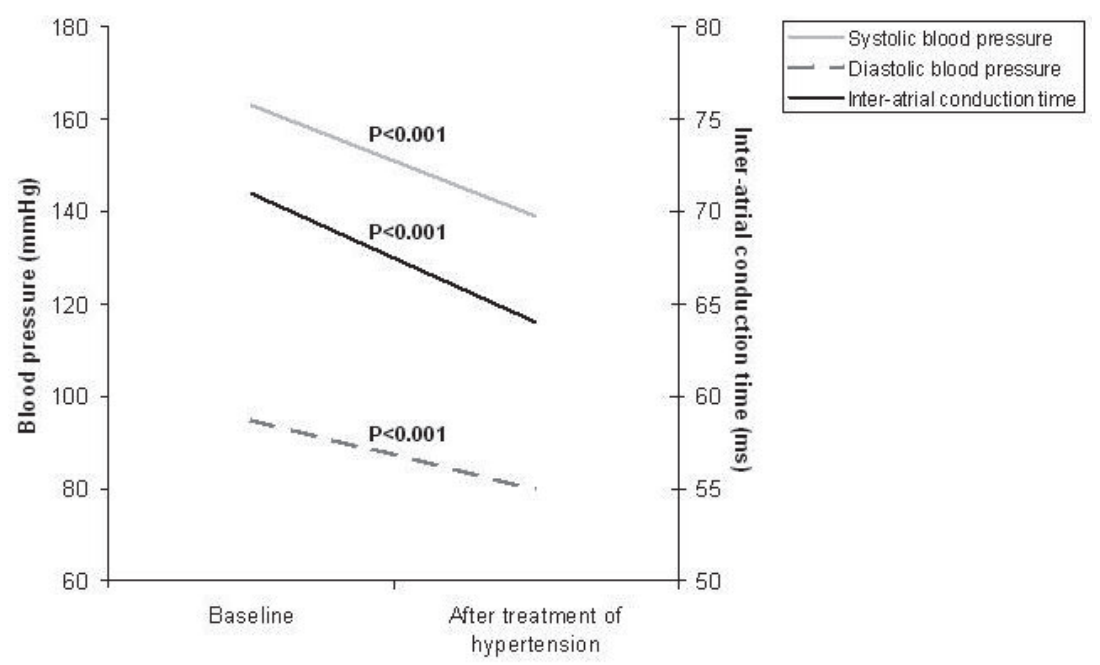

Figure 11.1 The effect of aggressive treatment of hypertension on the inter-atrial conduction time measured using the mitral Doppler signal. (based on Fuenmayor et al. International Journal of Cardiology. 2005, modified by Cees de Vos).

\section{Echo-electrocardiography to characterize the substrate for atrial fibrillation during atrial fibrillation}

In the third part of this thesis we studied new, non-invasive, electrophysiology-derived echocardiographic parameters to characterize patients during AF. Characterization of AF could lead to prediction of arrhythmia prognosis and response to therapy. To prevent recurrences, a large part of AF patients is treated with oral anti-arrhythmic drugs, catheter ablation near the ostia of the pulmonary veins, or AF surgery. Unfortunately, therapy does not always result in lasting sinus rhythm and we do not know to which therapy the patient will have the best response. In addition, therapy for AF can be perilous and result in complications. ${ }^{11}$ Electrical cardioversion requires general anesthesia. Anti-arrhythmic drugs can cause pro-arrhythmia, heart failure and conduction disorders. AF surgery and catheter ablation near the ostia of the pulmonary veins are invasive procedures that may lead to infection, perforation, stroke, bleeding and death. As we have to avoid unnecessary exposure of the patient to the risks of therapy, we require powerful tools to assist the physician in the choice of the best individual therapy for each patient with AF.

Electrophysiology studies show that the arrhythmia is associated with shortening of atrial refractoriness as represented by a reduced atrial fibrillation cycle length (AFCL). ${ }^{23,45,46}$ In addition, increased dispersion of refractoriness as well as heterogeneity of conduction, prolonged conduction times, and fractionation of intracardiac atrial electrograms are common findings in patients with AF. ${ }^{47-49}$ We 
believe that these parameters representing atrial remodeling, may help to predict arrhythmia prognosis and response to therapy. Recent studies found a strong temporal correlation between atrial mechanical contraction assessed by tissue Doppler imaging (TDI) and the electrical fibrillatory cycle length assessed by the intracardiac electrogram. $^{50}$

In chapter $\mathbf{8}$ we present the concept of atrial fibrillatory wall motion as determined by tissue velocity echocardiography. Tissue velocity imaging (TVI) is a relatively new echocardiographic technique employed for non-invasive quantification and timing of local myocardial wall motion. ${ }^{51}$ The technique is derived from tissue Doppler imaging and yet the basic principles are similar. However TVI enables to record myocardial wall motion patterns at several myocardial locations simultaneously.

We performed TVI echocardiography in two patients: the first patient had a nonremodeled left atrium and the other patient had a remodeled atrium. The recordings of the atrial fibrillatory wall movements showed a 4 times lower velocity in the remodeled compared to the non-remodeled left atrium. We hypothesized that this may relate to atrial contractile failure or higher atrial afterload. In addition to that, the frequency of the fibrillating myocardium was higher in the remodeled atrium, which possibly reflects a shorter atrial refractory period. Chapter 9 develops these notions further. The study presented therein shows that echocardiographic TVI of the left and right atrial fibrillatory wall motion closely correlates to electrophysiological parameters during AF. We found a strong correlation between the mechanical fibrillation cycle length determined with tissue velocity echocardiography (AFCL-tvi) and the electrical atrial fibrillation cycle length determined during electrophysiology study (AFCL-egm). In addition, electrophysiological AF type was associated with specific TVI patterns. With increasing electrophysiological complexity, the AFCL-tvi shortened, the AFCL-tvi variability increased and the AFV-tvi decreased. The morphology of the atrial electrograms and duration of the AFCL-egm provides valuable information in patients with $\mathrm{AF}$ regarding prognosis and response to therapy. ${ }^{52-55}$ Therefore, we strongly believe that TVI of the atrial fibrillatory wall movement may enable prediction of prognosis and response to therapy in patients with AF. In Chapter 10 we prospectively evaluated the relation between AFCL-tvi, AFV-tvi and success of ECV in patients with $A F$. We found that higher atrial fibrillatory wall velocities and longer AFCLs determined by echocardiography are associated with acute success of ECV and long term maintenance of sinus rhythm. We hypothesized that to improve outcome, prophylactic antiarrhythmic drugs may be considered including pretreatment before ECV in patients with shorter AFCL-tvi or lower AFV-tvi. Taken together, our data suggest that noninvasive assessment of electrophysiological, functional and structural atrial characteristics using TVI echocardiography may be used to predict success of ECV and long term maintenance of sinus rhythm in patients with persistent AF. However, further studies are needed to show that refining our AF diagnostics using TVI will indeed enhance efficiency of rhythm control in persistent AF. 


\section{References}

1. Krahn AD, Manfreda J, Tate RB, Mathewson FA, Cuddy TE. The natural history of atrial fibrillation: incidence, risk factors, and prognosis in the Manitoba Follow-Up Study. Am J Med 1995;98:476-484.

2. Stewart S, Murphy NF, Walker A, McGuire A, McMurray JJ. Cost of an emerging epidemic: an economic analysis of atrial fibrillation in the UK. Heart 2004;90:286-292.

3. Le Heuzey JY, Paziaud O, Piot O, Said MA, Copie X, Lavergne T, Guize L. Cost of care distribution in atrial fibrillation patients: the COCAF study. Am Heart J. 2004;147:121-126.

4. de Vos CB, Nieuwlaat R, Crijns HJ, Camm AJ, LeHeuzey JY, Kirchhof CJ, Capucci A, Breithardt G, Vardas $P E$, Pisters R, Tieleman RG. Autonomic trigger patterns and anti-arrhythmic treatment of paroxysmal atrial fibrillation: data from the Euro Heart Survey. Eur Heart J 2008;29:632-639.

5. Coumel P, Attuel P, Lavallee J, Flammang D, Leclercq JF, Slama R. The atrial arrhythmia syndrome of vagal origin. Arch Maladies du Coeur Vaiss 1978;71:645-656.

6. Lim PB, Malcolme-Lawes LC, Stuber T, Kojodjojo P, Wright IJ, Francis DP, Wyn Davies D, Peters NS, Kanagaratnam P. Stimulation of the intrinsic cardiac autonomic nervous system results in a gradient of fibrillatory cycle length shortening across the atria during atrial fibrillation in humans. J Cardiovasc Electrophysio. 2011;22:1224-1231.

7. Lim PB, Malcolme-Lawes LC, Stuber T, Wright I, Francis DP, Davies DW, Peters NS, Kanagaratnam P. Intrinsic cardiac autonomic stimulation induces pulmonary vein ectopy and triggers atrial fibrillation in humans. J Cardiovasc Electrophysiol 2011;22:638-646.

8. Oliveira M, da Silva N, Cunha P, Ramos R, Marques F, Santos S, Rocha I, Silva-Carvalho L, Ferreira R. Effects of acute autonomic modulation on atrial conduction delay and local electrograms duration in paroxysmal atrial fibrillation. Int J Cardiol 2011;149:290-295.

9. Oliveira M, da Silva MN, Geraldes V, Xavier R, Laranjo S, Silva V, Postolache G, Ferreira R, Rocha I. Acute vagal modulation of electrophysiology of the atrial and pulmonary veins increases vulnerability to atrial fibrillation. Exp Ohysiol 2011;96:125-133.

10. Lu Z, Scherlag BJ, Lin J, Niu G, Ghias M, Jackman WM, Lazzara R, Jiang H, Po SS. Autonomic mechanism for complex fractionated atrial electrograms: evidence by fast fourier transform analysis. $J$ Cardiovasc Electrophysiol 2008;19:835-842.

11. Camm AJ, Kirchhof P, Lip GY, Schotten U, Savelieva I, Ernst S, Van Gelder IC, Al-Attar N, Hindricks G, Prendergast B, Heidbuchel H, Alfieri O, Angelini A, Atar D, Colonna P, De Caterina R, De Sutter J, Goette A, Gorenek B, Heldal M, Hohloser SH, Kolh P, Le Heuzey JY, Ponikowski P, Rutten FH. Guidelines for the management of atrial fibrillation. European Heart Journal 2010;31:2369-2429.

12. Nieuwlaat R, Capucci A, Camm AJ, Olsson SB, Andresen D, Davies DW, Cobbe S, Breithardt G, Le Heuzey JY, Prins MH, Levy S, Crijns HJ. Atrial fibrillation management: a prospective survey in ESC member countries: the Euro Heart Survey on Atrial Fibrillation. Eur Heart J 2005;26:2422-2434.

13. Le Heuzey JY, Breithardt G, Camm J, Crijns H, Dorian P, Kowey PR, Merioua I, Prystowsky EN, Schwartz PJ, Torp-Pedersen C, Weintraub W. The RecordAF study: design, baseline data, and profile of patients according to chosen treatment strategy for atrial fibrillation. Am J Cardiol 2010;105:687-693.

14. Levy S, Maarek M, Coumel P, Guize L, Lekieffre J, Medvedowsky JL, Sebaoun A. Characterization of different subsets of atrial fibrillation in general practice in France: the ALFA study. The College of French Cardiologists. Circulation 1999;99:3028-3035.

15. Kerr CR, Humphries KH, Talajic M, Klein GJ, Connolly SJ, Green M, Boone J, Sheldon R, Dorian P, Newman D. Progression to chronic atrial fibrillation after the initial diagnosis of paroxysmal atrial fibrillation: results from the Canadian Registry of Atrial Fibrillation. Am Heart J 2005;149:489-496.

16. Ruigomez A, Johansson S, Wallander MA, Garcia Rodriguez LA. Predictors and prognosis of paroxysmal atrial fibrillation in general practice in the UK. BMC Cardiovasc Disord 2005;5:20.

17. Parkash R, Green MS, Kerr CR, Connolly SJ, Klein GJ, Sheldon R, Talajic M, Dorian P, Humphries KH. The association of left atrial size and occurrence of atrial fibrillation: a prospective cohort study from the Canadian Registry of Atrial Fibrillation. Am Heart J 2004;148:649-654.

18. Kato T, Yamashita T, Sagara K, linuma H, Fu LT. Progressive nature of paroxysmal atrial fibrillation. Observations from a 14-year follow-up study. Circ J 2004;68:568-572. 
19. de Vos CB, Pisters R, Nieuwlaat R, Prins MH, Tieleman RG, Coelen RJ, van den Heijkant AC, Allessie MA, Crijns HJ. Progression from paroxysmal to persistent atrial fibrillation clinical correlates and prognosis. J Am Coll Cardiol 2010;55:725-731.

20. Eckstein J, Verheule S, de Groot N, Allessie M, Schotten U. Mechanisms of perpetuation of atrial fibrillation in chronically dilated atria. Prog Biophys Mol Biol 2008;97:435-451.

21. Schotten U, Verheule S, Kirchhof $P$, Goette A. Pathophysiological mechanisms of atrial fibrillation: a translational appraisal. Physiol Rev 2011;91:265-325.

22. Jahangir A, Murarka S. Progression of paroxysmal to persistent atrial fibrillation factors promoting the HATCH score. J Am Coll Cardiol 2010;55:732-734.

23. Wijffels MC, Kirchhof CJ, Dorland R, Allessie MA. Atrial fibrillation begets atrial fibrillation. A study in awake chronically instrumented goats. Circulation 1995;92:1954-1968.

24. Page RL, Connolly SJ, Crijns HJ, van Eickels M, Gaudin C, Torp-Pedersen C, Hohnloser SH. Rhythm- and rate-controlling effects of dronedarone in patients with atrial fibrillation (from the ATHENA trial). Am J Cardiol 2011;107:1019-1022.

25. Chugh SS, Blackshear JL, Shen WK, Hammill SC, Gersh BJ. Epidemiology and natural history of atrial fibrillation: clinical implications. J Am Coll Cardiol 2001;37:371-378.

26. Wolf PA, Kannel WB, McGee DL, Meeks SL, Bharucha NE, McNamara PM. Duration of atrial fibrillation and imminence of stroke: the Framingham study. Stroke 1983;14:664-667.

27. Shimizu A, Centurion OA. Electrophysiological properties of the human atrium in atrial fibrillation. Cardiovasc Res 2002;54:302-314.

28. Dilaveris P, Batchvarov V, Gialafos J, Malik M. Comparison of different methods for manual P wave duration measurement in 12-lead electrocardiograms. Pacing Clin Electrophysiol 1999;22:1532-1538.

29. Merckx KL, De Vos CB, Palmans A, Habets J, Cheriex EC, Crijns HJ, Tieleman RG. Atrial activation time determined by transthoracic Doppler tissue imaging can be used as an estimate of the total duration of atrial electrical activation. J Am Soc Echocardiogr 2005;18:940-944.

30. Weijs B, de Vos CB, Tieleman RG, Pisters R, Cheriex EC, Prins MH, Crijns HJ. Clinical and echocardiographic correlates of intra-atrial conduction delay. Europace 2011;13:1681-1687.

31. Pytkowski M, Jankowska A, Maciag A, Kowalik I, Sterlinski M, Szwed H, Saumarez RC. Paroxysmal atrial fibrillation is associated with increased intra-atrial conduction delay. Europace 2008;10:1415-1420.

32. Abildskov JA. Additions to the wavelet hypothesis of cardiac fibrillation. J Cardiovasc Electrophysiol. 1994;5:553-559.

33. Moe GK, Rheinboldt WC, Abildskov JA. A Computer Model of Atrial Fibrillation. Am Heart J 1964;67:200-220.

34. Yagmur J, Yetkin O, Cansel M, Acikgoz N, Ermis N, Karakus Y, Tasolar H. Assessment of atrial electromechanical delay and influential factors in patients with obstructive sleep apnea. Sleep Breath. 2012;16:83-88.

35. Babcock MJ, Soliman EZ, Ding J, R AK, Goff DC, Jr. Pericardial fat and atrial conduction abnormalities in the Multiethnic Study of Atherosclerosis (MESA). Obesity 2011;19:179-184.

36. Henein MY. Atrial electromechanical function. Europace 2011;13:1665-1666.

37. De Vos CB, Weijs B, Crijns HJ, Cheriex EC, Palmans A, Habets J, Prins MH, Pisters R, Nieuwlaat R, Tieleman RG. Atrial tissue Doppler imaging for prediction of new-onset atrial fibrillation. Heart 2009;95:835-840.

38. Antoni ML, Bertini M, Atary JZ, Delgado V, ten Brinke EA, Boersma E, Holman ER, van der Wall EE, Schalij MJ, Bax JJ, van de Veire NR. Predictive value of total atrial conduction time estimated with tissue Doppler imaging for the development of new-onset atrial fibrillation after acute myocardial infarction. Am J Cardiol 2010;106:198-203.

39. Bertini M, Borleffs CJ, Delgado V, Ng AC, Piers SR, Shanks M, Antoni ML, Biffi M, Boriani G, Schalij MJ, Bax JJ, Van de Veire NR. Prediction of atrial fibrillation in patients with an implantable cardioverterdefibrillator and heart failure. Eur J Heart Fail 2010;12:1101-1110.

40. Roshanali F, Mandegar MH, Yousefnia MA, Rayatzadeh H, Alaeddini F, Amouzadeh F. Prediction of atrial fibrillation via atrial electromechanical interval after coronary artery bypass grafting. Circulation 2007;116:2012-2017.

41. Chao TF, Sung SH, Wang KL, Lin YJ, Chang SL, Lo LW, Hu YF, Tuan TC, Suenari K, Li CH, Ueng KC, Wu TJ, Chen SA. Associations between the atrial electromechanical interval, atrial remodelling and outcome of catheter ablation in paroxysmal atrial fibrillation. Heart 2011;97:225-230. 
42. den Uijl DW, Gawrysiak M, Tops LF, Trines SA, Zeppenfeld K, Schalij MJ, Bax JJ, Delgado V. Prognostic value of total atrial conduction time estimated with tissue Doppler imaging to predict the recurrence of atrial fibrillation after radiofrequency catheter ablation. Europace 2011;13:1533-1540.

43. Fuenmayor AJ, Moreno G, Landaeta A, Fuenmayor AM. Inter-atrial conduction time shortens after blood pressure control in hypertensive patients with left ventricular hypertrophy. Int J Cardiol 2005; 102:443-446.

44. Li Y, Li W, Yang B, Han W, Dong D, Xue J, Li B, Yang S, Sheng L. Effects of Cilazapril on atrial electrical, structural and functional remodeling in atrial fibrillation dogs. J Electrocardiol 2007;40:100 e101-106.

45. Attuel P, Childers R, Cauchemez B, Poveda J, Mugica J, Coumel P. Failure in the rate adaptation of the atrial refractory period: its relationship to vulnerability. Int J Cardiol 1982;2:179-197.

46. Capucci A, Biffi M, Boriani G, Ravelli F, Nollo G, Sabbatani P, Orsi C, Magnani B. Dynamic electrophysiological behavior of human atria during paroxysmal atrial fibrillation. Circulation 1995;92:1193-1202.

47. Misier AR, Opthof T, van Hemel NM, Defauw JJ, de Bakker JM, Janse MJ, van Capelle FJ. Increased dispersion of "refractoriness" in patients with idiopathic paroxysmal atrial fibrillation. J Am Coll Cardiol 1992;19:1531-1535.

48. Sanders P, Morton JB, Davidson NC, Spence SJ, Vohra JK, Sparks PB, Kalman JM. Electrical remodeling of the atria in congestive heart failure: electrophysiological and electroanatomic mapping in humans. Circulation 2003;108:1461-1468.

49. Li D, Fareh S, Leung TK, Nattel S. Promotion of atrial fibrillation by heart failure in dogs: atrial remodeling of a different sort. Circulation 1999;100:87-95.

50. Duytschaever M, Heyse A, de Sutter J, Crijns H, Gillebert T, Tavernier R, Tieleman R. Transthoracic tissue Doppler imaging of the atria: a novel method to determine the atrial fibrillation cycle length. $J$ Cardiovasc Electrophysiol 2006;17:1202-1209.

51. Abraham TP, Dimaano VL, Liang HY. Role of tissue Doppler and strain echocardiography in current clinical practice. Circulation 2007;116:2597-2609.

52. Haissaguerre M, Lim KT, Jacquemet V, Rotter M, Dang L, Hocini M, Matsuo S, Knecht S, Jais P, Virag N. Atrial fibrillatory cycle length: computer simulation and potential clinical importance. Europace 2007;9 Suppl 6:vi64-70.

53. Lo LW, Tai CT, Lin YJ, Chang SL, Udyavar AR, Hu YF, Ueng KC, Tsai WC, Tuan TC, Chang CJ, Kao T, Tsao HM, Wongcharoen W, Higa S, Chen SA. Predicting factors for atrial fibrillation acute termination during catheter ablation procedures: implications for catheter ablation strategy and long-term outcome. Heart Rhythm 2009;6:311-318.

54. Atienza F, Almendral J, Jalife J, Zlochiver S, Ploutz-Snyder R, Torrecilla EG, Arenal A, Kalifa J, FernandezAviles $F$, Berenfeld $O$. Real-time dominant frequency mapping and ablation of dominant frequency sites in atrial fibrillation with left-to-right frequency gradients predicts long-term maintenance of sinus rhythm. Heart Rhythm 2009;6:33-40.

55. Boahene KA, Klein GJ, Yee R, Sharma AD, Fujimura O. Termination of acute atrial fibrillation in the Wolff-Parkinson-White syndrome by procainamide and propafenone: importance of atrial fibrillatory cycle length. J Am Coll Cardiol 1990;16:1408-1414. 
Summary

Samenvatting Dankwoord Curriculum Vitae List of publications Valorisatie 


\section{Summary}

The general introduction of this thesis (chapter 1) describes the background of atrial fibrillation (AF), explains why it is important to screen patients for atrial fibrillation, pictures the potential benefits of predicting AF progression to more sustained forms and predicting response to therapy in patients who already have the arrhythmia.

$\mathrm{AF}$ is the most common cardiac arrhythmia in the world. Its prevalence increases considerably with advancing age. In people older than 80 years, almost 1 out of 10 has AF. Due to aging of the "baby-boom generation" and the fact that people get older in general, it is expected that the number of patients with AF will increase tremendously within the next decades. AF may result in life-threatening complications such as ischemic stroke and heart failure. Therefore, there is a need for primary prevention by screening to detect patients at risk for the development of AF. In patients who already developed $A F$, knowing the factors causing progression of AF from paroxysmal to more persistent forms is essential. Treating reversible causes of AF progression may prevent the progression to sustained forms refractory to therapeutic interventions. In addition to that, we require powerful tools to predict individual response to therapy, as we have to avoid unnecessary exposure of the patient to the risks of therapy.

In the first part of this thesis, we evaluated the role of clinical parameters to characterize AF. A better characterization of AF using clinical parameters may improve treatment of the arrhythmia. In chapter $\mathbf{2}$, we studied the clinical characteristics and management of patients with paroxysmal AF associated with autonomic triggers. We found an autonomic trigger pattern in $33 \%$ of all patients with paroxysmal AF in the Euro Heart Survey. It is important to classify these patients correctly since successful management of autonomic AF may depend on its recognition. Our data suggest that beta-blocking drugs, sotalol, digitalis and propafenone should be avoided in vagal AF since they may exacerbate the episodes of AF. In Chapters 3 and 4 we studied AF progression in two different cohorts. Approximately $15 \%$ of the patients had AF progression in one year. In clinical practice, one can discriminate three clinical AF types: paroxysmal AF (the episodes of the arrhythmia terminate spontaneously), persistent AF (the episodes are not self- terminating), and permanent AF (the physician decides that further attempts to restore normal sinus rhythm are useless). We found that heart failure, previous stroke or TIA, COPD, hypertension, and age were independent predictors of AF progression. We developed a new simple prediction rule to estimate the probability of AF progression in patients with paroxysmal AF: the $\mathrm{HATCH}$ score. Besides heart failure and hypertension, treatment strategy (rate- versus rhythm-control) was found to be an independent predictor of AF progression in the RecordAF population.

In the second part of this thesis we studied new, non-invasive, electrophysiologyderived echocardiographic parameters to identify patients vulnerable for the 
development of AF. We believe that prediction of new-onset AF enables to start adequate therapy on time reducing the development of AF-related complications.

The total atrial conduction time or TACT (the total time required for atrial electrical activation) is an important electrophysiological parameter. The longer TACT is, the higher the risk of developing AF. In chapter $\mathbf{5}$ we validated a new echocardiographic technique to estimate the TACT using pulsed-wave tissue Doppler echocardiography, namely PA-TDI. In chapter 6, we studied the clinical and echocardiographic determinants of a prolonged TACT using PA-TDI in a large population. AF in history, hypertension, valve disease, age, body mass, diastolic dysfunction and enlarged left atrium and aortic root dimensions were independently associated with the PA-TDI interval. In chapter 7 we evaluated the role of PA-TDI to identify subjects at risk for development of new-onset AF. PA-TDI was the strongest predictor of new-onset AF in the studied population. The longer the PA-TDI interval, the higher the incidence of new-onset AF. One could hypothesize that reducing the duration of PA-TDI (or preventing its lengthening) might improve primary and secondary prevention of AF.

In the third part of this thesis we studied new, non-invasive, electrophysiology-derived echocardiographic parameters to characterize patients during AF. As we have to avoid unnecessary exposure of the patient to the risks of therapy, we require powerful tools to determine to which therapy the patient is most likely to respond. Electrophysiology studies show that AF is associated with shortening of atrial refractoriness as represented by a reduced atrial fibrillation cycle length ( $A F C L)$. We believe that these parameters representing atrial remodeling, may help to predict arrhythmia prognosis and response to therapy. In chapter $\mathbf{8}$ we present the concept of atrial fibrillatory wall motion as determined by tissue velocity echocardiography. Tissue velocity imaging (TVI) is a relatively new echocardiographic technique employed for non-invasive quantification and timing of local myocardial wall motion. Chapter 9 develops these notions further. We show that the atrial fibrillatory wall motion detected with echocardiographic TVI of the left and right atrial fibrillatory wall motion closely correlates to electrophysiological parameters during AF such as AFCL. In Chapter 10 we prospectively evaluated the relation between the atrial fibrillatory wall motion detected with echocardiographic TVI and success of electrical cardioversion (ECV) in patients with AF. We found that higher atrial fibrillatory wall velocities and longer AFCLs determined by echocardiography are associated with acute success of ECV and long term maintenance of sinus rhythm. Our data suggest that non-invasive assessment of electrophysiological, functional, and structural atrial characteristics using TVI echocardiography may be used to predict success of ECV and long term maintenance of sinus rhythm in patients with persistent AF. 


\section{Samenvatting}

Boezemfibrilleren of atriumfibrilleren (AF) is de meest voorkomende hartritmestoornis ter wereld. De ritmestoornis ontstaat door een soort elektrische storing in de boezems van het hart, waardoor deze niet meer normaal kunnen samentrekken maar fibrilleren. Hoe ouder men is, hoe groter de kans op het ontwikkelen van AF. Bij patiënten boven de 80 jaar oud heeft zelfs 1 op de 10 AF. De ritmestoornis kan tot levensbedreigende complicaties leiden zoals een beroerte of hartfalen. Daarom is het essentieel om te kunnen voorspellen wie AF zal gaan ontwikkelen in de toekomst zodat behandeling vroegtijdig gestart kan worden. Als een patiënt eenmaal AF heeft ontwikkeld, is het belangrijk om te weten bij welke patiënt een "verergering" van de ritmestoornis te verwachten valt en of een behandeling zal aanslaan of niet.

In dit proefschrift wordt een nieuwe hartecho meting beschreven (PA-TDI) die bij cardiologische patiënten duidelijk gerelateerd is aan het ontwikkelen van AF. Hoe langer PA-TDI, hoe groter de kans dat een patiënt AF zal ontwikkelen. Ook is gekeken welke aandoeningen er voor zorgen dat deze PA-TDI meting langer wordt. Wellicht dat het agressief behandelen van deze aandoeningen, verlenging van PA-TDI kan voorkomen en daarmee ook het ontwikkelen van $A F$ in de toekomst zou kunnen voorkomen.

We hebben factoren onderzocht die een aanval van AF kunnen uitlokken en zogenaamde autonome patronen hierin herkend. Deze autonome patronen kunnen ontstaan wanneer een bepaald deel van het zenuwstelsel uit balans raakt. We laten in dit proefschrift zien dat het belangrijk is om deze patronen te herkennen, omdat bepaalde min of meer standaard behandelingen bij AF dan beter vermeden kunnen worden om verergering van AF type te voorkomen. Er zijn 3 verschillende klinische AF typen: paroxysmaal (enkel korte aanvallen van de ritmestoornis die spontaan over gaan), persisterend (aanvallen duren langer en gaan niet vanzelf over) en permanent (de arts beslist dat pogingen om normaal sinus ritme te herstellen geen zin meer hebben en de ritmestoornis wordt geaccepteerd). We hebben in dit proefschrift gekeken naar factoren die aan progressie (of verergering) van het AF type gerelateerd zijn. Op basis hiervan is een score ontwikkeld (de HATCH score) die kan voorspellen hoe groot de kans is dat een patiënt met paroxysmaal AF een verergering van AF type ondergaat.

Daarnaast is het van belang om de beste individuele behandelstrategie te kiezen. Immers, alle verschillende behandelingen die kunnen worden toegepast, kunnen weer bijwerkingen en complicaties geven. Het is daarom belangrijk om patiënten zo adequaat mogelijk te behandelen zonder ze bloot te stellen aan de gevaren van zinloze behandelingen. In het laatste deel van het proefschrift, worden enkele hartecho metingen beschreven die kijken naar de frequentie en snelheid van het bewegen van 
de boezems. We hebben gevonden dat deze echo metingen sterk gerelateerd zijn aan de mate van elektrische storing in de boezems en daardoor zou kunnen aangeven hoe ver gevorderd de ritmestoornis is en of een bepaalde behandeling kans van slagen heeft. 


\section{Dankwoord}

Ik ben dankbaar dat ik tijdens mijn promotietraject kennis heb mogen maken met de verschillende aspecten van wetenschappelijk onderzoek. Ik heb in deze periode uiteraard veel geleerd maar ook zeker veel plezier gehad. Er zijn vele mensen die mij in de afgelopen jaren hierbij hebben geholpen. Het is onmogelijk om iedereen hier afzonderlijk te noemen. Ik dank alle patiënten die hebben deelgenomen aan mijn projecten, mijn begeleiders voor hun inspirerende rol en alle mogelijkheden die zij voor mij hebben gecreëerd, collega-onderzoekers voor de fijne samenwerking en de afleiding waarvoor zij hebben gezorgd, mijn lieve vrienden en familie voor hun support en natuurlijk in het bijzonder mijn vrouw Judith, de allerleukste vrouw die er bestaat. 


\section{Curriculum Vitae}

Cees de Vos was born the $20^{\text {th }}$ of October 1980 in Liempde, the Netherlands. After completing secondary school at Lycée Saint Adrien in Villeneuve d'ascq (France) in 1999, he started his medical training at Maastricht University. As a medical student, he became involved in professor Crijns's research group at the department of Cardiology in Maastricht University Medical Center in 2003. After obtaining his medical degree in 2005, he became a PhD fellow under supervision of Prof. dr. HJGM Crijns and dr. RG Tieleman focussing on the clinical management of patients with atrial fibrillation and new echocardiographic parameters to characterize patients with atrial fibrillation. He was allowed to present his work on many occasions at large international congresses. His cardiology training at Maastricht University Medical Center, guided by Prof. dr. HJGM Crijns and dr. EC Cheriex, started in 2009 with 2 years of Internal Medicine at the Orbis Medical Center in Sittard under supervision of dr. BJ Looij. In 2012 followed one year of training at Viecuri Medical Center in Venlo under supervision of dr. JG Meeder. Presently, he is completing his Cardiology training in Maastricht University Medical Center. 


\section{List of publications}

\section{Articles}

de Vos CB, Limantoro I, Pisters R, Delhaas T, Schotten U, Cheriex EC, Tieleman RG, Crijns HJ. The mechanical fibrillation pattern of the atrial myocardium is associated with acute and long-term success of electrical cardioversion in patients with persistent atrial fibrillation. Heart Rhythm. 2014;11(9):1514-21.

van Breugel HN, Gelsomino S, de Vos CB, Accord RE, Tieleman RG, Lucà F, Rostagno C, Renzulli A, Parise O, Lorusso R, Crijns HJ, Maessen JG. Maintenance of sinus rhythm after electrical cardioversion for recurrent atrial fibrillation following mitral valve surgery with or without associated radiofrequency ablation. Int J Cardiol. 2014;175(2):290-6

Limantoro I, de Vos CB, Delhaas T, Weijs B, Blaauw Y, Schotten U, Kietselaer B, Pisters R, Crijns HJ. Clinical correlates of echocardiographic tissue velocity imaging abnormalities of the left atrial wall during atrial fibrillation. Europace. 2014. [Epub ahead of print]

Limantoro I, de Vos CB, Delhaas T, Marcos E, Blaauw Y, Weijs B, Tieleman RG, Pisters R, Schotten $U$, Van Gelder IC, Crijns HJ. Tissue velocity imaging of the left atrium predicts response to flecainide in patients with acute atrial fibrillation. Heart Rhythm. 2014;11(3):478-84

Weijs B, de Vos CB, Tieleman RG, Peeters FE, Limantoro I, Kroon AA, Cheriex EC, Pisters $\mathrm{R}$, Crijns HJ. The occurrence of cardiovascular disease during 5-year follow-up in patients with idiopathic atrial fibrillation. Europace. 2013;15(1):18-23.

de Vos CB, Breithardt G, Camm AJ, Dorian P, Kowey PR, Le Heuzey JY, Naditch-Brûlé L, Prystowsky EN, Schwartz PJ, Torp-Pedersen C, Weintraub WS, Crijns HJ. Progression of atrial fibrillation in the REgistry on Cardiac rhythm disORDers assessing the control of Atrial Fibrillation cohort: clinical correlates and the effect of rhythm-control therapy. Am Heart J. 2012;163(5):887-93.

Fumagalli S, Nieuwlaat R, Tarantini F, de Vos CB, Werter CJ, Le Heuzey JY, Marchionni $\mathrm{N}$, Crijns HJ. Characteristics, management and prognosis of elderly patients in the Euro Heart Survey on atrial fibrillation. Aging Clin Exp Res. 2012;24(5):517-23.

Weijs B, de Vos CB, Limantoro I, Cheriex EC, Tieleman RG, Crijns HJ. The presence of an atrial electromechanical delay in idiopathic atrial fibrillation as determined by tissue Doppler imaging. Int J Cardiol. 2012;156(1):121-2. 
Weijs B*, de Vos CB*, Tieleman RG, Pisters R, Cheriex EC, Prins MH, Crijns HJ. Clinical and echocardiographic correlates of intra-atrial conduction delay. Europace. 2011;13(12):1681-7. *Both authors contributed equally

Pisters R, van Oostenbrugge RJ, Knottnerus IL, de Vos CB, Boreas A, Lodder J, Prins MH, Crijns HJ, Tieleman RG. The likelihood of decreasing strokes in atrial fibrillation patients by strict application of guidelines. Europace. 2010;12(6):779-84

Pisters R, Lane DA, Nieuwlaat R, de Vos CB, Crijns HJ, Lip GY. A novel user-friendly score (HAS-BLED) to assess 1-year risk of major bleeding in patients with atrial fibrillation: the Euro Heart Survey. Chest. 2010;138(5):1093-100

de Vos CB, Pisters R, Nieuwlaat R, Prins MH, Tieleman RG, Coelen RJ, van den Heijkant $A C$, Allessie MA, Crijns HJ. Progression from paroxysmal to persistent atrial fibrillation clinical correlates and prognosis. J Am Coll Cardiol. 2010;55(8):725-31.

de Vos CB, Pison L, Pisters R, Schotten U, Cheriex EC, Prins MH, Delhaas T, Crijns HJGM, Tieleman RG. Atrial fibrillatory wall motion and degree of atrial remodeling in patients with atrial fibrillation: a tissue velocity imaging study. J Cardiovasc Electrophysiol. 2009;20(12):1374-81.

Folkeringa RJ, de Vos CB, Pinto YM, Habets J, De Leeuw PW, Tieleman RG, Prins MH, Van Dieijen-Visser $M$, Crijns $H J$. No effect of rosuvastatin on left ventricular hypertrophy in patients with hypertension: A prospective randomised open-label study with blinded endpoint assessment. Int J Cardiol. 2010;145(1):156-8.

Pisters R, de Vos CB, Dennert R, Crijns HJ. Undetected paroxysmal atrial fibrillation in chronic heart failure patients: is it clinically relevant to catch the atrial phantom? Europace. 2009;11(10):1257-9.

Pisters R, de Vos CB, Nieuwlaat R, Crijns HJ. Use and Underuse of Oral Anticoagulation for Stroke Prevention in Atrial Fibrillation: Old and New Paradigms. Semin Thromb Hemost. 2009;35(6):554-9.

Pisters R, Nieuwlaat R, de Vos CB, Crijns HJ. Comprehensive upstream treatment for $\mathrm{AF}$, when and how? Europace. 2009 Apr;11(4):397-9

de Vos CB, Weijs B, Crijns HJ, Cheriex EC, Palmans A, Habets J, Prins MH, Pisters R, Nieuwlaat R, Tieleman RG. Atrial Tissue Doppler Imaging For Prediction Of New-Onset Atrial Fibrillation. Heart. 2009;95;835-840. 
de Vos CB, Crijns HJ, Tieleman RG. The Fibrillating Atrial Myocardium Visualized: An Unexploited Source Of Information. Heart Rhythm. 2009;6(8):1247-8.

de Vos CB, Nieuwlaat R, Crijns HJ, Camm AJ, LeHeuzey JY, Kirchhof C, Capucci A, Breithardt G, Vardas P, Pisters R, Tieleman RG. Autonomic Trigger Patterns And AntiArrhythmic Treatment Of Paroxysmal Atrial Fibrillation: Data From The Euro Heart Survey. European Heart Journal. 2008;29(5):632-9

Merckx KL, de Vos CB, Palmans A, Habets J, Cheriex EC, Crijns HJ, Tieleman RG. Atrial activation time determined by transthoracic Doppler tissue imaging can be used as an estimate of the total duration of atrial electrical activation. J Am Soc Echocardiogr. 2005;18(9):940-4

\section{Book Chapters}

de Vos CB, Crijns HJ. Hartritmestoornissen. Het cardiovasculair formularium: Een praktische leidraad. Bohn Stafleu van Loghum. 2014

de Vos CB, Crijns HJ. Antiaritmica. Het cardiovasculair formularium: Een praktische leidraad. Bohn Stafleu van Loghum. 2014

\section{Published Abstracts}

de Vos CB, Weijs B, Crijns HJ, Cheriex EC, Palmans A, Habets J, Prins MH, Pisters R, Nieuwlaat R, Tieleman RG. Atrial Tissue Doppler Imaging For Prediction Of New-Onset Atrial Fibrillation. Circulation, 2008; 118:S1069.

de Vos CB, Crijns HJ, Delhaas T, Pisters R, Tieleman RG. Non-invasive Measurement Of The Atrial Fibrillation Cycle Length Using Tissue Velocity Imaging Predicts Long-term Success Of Electrical Cardioversion. Heart Rhythm. 2008;5:S199.

Weijs B, de Vos CB, Crijns HJ, Broos C, Boxtel A, Zhang E, Palmans A, Habets J, Cheriex EC, and Tieleman RG. Tissue Doppler Imaging to Identify Patients with a Substrate Vulnerable for Atrial Fibrillation. Circulation. 2007; 116: II570.

de Vos CB, Crijns HJ, Delhaas T, Pisters R, Tieleman RG. Evaluation of the atrial fibrillation cycle length with colour tissue velocity imaging and prediction of succes of electrical cardioversion. Heart Rhythm. 2007;4:S244-245.

de Vos CB, Crijns HJ, Delhaas T, Pisters R, Tieleman RG. Colour tissue velocity imaging to determine the atrial fibrillation cycle length. Heart Rhythm. 2007;4:S251. 
de Vos CB, Nieuwlaat R, Crijns HJ, Tieleman RG. Autonomic trigger patterns and antiarrhythmic treatment of Atrial Fibrillation: data from the Euro Heart Survey. Heart Rhythm. 2007;4:S120.

Merckx KL, de Vos CB, Beckers B, Palmans A, Habets J, Cheriex, Crijns HJ, Tieleman RG. Prolonged atrial activation time as determined by tissue Doppler echocardiography is associated with recurrence of atrial fibrillation after a successful cardioversion. Heart Rhythm. 2005:S268-S269.

de Vos CB, Crijns HJ, Merckx KL, Palmans A, Habets J, Cheriex, Tieleman RG. Transthoracic left atrial tissue Doppler imaging to determine total atrial activation time during sinus rhythm. Heart Rhythm. 2004;1:S195-196.

Tieleman RG, Merckx KL, de Vos CB, Palmans A, Habets J, Cheriex, Crijns HJ. Total Atrial Activation Time as Determined by Trans-thoracic Tissue Doppler Imaging in Patients with a History of Atrial Fibrillation is Prolonged Independent of Atrial Size. Heart Rhythm. 2004;1:S2. 


\section{Valorisatie}

\section{Relevantie}

Gezien de dubbele vergrijzing zal het aantal patiënten met atriumfibrilleren (AF) enorm toenemen de komende jaren. De meest beruchte complicaties van AF, herseninfarct en hartfalen, zijn aandoeningen die afschuwelijke gevolgen hebben voor de patiënt maar ook resulteren in hoge kosten binnen de gezondheidszorg. In dit proefschrift zijn een aantal klinische en echocardiografische parameters beschreven die er voor kunnen zorgen dat het optreden van AF beter kan worden voorspeld en AF gerichter kan worden behandeld. Dit zou het aantal complicaties die voorvallen bij AF kunnen reduceren. Daarnaast kunnen deze "tools" helpen bij het selecteren van de juiste behandeling voor de individuele patiënt. Beiden kunnen tot een kostenbesparing leiden.

\section{Doelgroepen}

De onderzoeksresultaten die gerapporteerd zijn in dit proefschrift kunnen van betekenis zijn voor patiënten en behandelend artsen (cardiologen en huisartsen). Wat de patiënten betreft zijn de beschreven resultaten met name toepasbaar bij patiënten die zich presenteren op een polikliniek of afdeling Cardiologie. Daarnaast zouden patiënten in de huisartsenpraktijk met een reeds wat verhoogde a priori kans voor het ontwikkelen van AF (bijvoorbeeld vanaf de leeftijd van 65 jaar of bij bepaalde onderliggende aandoeningen) kunnen profiteren van de bevindingen beschreven in dit proefschrift.

\section{Activiteiten/Producten}

Een aantal klinische en echocardiografische parameters beschreven in dit proefschrift zouden kunnen worden opgenomen in een screeningsproces, bijvoorbeeld screening om patiënten die in de toekomst AF zullen ontwikkelen vroegtijdig te detecteren, screening naar progressie van AF indien de ritmestoornis reeds aanwezig is en screening voor de optimale therapie voor de individuele patiënt.

\section{Innovatie, Planning \& Realisatie}

Op dit moment is de screening voor AF nog niet toereikend. AF wordt vaak te laat herkend. Een herseninfarct of hartfalen zijn dan de eerste uiting van de ritmestoornis. Daarnaast is de behandeling van de individuele patiënt met AF nog te vaak het resultaat van "trial and error". De klinische en echocardiografische parameters beschreven in dit proefschrift zouden kunnen bijdragen aan een adequatere screening en "tailored therapy". Deze "tools" zouden eventueel kunnen worden opgenomen in huidige screening methoden in de huisartspraktijk of een centrum voor 1,5 lijnszorg. 
In het ziekenhuis zou men het standaard echo protocol kunnen uitbreiden aangezien alle patiënten met $\mathrm{AF}$ ten minste 1 maar vaak meerdere echocardiogrammen ondergaan. De progressie score, het autonome patroon herkenning en echo metingen zouden kunnen worden opgenomen in het ziekenhuis EPD en bij elke bezoek worden geëvalueerd. De behandelend arts kan dan deze parameters consulteren om een optimaal behandelplan te maken voor de patiënt. 